\title{
Analysis of Vadose Zone Tritium Transport from an Underground Storage Tank Release Using Numerical Modeling and Geostatistics
}

Kenrick Hugh Lee

PhD Thesis

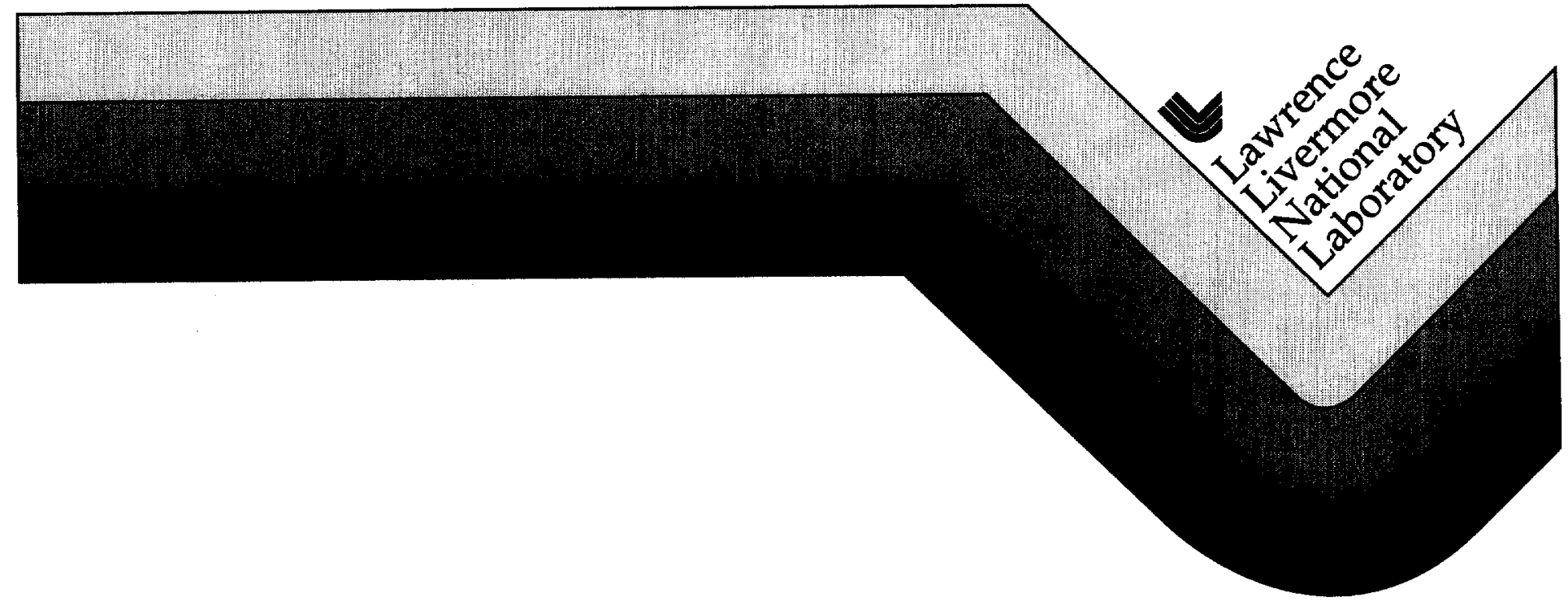




\section{DISCLAIMER}

This document was prepared as an account of work sponsored by an agency of the United States Government. Neither the United States Covernment nor the University of California nor any of their employees, makes any warranty, express or implied, or assumes any legal liability or responsibility for the accuracy, completeness, or usefulness of any information, apparatus, product, or process disclosed, or represents that its use would not infringe privately owned rights. Reference herein to any spedific commercial product, process, or service by trade name, trademark, manufacturer, or otherwise, does not necessarily constitute or imply its endorsement, recommendation, or favoring by the United States Government or the University of California. The views and opinions of authors expressed herein do not necessarily state or reflect those of the United States Government or the University of California, and shall not be used for advertising or product endorsement purposes.

This report has been reproduced directly from the best available copy.

Available to DOE and DOE contractors from the Office of Scientific and Technical Information

P.O. Box 62, Oak Ridge, TN 37831

Prices available from (615) 576-8401, FTS 626-8401

Available to the public from the National Technical Information Service

U.S. Department of Commerce 5285 Port Royal Rd., Springfield, VA 22161

Work performed under the auspices of the U.S. Department of Energy by Lawrence Livermore National Laboratory under Contract W-7405-ENG-48. 
UCRL-LR-128840

\section{Analysis of Vadose Zone Tritium Transport from an Underground Storage Tank Release Using Numerical Modeling and Geostatistics}

Kenrick Hugh Lee

Doctor of Philosophy

Thesis

Manuscript date: September 1997 


\title{
Analysis of Vadose Zone Tritium Transport from an Underground Storage Tank Release Using Numerical Modeling and Geostatistics
}

\author{
by
}

Kenrick Hugh Lee

B.S. (Queens University, Kingston, Ontario, Canada) 1978

M.S. (New Mexico Institute of Mining and Technology, Socorro, New Mexico) 1986

A dissertation submitted in partial satisfaction of the requirements for the degree of

Doctor of Philosophy

in

Engineering-Materials Science

and Mineral Engineering

in the

GRADUATE DIVISION

of the

UNIVERSITY OF CALIFORNIA AT BERKELEY

Committee in charge:

Professor Neville G. W. Cook, Co-chair

Professor Tadeusz W. Patzek, Co-chair

Professor Fiona M. Doyle

Professor Nicholas Sitar

Doctor John J. Nitao

Fall 1997 
The dissertation of Kenrick Hugh Lee is approved:
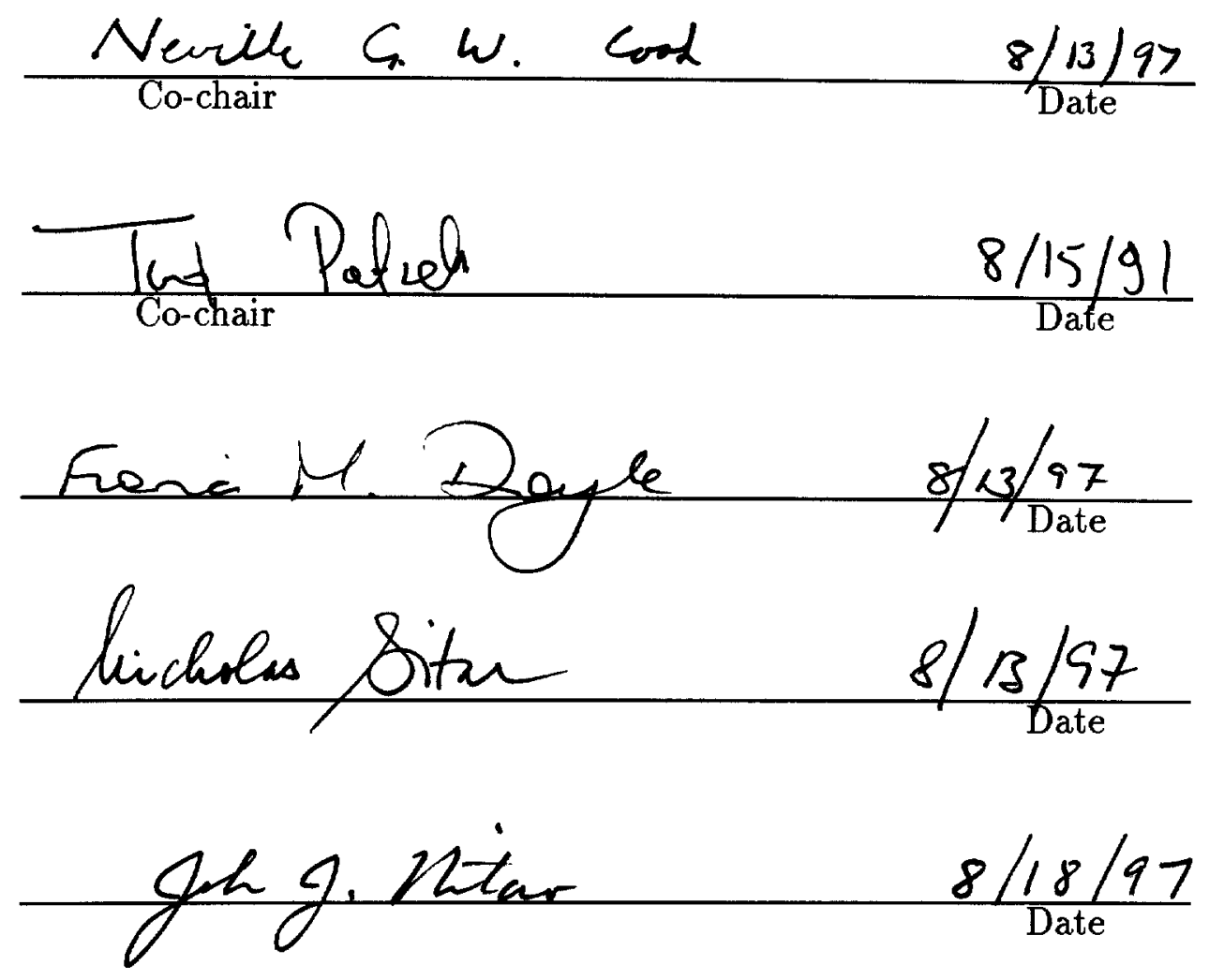

University of California, Berkeley 

Analysis of Vadose Zone Tritium Transport from an Underground Storage Tank Release Using Numerical Modeling and Geostatistics

Copyright (C) 1997

by

Kenrick Hugh Lee 


\title{
Abstract \\ Analysis of Vadose Zone Tritium Transport from an Underground Storage Tank Release Using Numerical Modeling and Geostatistics
}

\author{
by \\ Kenrick Hugh Lee \\ Doctor of Philosophy in Engineering \\ Materials Science and Mineral Engineering \\ University of California, Berkeley \\ Professor Neville G. W. Cook, Co-chair \\ Professor Tadeusz W. Patzek, Co-chair
}

Numerical and geostatistical analyses show that the artificial smoothing effect of kriging removes high-permeability flow paths from hydrogeologic data sets, reducing simulated contaminant transport rates in heterogeneous vadose zone systems. Therefore, kriging alone is not recommended for estimating the spatial distribution of soil hydraulic properties for contaminant transport analysis at vadose zone sites. Vadose zone transport is modeled more effectively by combining kriging with stochastic simulation to better represent the high degree of spatial variability usually found in the hydraulic properties of field soils. However, kriging is a viable technique for estimating the initial mass distribution of contaminants in the subsurface.

One of the more challenging problems faced by earth scientists in vadose zone studies is the characterization of heterogeneous field sites with limited data. This dissertation presents and demonstrates a methodology that will increase substantially the effectiveness of vadose zone contaminant transport analyses while reducing the high cost usually associated with site characterization in heterogeneous soils. Our approach combines stochastic simulation and ordinary kriging with soil property correlation and numerical modeling to optimize the 
utilization of scarce data.

The study site is the Building 292 Area at Lawrence Livermore National Laboratory, where the soil close to an underground tank storing tritiated water was contaminated with ${ }^{3} \mathrm{H}$ at levels up to 220 million $\mathrm{pCi} / \mathrm{L}$ of soil water. Our principal objectives were to investigate the applicability of geostatistical techniques, soil property correlation, and numerical modeling to study the transport behavior of tritium at the heterogeneous vadose zone site, and to use data available from site characterization and monitoring to predict the impact of the release on future soil and groundwater quality at the site.

The analysis shows no serious long term threat to groundwater quality at the site, but high soil water ${ }^{3} \mathrm{H}$ concentrations will persist in the vadose zone for several decades. The impact of the release on groundwater quality is substantially reduced by a blacktop that partially covers the site. Vapor diffusion is not important to ${ }^{3} \mathrm{H}$ transport under current site conditions.

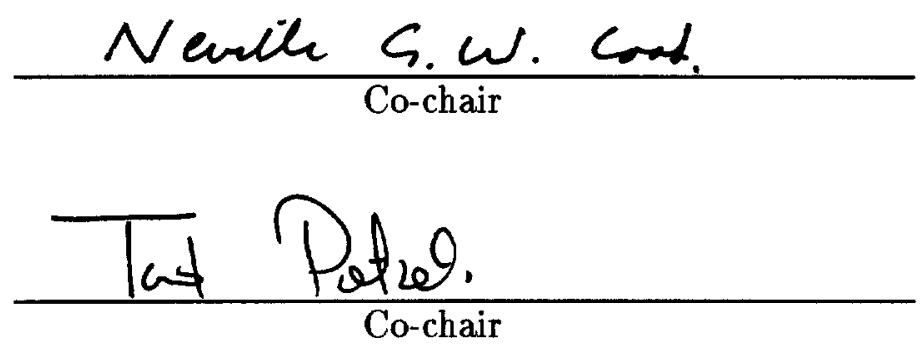




\section{Dedication}

To Seham, Lawrence, Roderick, and Shaima, with love. 


\section{Contents}

1 Introduction 1

2 Background 7

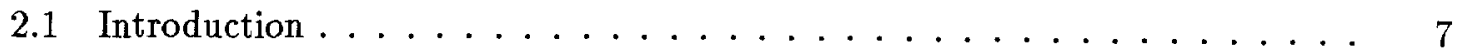

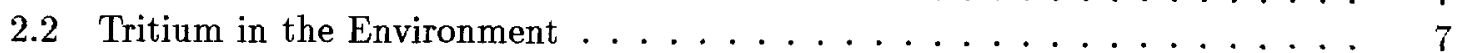

2.2 .1 Sources of ${ }^{3} \mathrm{H} \ldots \ldots \ldots \ldots \ldots$

$2.2 .2{ }^{3} \mathrm{H}$ as Hydrologic Tracer . . . . . . . . . . . . . . . . . . . . . 9

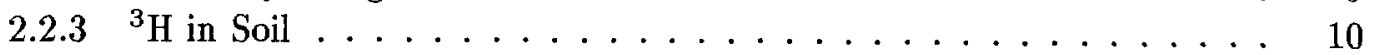

$2.2 .4{ }^{3} \mathrm{H}$ Measurement . . . . . . . . . . . . . . . . . . . . . . . . 12

2.2 .5 Health Hazard . . . . . . . . . . . . . . . . . . . . 12

2.3 State of Vadose Zone Transport Modeling . . . . . . . . . . . . . . 13

3 Site Investigation $\quad 17$

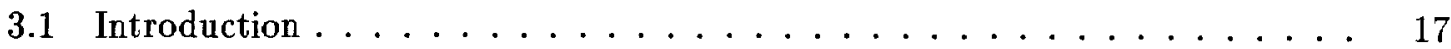

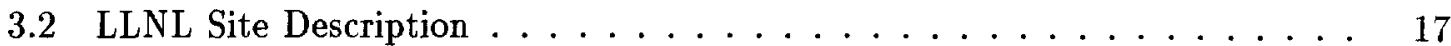

3.3 Tritium Release Site . . . . . . . . . . . . . . . . 20

3.4 Site Characterization and Monitoring ................ 22

3.4.1 Initial ${ }^{3} \mathrm{H}$ Concentrations . . . . . . . . . . . . . . 25

3.4.2 Temporal Concentration Changes in Monitored Boreholes . . . . . . 31

3.4.3 Soil Properties from Laboratory Measurements . . . . . . . . . . . . . 33

3.4 .4 van Genuchten's Soil Parameters . . . . . . . . . . . . . . . . 41

4 Geostatistical Estimation and Simulation of Soil Properties 44

4.1 Introduction . . . . . . . . . . . . . . . . . 44

4.2 Soil Property Correlations . . . . . . . . . . . . . . . . 45

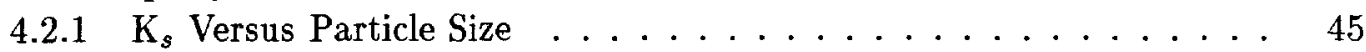

4.2 .2 Initial Water Content Versus $\mathrm{K}_{s} \ldots \ldots \ldots \ldots$

4.2 .3 Alpha Versus $\mathrm{K}_{s} \ldots \ldots \ldots \ldots \ldots \ldots$

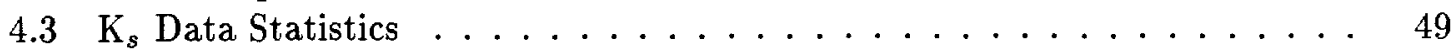

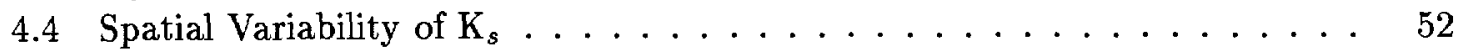

$4.4 .1 \mathrm{~K}_{s}$ Sample Variograms . . . . . . . . . . . . . . . 52

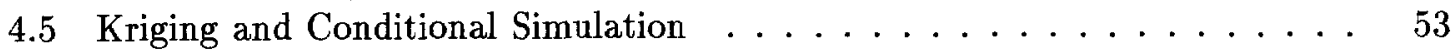

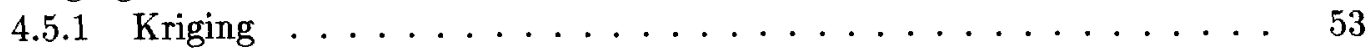

4.5 .2 Conditional Simulation ................. 55

4.5.3 Estimation and Simulation of Permeability Field . . . . . . . . 59

4.5.4 Examples of Permeability Fields from Kriging and Simulation . . . . 62

5 Estimation of the Initial Concentration Field 65

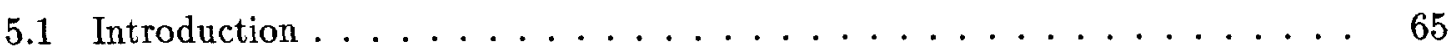

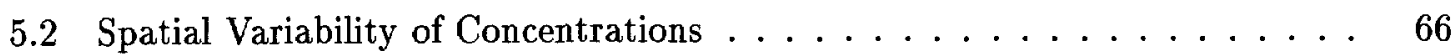

5.3 Field Concentrations from Kriging ... . . . . . . . . . . . 67

5.4 Total Tritium Activity in Subsurface . . . . . . . . . . . . . . 69 
6 Conceptual and Mathematical Models

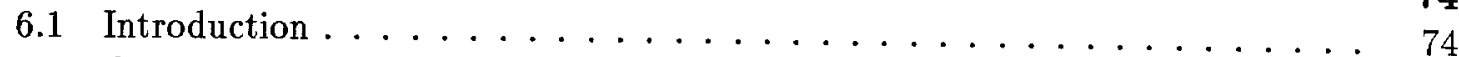

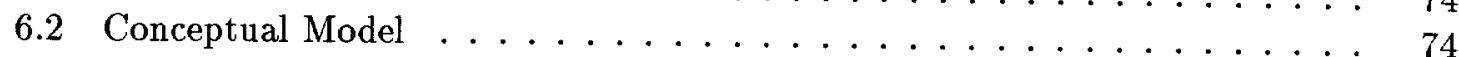

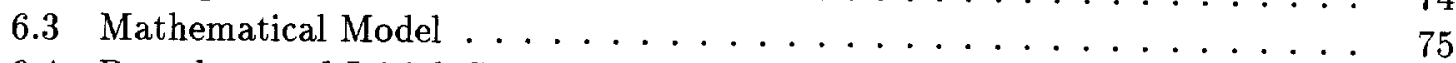

6.4 Boundary and Initial Conditions $\ldots \ldots \ldots \ldots \ldots$

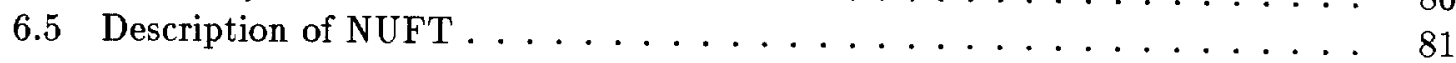

7 Two-Dimensional Analysis $\quad 84$

7.1 Introduction . . . . . . . . . . . . . . . . . 84

7.2 Summary of Findings $\ldots \ldots \ldots \ldots \ldots \ldots$

7.3 Monte-Carlo Analysis $\ldots \ldots \ldots \ldots \ldots \ldots$

7.3.1 Generation of the 2D Permeability Field . . . . . . . . . . 87

7.3 .2 Numerical Simulation Model . . . . . . . . . . . . . . . . . . . 89

7.3 .3 Grid Design . . . . . . . . . . . . . . . . . . . . . 89

7.3.4 Initial and Boundary Conditions .............. 90

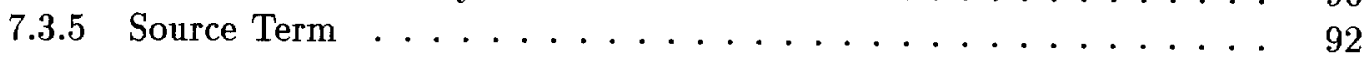

7.3.6 Results of Monte-Carlo Analysis . . . . . . . . . . . . . . . 93

7.4 Effect of Infiltration and Vapor Diffusion on ${ }^{3} \mathrm{H}$ Transport . . . . . . . . 113

7.4 .1 Effect of Infiltration . . . . . . . . . . . . . . . . 113

7.4 .2 Effect of Vapor Diffusion . . . . . . . . . . . 117

8 Three-Dimensional Analysis $\quad 129$

8.1 Introduction . . . . . . . . . . . . . . . . . . . 129

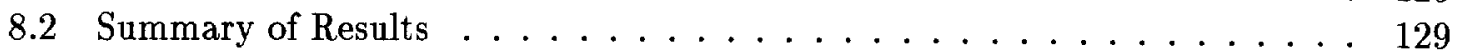

8.3 Method of Analysis . . . . . . . . . . . . . . . . . . . . . . . . . . . . . . .

8.4 Description of the 3D Model . . . . . . . . . . . . . . . . 132

8.4.1 Realizations of Permeability Field . . . . . . . . . . . . . 133

8.4.2 Conceptual and Mathematical Models . . . . . . . . . . . . 136

8.4.3 Grid Design . . . . . . . . . . . . . . . . . . 136

8.4.4 Initial and Boundary Conditions . . . . . . . . . . . 137

8.4.5 Source Term . . . . . . . . . . . . . . . . . . 139

8.5 Runs using Soil Properties from Conditional Simulation . . . . . . . . . 139

8.5 .1 Results . . . . . . . . . . . . . . . . 140

8.6 Simulations using Soil Properties from Kriging . . . . . . . . . . . 155

8.6.1 Kriging Simulation Results . . . . . . . . . . . . . . . 158

8.7 Comparison of Transport Results Using Soil Properties from Conditional Simulation and Kriging . . . . . . . . . . . . . . . . . . 162

8.8 Comparison of Numerical Calculations with Measured Concentrations . . . 164

8.9 Simulation Results with Best-fit Realization . . . . . . . . . . . 165

8.9 .1 Vadose Zone . . . . . . . . . . . . . . . . 165

8.9 .2 Groundwater ....................... 166

9 Summary and Conclusions $\quad \mathbf{1 7 2}$

9.1 Summary . . . . . . . . . . . . . . . . . . . . . 172

9.2 General Findings . . . . . . . . . . . . . . . . . . . 174

9.3 Findings Specific to Building 292 Area . . . . . . . . . . . . . 175

9.4 Recommendations for Future Work . . . . . . . . . . . . . . 178

9.4 .1 General . . . . . . . . . . . . . . . . 178 
9.4 .2 Building 292 Area . . . . . . . . . . . . . . 178

Appendix A Conversion from HTO Mass to ${ }^{3} \mathrm{H}$ Activity 188

$\begin{array}{lll}\text { Appendix B Water Retention Data } & 189\end{array}$

Appendix C $K_{s}$ Data for the 57-sample and 132-sample Data Sets 191

Appendix D Maximum and Time of Occurrence of Maximum Groundwater Concentration for 2D Runs using Soil Properties Generated by Conditional Simulation.

\section{List of Figures}

2.1 Variations of ${ }^{3} \mathrm{H}$ concentration in precipitation at Ottawa, Canada between 1953 and 1976. Mean monthly concentrations are shown. (After Freeze and

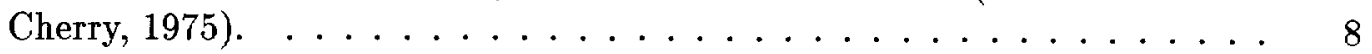

3.1 Regional setting of the LLNL Livermore Site. . . . . . . . . . . . . . 18

3.2 Layout of LLNL Livermore Site showing location of the ${ }^{3} \mathrm{H}$ release in the Building 292 Area. . . . . . . . . . . . . . . . . 19

3.3 Three-dimensional schematic showing the location of Tank R1U1 with respect to the water table and structures in the LLNL Building 292 Area. . . . . . 21

3.4 Water table elevation contours in the LLNL Building 292 Area. Borehole 1 (B-1) is shown at the northeastern edge of Tank R1U1. . . . . . . . .

3.5 Plan view of the LLNL Building 292 Area showing locations of boreholes,

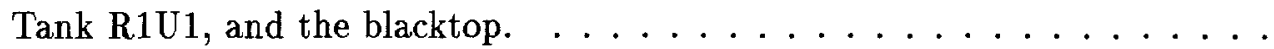

3.6 Soil water ${ }^{3} \mathrm{H}$ concentration profiles along boreholes (a) B-1, (b) B-2, (c) B-15, (d) B-16, and (e) B-17. Concentrations measured during initial site characterization in the period $1989-1992 . \ldots \ldots \ldots \ldots$

3.7 Soil water ${ }^{3} \mathrm{H}$ concentration profiles along boreholes (a) B-3, (b) B-4, (c) B-18, and (d) B-19. Concentrations measured during initial site characterization in the period 1989-1992. . . . . . . . . . . . . . . .

3.8 Soil water ${ }^{3} \mathrm{H}$ concentrations along Section AA' from Figure 3.5. Concentrations are shown in $\log _{10} \mathrm{pCi} / \mathrm{L}$ (After Mallon, 1995). . . . . . . . .

3.9 Tritium concentration profile for Borehole 16 at six times between May 1991 and April 1995 (After Mallon, 1995). . . . . . . . . . . . . .

3.10 Tritium concentration profile for Borehole 17 at six times between May 1991 and January 1995 (After Mallon, 1995). . . . . . . . . . . . . .

3.11 Groundwater ${ }^{3} \mathrm{H}$ concentration histories in Boreholes 1 and 15 in the Building 292 Area (After Mallon, 1995). . . . . . . . . . . . . .

3.12 Water retention data and van Genuchten curve fit parameters for 16 soil samples from boreholes in the LLNL Building 292 Area. . . . . . . . . .

4.1 Saturated hydraulic conductivity versus particle size for (a) D30, (b) D40, and (c) D50 grain sizes obtained from core samples recovered from Boreholes 1,15 , and 20 in the LLNL Building 292 Area. . . . . . . . .

4.2 Regression plot of initial water content, $\theta_{i}$, versus saturated hydraulic conductivity, $\mathrm{K}_{s}$, for soil samples recovered from the LLNL Building 292 Area. 
4.3 Regression plot of van Genuchten's $\alpha$ versus saturated hydraulic conductivity, $\mathrm{K}_{s}$, for soil samples recovered from the LLNL Building 292 Area. . . . . .

4.4 Permeability histogram of the 57-sample data set for soil samples from the LLNL Building 292 Area. . . . . . . . . . . . . . . . . .

4.5 Permeability histogram of the 132 -sample data set for soil samples from the LLNL Building 292 Area. . . . . . . . . . . . . . . . . . . .

4.6 Horizontal soil permeability variogram for samples from the LLNL Building 292 Area. . . . . . . . . . . . . . . . . . . . . .

4.7 Vertical soil permeability variogram for samples from the LLNL Building 292 Area. . . . . . . . . . . . . . . . . . . .

4.8 Comparison of permeability fields generated by kriging and conditional simulation, using the same sample data. The figure shows an east-west section through the leak point with permeability generated by (a) kriging, and (b) conditional simulation. . . . . . . . . . . . . . .

5.1 Sample variogram for soil water tritium concentration for samples recovered from the LLNL Building 292 Area. . . . . . . . . . . . . . . . . . . .

5.2 Tritium concentrations along horizontal plane at elevation $575 \mathrm{ft}$, about 12 ft below the ground surface in the LLNL Building 292 Area. Concentrations estimated by kriging with the borehole sample data. . . . . . . . . .

5.3 Tritium concentrations along north-south section through E8651, about $4 \mathrm{ft}$ west of Borehole 1 in the LLNL Building 292 Area. Concentrations estimated by kriging with the borehole sample data. . . . . . . . . . .

5.4 Tritium concentrations along east-west section through $\mathrm{N} 12783$, about $3 \mathrm{ft}$ north of the tank's north face in the LLNL Building 292 Area. Concentrations estimated by kriging with the borehole sample data. . . . . . . . . .

7.1 Grid design for 2D model. The leak node has coordinates $(919.6,9.0)$. . .

7.2 Histogram of plume arrival times at the water table for Monte-Carlo simulation runs. The histogram is drawn for 99 realizations because the 20,000 $\mathrm{pCi} / \mathrm{L}$ isoconcentration line for one realization never reached the water table.

7.3 Histogram of natural logarithm of plume arrival times at the water table for Monte-Carlo simulation runs. . . . . . . . . . . . . .

7.4 Histogram of plume arrival times at the water table, adjusted to remove the effect of radioactive decay. . . . . . . . . . . . . . . .

7.5 Histogram of natural logarithm of plume arrival times at the water table, adjusted to remove the effect of radioactive decay. ...........

7.6 Groundwater ${ }^{3} \mathrm{H}$ concentration history at the water table $100 \mathrm{ft}$ downstream of leak; comparison of the CS and kriging cases. . . . . . . . . . .

7.7 Comparison of peak groundwater ${ }^{3} \mathrm{H}$ concentration histories from the CS case and the kriging case. . . . . . . . . . . . . .

7.8 Histogram of maximum groundwater ${ }^{3} \mathrm{H}$ concentration for 100 realizations derived by conditional simulation. . . . . . . . . . . .

7.9 Histogram of natural logarithm of maximum groundwater ${ }^{3} \mathrm{H}$ concentration for 100 realizations derived by conditional simulation. . . . . . . . . .

7.10 Histogram of time of occurrence of maximum groundwater ${ }^{3} \mathrm{H}$ concentration for 100 realizations derived by conditional simulation. . . . . . . . . .

7.11 Comparison of cumulative ${ }^{3} \mathrm{H}$ activity histories across the water table for the CS case and the kriging case. . . . . . . . . . . . . . . . 104 
7.12 Comparison total groundwater ${ }^{3} \mathrm{H}$ activity histories for the mean CS case

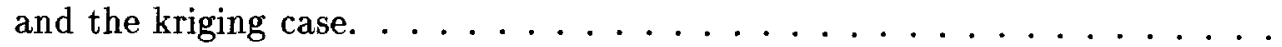

7.13 Comparison of history plots of the ${ }^{3} \mathrm{H}$ plume's center-of-mass depth in the vadose zone, for the mean CS case and the kriging case. . . . . . . . . .

7.14 Comparison of the peak vadose zone ${ }^{3} \mathrm{H}$ concentration histories for the CS case and the kriging case. . . . . . . . . . . . . . . 106

7.15 Histories of the depth at peak vadose zone ${ }^{3} \mathrm{H}$ concentration for the CS case

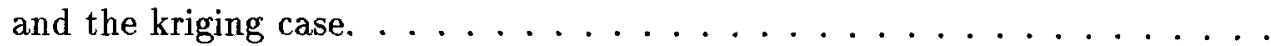

7.16 Histories of the spreading parameter in the x-direction, $\sigma_{x}$, for the mean CS and the kriging cases. $\sigma_{x}$ is the square root of the second moment of ${ }^{3} \mathrm{H}$ concentration distribution in the vadose zone. . . . . . . . . . .

7.17 Histories of the spreading parameter in the $z$-direction, $\sigma_{z}$, for the mean CS and the kriging cases. $\sigma_{z}$ is the square root of the second moment of ${ }^{3} \mathrm{H}$ concentration distribution in the vadose zone. . . . . . . . . . .

7.18 Comparison of total ${ }^{3} \mathrm{H}$ activity histories in the vadose zone for the CS and

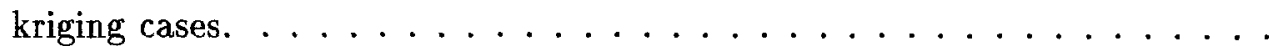

7.19 Steady-state water content versus infiltration rate for a realization of soil permeability field generated by conditional simulation. . . . . . . . .

7.20 Histogram of mean liquid saturation after initialization for simulation runs using soil properties from 100 realizations. . . . . . . . . . . . . 113

7.21 Peak groundwater ${ }^{3} \mathrm{H}$ concentration histories for various infiltration rates. . 115

7.22 Histories of total groundwater ${ }^{3} \mathrm{H}$ activity for various infiltration rates. . . . 115

7.23 Histories of the plume's center-of-mass depth for various infiltration rates. . 116

7.24 Histories of the ${ }^{3} \mathrm{H}$ plume's spreading parameter, $\sigma_{x}$, for various infiltration rates. . . . . . . . . . . . . . . . . . .

7.25 Steady-state liquid saturation profile through the leak node for four different infiltration rates. . . . . . . . . . . . . . . . 118

7.26 Relationship between vertical liquid saturation and permeability profiles through leak node. Liquid saturation profile shown for an infiltration rate of $2.0 \mathrm{in} / \mathrm{yr} .119$

7.27 Results of neutron probe field measurements of water content profiles in Boreholes 17, 18, and 19, conducted in November 1991. Lithologic descriptions shown for Boreholes 17 and 19 obtained from analysis of core samples. (After

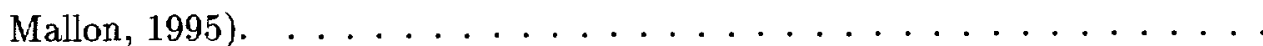

7.28 Effect of vapor diffusion on peak groundwater ${ }^{3} \mathrm{H}$ concentration history for various infiltration rates. . . . . . . . . . . . . . .

7.29 Effect of vapor diffusion on groundwater ${ }^{3} \mathrm{H}$ activity history for various infil-

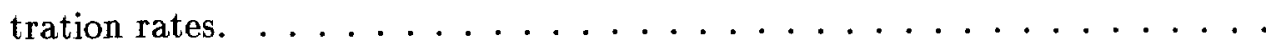

7.30 Effect of vapor diffusion on soil water ${ }^{3} \mathrm{H}$ concentration for an infiltration rate of $0.0 \mathrm{in} / \mathrm{yr}$. Concentrations are shown along a horizontal line through the depth of plume's center-of-mass at $20 \mathrm{yr} . \ldots \ldots \ldots$

7.31 Effect of vapor diffusion on soil water ${ }^{3} \mathrm{H}$ concentration for an infiltration rate of $1.0 \mathrm{in} / \mathrm{yr}$. Concentrations are shown along a horizontal line through the depth of plume's center-of-mass at $20 \mathrm{yr} . \ldots \ldots \ldots$

7.32 Effect of vapor diffusion on soil water ${ }^{3} \mathrm{H}$ concentration for an infiltration rate of $5.0 \mathrm{in} / \mathrm{yr}$. Concentrations are shown along a horizontal line through the depth of plume's center-of-mass at $20 \mathrm{yr} . \ldots \ldots \ldots$

7.33 Effect of vapor diffusion on Histories of the horizontal plume dispersion parameter, $\sigma_{x}$, for various infiltration rates. .......... 04 06 
8.1 Images of an east-west section through the 3D permeability field generated by kriging and each of the ten realizations of the field generated by conditional simulation. The section passes through the suspected leak point at E8652, N12780. . . . . . . . . . . . . . . . . . . . . . . . . .

8.2 Grid showing discretization for three-dimensional calculations. . . . . . . .

8.3 Column plot showing peak groundwater ${ }^{3} \mathrm{H}$ concentrations at 20 yr for the ten realizations with partial blacktop cover. . . . . . . . . . . .

8.4 Column plot showing the cumulative flux of ${ }^{3} \mathrm{H}$ into the groundwater at 20 yr for the ten realizations with partial blacktop cover. . . . . . . . . . .

8.5 Column plot showing ${ }^{3} \mathrm{H}$ plume arrival times at water table for the ten realizations with partial blacktop cover. . . . . . . . . . . . .

8.6 Column plot showing time of occurrence of the peak groundwater concentration for ten realizations with partial blacktop cover.

8.7 History of total ${ }^{3} \mathrm{H}$ activity in the vadose zone with partial blacktop cover. The three plots are 1) the average for Realizations rl3d101 through rl3d110, 2) $\mathrm{rl3d} 103$, and 3$) \mathrm{rl} 3 \mathrm{~d} 110 \ldots \ldots \ldots \ldots \ldots$

8.8 History of peak soil water ${ }^{3} \mathrm{H}$ concentration in the vadose zone with partial blacktop cover. The three plots are 1) the average for Realizations rl3d101 through $\mathrm{rl3d} 110,2) \mathrm{rl3d} 103$, and 3 ) $\mathrm{rl3d} 110 \ldots \ldots \ldots \ldots$

8.9 History of peak groundwater ${ }^{3} \mathrm{H}$ concentration in the vadose zone with partial blacktop cover. The three plots are 1) the average for Realizations rl3d101 through $\mathrm{rl3d} 110,2) \mathrm{rl} 3 \mathrm{~d} 103$, and 3$) \mathrm{rl} 3 \mathrm{~d} 110 \ldots \ldots \ldots \ldots$

8.10 History of cumulative flux of ${ }^{3} \mathrm{H}$ into the groundwater with partial blacktop cover. The three plots are 1) the average for Realizations rl3d101 through $\operatorname{rl3d} 110,2) \mathrm{rl3d} 103$, and 3) $\mathrm{rl3d} 110 \ldots \ldots \ldots \ldots \ldots$

8.11 History of total ${ }^{3} \mathrm{H}$ activity in the groundwater with partial blacktop cover. The three plots are 1) the average for Realizations rl3d101 through rl3d110,

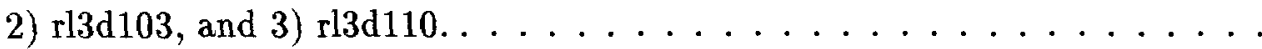

8.12 History of depth of plume's center-of-mass in the vadose zone with partial blacktop cover. The three plots are 1) the average for Realizations rl3d101 through rl3d110, 2) rl3d103, and 3) rl3d110. . . . . . . . . . . .

8.13 History of the spreading parameter $\sigma_{x}$ with partial blacktop cover. The three plots are 1) the average for Realizations rl3d101 through $\mathrm{rl3d} 110,2) \mathrm{rl3d} 103$, and 3$)$ rl3d110. . . . . . . . . . . . . . . . . .

8.14 History of the spreading parameter $\sigma_{y}$ with partial blacktop cover. The three plots are 1) the average for Realizations rl3d101 through rl3d110, 2) rl3d103,

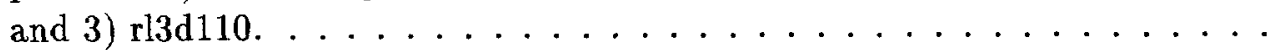

8.15 Effect of blacktop on peak groundwater concentration history for Realization

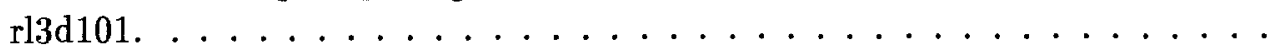

8.16 Effect of blacktop on peak groundwater concentration history for Realization rl3d110. . . . . . . . . . . . . . . . . . .

8.17 Effect of blacktop on cumulative flux of ${ }^{3} \mathrm{H}$ into the groundwater, for Real-

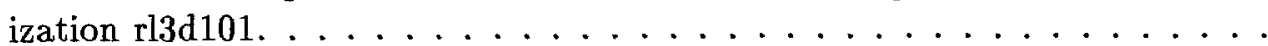

8.18 Effect of blacktop on cumulative flux of ${ }^{3} \mathrm{H}$ into the groundwater, for Real-

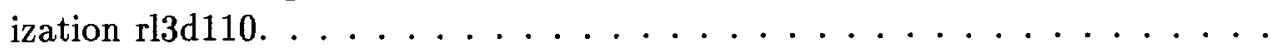

8.19 Effect of blacktop on movement of the plume's center-of-mass in the vadose zone, for Realization $\mathrm{rl3d} 101 . \ldots \ldots \ldots \ldots$. . . . . . . . . 156 
8.20 Effect of blacktop on movement of the plume's center-of-mass in the vadose zone, for Realization rl3d110. . . . . . . . . . . . . . .

8.21 Peak groundwater ${ }^{3} \mathrm{H}$ concentrations for ten kriging runs with partial blacktop cover. The permeability field was the same for each run, but the van Genuchten parameter and porosity fields varied from run to run. . . . . . .

8.22 Effect of blacktop on history of peak groundwater ${ }^{3} \mathrm{H}$ concentration, using permeability field rl3d301 from kriging. . . . . . . . . . . . . .

8.23 Effect of blacktop on history of cumulative ${ }^{3} \mathrm{H}$ activity entering the groundwater, using permeability field rl3d301 from kriging. . . . . . . . . . .

8.24 Effect of blacktop on history of peak groundwater ${ }^{3} \mathrm{H}$ concentration, using permeability field $\mathrm{rl} 3 \mathrm{~d} 310$ from kriging. . . . . . . . . . . . .

8.25 Effect of blacktop on history of cumulative ${ }^{3} \mathrm{H}$ activity entering the groundwater, using permeability field rl3d 310 from kriging. . . . . . . . . . .

8.26 Images of vadose zone soil water ${ }^{3} \mathrm{H}$ concentrations along east-west section through the leak for simulation run using stochastic realization rl3d108. . .

8.27 Soil water tritium concentration profile along vertical line through leak node at various times. Results of run using stochastic realization rl3d108.

8.28 History of maximum vadose zone soil water ${ }^{3} \mathrm{H}$ concentration for stochastic realization $\mathrm{rl3d} 108$ and for the mean CS case. . . . . . . . . . .

8.29 History of maximum groundwater ${ }^{3} \mathrm{H}$ concentration for best-fit stochastic

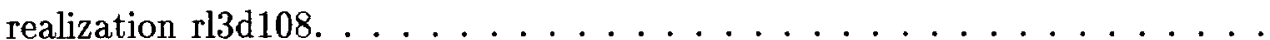

8.30 Images of groundwater ${ }^{3} \mathrm{H}$ concentrations at the water table, from best-fit stochastic realization $\mathrm{rl} 3 \mathrm{~d} 108$. Outer edge of plume shown is the groundwater standard for ${ }^{3} \mathrm{H}, 20,000 \mathrm{pCi} / \mathrm{L} . \ldots \ldots \ldots \ldots \ldots$

8.31 Groundwater ${ }^{3} \mathrm{H}$ concentrations along an east-west line at the water table directly beneath the leak. Results from best-fit stochastic realization rl3d108 at various times. . . . . . . . . . . . . . . . . .

\section{List of Tables}

2.1 Vapor pressure (V.P.) of $\mathrm{H}_{2} \mathrm{O}$ and HTO in the temperature range of $10-100^{\circ} \mathrm{C}$ (After Popov et al., 1960). . . . . . . . . . . . . . .

3.1 Borehole locations and peak ${ }^{3} \mathrm{H}$ concentrations from initial site characterization and monitoring program for the Building 292 release. The leak point was assumed as the pipe inlet on the north face of the tank, with LLNL coordinates $(8652.1,12780.5) . \ldots \ldots \ldots \ldots$

3.2 Dry bulk density, porosity, initial water saturation, and saturated hydraulic conductivity for 16 Soil Samples in the LLNL Building 292 Area. . . . . .

3.3 Particle Size Distribution Parameters and Saturated Hydraulic Conductivity for 16 Soil Samples in the LLNL Building 292 Area. . . . . . . . . . . .

3.4 van Genuchten's soil water retention and hydraulic conductivity parameters for 16 soil samples in the LLNL Building 292 Area. . . . . . . . . . . .

5.1 Tritium activities computed for quadrants of the ${ }^{3} \mathrm{H}$ release site centered at the leak point which has LLNL coordinates E8652, N12780.5. Each quadrant is taken as a square of length $33 \mathrm{ft} \ldots \ldots \ldots \ldots 73$

6.1 List of independent variables. . . . . . . . . . . . . . 78 
7.1 CS mean and coefficient of variation of peak groundwater ${ }^{3} \mathrm{H}$ concentrations $100 \mathrm{ft}$ downstream of leak, compared with peak kriging concentrations. . .

7.2 Comparison of vadose zone ${ }^{3} \mathrm{H}$ activity at various times for the mean CS case, the kriging case, and estimates based on ${ }^{3} \mathrm{H}$ losses due only to radioactive

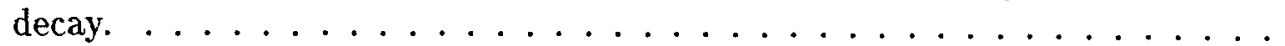

7.3 Estimate of time required for various relative mass fractions of HTO to reach a distance of $10 \mathrm{ft}$ from the source by vapor diffusion. Estimates made by assuming one-dimensional diffusion, $\phi=0.35$, and $S_{l}=0.75 . \ldots \ldots$.

8.1 Summary of tritium transport results for three-dimensional simulation runs using realizations of soil permeability fields derived by conditional simulation. Run $\mathrm{rl} 3 \mathrm{~d} 201$ is a repeat of $\mathrm{rl} 3 \mathrm{~d} 101$ with the blacktop removed, and Run $\mathrm{rl} 3 \mathrm{~d} 210$ is a repeat of $\mathrm{r} 13 \mathrm{~d} 110$ with the blacktop removed. . . . . . . . .

8.2 Summary of tritium transport results for three-dimensional simulation runs using a soil permeability field derived by ordinary kriging, with van Genuchten parameters and porosity selected using soil property correlations and random sampling. The same permeability field is used for each run, while the van Genuchten parameters and porosity vary from run to run. Run $\mathrm{rl} 3 \mathrm{~d} 401$ is a repeat of rl3d301 with the blacktop removed, and Run rl3d410 is a repeat of rl3d310 with the blacktop removed. . . . . . . . . . . . . .

8.3 Comparison of some parameters that describe the ${ }^{3} \mathrm{H}$ transport for simulations using soil properties from conditional simulation and kriging. The blacktop cover was in place for these simulations. . . . . . . . . . . . .

8.4 Comparison of root mean squared difference (RMSD) between concentration fields from numerical calculations using conditional simulation and from field sampling. . . . . . . . . . . . . . . . . .

8.5 Comparison of root mean squared difference (RMSD) between concentration fields from numerical calculations using kriging and from field sampling. . .

B.1 Retention data for 16 soil samples from the LLNL Building 292 area. The data, tabulated here as negative pressure head $\psi$ versus volumetric water content $\theta$, were obtained from the initial drainage curve. . . . . . . .

C.1 $\mathrm{K}_{s}$ with three-dimensional coordinates for the 57-sample data set. Hydraulic conductivity obtained by direct measurement and by correlation with particle size data. . . . . . . . . . . . . . . . . .

C.2 $\mathrm{K}_{s}$ with three-dimensional coordinates for the 132 -sample data set. Hydraulic conductivity obtained by direct measurement and by correlation with particle

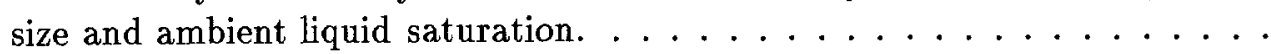

D.1 Maximum groundwater ${ }^{3} \mathrm{H}$ concentration and time of occurrence of the maximum for simulation runs using 100 realizations of soil property fields generated by conditional simulation. . . . . . . . . . . . 


\section{Acknowledgments}

I appreciate the support I received from many individuals during my studies at Berkeley. I am deeply indebted to Doctor john Nitao of LLNL for his guidance, support, and encouragement throughout the various phases of this research. This dissertation would not be possible without our frequent meetings to discuss strategy and technical details, and to review preliminary results and drafts. I must credit John with playing a central role not only in this research, but also in my career development at LLNL. I'm very greatful that I was able to benefit from John's keen mind and humble mentoring. He has taught me things "I never knew I never knew". They say if you owe the bank a thousand dollars then you have a problem, but if you owe a million dollars then the bank has a problem. With this perspective, I believe that John has a problem.

I am very greatful to my academic advisor, Professor Neville Cook, who gave me the opportunity to pursue my doctoral degree. I have benefitted greatly from Professor Cook's guidance and encouragement during the course of my studies at Berkeley. His deep devotion to the academic and professional development of his students is truly special. I consider myself very lucky to be one of his students.

I would like to thank the members of my dissertation committee for their insightful and timely reviews of the manuscript. Along with Doctor Nitao and Professor Cook (cochair), the committee members who helped to guide this research are Professors Tad Patzek (co-chair), Fiona Doyle, and Nicholas Sitar.

Many thanks to the students and colleagues at UC Berkeley, LBNL, and LLNL, who have helped this research through technical discussions and encouragement. I am especially

greatful to Doctor Erica Schleuter of LBNL who always found the appropriate words of 
encouragement to keep me focussed. Acknowledgements are due to the following colleagues at LLNL: Steve Blair, Barbara Mallon, Bob Gelinas, John Ziagos, Leah Rogers, Andy Tompson, Charles Carrigan, Tom Buscheck, Ken Jackson, Jesse Yow, Denice Williams, and Adrienne Ridolfi. I also want to express my gratitude to Dan Fletcher and Paul Harding who helped to prepare the figures.

I greatfully acknowledge the support of the Environmental Restoration Division at LLNL, and the Yucca Mountain Project.

Special thanks to my dad, Charles Lee, who taught me the work ethic, and my mom, Linda Lee, whose love and support gave me the strength and courage to aim for the stars. For their love and encouragement, I would also like to thank my sister, Erlene, and brothers Charles, Aubrey, Oscar, Michael, Desmond, Terry, Jerry, and Brian.

Last but not least, I would like to thank my wife Seham, my sons Lawrence and Roderick, and my daughter Shaima. It was their love that gave me the energy to complete this dissertation. 



\section{Introduction}

The role of the vadose zone (or unsaturated zone) in groundwater contamination has received increasing attention recently. This attention is caused by rising public interest in groundwater contamination, and the recognition by groundwater professionals that most sources of groundwater contamination originate at the ground surface or within the vadose zone. Contaminants in the vadose zone often leak into the groundwater over periods that extend for decades after the original source is removed. Therefore, the vadose zone may act as a secondary source of contamination to the groundwater. The emerging approach adopted by investigators is to analyze the behavior of the contaminant in the entire subsurface environment, instead of the past practice of focusing almost exclusively on the saturated zone. This new awareness of the role of the vadose zone in groundwater contamination highlights the need for improved understanding of the controlling processes that affect migration of chemicals in partially saturated geologic media.

One of the more serious challenges faced by investigators in subsurface hydrologic studies is the characterization of soil heterogeneity. The hydraulic properties of earth materials exhibit varying degrees of spatial variability, and highly variable soil properties are the rule rather than the exception. Permeability, for example, is often observed to vary over orders of magnitude within a distance of a few feet or less. Even with the most extravagant site characterization program, there is usually substantial uncertainty associated with estimates of soil properties at unsampled locations. Interpolation schemes commonly used to estimate soil properties at unsampled locations usually modify the spatial variability of the property and may lead to misleading modeling results.

Site characterization and contaminant transport modeling in the vadose zone present problems that in many ways are even more challenging than the problems faced in the 
saturated zone. A much larger number of model parameters is needed for the vadose zone, and therefore the interaction between parameters becomes more important. Moreover, many vadose zone parameters are more difficult and costly to measure. The equations of motion for unsaturated flow are nonlinear due to the dependence of both effective hydraulic conductivity and moisture content on matric potential. This nonlinearity makes unsaturated flow problems more difficult to solve than saturated flow problems, and results in a much greater computational burden for numerical solutions.

There is a great need to find effective methods of dealing with spatial heterogeneity in the vadose zone. Soil property variability is believed to have a much greater impact on solute transport in the vadose zone than in the saturated zone. Many investigators question the validity of model results obtained using effective hydraulic properties obtained by averaging over local values (Gee et al., 1991). New approaches using stochastic subsurface transport theories attempt to quantify the spatial variability due to soil heterogeneity instead of averaging which usually results in artificial smoothing (Sudicky and Huyakorn, 1991). While stochastic approaches appear quite promising in addressing uncertainty, many modelers are unable to find an effective way to apply these techniques to practical field problems. The largely unanswered question remains: how do we model contaminant transport at a heterogeneous vadose zone site with limited field data?

The soil close to an underground tank storing tritiated water (HTO) in the Building 292 Area of the Livermore Site of Lawrence Livermore National Laboratory (LLNL) was contaminated with tritium at levels measured up to 220 million $\mathrm{pCi} / \mathrm{L}$ of soil water. The EPA drinking water standard for tritium is $20,000 \mathrm{pCi} / \mathrm{L}$. The soil is made up of highly heterogeneous fluvial and lacustrine sediments, dominated by silts and clays, with a small percentage of sands and gravels. Tank leakage apparently resulted in a plume of tritium in 
the vadose zone, with lower concentrations reaching the water table about $48 \mathrm{ft}(14.6 \mathrm{~m})$ below the ground surface. The leak history is unclear. However, it is known that the tank contained tritiated water from 1977 through 1987. A site characterization and monitoring program has since been initiated (Mallon, 1995). The program includes installation of a number of borings and wells, soil water and soil gas sampling, water content measurement using neutron probes, and laboratory measurement of saturated hydraulic conductivity, water retention curves, and particle size distribution.

The tritium release presents a rare opportunity for studying the applicability of numerical modeling and geostatistics to vadose zone transport through heterogeneous soils at a moderately well monitored field site in a semiarid environment. Because tritium is one of the best known soil and ground water tracers, the release also offers a chance to study liquid and gas movement in the soil environment.

The primary objective of this dissertation is to apply numerical modeling and geostatistical techniques to study the transport behavior of tritium in the heterogeneous vadose zone at the release site. Using the limited data generated from site characterization and monitoring, we formulate a strategy for applying numerical modeling and conditional simulation techniques to study the impact of uncertainty, due to variability in the hydraulic properties of the soil, on transport calculations. This strategy incorporates the development of soil property correlations to maximize the utility of scarce data. We also investigate the relative importance of different transport mechanisms affecting the fate of tritium in the soil, and estimate the impact of the release on future soil and groundwater quality at the site. A central feature of the study is a Monte Carlo analysis of tritium transport to investigate the effect of soil property uncertainty on the transport calculations. The analysis includes 100 two-dimensional (2D) numerical simulation runs using stochastic realizations 
of soil property fields generated by conditional simulation and soil property correlation. We compare results of the Monte Carlo analysis with results of a simulation run that used soil properties generated by ordinary kriging. We follow the $2 \mathrm{D}$ analysis by $3 \mathrm{D}$ simulations on 10 stochastic realizations of soil property fields, and again compare the transport results with results of a simulation using a field generated by ordinary kriging. The 3D analysis includes site features that could not be included in the $2 \mathrm{D}$ analysis. The impact of the release on future groundwater quality at the site is forecast based on average groundwater tritium concentrations from the $3 \mathrm{D}$ simulations and concentrations obtained from the realization that best matches the vadose zone concentrations measured in the field. We also varied the van Genuchten parameters for the 3D permeability field derived by kriging and observed the impact on modeled vadose zone transport and groundwater quality.

We model the tritium transport as a two-phase, three-component system. The two phases are liquid and gas, and the three components are water, tritiated water, and air. Air is treated as a pseudocomponent with averaged properties. Components may partition between the two phases and tritium is subject to radioactive decay. We are using the NUFT (Nonisothermal Unsaturated Flow and Transport) code to perform the numerical modeling. NUFT (Nitao, 1993) is a suite of multiphase, multicomponent models for numerical solution of isothermal or nonisothermal fluid flow and chemical transport in porous media. The code was developed at LLNL primarily for application to the Livermore Site where the soil and groundwater are contaminated with VOCs and other chemicals.

Because of the high degree of uncertainty in site characterization, due to soil heterogeneity and limited data availability, we rely heavily on stochastic analysis in our effort to predict the impact of the release on the groundwater. Lack of reliable information on the source term contributes an additional component of uncertainty to our prediction of the 
behavior of the plume. Our approach is as follows:

- Develop conceptual and mathematical models of tritium transport in the soil.

- Perform statistical and geostatistical analyses of field and laboratory data; analysis includes construction of soil property correlations and permeability variograms.

- Apply geostatistical techniques, including stochastic simulation, to estimate the threedimensional distribution of flow and transport coefficients for the heterogeneous soil. Soil properties are generated from sample data by both kriging and conditional stochastic simulation.

- Apply geostatistical techniques to field measurements of tritium concentration to estimate the full three-dimensional distribution of tritium at the site, and compute the total activity of tritium in the vadose zone.

- Use conditional simulation to generate 100 realizations of the permeability field and perform a $2 \mathrm{D}$ simulation run on each field to assess the statistics of tritium transport for different realizations. Transport statistics accumulated include plume watertable arrival times, peak groundwater concentrations, movement of the plume's center-ofmass, peak vadose zone concentration, and vadose zone plume geometry parameters. These stochastic results are compared with results obtained from a simulation using a permeability field generated by kriging.

- Conduct sensitivity analyses to study the effect of vapor diffusion and infiltration on ${ }^{3} \mathrm{H}$ transport.

- Perform 3D simulation runs and use the results to forecast the impact of the release on future soil and groundwater quality at the site. A number of $3 \mathrm{D}$ runs are conducted 
on permeability fields generated by conditional simulation and kriging. We conduct simulation runs on the permeability field from kriging using randomly selected van Genuchten parameters.

Chapter 2 of this dissertation presents reviews of tritium in the environment and chemical transport in heterogeneous vadose zone soils. The tritium release at LLNL and the main features of the subsequent site characterization and monitoring program are described in Chapter 3. In Chapter 4, we discuss the application of soil property correlations, geostatistics, and stochastic simulation to estimate soil properties at unsampled locations. The application of kriging to field data for the estimation of concentrations and total tritium activity at the site is addressed in Chapter 5 . A conceptual model and the resulting mathematical model of tritium transport in the vadose zone are outlined in Chapter 6 . The NUFT code, used to make the numerical calculations, is also described in Chapter 6. Chapter 7 presents results of the $2 \mathrm{D}$ analysis of transport runs on 100 different permeability fields generated by conditional simulation, and results of sensitivity analyses to study the effect of vapor diffusion and infiltration on ${ }^{3} \mathrm{H}$ transport. Results of fully three-dimensional runs are presented in Chapter 8 , followed by a summary and a conclusion section in Chapter 9 . 


\section{Background}

\subsection{Introduction}

In this chapter we review the physical properties of ${ }^{3} \mathrm{H}$ and the behavior of the isotope in the environment, including previous studies of ${ }^{3} \mathrm{H}$ transport in the subsurface. We also examine the state of contaminant transport modeling in the vadose zone.

\subsection{Tritium in the Environment}

Tritium $\left({ }^{3} \mathbf{H}\right)$ is a radioactive isotope of hydrogen that decays to the noble gas helium 3 $\left({ }^{3} \mathrm{He}\right)$ by low-energy $\beta$-emission. ${ }^{3} \mathrm{H}$ has a half-life of 12.4 years. It is also the heaviest isotope of hydrogen. Two other common isotopes of hydrogen are stable: hydrogen or proteum $\left({ }^{1} \mathrm{H}\right)$, and deuterium or "heavy hydrogen" $\left({ }^{2} \mathrm{H}\right)$. The relative abundance of these three hydrogen isotopes in natural water is about $99.984 \%$ proteum, $0.016 \%$ deuterium, and 0-10-15\% tritium (Freeze and Cherry, 1979).

\subsubsection{Sources of ${ }^{3} \mathbf{H}$}

${ }^{3} \mathrm{H}$ production by natural processes was discovered by Libby (1946) and has been reviewed by Nir et al. (1966). ${ }^{3} \mathrm{H}$ is a normal constituent of the atmosphere and biosphere, produced by the fission of radioactive elements in the earth's crust, as well as by cosmic ray irradiation of stable nitrogen in the atmosphere (NCRP Report, 1979). The natural occurrence of ${ }^{3} \mathrm{H}$ in precipitation has been reported by Van Grosse et al. (1951). Other sources that release ${ }^{3} \mathrm{H}$ to the environment are tritium separation plants, nuclear power reactors, nuclear fuel reprocessing plants, particle accelerators, and the detonation of nuclear devices.

${ }^{3} \mathrm{H}$ has become popular as a groundwater tracer and dating tool since the early $1950 \mathrm{~s}$ after the atmospheric concentrations over continental areas had increased substantially as a result of atmospheric testing of high-yield thermonuclear devices beginning in 1953 (In- 


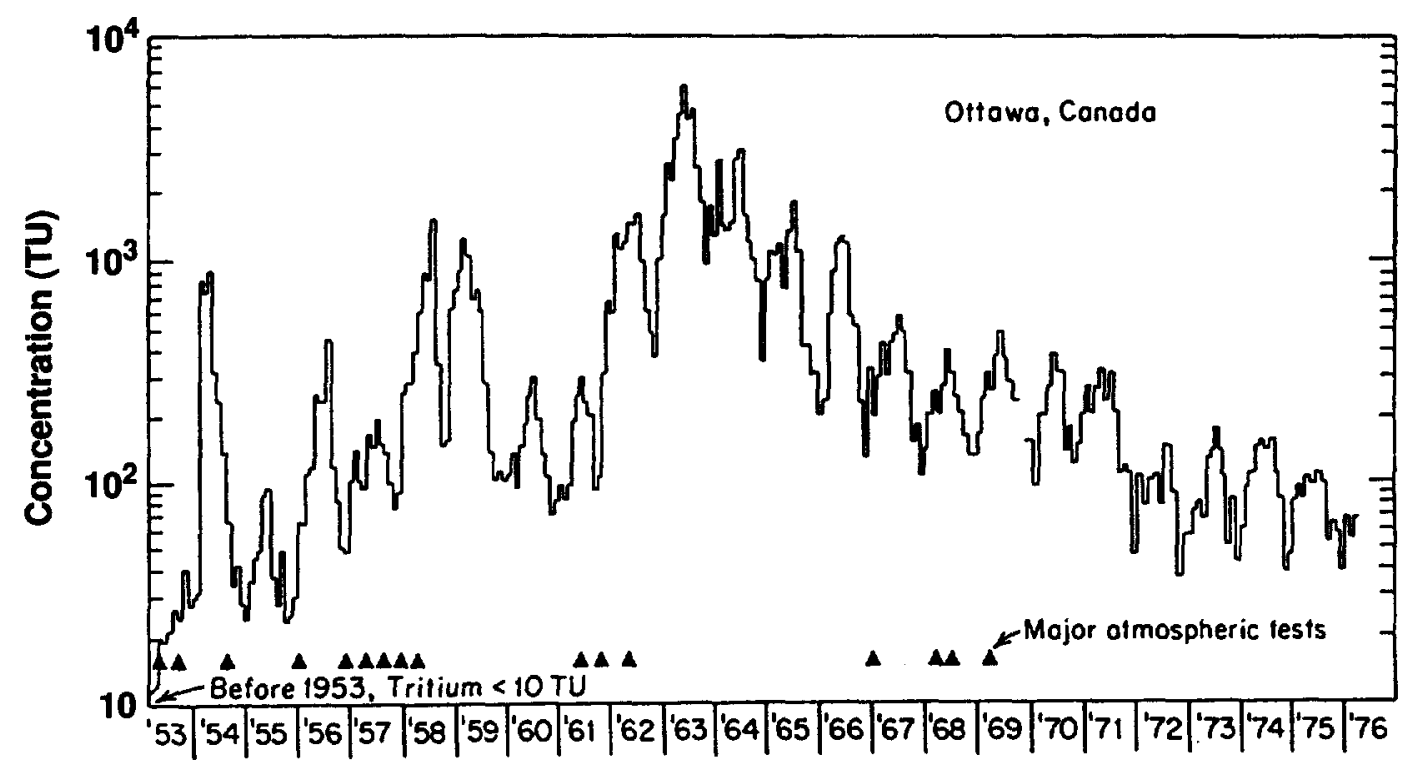

Figure 2.1: Variations of ${ }^{3} \mathrm{H}$ concentration in precipitation at Ottawa, Canada between 1953 and 1976. Mean monthly concentrations are shown. (After Freeze and Cherry, 1975).

ternational Atomic Energy Agency (IAEA), 1983). Prior to that time, almost all ${ }^{3} \mathrm{H}$ in the atmosphere was produced naturally. Rainwater concentrations in Ottawa, Canada, between 1953 and 1976 are shown in Figure 2.1. The concentrations are shown in tritium units (TU). $\mathrm{A} \mathrm{TU}$ is the equivalent of one tritium atom in $10^{18}$ atoms of hydrogen, which equates to 3.2 $\mathrm{pCi} / \mathrm{L}$ water. The ${ }^{3} \mathrm{H}$ fallout from thermonuclear detonations caused concentrations in the northern hemisphere precipitation to increase by orders of magnitude from less than one TU to thousands of TUs, peaking in 1963-1964. Rainwater ${ }^{3} \mathrm{H}$ concentrations varied from location to location, but the dramatic increase seen in Ottawa was observed in many other areas in the northern hemisphere. Concentrations have been decreasing since 1964 .

A large fraction of the tritium produced in North America has been released to the ground (Horton, 1963; Parsons, 1963; Hawkins and Schmaltz, 1965). At Hanford, Washington, approximately one-half to two-thirds of the tritium produced by fission has been 
released to the ground (Haney et al., 1962). At Savannah River, nearly all of the tritiated water from the aqueous stream used in fuel reprocessing was discharged to open seepage pits, and most of this tritium eventually entered the ground (Horton, 1963). Approximately $18,000 \mathrm{Ci}$ of tritium was released to the ground at the National Reactor Testing Station in Idaho between 1963 and 1965 (Hawkins and Schmaltz, 1965). Tritium was also released to waste seepage pits at the Oak Ridge National Laboratory during the period 1952 to 1966 .

\subsection{2 ${ }^{3} \mathrm{H}$ as Hydrologic Tracer}

Tritium $\left({ }^{3} \mathrm{H}\right)$ is now one of the most commonly used tracers in hydrology. The increase in ${ }^{3} \mathrm{H}$ concentrations in precipitation caused by bomb testing has turned out to be a valuable tool in many types of vadose zone and groundwater investigations. The presence of large concentrations of ${ }^{3} \mathrm{H}$ in groundwater is often interpreted to imply large recharge to the groundwater zone sometime after 1953 . Beginning in the early $1960 \mathrm{~s},{ }^{3} \mathrm{H}$ has been used in a large number of saturated and unsaturated solute transport studies (e.g., Brown, 1961; Biggar and Nielsen, 1962; Krupp et al., 1972; Payne, 1972; James and Rubin, 1986). ${ }^{3} \mathrm{H}$ has been used as an environmental tracer in studies of surface water budgets (e.g., Kaufman and Libby, 1954; Brown, 1961), groundwater age, flow velocities, and recharge (e.g. Egboka, 1983; Larson et al., 1987; Robertson and Cherry, 1989). The tracer is also used to measure dispersion in groundwater (Atakan, 1972; Egboka, 1983), and diffusion in groundwater (Foster, 1975).

Tritium has a number of advantages over other tracers used in hydrology:

- It is incorporated directly into the water molecule and therefore reduces the problem of tracer adsorption.

- It is radioactive with a sufficiently long half-life for many practical hydrologic inves- 
tigations.

- It is inexpensive and easily monitored in tracer concentrations.

- For many field investigations, its behavior resembles that of proteum close enough so that its movement depicts the movement of water with an accuracy equal to or better than other commonly used tracers.

\subsection{3 ${ }^{3} \mathrm{H}$ in Soil}

Most of the tritium produced, both natural and anthropogenic, combines with oxygen to form tritiated water (HTO), which may exist as liquid tritiated water or tritiated water vapor. HTO is the most commonly encountered form of tritium in the environment, and is the form in which tritium usually exists in the subsurface. HTO is transferred from the atmosphere to the surface of the earth mainly by precipitation, but there is also some transfer by vapor exchange. Essentially all of the tritium released by nuclear reactors, or by the underground detonation of nuclear devices, is assumed to form HTO.

HTO in soil and groundwater is generally assumed to exhibit the same flow and transport characteristics as water, except for very small differences in vapor pressure (NCRP Report No. 62,1979 ). Table 2.1 compares a few points on the vapor pressure curves of HTO and $\mathrm{H}_{2} \mathrm{O}$. The vapor pressure of HTO is slightly less than the vapor pressure of $\mathrm{H}_{2} \mathrm{O}$, and HTO has a slightly higher boiling point at $100.8^{\circ} \mathrm{C}$ (Popov and Tazemdinov, 1960; Price, 1958). The diffusion coefficient of HTO in natural waters was measured at $25^{\circ} \mathrm{C}$ and found to be about $2.4 \times 10^{-5} \mathrm{~cm}^{2} / \mathrm{s}$ (Wang et al., 1953; Nakayama and Jackson, 1963).

Controlled field experiments to study the behavior of tritium in the environment were conducted in Canada (Burnham et al., 1988) and France (Paillard et al., 1988). In both experiments, a controlled release of tritiated hydrogen (HT) to the atmosphere was con- 
Table 2.1: Vapor pressure (V.P.) of $\mathrm{H}_{2} \mathrm{O}$ and $\mathrm{HTO}$ in the temperature range of $10-100^{\circ} \mathrm{C}$ (After Popov et al., 1960).

\begin{tabular}{c|r|r}
\hline \hline Temp. $\left({ }^{\circ} \mathrm{C}\right)$ & \multicolumn{2}{|c}{ V.P. $(\mathrm{mm}$ of $\mathrm{Hg})$} \\
\cline { 2 - 3 } & $\mathrm{H}_{2} \mathrm{O}$ & $\mathrm{HTO}$ \\
\hline 10 & 9.2 & 8.2 \\
25 & 23.8 & 21.7 \\
40 & 55.3 & 51.4 \\
60 & 149.4 & 141.5 \\
80 & 355.1 & 341.3 \\
100 & 760.0 & 738.8 \\
\hline \hline
\end{tabular}

ducted, and the rate of conversion of HT to HTO measured. The studies found no rapid oxidation of HT in air. The conversion of HT to HTO in soil followed by some re-emission to the atmosphere was responsible for the persistence of HTO in the soil and air.

Measurements at the sites of these controlled field experiments, as well as in the laboratory, suggest that tritiated water is transported through the environment in much the same way as natural water (Murphy et al., 1982). HTO is volatile, and therefore partitions between the aqueous and gas phases of the soil. It may be transported through the soil by gravity and capillary forces, or be removed from the soil surface by evapotranspiration. Amano and Garten (1991) examined the uptake of tritiated water from the soil by plants.

Many laboratory studies have been conducted on the movement of tritium in soil, however, relatively little is known about the movement of this tracer in natural soils. Tritium transport in natural soils has been investigated in a relatively small number of studies (e. g. Schmalz and Polzer, 1969; Gvirtzman and Margaritz, 1986; Phillips et al., 1988). Results from these field studies often contradict findings from laboratory experiments. For example, laboratory column experiments using partially saturated soils usually show more rapid movement of chlorine 36 than tritium (e.g. James and Rubin, 1986), possibly due 
to the anion exclusion effect. In contrast, field studies usually show tritium penetrating substantially faster than chlorine 36 (Phillips et al., 1988). The reason for this difference is unclear.

\subsection{4 ${ }^{3}$ H Measurement}

A common method of analyzing soil samples for soil water ${ }^{3} \mathrm{H}$ concentration is by liquid scintillation counting. Tritium activity is expressed in a number of different units. The SI unit of activity of a radionuclide is the becquerel $(\mathrm{Bq})$. One $\mathrm{Bq}$ equals one disintegration per second. A more commonly used unit is the curie $(\mathrm{Ci})$, equal to $3.7 \times 10^{10} \mathrm{~Bq}$. The specific activity of ${ }^{3} \mathrm{H}$ in soil water, referred to as the soil water concentration in this report, is often expressed in tritium units (TU), or in picocuries per liter $(\mathrm{pCi} / \mathrm{L})$. The conversion factor is $3.2 \mathrm{pCi} / \mathrm{L}$ equals one $\mathrm{TU}$.

HTO is the chemical component treated as the contaminant in numerical calculations for this study. The NUFT code computes HTO concentrations in the liquid and gas phases in either mole fraction or mass fraction. The mass of $\mathrm{HTO}$ having an activity of $1 \mathrm{Ci}$ is

$6.908 \times 10^{-7} \mathrm{~kg}$. This conversion factor is derived in Appendix A. For HTO in water under standard conditions, a specific activity of $1 \mathrm{pCi} / \mathrm{L}$ is equivalent to an $\mathrm{HTO}$ mass fraction of $6.908 \times 10^{-19} \mathrm{~kg} / \mathrm{kg}$.

\subsubsection{Health Hazard}

The transfer of tritium into the human body is by inhalation, ingestion, and by absorption through the skin. Tritium may enter the body as liquid HTO or in a gaseous form. Tritiated water presents a greater biological hazard than tritium gas. External radiation from tritium does not present a serious health hazard, because the horny layers of the skin prevent 
penetration of the low-energy $\beta$-particles. However, the ingestion or inhalation of tritium in any form does present a potential health hazard. It is, therefore, necessary to protect personnel from breathing air contaminated with volatile tritiated water, or drinking water containing high HTO concentrations. The U.S. Environmental Protection Agency's (EPA) drinking water standard for ${ }^{3} \mathrm{H}$ is $20,000 \mathrm{pCi} / \mathrm{L}$ or $6250 \mathrm{TU}$.

Incidents of accidental contamination with tritium have been reported in humans (Levine, 1980). Tritium entering the body, in the form of tritiated water, is rapidly assimilated into body fluids throughout the body (Conklin and Walker, 1987). The kinetics of HTO in the body follows that of water, except that a small portion of the intake becomes organically bound in tissue and is retained for somewhat longer periods. High doses of tritium exposure can lead to clinical symptoms of nausea and exhaustion and even death (Conklin and Walker, 1987).

\subsection{State of Vadose Zone Transport Modeling}

A common theme in all recent reviews of vadose zone flow and transport modeling is the recognition that our ability to measure, model, and manage hydrologic processes in the vadose zone is seriously complicated by the extreme heterogeneity of the hydrologic environment. van Genuchten (1991), in his report documenting progress and opportunities in hydrologic research for the quadrennium 1987-1990, points out that the problem of heterogeneity in subsurface hydrology has resulted in the development of a large number of stochastic models and statistical data collection protocols. van Genuchten also mentions the growing skepticism expressed by many investigators about the validity of the classical Fickian-based advection-dispersion equation for heterogeneous field applications, especially under unsaturated conditions.

Recent studies of flow and transport in the vadose zone were reviewed by Gee et al. 
(1991). The work summarizes our understanding of the subject by reviewing such vadose zone-related issues as unstable flow in layered soil (Hillel, 1987), macropore flow (Germann, 1985), advances in unsaturated flow modeling (Milly, 1988), and solute transport in field soils (van Genuchten and Shouse, 1989). Conferences and workshops were held on topics such as model validation in the unsaturated zone (Wierenga and Bachelet, 1988, 1991), rapid and far-reaching hydrologic processes (Germann, 1988), and estimating soil hydraulic properties (van Genuchten et al., 1991b).

While the classical flow and transport models apparently perform satisfactorily for applications such as homogeneous or well-characterized heterogeneous laboratory soil columns, their effectiveness when applied to heterogeneous field-scale situations is increasingly being questioned (Gee et al., 1991). El-Kadi (1987) used a Monte Carlo analysis to show that neglecting spatial variability in estimating infiltration may lead to unacceptable errors. Field soils are, by nature, usually very spotty with hydraulic properties that exhibit a high degree of spatial variability. Since it is not possible to completely characterize the subsurface, the flow and transport models depend largely on the use of averaged properties. The classical approach, which essentially is current practice, is to ignore the variability or assume that homogeneous parameters in various zones will adequately describe the situation. Such deterministic modeling presumes that the equations are valid in some average sense. It is not known whether unsaturated flow and transport can be modeled in terms of effective hydraulic properties that are averaged over local values. Milly (1988) points out that the highly nonlinear equations of unsaturated flow preclude simply substituting averaged hydraulic properties into Richard's equation to predict flow in heterogeneous soils. Another important drawback of the deterministic approach, identified by Gelhar (1993), is the failure to consider effects of variability and reliability of predictions from the model, 
thus giving the false impression that the model represents exactly what occurs in the field. Transport models are affected by spatial variability in hydraulic properties even more than flow models. In transport processes, variations in hydraulic conductivity have a much greater influence than in the case of flow problems where the main concern is the pressure or head variation in the flow system. Transport processes are affected more because the concentration distribution is substantially influenced by the complicated paths taken by fluids moving through a heterogeneous medium.

Because of the inability of the classical transport models to adequately handle field scale heterogeneity, stochastic models of solute transport continue to be developed and used in the research community. The focus of these stochastic methods is to take relatively limited local observations of a soil property and account for systemwide variability of that property in terms of only statistical characteristics. The actual field and the simulated field are considered realizations of the same spatial random field (Christakos, 1992; Deutsch and Journel, 1992). They share the same mean, covariance or semivariogram, and probability distribution. In addition, the simulated field will honor measured values at the data points if the simulation is conditional. The hope is that the first and second order statistical moments are sufficient to characterize the random variability.

A number of different stochastic models of flow and transport have been presented (Cushman, 1987; Gelhar, 1993). A serious impediment to the application of stochastic transport models is the lack of field-scale testing. Relatively few well-characterized field studies of vadose zone transport have been documented. Two of the few intensely measured field sites useful for validations are described by Polmann et al. (1988) and Butters et al. (1989).

The Monte Carlo method is often used with a large number of stochastic realizations to 
study the effect of soil property uncertainty on numerical calculations. The Monte Carlo method as used here refers to a set of repetitive simulations to solve the deterministic flow and transport problem using different realizations of input parameters and the associated statistical analysis of the results. Freeze (1973) used the Monte Carlo technique to analyze the effect of a baseball batting order on team performance. The technique was also used by Freeze (1975) in a stochastic-conceptual analysis of one-dimensional flow in heterogeneous media, and El-Kadi (1987) to study the effect of uncertainty in unsaturated zone parameters on the variability of infiltration. 


\section{Site Investigation}

\subsection{Introduction}

In this chapter we describe the study site and the main features of the site characterization and monitoring program that was initiated in 1989 to study the extent of soil and groundwater contamination resulting from the Tank $\mathrm{R} 1 \mathrm{U} 1{ }^{3} \mathrm{H}$ release. We briefly describe the release and summarize available soil concentration and soil property data. We will present results of additional processing of these data in Chapters 4 and 5 when we apply geostatistical techniques to estimate soil water ${ }^{3} \mathrm{H}$ concentrations and soil hydraulic properties for the entire study area. Details of the site characterization and monitoring are presented by Mallon et al. (1994), and Mallon (1995).

\subsection{LLNL Site Description}

LLNL is a research facility owned by the U.S. Department of Energy (DOE) and managed by the Regents of the University of California under contract with the DOE. The LLNL Livermore Site is located in Southern Alameda County approximately 3 miles east of the downtown area of Livermore, California. The regional setting of the site is shown in Figure 3.1. The site, including an adjacent buffer zone, occupies approximately 800 acres, with the western boundary adjacent to the eastern Livermore city limits. Figure 3.2 is a plan view of the LLNL Livermore Site showing the location of the ${ }^{3} \mathrm{H}$ release in the Building 292 Area. The land surface is relatively flat: it slopes gently, about 0.5 to 1 degree downward to the northwest. A detailed description of the LLNL Livermore Site is given by Thorpe et al. (1990).

The climate is semiarid, characterized by warm, dry summers and mild, wet winters. The average precipitation is 14 in. per year. About $90 \%$ of the precipitation occurs from November to April and is usually associated with winter storms. The average temperature 


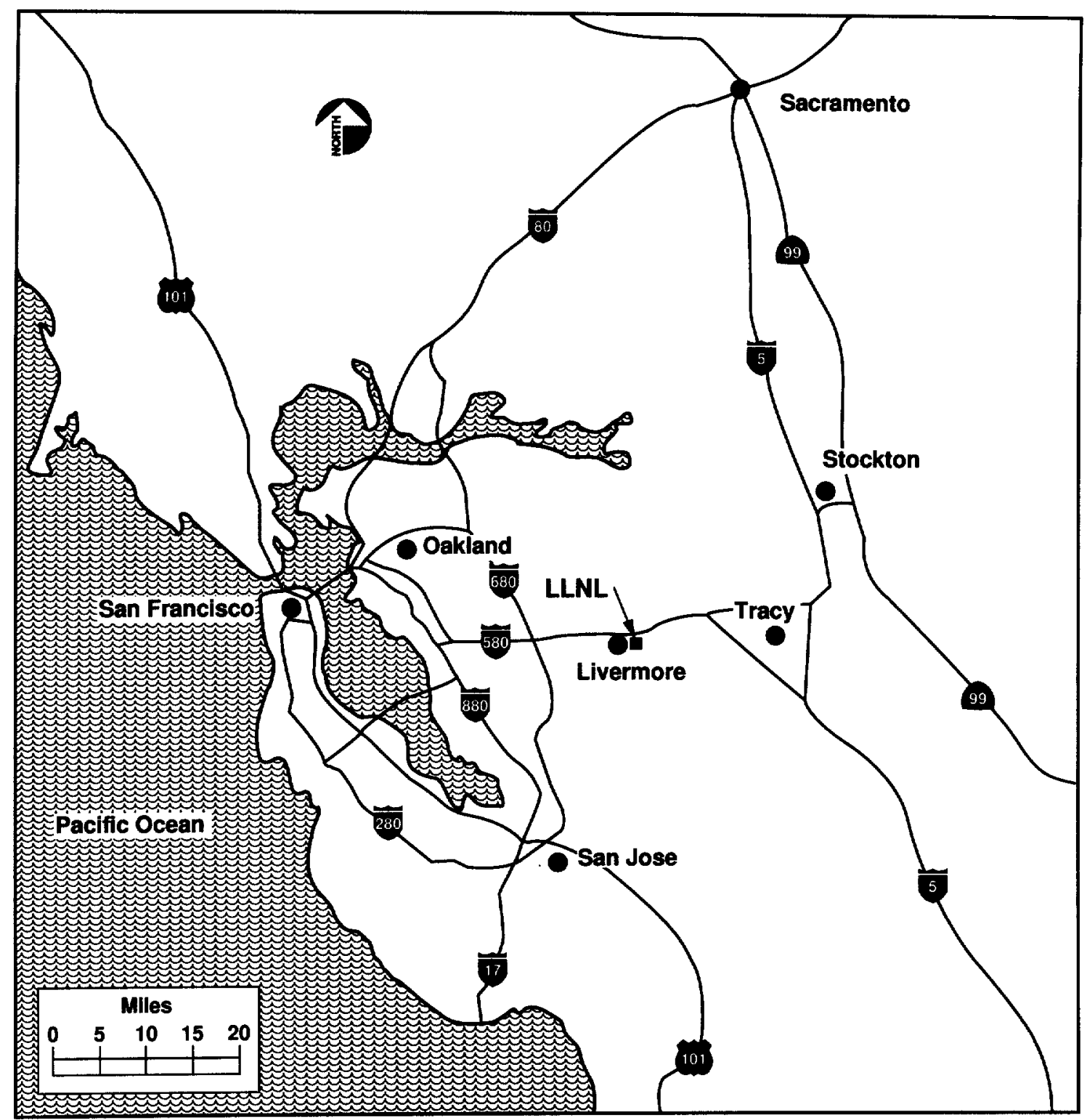

Figure 3.1: Regional setting of the LLNL Livermore Site. 


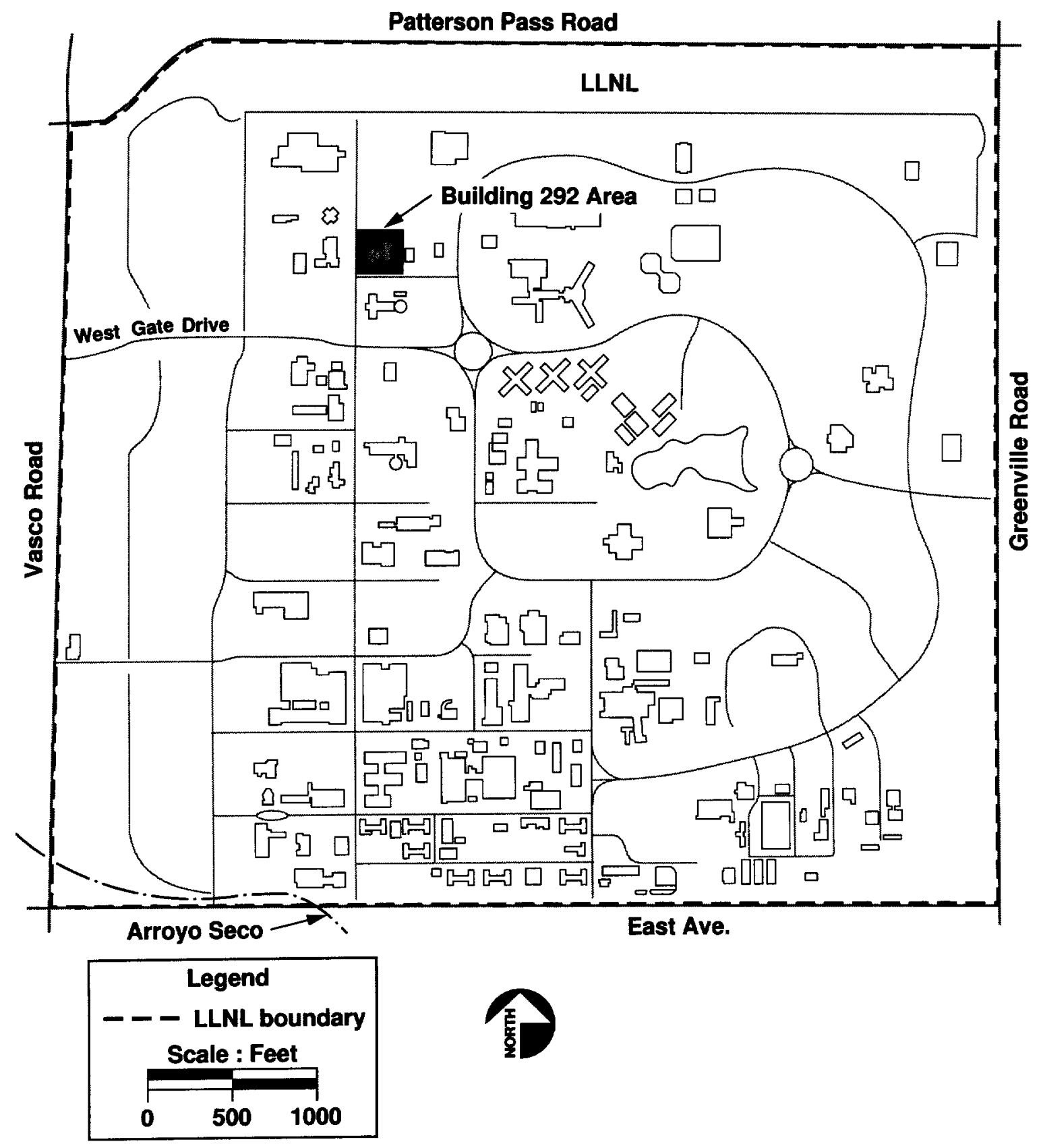

Figure 3.2: Layout of LLNL Livermore Site showing location of the ${ }^{3} \mathrm{H}$ release in the Building 292 Area. 
is $62^{\circ} \mathrm{F}\left(17^{\circ} \mathrm{C}\right)$. Abundant sunshine occurs almost throughout the year.

LLNL is located near the southeastern margin of the Livermore depositional basin where marine and continental sediments have been deposited (Thorpe et al., 1990). Soil at the LLNL site consists of highly heterogeneous fluvial and lacustrine sediments, characterized by complexly interbedded clay, silt, sand, and gravel. The thickness of the vadose zone varies from $130 \mathrm{ft}$ in the southeast corner of the LLNL site to less than $30 \mathrm{ft}$ in the northwest, next to the Rhonewood Subdivision west of LLNL. Details of the geology of the LLNL vicinity are described by Blume and Associates (1972), Herd (1977), Dibblee and Darrow (1981), Sweeney and Springer (1981), Springer (1983), and Carpenter et al. (1980, 1984).

The saturated zone beneath the LLNL site consists of a number of water bearing systems. The uppermost water bearing system is unconfined and is separated from the second system by a horizontally extensive confining layer consisting of low-permeability silt and clay. The upper system, also referred to as the upper aquifer, has a fairly small thickness, ranging up to a few feet. Groundwater flow is generally westward. The hydraulic gradient is steepest near the northeastern corner of LLNL, at about $0.15 \mathrm{ft} / \mathrm{ft}$, and decreases to about 0.002 $\mathrm{ft} / \mathrm{ft}$ west of LLNL.

\subsection{Tritium Release Site}

Figure 3.3 is a three-dimensional schematic of the ${ }^{3} \mathrm{H}$ release site in the Building 292 Area, showing the tank (R1U1) location with respect to nearby buildings, the ground surface, and the water table. The water table in the Building 292 Area is approximately $48 \mathrm{ft}$ below ground surface. The suspected leak point is on the north face where the pipeline enters the tank, approximately $9 \mathrm{ft}$ below the ground surface. Tank R1U1 is $7.3 \mathrm{ft}$ long, $4.0 \mathrm{ft}$ wide, and $4.3 \mathrm{ft}$ deep, with a storage capacity of 1000 gal. Following discovery of the leak, the tank was drained and filled with sand. 


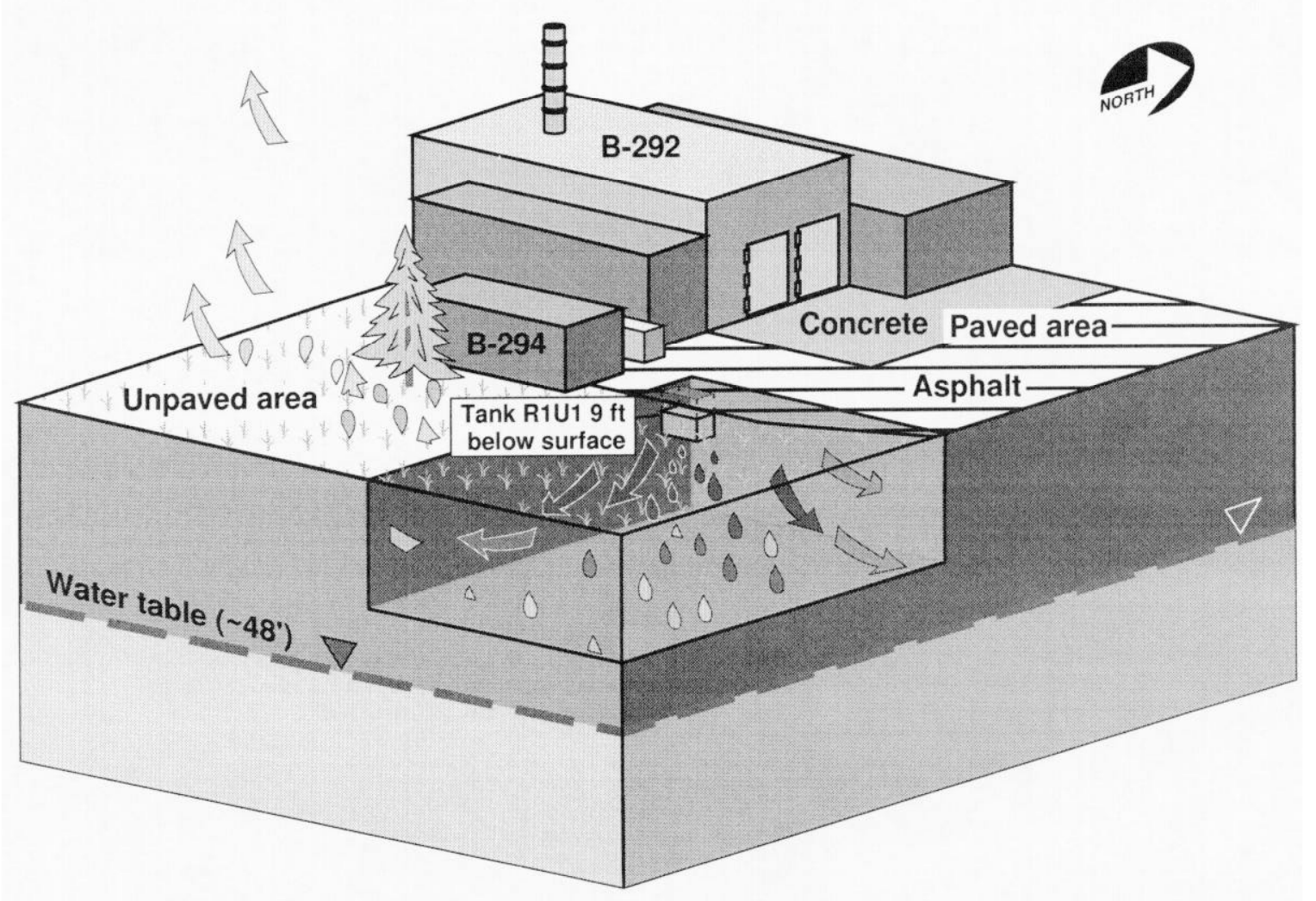

Figure 3.3: Three-dimensional schematic showing the location of Tank R1U1 with respect to the water table and structures in the LLNL Building 292 Area. 
Soil at the release site is partially covered by asphalt. The soil directly above the tank is completely covered by asphalt. The south edge of the asphalt cover is about $6 \mathrm{ft}$ south of the tank. Exposed soil occurs beyond that edge. Some cracks occur on the surface of the asphalt, possibly allowing some limited percolation of water into the soil.

Properties of the upper aquifer in the Building 292 Area were estimated from wells in the vicinity. The aquifer is about $5 \mathrm{ft}$ thick. The water table elevation is about $538 \mathrm{ft}$ but may fluctuate a few feet seasonally, rising during the rainy winter months and falling during the drier months, especially during the summer. The water table elevation also dropped a few feet during the drought of 1986-1992. Groundwater movement follows the general LLNL site trend, flowing in a west to southwesterly direction. Figure 3.4 shows the water table contours in the Building 292 Area. The gradient is about $0.0015 \mathrm{ft} / \mathrm{ft}$ which is a little flatter than gradients measured at other areas of the LLNL site. A slug test conducted in Borehole 1, at the north face of the tank, gave a saturated hydraulic conductivity of $1.4 \times 10^{-3} \mathrm{~cm} / \mathrm{s}(1.7 \mathrm{darcy})$, and a pump test conducted in Borehole MW-607, $200 \mathrm{ft}$ west of the tank, gave a saturated hydraulic conductivity of $4.7 \times 10^{-3} \mathrm{~cm} / \mathrm{s}(5.5$ darcy).

\subsection{Site Characterization and Monitoring}

Site characterization and monitoring were initiated in 1989 , following discovery of elevated concentrations of ${ }^{3} \mathrm{H}$ in the soil around Tank R1U1. By the end of 1992, 20 boreholes had been drilled to study the ${ }^{3} \mathrm{H}$ release problem in the Building 292 Area. In addition, a number of shallow borings were drilled specifically for soil ${ }^{3} \mathrm{H}$ concentration sampling. Details of the site characterization and monitoring program are presented by Mallon (1995).

Three different types of boreholes were constructed: vadose zone monitoring boreholes, piezometers, and boreholes drilled for characterization only. Boreholes drilled only for characterization purposes were carefully grouted on completion. The piezometers also function 


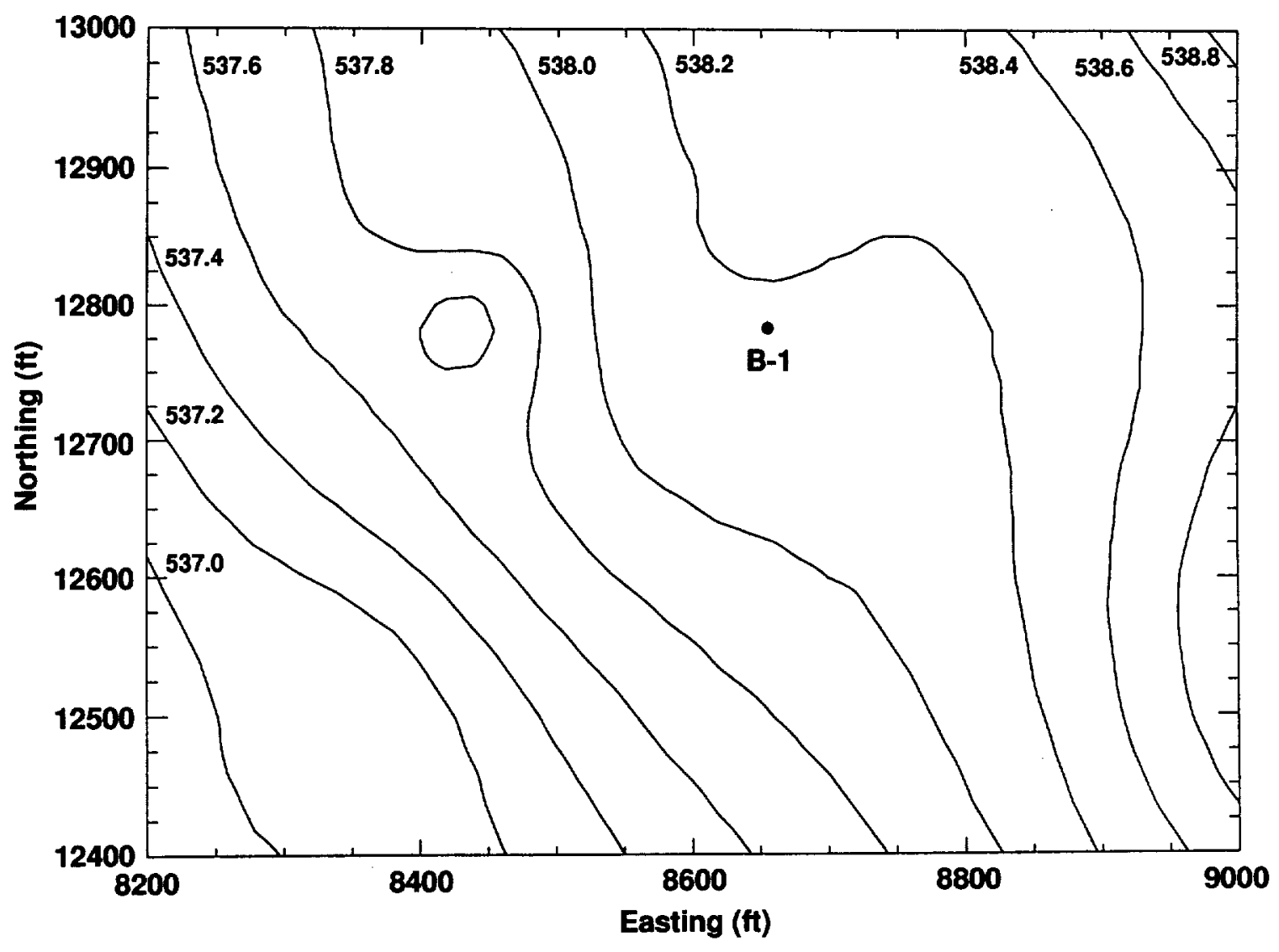

Figure 3.4: Water table elevation contours in the LLNL Building 292 Area. 
as groundwater monitoring wells. Soil water ${ }^{3} \mathrm{H}$ concentrations were measured from core samples recovered during drilling of all boreholes. Samples were generally taken at about five-foot intervals along each borehole but lower sampling intervals were sometimes used. Measurements of unsaturated hydraulic properties and other physical properties were also made on soil samples taken from a few boreholes. The properties measured were moisture retention, saturated hydraulic conductivity, initial water content, porosity, particle size distribution, bulk density, and skeletal density.

${ }^{3} \mathrm{H}$ concentrations are monitored by SEAMIST monitoring systems in the vadose zone. SEAMIST (Science and Engineering Associates, Santa Fe, New Mexico) is a monitoring system in which an instrumented membrane, usually constructed of laminated vinyl polyester, is inserted into an open borehole (Keller and Lowry, 1990). The membrane is fitted with gas ports or absorbent pads placed against the borehole wall at different depths. The membrane can be held open by air pressure, sand, or grout. If air pressure or sand is used, samples or instrumentation can be brought up and recovered or changed. Two types of SEAMIST systems are in operation at the Building 292 Area: the first has gas ports that extract and sample gas from the vadose zone, and the other uses absorbent pads that sample moisture from the vadose zone. The systems are described in more detail by Martins (1990).

Groundwater ${ }^{3} \mathrm{H}$ concentration and water table elevation are monitored in the piezometers. Groundwater ${ }^{3} \mathrm{H}$ concentrations are sampled by bailing water from the well. Sampling is usually conducted quarterly.

Field measurements of water content and matric potential are made by neutron log and tensiometer, respectively. Neutron logs are used to measure water content in three boreholes, down to a depth of $40 \mathrm{ft}$. Neutron log measurements are made at 2-week intervals. Matric potential is measured by a number of tensiometers installed in shallow boreholes to depths 
of 2 to $5 \mathrm{ft}$. Tensiometers are read manually at weekly intervals.

Figure 3.5 is a plan view of the release site showing locations of boreholes, the tank, and the asphalt cover. Boreholes $1,6,7,12,14,15$, and 20 are piezometers that monitor groundwater ${ }^{3} \mathrm{H}$ concentration and water table elevation. Borehole 20 , located about 240 $\mathrm{ft}$ northeast of the tank, is not shown in Figure 3.5. Borehole 1 was grouted and sealed in August 1995.

Boreholes $16,17,18$, and 19 are vadose zone monitoring boreholes, constructed to a depth of $40 \mathrm{ft}$, which is about $8 \mathrm{ft}$ above the water table. Water content measurements using neutron logging are made in Boreholes 17, 18, and 19. In addition, ${ }^{3} \mathrm{H}$ concentrations are measured in Boreholes 16 and 17 using the SEAMIST system. Note that Borehole 17 serves dual purposes: a SEAMIST borehole for ${ }^{3} \mathrm{H}$ concentration measurements, and a neutron $\log$ borehole for water content measurements.

\subsubsection{Initial ${ }^{3} \mathrm{H}$ Concentrations}

A number of ${ }^{3} \mathrm{H}$ concentration measurements were made on soil samples taken from cores recovered during borehole drilling between 1989 and 1992. A total of 23 boreholes were drilled for the investigation. Some of the data are summarized in Table 3.1, which gives borehole coordinates and depth, horizontal distance from the leak, maximum ${ }^{3} \mathrm{H}$ concentration in borehole, and depth at the maximum concentration.

The letters appearing before the dash in the borehole ID indicate the type of borehole. UP indicates a piezometer, UMB, a vadose zone monitoring borehole, and $\mathrm{U}$, a characterization-only borehole (grouted after drilling). The RH and E letters indicate shallow borings for sampling of soil water concentration. In this report we often identify a borehole by a shortened name, giving only the number following the last dash in the full 


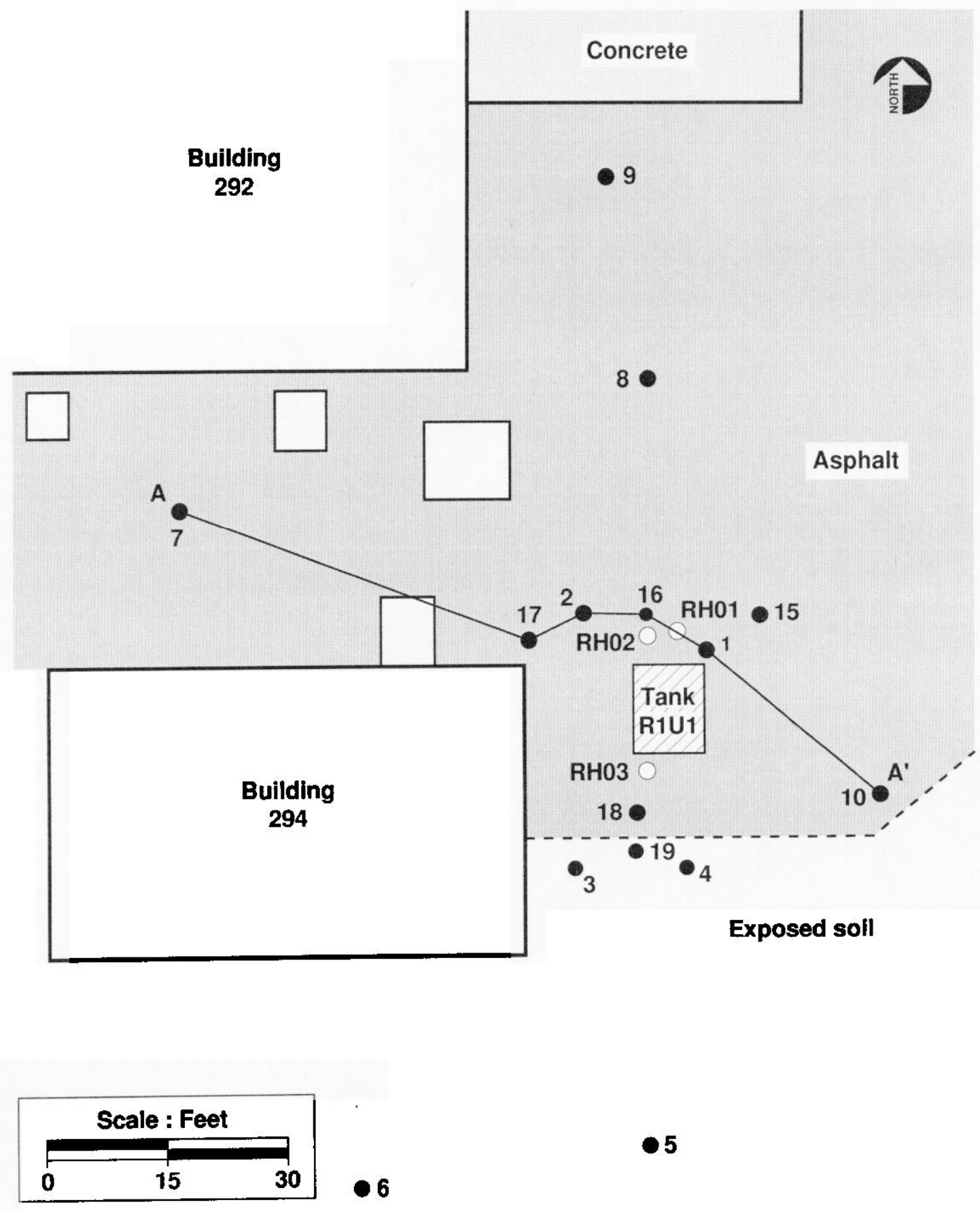

Figure 3.5: Plan view of the LLNL Building 292 Area showing locations of boreholes, Tank R1U1, and the blacktop. 
Table 3.1: Borehole locations and peak ${ }^{3} \mathrm{H}$ concentrations from initial site characterization and monitoring program for the Building 292 release. The leak point was assumed as the pipe inlet on the north face of the tank, with LLNL coordinates $(8652.1,12780.5)$.

\begin{tabular}{cccccc}
\hline \hline $\begin{array}{c}\text { Borehole } \\
\text { ID }\end{array}$ & $\begin{array}{c}\text { Coordinates } \\
\text { East, North })\end{array}$ & $\begin{array}{c}\text { Horiz. Dist. } \\
\text { from Leak } \\
(\mathrm{ft})\end{array}$ & $\begin{array}{c}\text { Borehole } \\
\text { Depth } \\
(\mathrm{ft})\end{array}$ & $\begin{array}{c}\text { Peak } \\
\text { Conc. } \\
(\mathrm{pCi} / \mathrm{L})\end{array}$ & $\begin{array}{c}\text { Depth at } \\
\text { Peak Conc. } \\
(\mathrm{ft})\end{array}$ \\
\hline UP-292-001 & $(8655.4,12781.0)$ & 3 & 51 & $1.9 \times 10^{8}$ & 12 \\
U-292-002 & $(8645.6,12784.9)$ & 8 & 51 & $3.2 \times 10^{7}$ & 16 \\
U-292-003 & $(8644.7,12762.1)$ & 19 & 41 & $4.0 \times 10^{4}$ & 36 \\
U-292-004 & $(8654.2,12762.0)$ & 18 & 51 & $1.3 \times 10^{5}$ & 11 \\
U-292-005 & $(8650.8,12739.5)$ & 41 & 11 & $1.1 \times 10^{5}$ & 11 \\
UP-292-006 & $(8625.9,12736.3)$ & 51 & 71 & $1.2 \times 10^{4}$ & 6 \\
UP-292-007 & $(8611.9,12791.8)$ & 42 & 51 & $1.8 \times 10^{3}$ & 51 \\
U-292-008 & $(8651.1,12802.0)$ & 22 & 51 & $1.3 \times 10^{7}$ & 11 \\
U-292-009 & $(8650.8,12820.5)$ & 41 & 51 & $4.1 \times 10^{6}$ & 11 \\
U-292-010 & $(8670.3,12769.3)$ & 21 & 51 & $2.0 \times 10^{3}$ & 51 \\
UP-292-012 & $(8662.4,12939.1)$ & 159 & 50 & $1.9 \times 10^{4}$ & 25 \\
U-292-013 & $(8663.1,12892.6)$ & 113 & 50 & $1.6 \times 10^{4}$ & 3 \\
UP-292-014 & $(8667.5,12847.6)$ & 69 & 53 & $1.8 \times 10^{5}$ & 15 \\
UP-292-015 & $(8661.8,12784.0)$ & 10 & 50 & $2.6 \times 10^{7}$ & 15 \\
UMB-292-016 & $(8650.4,12784.4)$ & 5 & 40 & $1.4 \times 10^{8}$ & 16 \\
UMB-292-017 & $(8642.6,12781.6)$ & 10 & 40 & $1.2 \times 10^{7}$ & 21 \\
UMB-292-018 & $(8649.2,12766.7)$ & 14 & 40 & $5.1 \times 10^{5}$ & 10 \\
UMB-292-019 & $(8649.2,12762.4)$ & 18 & 40 & $9.0 \times 10^{3}$ & 11 \\
UP-292-020 & $(8438.9,12881.7)$ & 236 & 65 & $N D^{*}$ & - \\
RH01 & $(8653.4,12783.5)$ & 4 & 18 & $1.5 \times 10^{8}$ & 18 \\
RH02 & $(8650.6,12783.4)$ & 4 & 15 & $2.2 \times 10^{8}$ & 11 \\
RH03 & $(8650.6,12772.4)$ & 8 & 15 & $3.5 \times 10^{5}$ & 10 \\
E1 & $(8656.9,12777.9)$ & 5 & 14 & $1.7 \times 10^{8}$ & 14 \\
\hline
\end{tabular}

* ND indicates nondetect: below $900 \mathrm{pCi} / \mathrm{L}$. 
ID. For example, the piezometer UP-292-001 is referred to as Borehole 1 or simply B-1.

Figure 3.6 presents ${ }^{3} \mathrm{H}$ soil water concentration profiles along the deeper boreholes (at least $40 \mathrm{ft}$ deep) located no more than $10 \mathrm{ft}$ away from the leak. These boreholes are B-1, B-2, B-15, B-16, and B-17. All five profiles follow the same general behavior: starting a few feet below the ground surface, we observe a sharp increase in ${ }^{3} \mathrm{H}$ concentration with depth, a peak of about $10^{7}$ to $10^{8} \mathrm{pCi} / \mathrm{L}$ at a depth between 12 and $21 \mathrm{ft}$, followed by a decrease down to the water table. The peak groundwater ${ }^{3} \mathrm{H}$ concentration measured during this initial characterization period was $3,000 \mathrm{pCi} / \mathrm{L}$ in $\mathrm{B}-15$.

Figure 3.7 presents concentration profiles for boreholes B-3, B-4, B-18, and B-19, all located south of the tank, at least $14 \mathrm{ft}$ from the leak. These profiles don't show the distinct trends with depth observed for boreholes closer to the leak. Lower ${ }^{3} \mathrm{H}$ concentration peaks on the order of $10^{4}$ to $10^{5} \mathrm{pCi} / \mathrm{L}$ are observed for $\mathrm{B}-3, \mathrm{~B}-4$, and $\mathrm{B}-18$. Concentrations in B-19 are close to background levels throughout the profile.

The main source of ${ }^{3} \mathrm{H}$ leakage into the soil does appear to be the point where the inlet pipe enters the north face of the tank. This is supported by the magnitude and distribution of peak concentrations in boreholes drilled within a horizontal distance of $5 \mathrm{ft}$ from the apparent leak point. The boreholes are B-1, B-16, RH01, RH02, and E1. All measured peak concentrations that exceed $1.0 \times 10^{8} \mathrm{pCi} / \mathrm{L}$ were found in these 5 boreholes, and the peak concentrations occur at depths ranging from $3 \mathrm{ft}$ to $9 \mathrm{ft}$ below the apparent leak point. This point has LLNL coordinates of $\mathrm{E} 8652.1, \mathrm{~N} 12780.5$, and elevation $577.8 \mathrm{ft}$ which is a depth of $9 \mathrm{ft}$ below the ground surface.

Some boreholes close to the concrete pad north of Tank R1U1 (see Figure 3.5) show concentrations that suggest the possibility of a second source. Boreholes 9 and 14 show moderate to high concentrations closer to the ground surface, and a rapid decline with 

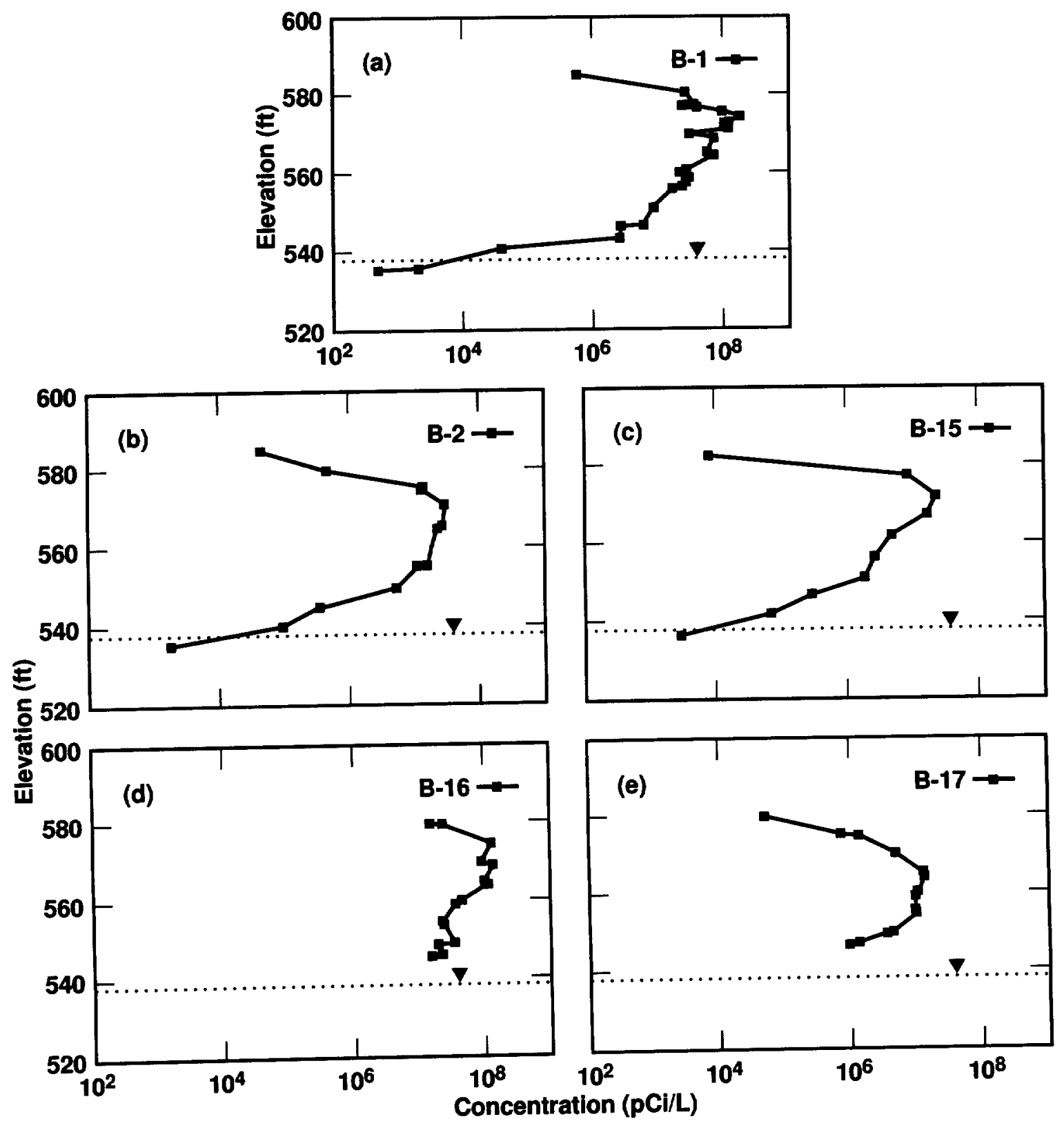

Figure 3.6: Soil water ${ }^{3} \mathrm{H}$ concentration profiles along boreholes (a) B-1, (b) B-2, (c) B-15, (d) B-16, and (e) B-17. Concentrations measured during initial site characterization in the period 1989-1992. 


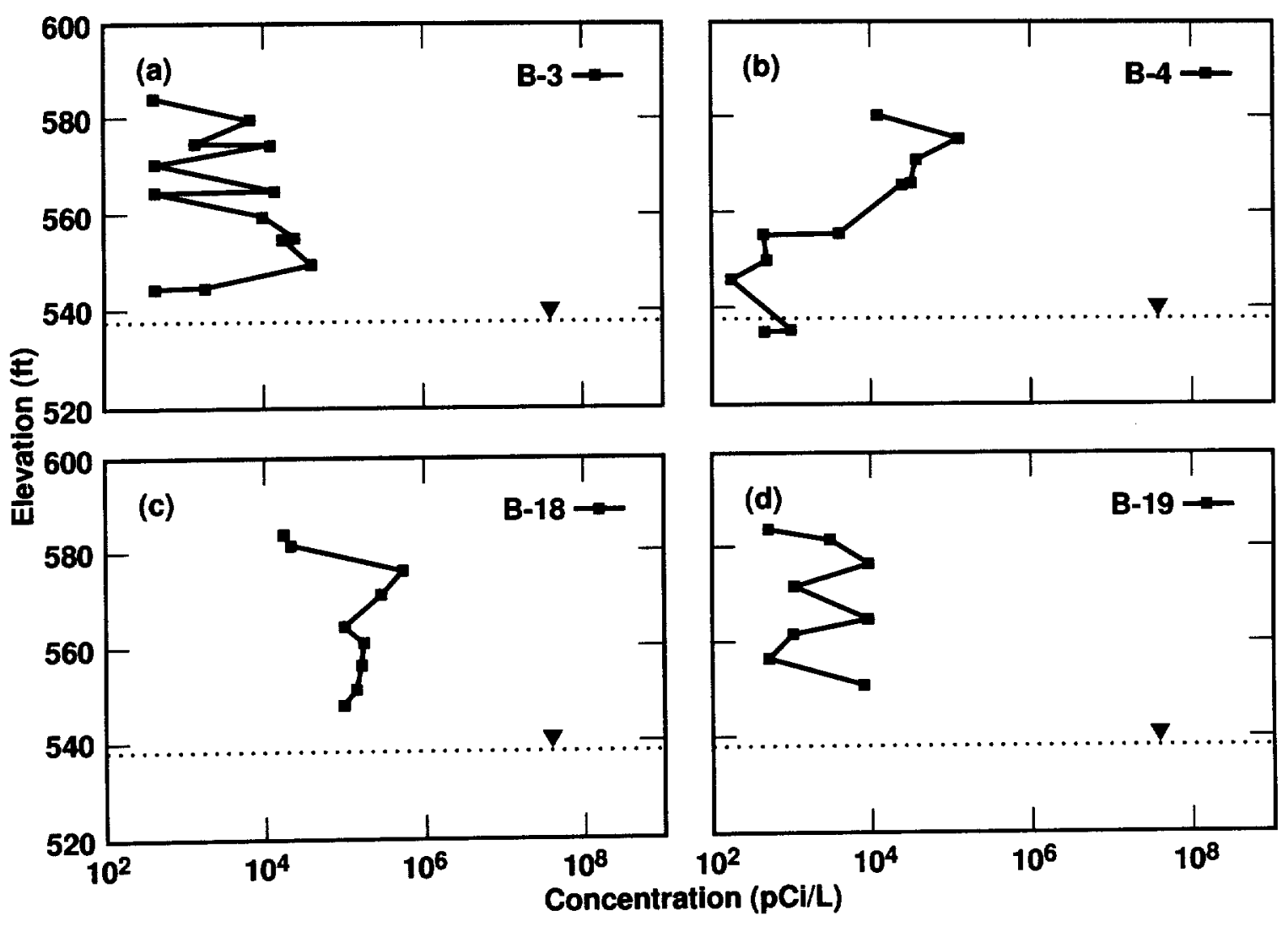

Figure 3.7: Soil water ${ }^{3} \mathrm{H}$ concentration profiles along boreholes (a) B-3, (b) B-4, (c) B-18, and (d) B-19. Concentrations measured during initial site characterization in the period 1989-1992. 
depth, falling off to nondetect below about $21 \mathrm{ft}$. This result would be consistent with the release of tritiated water on the concrete pad. Equipment used in the RNTS experiments was reportedly washed down on the concrete pad from time to time, possibly causing release of tritiated water that drained onto the soil along the edge of the pad. Another potential source is a possible pipe leak north of the tank. The pipeline that carried tritiated water from Building 292 to the tank was buried in a trench that ran along the eastern side of the building. The trench was backfilled with sand. A leak along the pipeline would cause ${ }^{3} \mathrm{H}$ to spread relatively fast along the sand-filled trench and migrate slowly downward into the less permeable soil.

Figure 3.8 is an east-west section along AA' (Figure 3.5) showing ${ }^{3} \mathrm{H}$ concentrations in the subsurface (Mallon, 1995). Concentrations are shown in $\log _{10} \mathrm{pCi} / \mathrm{L}$. This figure is a rough approximation that used log-linear interpolation and judgement to estimate concentrations at unmeasured locations. A more detailed estimate of the concentration distribution, using kriging, is presented later in Chapter 5.

\subsubsection{Temporal Concentration Changes in Monitored Boreholes}

Measurements of vadose zone and groundwater ${ }^{3} \mathrm{H}$ concentration changes in the Building 292 Area have been reported by Mallon (1995). From vadose zone monitoring measurements made in Boreholes 16 and 17 (the SEAMIST boreholes), decreases in ${ }^{3} \mathrm{H}$ concentrations were observed between May 1991 and April 1995. Figure 3.9 shows the concentration profile for Borehole 16 at six different times between May 1991 and April 1995. Over the 4-year period, the peak concentration was reduced from from $1.4 \times 10^{8} \mathrm{pCi} / \mathrm{L}$ to $3.0 \times 10^{7} \mathrm{pCi} / \mathrm{L}$, a drop of about $79 \%$. The depth at peak concentration moved from $15 \mathrm{ft}$ to $26 \mathrm{ft}$ over the period.

Figure 3.10 shows six ${ }^{3} \mathrm{H}$ concentration profiles for Borehole 17 over a period of $3.7 \mathrm{yr}$, 


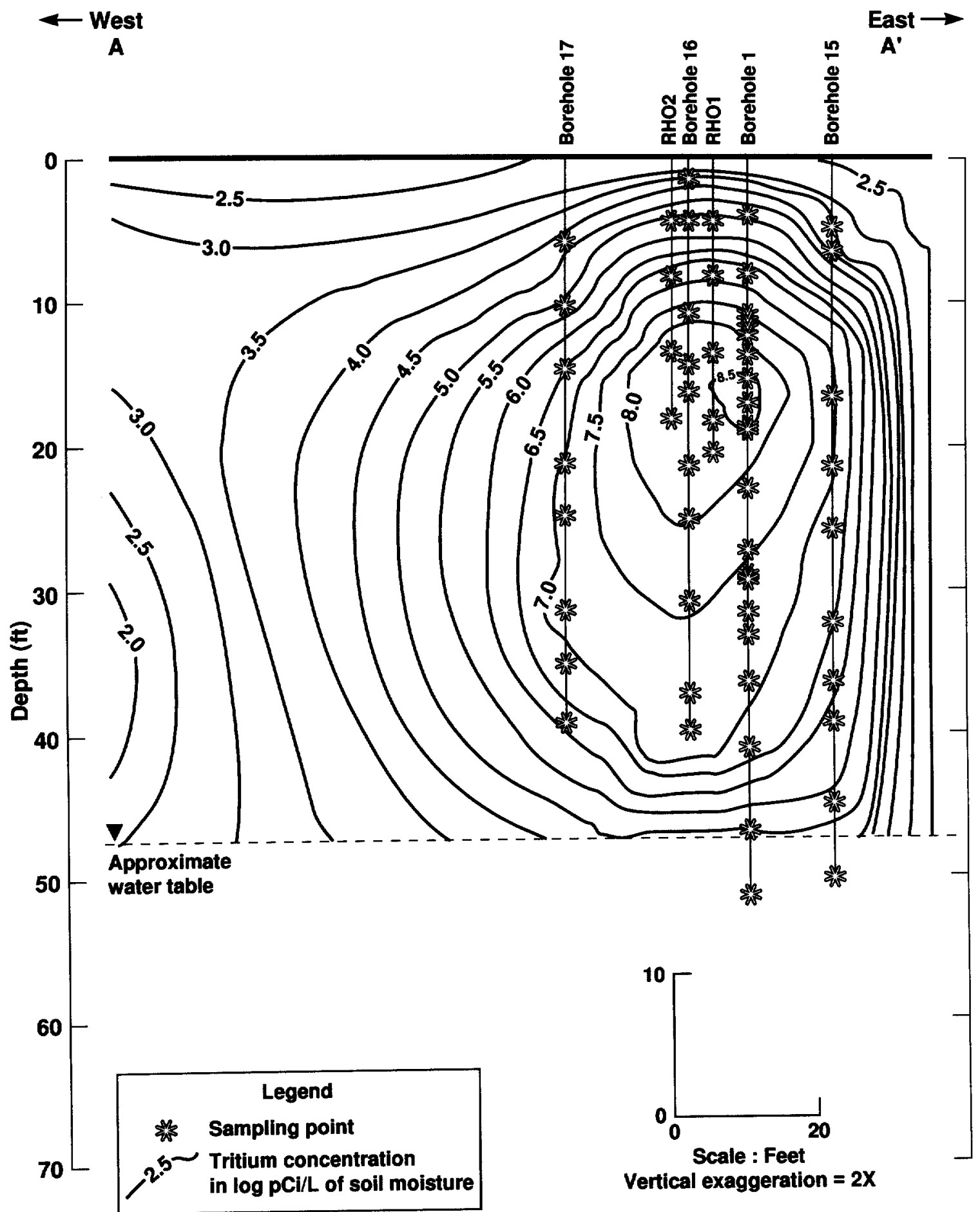

Figure 3.8: Soil water ${ }^{3} \mathrm{H}$ concentrations along Section $\mathrm{AA}^{\prime}$ from Figure 3.5. Concentrations are shown in $\log _{10} \mathrm{pCi} / \mathrm{L}$ (After Mallon, 1995). 
from May 1991 through January 1995. The peak concentration is reduced by $27 \%$, from $1.5 \times 10^{7} \mathrm{pCi} / \mathrm{L}$ to $1.1 \times 10^{7} \mathrm{pCi} / \mathrm{L}$. The depth of the peak concentration moved from about 22 to $24 \mathrm{ft}$. Clearly, reductions in ${ }^{3} \mathrm{H}$ concentrations and downward movement of the plume occur more rapidly in Borehole 16 than in Borehole 17.

Of the groundwater monitoring wells, only Borehole 1 showed significant groundwater ${ }^{3} \mathrm{H}$ concentrations. Figure 3.11 shows the groundwater ${ }^{3} \mathrm{H}$ concentration histories measured in Borehole 1 at a horizontal distance of $3 \mathrm{ft}$ east of the leak, and Borehole 15 at a horizontal distance of $10 \mathrm{ft}$ northeast of the leak. Concentrations in Borehole 1 went as high as $1.2 \times 10^{5}$ $\mathrm{pCi} / \mathrm{L}$, exceeding the groundwater standard of $2.0 \times 10^{4} \mathrm{pCi} / \mathrm{L}$ for about 7 months in 1994 and 3 months in the first half of 1995 . The large increases in concentration were believed to be caused by percolation of rainfall along a preferential flow path created by the well construction. Borehole 1 was subsequently grouted and sealed in August 1995. Groundwater concentrations in Borehole 15 and all other wells in the Building 292 Area remain close to background levels.

\subsubsection{Soil Properties from Laboratory Measurements}

Laboratory measurements of hydraulic soil properties were conducted on a number of core samples recovered as part of the site characterization effort. Sixteen samples were measured for moisture retention, saturated hydraulic conductivity, initial water content, porosity, particle size distribution, bulk density, and skeletal density. Ten of these samples were taken from B-15, five from B-1, and the remaining one from B-20. In addition, a number of samples from boreholes B-16, B-17, B-18, and B-19 were analyzed for particle size distribution only. Most of the laboratory measurements were performed by Daniel B. Stephens and Associates, Albuquerque, New Mexico. Particle size distribution analysis on some samples 


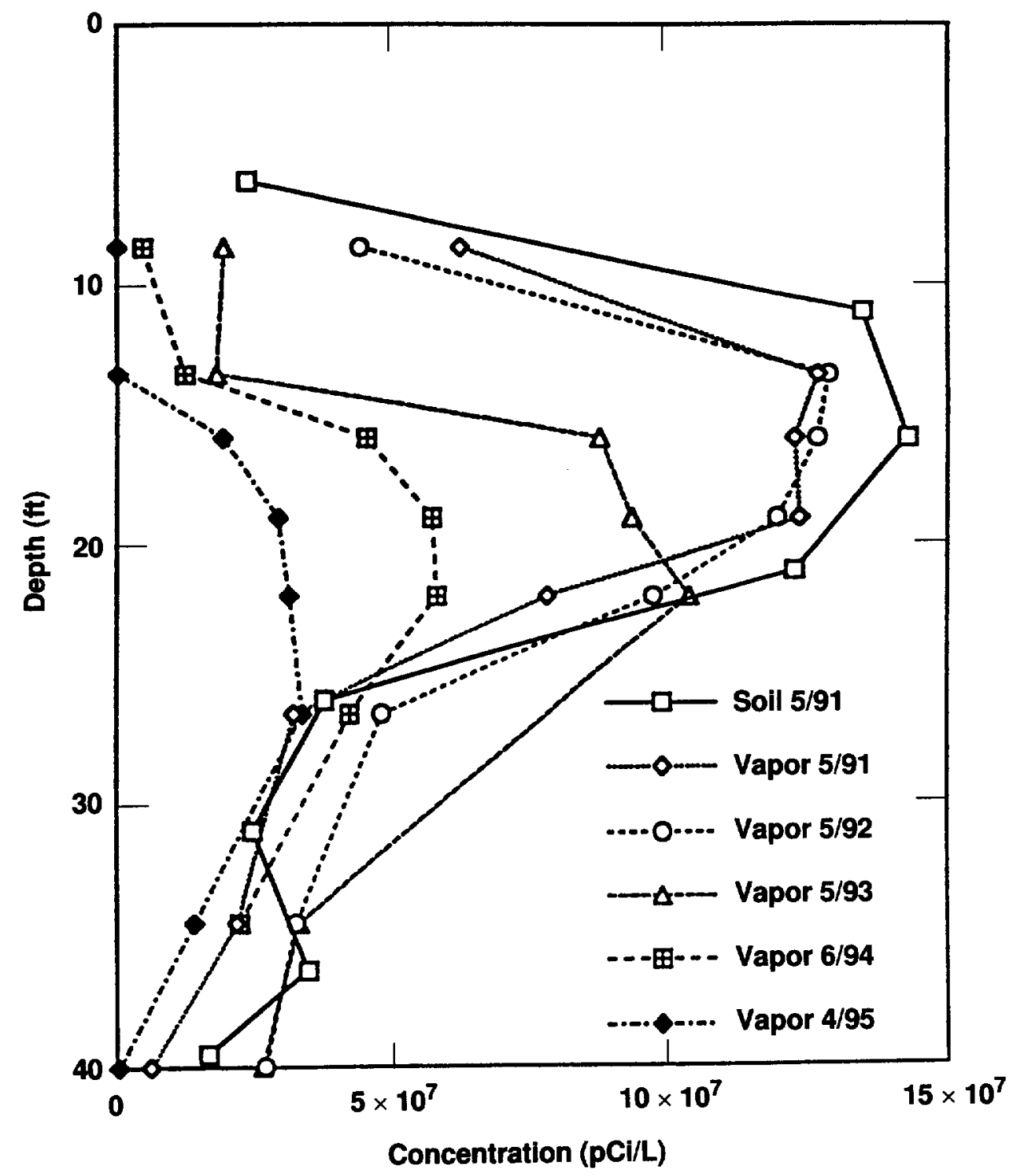

Figure 3.9: Tritium concentration profile for Borehole 16 at six times between May 1991 and April 19995 (After Mallon, 1995). 


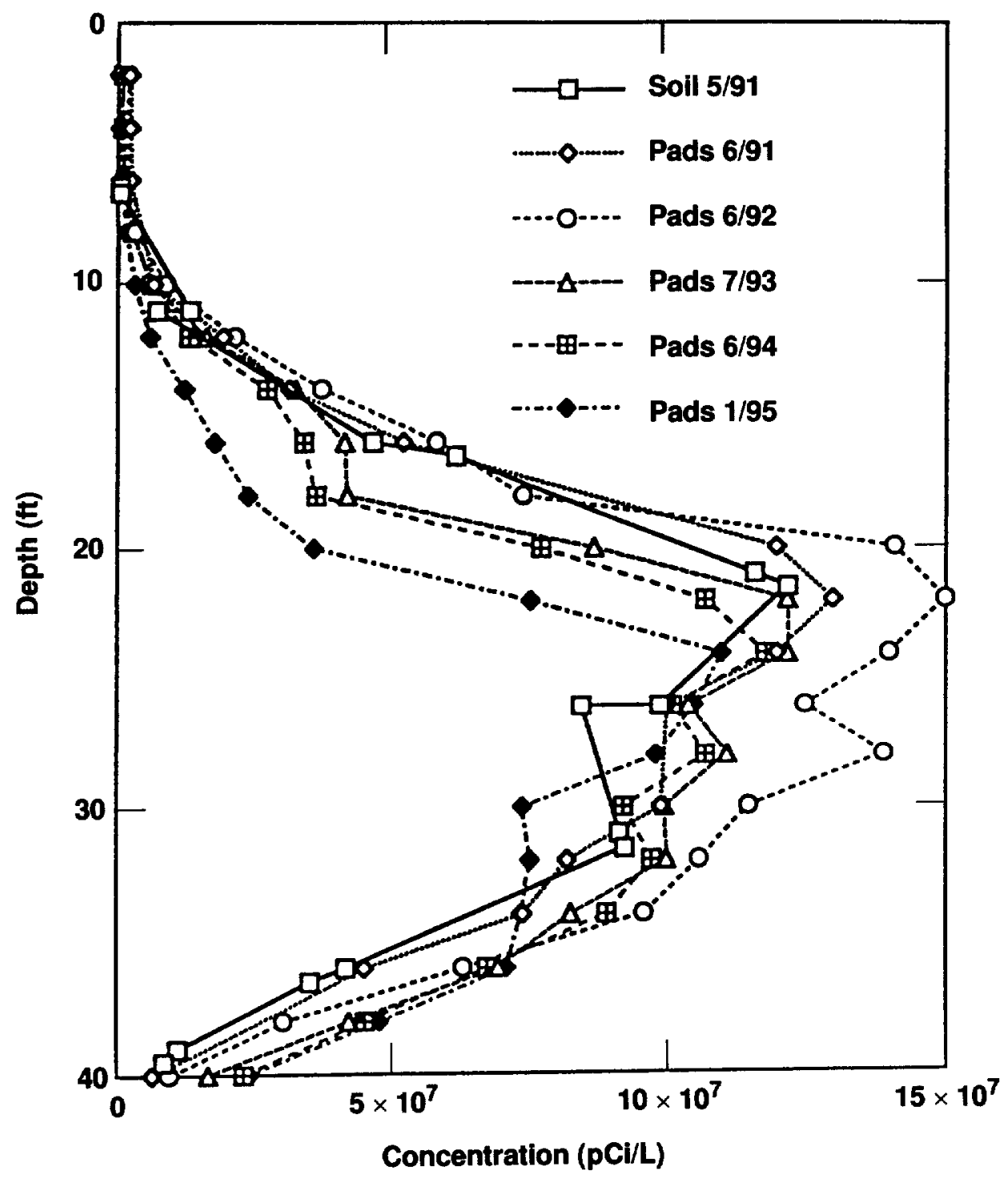

Figure 3.10: Tritium concentration profile for Borehole 17 at six times between May 1991 and January 1995 (After Mallon, 1995). 


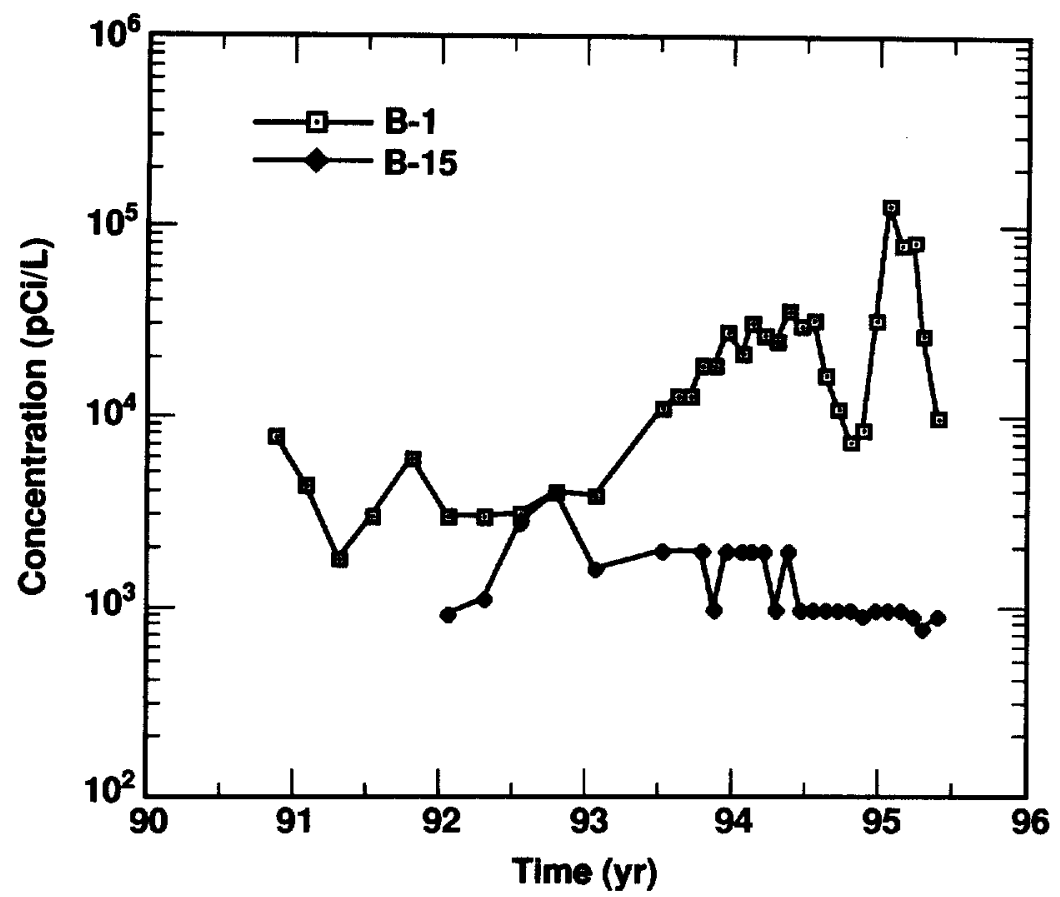

Figure 3.11: Groundwater ${ }^{3} \mathrm{H}$ concentration histories in Boreholes 1 and 15 in the Building 292 Area (After Mallon, 1995).

was performed by Woodward-Clyde Consultants, Concord, California.

The soil properties were measured by standard methods. Moisture retention was measured by a hanging column and pressure plate apparatus. Higher suctions were measured using a thermocouple psychrometer. Only the initial drainage curve was measured; the analysis did not include measurement of the imbibition curve or hysteresis. Particle size distribution analysis on coarser particle sizes was done by sieving, and finer sizes by sedimentation using a hydrometer. For some of the silts and clays, the finer particle size parameters could not be measured reliably using the hydrometer. The D10 and, in some cases, the D20 sizes were omitted in such cases. Saturated hydraulic conductivity was measured using a constant-head or a falling-head permeameter.

Table 3.2 presents bulk density $\left(\rho_{b}\right)$, porosity $(\phi)$, initial water saturation $\left(S_{i}\right)$, and saturated hydraulic conductivity $\left(K_{s}\right)$ for the 16 samples on which the full suite of unsat- 
Table 3.2: Dry bulk density, porosity, initial water saturation, and saturated hydraulic conductivity for 16 Soil Samples in the LLNL Building 292 Area.

\begin{tabular}{llcccc}
\hline \hline \multicolumn{1}{c}{ Texture } & Sample ID & $\begin{array}{c}\rho_{b} \\
\left(\mathrm{~g} / \mathrm{cm}^{3}\right)\end{array}$ & $\phi$ & $S_{i}$ & $\begin{array}{c}K_{s} \\
(\mathrm{~cm} / \mathrm{s})\end{array}$ \\
\hline Gravelly sand & $\mathrm{U} 292-001-45.5$ & 1.76 & 0.36 & 0.26 & $1.6 \mathrm{e}-2$ \\
Gravelly sand & $\mathrm{U} 292-001-5.75$ & 1.46 & 0.46 & 0.15 & $5.7 \mathrm{e}-3$ \\
Gravelly sand & $\mathrm{U} 292-015-20.8$ & 1.76 & 0.36 & 0.19 & $4.5 \mathrm{e}-3$ \\
Gravelly sand & $\mathrm{U} 292-015-45.3$ & 1.92 & 0.29 & 0.25 & $2.0 \mathrm{e}-3$ \\
Gravelly sand & $\mathrm{U} 292-015-15.3$ & 1.85 & 0.30 & 0.37 & $1.7 \mathrm{e}-3$ \\
Silty sand & $\mathrm{U} 292-015-40.8$ & 1.87 & 0.31 & 0.36 & $7.6 \mathrm{e}-4$ \\
Silty sand & $\mathrm{U} 292-001-27.75$ & 1.66 & 0.39 & 0.26 & $4.0 \mathrm{e}-4$ \\
Clayey sand & $\mathrm{U} 292-001-10.25$ & 1.51 & 0.45 & 0.35 & $1.5 \mathrm{e}-4$ \\
Sandy clay & $\mathrm{U} 292-015-35.3$ & 1.73 & 0.36 & 0.74 & $2.5 \mathrm{e}-5$ \\
Clayey sand & $\mathrm{U} 292-015-31.5$ & 1.74 & 0.36 & 0.44 & $1.5 \mathrm{e}-5$ \\
Sandy clay & $\mathrm{U} 292-001-35.0$ & 1.85 & 0.32 & 0.83 & $4.6 \mathrm{e}-7$ \\
Clay with sand & $\mathrm{U} 292-015-5.8$ & 1.79 & 0.32 & 0.78 & $2.5 \mathrm{e}-7$ \\
Clayey silt & $\mathrm{U} 292-015-10.3$ & 1.77 & 0.34 & 0.78 & $1.2 \mathrm{e}-7$ \\
Sandy clay & $\mathrm{U} 292-015-25.3$ & 1.85 & 0.31 & 0.93 & $1.6 \mathrm{e}-8$ \\
Clay with sand & $\mathrm{U} 292-015-4.3$ & 1.79 & 0.34 & 0.85 & $1.2 \mathrm{e}-8$ \\
Clayey silt & $\mathrm{U} 292-020-36.6$ & 1.77 & 0.35 & 0.95 & $1.2 \mathrm{e}-8$ \\
\hline \hline
\end{tabular}

urated hydraulic property measurements were made. The number following the last dash in the sample ID indicates the borehole depth from which the sample was recovered. The samples are presented in order of decreasing $\mathrm{K}_{s} . \mathrm{K}_{s}$ varies over seven orders of magnitude, from the silts and clays at $1.2 \times 10^{-8} \mathrm{~cm} / \mathrm{s}\left(1.2 \times 10^{-5}\right.$ darcy), to the sands and gravels at $1.6 \times 10^{-2} \mathrm{~cm} / \mathrm{s}$ (17 darcy). Initial liquid saturation, $\mathrm{S}_{i}$, also varies substantially, generally increasing with decreasing $\mathrm{K}_{s} . S_{i}$ varies from a minimum of 0.15 in the sands and gravels to a maximum of 0.95 in the silts and clays. A correlation plot of $S_{i}$ versus $\mathrm{K}_{s}$ is constructed later in Chapter 4. The porosity, $\phi$, varies from 0.29 to 0.46 with an average of 0.35 , and appears to be uncorrelated with soil type.

Table 3.3 summarizes the results of particle size distribution analysis on the samples. The D10 and D20 sizes are omitted for some samples because of limitations of the equipment at finer particle sizes. The $\mathrm{K}_{s}$ values are repeated here to show the general relationship 
Table 3.3: Particle Size Distribution Parameters and Saturated Hydraulic Conductivity for 16 Soil Samples in the LLNL Building 292 Area.

\begin{tabular}{llcccccccc}
\hline Texture & Sample ID & $\begin{array}{c}\mathrm{D} 10 \\
(\mathrm{~mm})\end{array}$ & $\begin{array}{c}\mathrm{D} 20 \\
(\mathrm{~mm})\end{array}$ & $\begin{array}{c}\mathrm{D} 30 \\
(\mathrm{~mm})\end{array}$ & $\begin{array}{c}\mathrm{D} 40 \\
(\mathrm{~mm})\end{array}$ & $\begin{array}{c}\mathrm{D} 50 \\
(\mathrm{~mm})\end{array}$ & $\begin{array}{c}\mathrm{D} 60 \\
(\mathrm{~mm})\end{array}$ & $\begin{array}{c}\mathrm{D} 70 \\
(\mathrm{~mm})\end{array}$ & $\begin{array}{c}K_{s} \\
(\mathrm{~cm} / \mathrm{s})\end{array}$ \\
\hline gravelly sand & $\mathrm{U} 292-001-45.5$ & $1.4 \mathrm{e}-1$ & $5.6 \mathrm{e}-1$ & $1.4 \mathrm{e} 00$ & $2.5 \mathrm{e} 00$ & $4.2 \mathrm{e} 00$ & $6.5 \mathrm{e} 00$ & $9.2 \mathrm{e} 00$ & $1.6 \mathrm{e}-2$ \\
gravelly sand & $\mathrm{U} 292-001-5.75$ & $1.1 \mathrm{e}-1$ & $1.3 \mathrm{e}-1$ & $1.4 \mathrm{e}-1$ & $1.7 \mathrm{e}-1$ & $2.1 \mathrm{e}-1$ & $2.3 \mathrm{e}-1$ & $2.5 \mathrm{e}-1$ & $5.73 \mathrm{e}-3$ \\
gravelly sand & $\mathrm{U} 292-015-20.8$ & $1.1 \mathrm{e}-1$ & $5.0 \mathrm{e}-1$ & $9.6 \mathrm{e}-1$ & $1.7 \mathrm{e} 00$ & $3.8 \mathrm{e} 00$ & $6.4 \mathrm{e} 00$ & $9.1 \mathrm{e} 00$ & $4.5 \mathrm{e}-3$ \\
gravelly sand & $\mathrm{U} 292-015-45.3$ & $1.2 \mathrm{e}-1$ & $2.5 \mathrm{e}-1$ & $4.5 \mathrm{e}-1$ & $9.5 \mathrm{e}-1$ & $2.2 \mathrm{e} 00$ & $3.9 \mathrm{e} 00$ & $5.8 \mathrm{e} 00$ & $2.0 \mathrm{e}-3$ \\
gravelly sand & $\mathrm{U} 292-015-15.3$ & $3.2 \mathrm{e}-2$ & $6.5 \mathrm{e}-2$ & $3.8 \mathrm{e}-1$ & $2.2 \mathrm{e} 00$ & $4.4 \mathrm{e} 00$ & $6.7 \mathrm{e} 00$ & $8.8 \mathrm{e} 00$ & $1.7 \mathrm{e}-3$ \\
silty sand & $\mathrm{U} 292-015-40.8$ & $6.5 \mathrm{e}-2$ & $1.3 \mathrm{e}-1$ & $2.0 \mathrm{e}-1$ & $2.7 \mathrm{e}-1$ & $3.8 \mathrm{e}-1$ & $5.8 \mathrm{e}-1$ & $1.0 \mathrm{e} 00$ & $7.6 \mathrm{e}-4$ \\
silty sand & $\mathrm{U} 292-001-27.75$ & - & $1.2 \mathrm{e}-2$ & $3.4 \mathrm{e}-2$ & $7.7 \mathrm{e}-2$ & $1.3 \mathrm{e}-1$ & $2.1 \mathrm{e}-1$ & $3.2 \mathrm{e}-1$ & $4.0 \mathrm{e}-4$ \\
clayey sand & $\mathrm{U} 292-001-10.25$ & - & $1.8 \mathrm{e}-2$ & $5.0 \mathrm{e}-2$ & $8.6 \mathrm{e}-2$ & $1.4 \mathrm{e}-1$ & $1.9 \mathrm{e}-1$ & $2.5 \mathrm{e}-1$ & $1.5 \mathrm{e}-4$ \\
sandy clay & $\mathrm{U} 292-015-35.3$ & - & $1.0 \mathrm{e}-3$ & $9.2 \mathrm{e}-3$ & $3.9 \mathrm{e}-2$ & $7.5 \mathrm{e}-2$ & $1.2 \mathrm{e}-1$ & $1.8 \mathrm{e}-1$ & $2.5 \mathrm{e}-5$ \\
clayey sand & $\mathrm{U} 292-015-31.5$ & $3.6 \mathrm{e}-2$ & $9.0 \mathrm{e}-2$ & $1.2 \mathrm{e}-1$ & $2.0 \mathrm{e}-1$ & $3.6 \mathrm{e}-1$ & $2.0 \mathrm{e} 00$ & $5.4 \mathrm{e} 00$ & $1.5 \mathrm{e}-5$ \\
sandy clay & $\mathrm{U} 292-001-35.0$ & - & - & $1.0 \mathrm{e}-3$ & $4.4 \mathrm{e}-3$ & $1.4 \mathrm{e}-2$ & $3.7 \mathrm{e}-2$ & $8.8 \mathrm{e}-2$ & $4.6 \mathrm{e}-7$ \\
clay with sand & $\mathrm{U} 292-015-5.8$ & - & - & $3.3 \mathrm{e}-3$ & $8.0 \mathrm{e}-3$ & $2.3 \mathrm{e}-2$ & $3.5 \mathrm{e}-2$ & $5.5 \mathrm{e}-2$ & $2.5 \mathrm{e}-7$ \\
clayey silt & $\mathrm{U} 292-015-10.3$ & - & - & $5.0 \mathrm{e}-3$ & $1.3 \mathrm{e}-2$ & $2.2 \mathrm{e}-2$ & $3.6 \mathrm{e}-2$ & $5.5 \mathrm{e}-2$ & $1.2 \mathrm{e}-7$ \\
sandy clay & $\mathrm{U} 292-015-25.3$ & - & - & $4.5 \mathrm{e}-3$ & $1.2 \mathrm{e}-2$ & $2.9 \mathrm{e}-2$ & $5.5 \mathrm{e}-2$ & $1.0 \mathrm{e}-1$ & $1.6 \mathrm{e}-8$ \\
clay with sand & $\mathrm{U} 292-015-4.3$ & - & - & - & $2.0 \mathrm{e}-3$ & $5.7 \mathrm{e}-3$ & $2.2 \mathrm{e}-2$ & $4.2 \mathrm{e}-2$ & $1.2 \mathrm{e}-8$ \\
clayey silt & $\mathrm{U} 292-020-36.6$ & - & - & $2.3 \mathrm{e}-3$ & $8.5 \mathrm{e}-3$ & $1.8 \mathrm{e}-2$ & $2.8 \mathrm{e}-2$ & $4.3 \mathrm{e}-2$ & $1.2 \mathrm{e}-8$ \\
\hline \hline
\end{tabular}

between particle size and saturated hydraulic conductivity for soils at the site. Table 3.3 will be used later in Chapter 4 to construct correlations between $\mathrm{K}_{s}$ and the particle size parameters.

Water retention data for each sample, along with the van Genuchten curve fit, are plotted in Figure 3.12 as negative pressure head or matric suction $(\psi)$ versus volumetric water content $(\theta)$. The data are tabulated in Appendix Table B.1. Pressure heads at lower water contents were not measured for the silts and clays, because of the high suctions required to attain the low water contents. However, water contents reached by silts and clays in the field, and in the simulations, always remain within the range of the retention functions plotted in Figure 3.12. Ambient water saturations for the silts and clays usually exceed about $70 \%$, as was shown in Table 3.2 . 

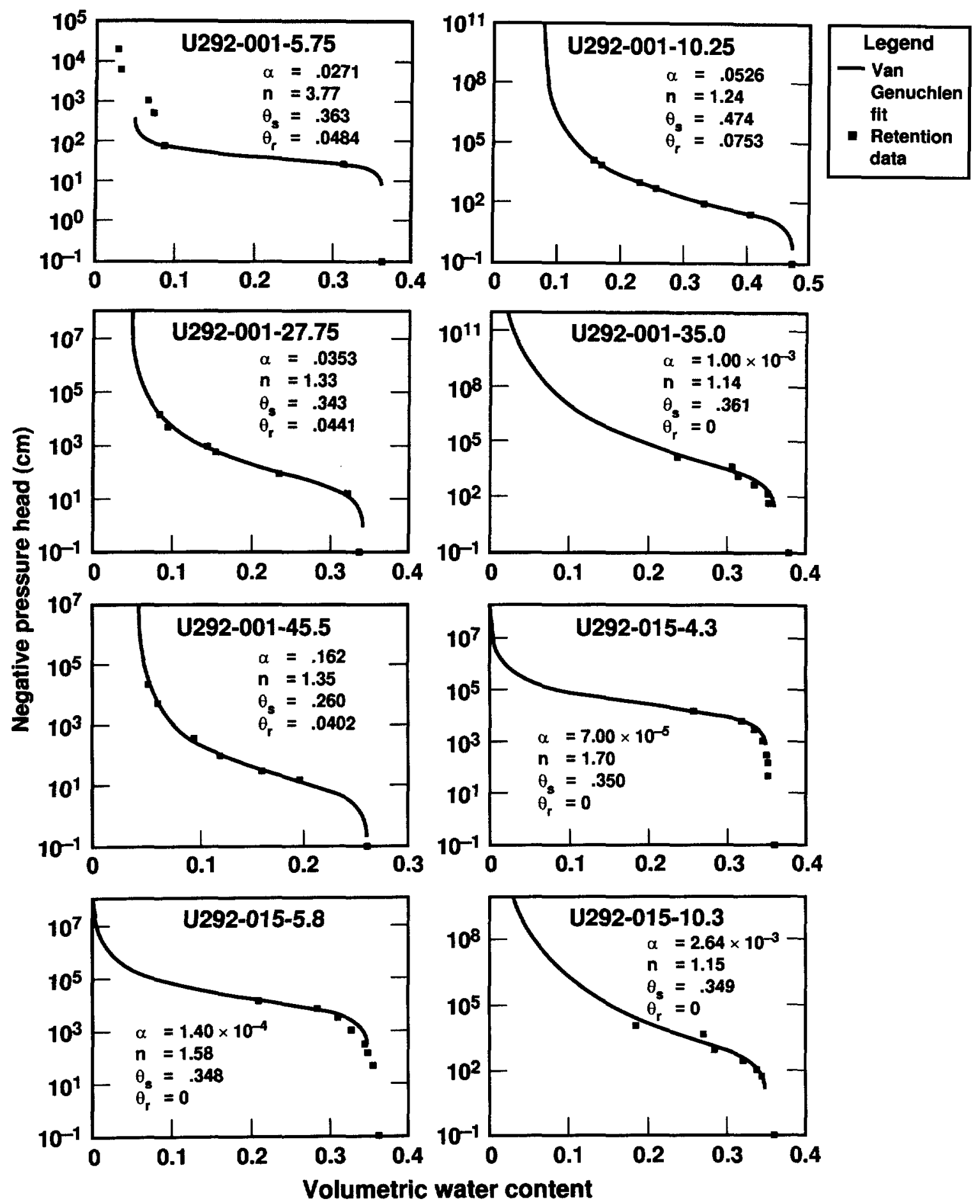

Figure 3.12a: Water retention data and van Genuchten curve fit parameters for first 8 of 16 soil samples from boreholes in the LLNL Building 292 Area. 

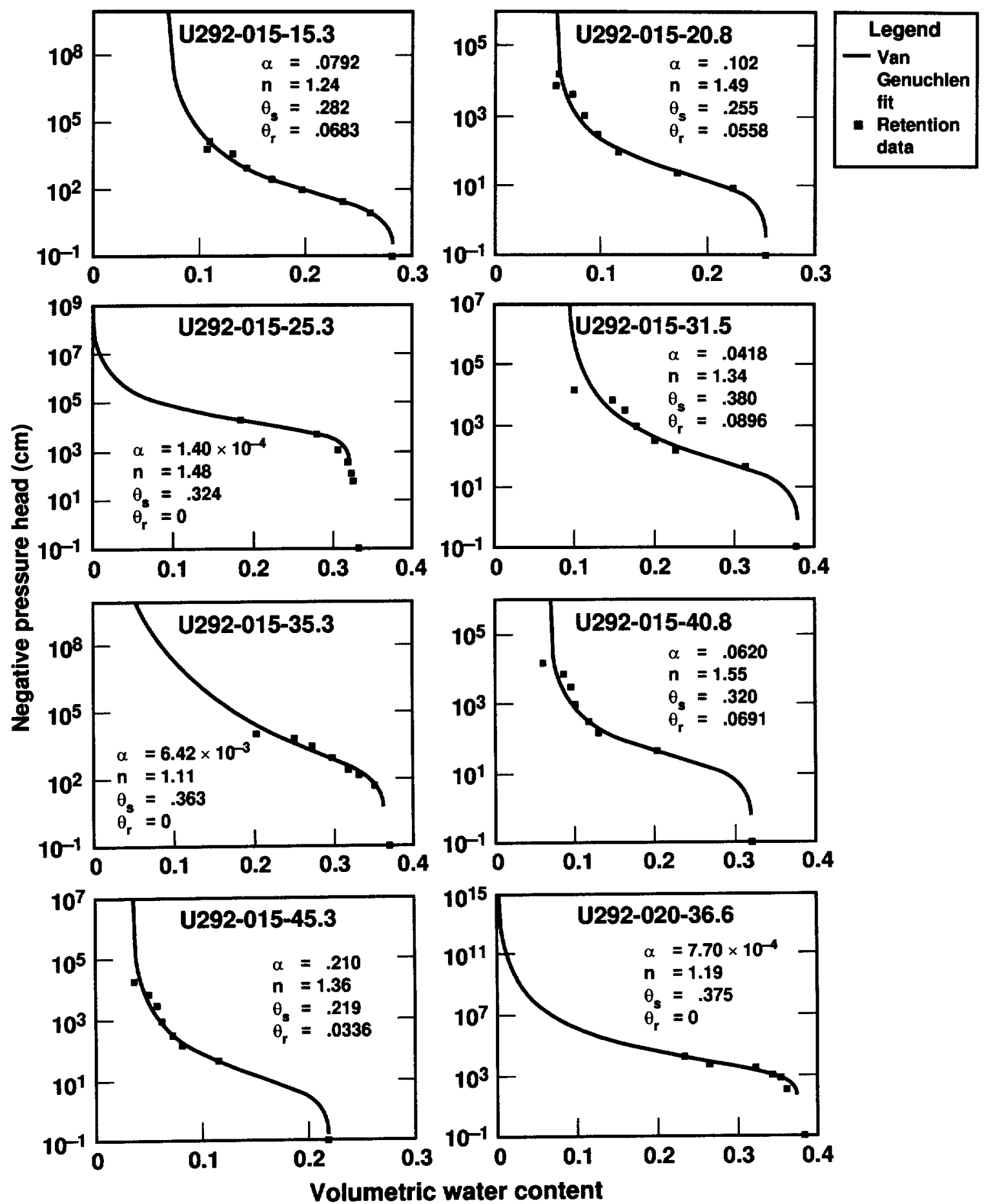

Figure 3.12b: Water retention data and van Genuchten curve fit parameters for second 8 of 16 soil samples from boreholes in the LLNL Building 292 Area. 


\subsection{4 van Genuchten's Soil Parameters}

The NUFT code will accept water retention data in tabulated form. However, if the unsaturated hydraulic conductivity function needs to be derived from water retention, as is usually the case, then the data have to be analyzed to obtain van Genuchten curve fitting parameters. We follow this common practice of curve-fitting the water retention data to obtain the van Genuchten parameters then using the parameters to obtain the unsaturated hydraulic conductivity function (van Genuchten, 1980).

A number of closed-form functions have been proposed to empirically describe the soil water retention curve (van Genuchten et. al, 1991a). One relationship that adequately fits the retention curves for a wide range of soils, and is widely used in computer models of unsaturated flow, is the van Genuchten equation (van Genuchten, 1980):

$$
S_{e}=\frac{1}{\left[1+(\alpha \psi)^{n}\right]^{m}}
$$

where the reduced saturation $S_{e}$, is defined as

$$
S_{e}=\frac{\theta-\theta_{r}}{\theta_{s}-\theta_{r}}
$$

The symbol $\psi$ denotes the negative of the matric potential, often referred to as the soil suction, and $\alpha, \mathrm{n}$, and $\mathrm{m}$ are empirical curve-fitting parameters, where $\mathrm{m}$ and $\mathrm{n}$ are related by

$$
m=1-\frac{1}{n}
$$

The parameter $\alpha$ is positive and roughly corresponds to the inverse of the air entry porewater pressure head. $\theta_{r}$ and $\theta_{s}$ are the residual and saturated water content of the soil, respectively. Although $\theta_{r}$ is formally defined as the maximum water content at which the effective hydraulic conductivity goes to zero, it is actually an extrapolated parameter here 
and not the minimum possible water content. Nitao and Bear (1996) show that the matric potential goes to infinity at $\theta=0$ and not at $\theta_{r}>0$. Vaporization of water may cause drying of the soil to water contents even lower than $\theta_{r}$. Also, the saturated water content, $\theta_{s}$, of field soils is usually 5 to $10 \%$ less than the porosity, because of the presence of entrapped air. The parameters $\theta_{\mathrm{r}}$ and $\theta_{s}$ should therefore be viewed as essentially curve fitting parameters and not be given much physical meaning (van Genuchten and Nielson, 1985; Luckner et al., 1989).

Unsaturated hydraulic conductivity is very time-consuming and difficult to measure directly in the field or laboratory. A commonly used alternative to direct measurement is to use theoretical methods to estimate unsaturated hydraulic conductivity from the more easily measured soil water retention (van Genuchten et al., 1991a). These theoretical methods are usually based on the assumption of water flow through cylindrical pores, and incorporate Darcy's and Poiseuille's equations (Childs and Collis-George, 1950; Burdine, 1953; Millington and Quirk, 1961; Brooks and Corey, 1964; Mualem, 1976). van Genuchten (1980) presented an analytical solution to the theoretical model developed by Mualem (1976):

$$
K_{r}(\psi)=\frac{\left\{1-(\alpha \psi)^{n-1}\left[1+(\alpha \psi)^{n}\right]^{-m}\right\}^{2}}{\left[1+(\alpha \psi)^{n}\right]^{m / 2}}
$$

where $K_{r}$ is the relative hydraulic conductivity, defined as the ratio of the effective hydraulic conductivity to the saturated hydraulic conductivity,

$$
K_{r}=\frac{K_{e}}{K_{s}}
$$

van Genuchten parameters for the 16 soil samples are presented in Table 3.4. The samples are arranged in order of decreasing $\mathrm{K}_{s}$. We used the RETC code of van Genuchten et al. (1991a) to determine the van Genuchten parameters from the retention functions in Figure 3.12. The RETC code is a curve fitting code for quantifying the hydraulic functions 
Table 3.4: van Genuchten's soil water retention and hydraulic conductivity parameters for 16 soil samples in the LLNL Building 292 Area.

\begin{tabular}{llccccc}
\hline \hline \multicolumn{1}{c}{ Texture } & Sample ID & $\theta_{r}$ & $\theta_{s}$ & $\begin{array}{c}\alpha \\
(1 / \mathrm{cm})\end{array}$ & $\mathrm{n}$ & $\begin{array}{c}K_{s} \\
(\mathrm{~cm} / \mathrm{s})\end{array}$ \\
\hline Gravelly sand & $\mathrm{U} 292-001-45.5$ & 0.0402 & 0.260 & $1.62 \mathrm{e}-1$ & 1.35 & $1.6 \mathrm{e}-2$ \\
Gravelly sand & $\mathrm{U} 292-001-5.75$ & 0.0484 & 0.363 & $2.71 \mathrm{e}-2$ & 3.77 & $5.7 \mathrm{e}-3$ \\
Gravelly sand & $\mathrm{U} 292-015-20.8$ & 0.0559 & 0.255 & $1.02 \mathrm{e}-1$ & 1.49 & $4.5 \mathrm{e}-3$ \\
Gravelly sand & $\mathrm{U} 292-015-45.3$ & 0.0336 & 0.219 & $2.10 \mathrm{e}-1$ & 1.36 & $2.0 \mathrm{e}-3$ \\
Gravelly sand & $\mathrm{U} 292-015-15.3$ & 0.0683 & 0.282 & $7.92 \mathrm{e}-2$ & 1.24 & $1.7 \mathrm{e}-3$ \\
Silty sand & $\mathrm{U} 292-015-40.8$ & 0.0691 & 0.320 & $6.20 \mathrm{e}-2$ & 1.55 & $7.6 \mathrm{e}-4$ \\
Silty sand & $\mathrm{U} 292-001-27.75$ & 0.0441 & 0.343 & $3.53 \mathrm{e}-2$ & 1.33 & $4.0 \mathrm{e}-4$ \\
Clayey sand & $\mathrm{U} 292-001-10.25$ & 0.0753 & 0.474 & $5.26 \mathrm{e}-2$ & 1.24 & $1.5 \mathrm{e}-4$ \\
Sandy clay & $\mathrm{U} 292-015-35.3$ & 0.0 & 0.363 & $6.42 \mathrm{e}-3$ & 1.11 & $2.5 \mathrm{e}-5$ \\
Clayey sand & $\mathrm{U} 292-015-31.5$ & 0.0896 & 0.380 & $4.18 \mathrm{e}-2$ & 1.34 & $1.5 \mathrm{e}-5$ \\
Sandy clay & $\mathrm{U} 292-001-35.0$ & 0.0 & 0.361 & $1.00 \mathrm{e}-3$ & 1.14 & $4.6 \mathrm{e}-7$ \\
Clay with sand & $\mathrm{U} 292-015-5.8$ & 0.0 & 0.348 & $1.40 \mathrm{e}-4$ & 1.58 & $2.5 \mathrm{e}-7$ \\
Clayey silt & $\mathrm{U} 292-015-10.3$ & 0.0 & 0.349 & $2.64 \mathrm{e}-3$ & 1.15 & $1.2 \mathrm{e}-7$ \\
Sandy clay & $\mathrm{U} 292-015-25.3$ & 0.0 & 0.324 & $1.40 \mathrm{e}-4$ & 1.48 & $1.6 \mathrm{e}-8$ \\
Clay with sand & $\mathrm{U} 292-015-4.3$ & $\mathbf{0 . 0}$ & 0.350 & $7.00 \mathrm{e}-5$ & 1.70 & $1.2 \mathrm{e}-8$ \\
Clayey silt & $\mathrm{U} 292-020-36.6$ & $\mathbf{0 . 0}$ & 0.375 & $7.70 \mathrm{e}-4$ & 1.19 & $1.2 \mathrm{e}-8$ \\
\hline \hline
\end{tabular}

of unsaturated soils. From the water retention data, we were able to determine the van Genuchten parameters that define closed-form equations for both the water retention and unsaturated hydraulic conductivity functions. We use data from Table 3.4 extensively to supply water retention and relative hydraulic conductivity functions for the numerous numerical simulations in this study. 


\section{Geostatistical Estimation and Simulation of Soil Properties}

\subsection{Introduction}

A number of field studies have shown that the hydraulic properties of soils are spatially variable because the subsurface is naturally heterogeneous (Gee et al., 1991). Spatially variable soil properties include hydraulic conductivity, water retention relations and porosity. Traditional methods of dealing with soil heterogeneity in flow and transport analyses are characterized by extensive field measurements to support deterministic modeling approaches. These approaches rely heavily on interpolation techniques to estimate soil properties at unsampled locations. One significant disadvantage of most of these interpolation techniques is that they apply an artificial smoothing effect on the domain, reducing the variance of the estimates with respect to the variance of the data set. This smoothing effect is more severe in areas of sparse data. In kriging, for example, the local estimation error variance is minimized, but smoothing occurs regardless of the variance of the data. More recently, increasing attention has been given to stochastic models that attempt to better preserve the global features of the data, and to find realistic methods of addressing the uncertainties that stem from spatial variability of the soil's hydraulic properties.

In this chapter, we describe the approach we adopt to estimate and simulate hydraulic properties of the soils at the site, using the limited data available. We apply ordinary kriging as well as conditional simulation to generate a number of different realizations of flow domain soil properties from the same data set. The procedure will be applied later in Chapter 7, where we present the results of two-dimensional transport simulation runs on different realizations of soil properties to study the effect of data uncertainty on the transport calculations. The procedure will also be used in Chapter 8 where additional 
realizations are generated for three-dimensional transport calculations.

We begin with the full suite of unsaturated soil property measurements on the 16 samples presented in Tables 2, 3, and 4 back in Chapter 3 . These samples were all recovered from Boreholes 1, 15 and 20. However, samples from Boreholes 16, 17, 18, and 19 were analyzed for particle size distribution only. Initial water content $\left(\theta_{i}\right)$ data were available for some samples from a few other boreholes. Using data from Boreholes 1, 15 and 20, we constructed correlations of $K_{s}$ versus particle size and $\theta_{i}$ versus $K_{s}$, and use these correlations to estimate $K_{s}$ at sample locations in boreholes where $K_{s}$ was not measured. With this procedure we compiled an extended data set which we used to construct sample variograms. Kriging and conditional simulation were applied to the extended data set to

estimate and simulate $K_{s}$ at unsampled locations. A number of different realizations of the simulated field were generated. van Genuchten parameters were obtained by soil property correlation and random sampling.

\subsection{Soil Property Correlations}

We constructed the following soil property correlations from the sample data:

- $K_{s}$ versus various particle size parameters

- Initial water content $\left(\theta_{i}\right)$ versus $K_{s}$

- van Genuchten's $\alpha$ parameter versus $\sqrt{K_{s}}$.

\subsection{1 $\mathbf{K}_{s}$ Versus Particle Size}

Figure 4.1 shows particle size correlations with saturated hydraulic conductivity for the 16 soil samples recovered from Boreholes 1,15 , and 20 . The particle sizes shown here were obtained from standard particle size analyses. The D30 grain size, for example, is the grain 
diameter, in $\mathrm{mm}$, for which $30 \%$ of the sample mass is finer.

Higher correlations were obtained for the D30, D40, and D50 grain sizes, which each gave a linear $\log -\log$ correlation coefficient of at least $88 \%$. Of these three grain sizes, D40 correlated best with saturated hydraulic conductivity, fitting the relationship

$$
K_{s}=3.31 \times 10^{-3} D_{40}^{2}
$$

where $K_{s}$ is the saturated hydraulic conductivity in $\mathrm{cm} / \mathrm{s}$ and $D_{40}$ is the $40 \%$ passing grain size expressed in $\mathrm{mm}$. The correlation coefficient for this fit was $91 \%$. The correlation fit for the median grain size, D50, is

$$
K_{s}=9.15 \times 10^{-4} D_{50}^{2.05}
$$

with a correlation coefficient of $88 \%$. For the D30 size, the fit is

$$
K_{s}=1.27 \times 10^{-2} D_{30}^{1.87}
$$

with a correlation coefficient of $90 \%$. Insufficient data were available to study D10 and D20 correlations adequately.

\subsubsection{Initial Water Content Versus $\mathrm{K}_{s}$}

Figure 4.2 is a $\log$-linear regression plot of $\theta_{i}$ versus $K_{s}$, with a correlation coefficient of 95\%. The relationship derived from this fit is

$$
\theta_{i}=\log K_{s}^{-.041}-9.2 \times 10^{-3}
$$

where $K_{s}$ is expressed in $\mathrm{cm} / \mathrm{s}$. Field water content profiles measured by neutron probe in Boreholes 17,18 , and 19 showed that $\theta_{i}$ is not a function of depth but a strong function of soil type (Mallon et al., 1994). Large variability in the water retention function dominates the effect of elevation on $\theta_{i}$ usually expected for a soil profile at equilibrium. 

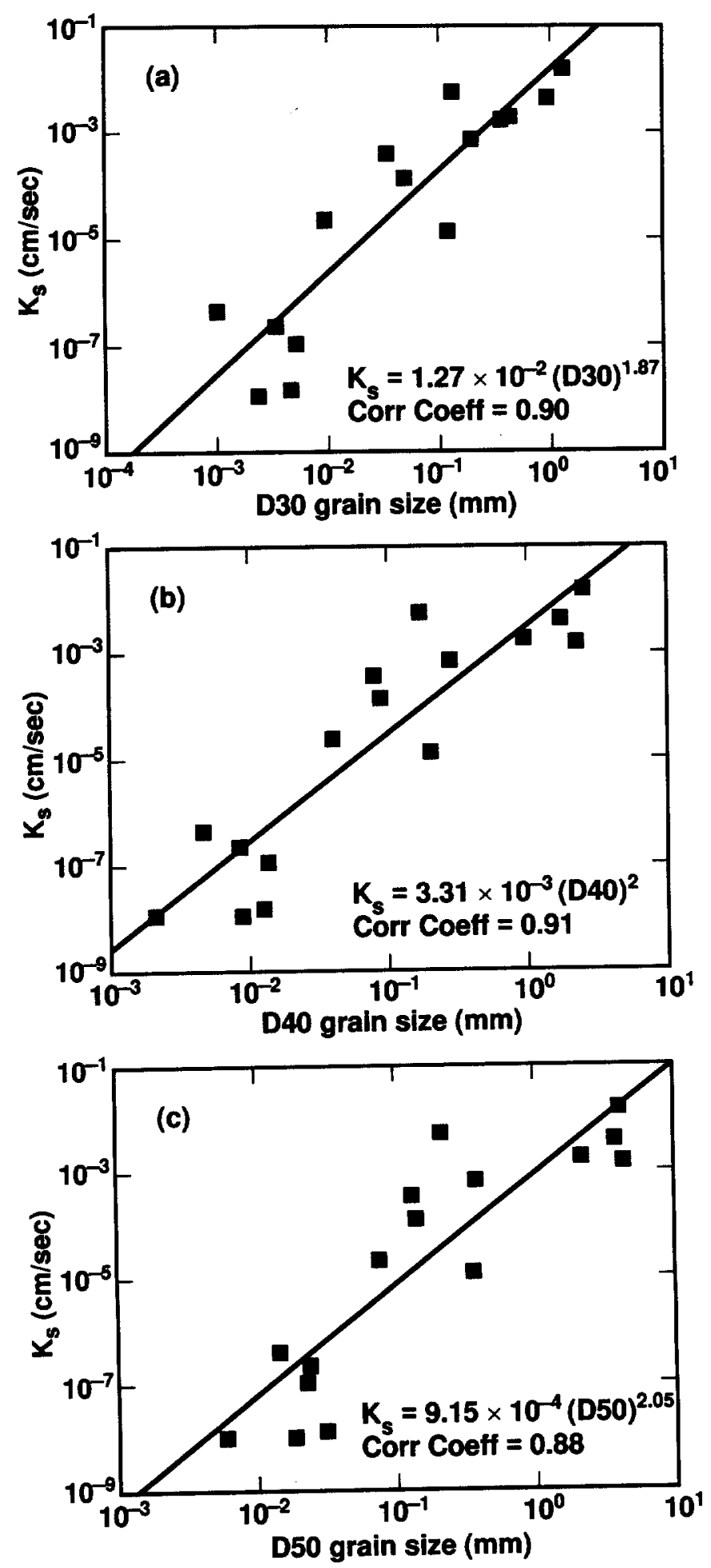

Figure 4.1: Saturated hydraulic conductivity versus particle size for (a) D30, (b) D40, and (c) D50 grain sizes obtained from core samples recovered from Boreholes 1, 15 , and 20 in the LLNL Building 292 Area. 


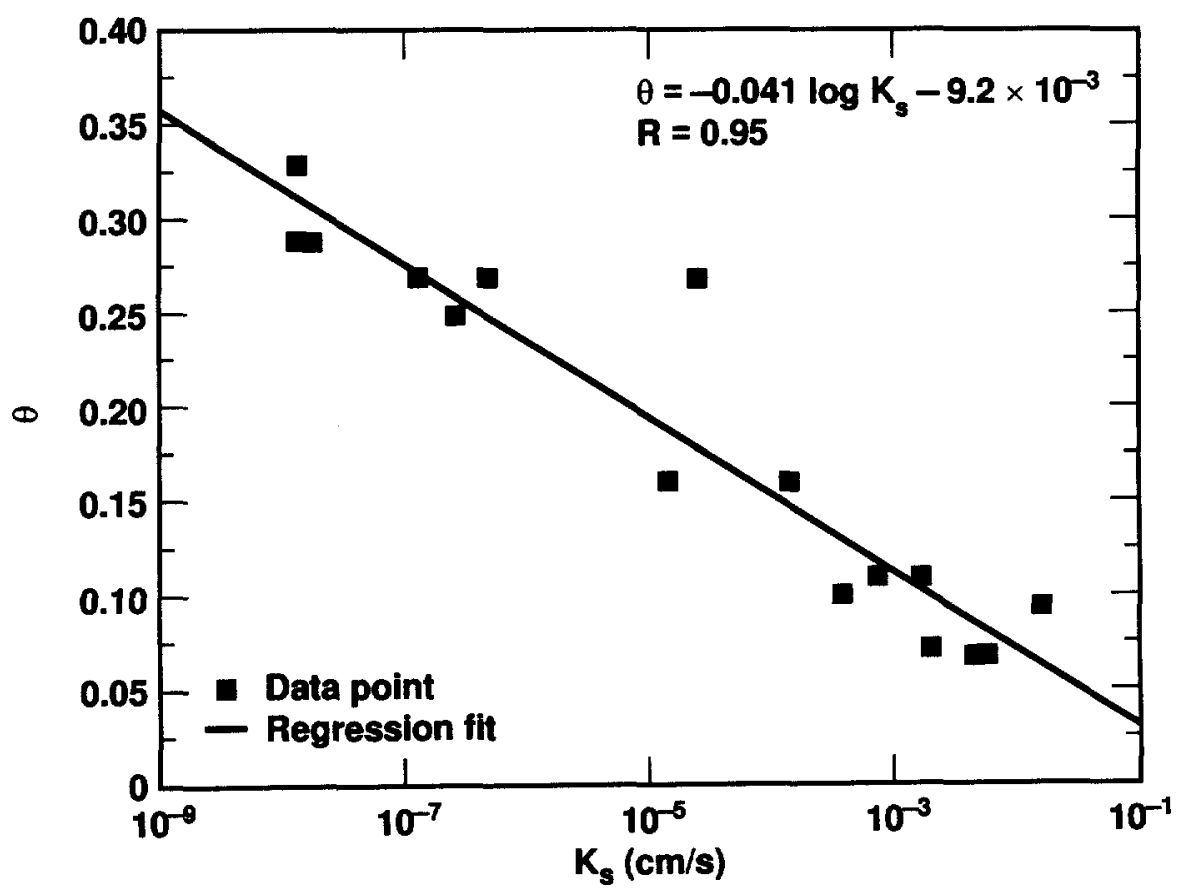

Figure 4.2: Regression plot of initial water content, $\theta_{i}$, versus saturated hydraulic conductivity, $K_{s}$, for soil samples recovered from the LLNL Building 292 Area.

\subsubsection{Alpha Versus $\mathrm{K}_{s}$}

Figure 4.3 is a $\log$-log regression plot of van Genuchten's $\alpha$ versus $\sqrt{K}_{s}$. The correlation coefficient is $92 \%$. The relationship from this fit is

$$
\alpha=1.73 K_{s}^{.493}
$$

or approximately

$$
\alpha=1.7 \sqrt{K}_{s}
$$

where $\alpha$ is expressed in $\mathrm{cm}^{-1}$ and $K_{s}$ in $\mathrm{cm} / \mathrm{s}$. This relationship is consistent with the findings of Leverett (1941) who showed that

$$
\frac{1}{P_{c}^{\text {entry }}} \propto \sqrt{\frac{k}{\phi}}
$$




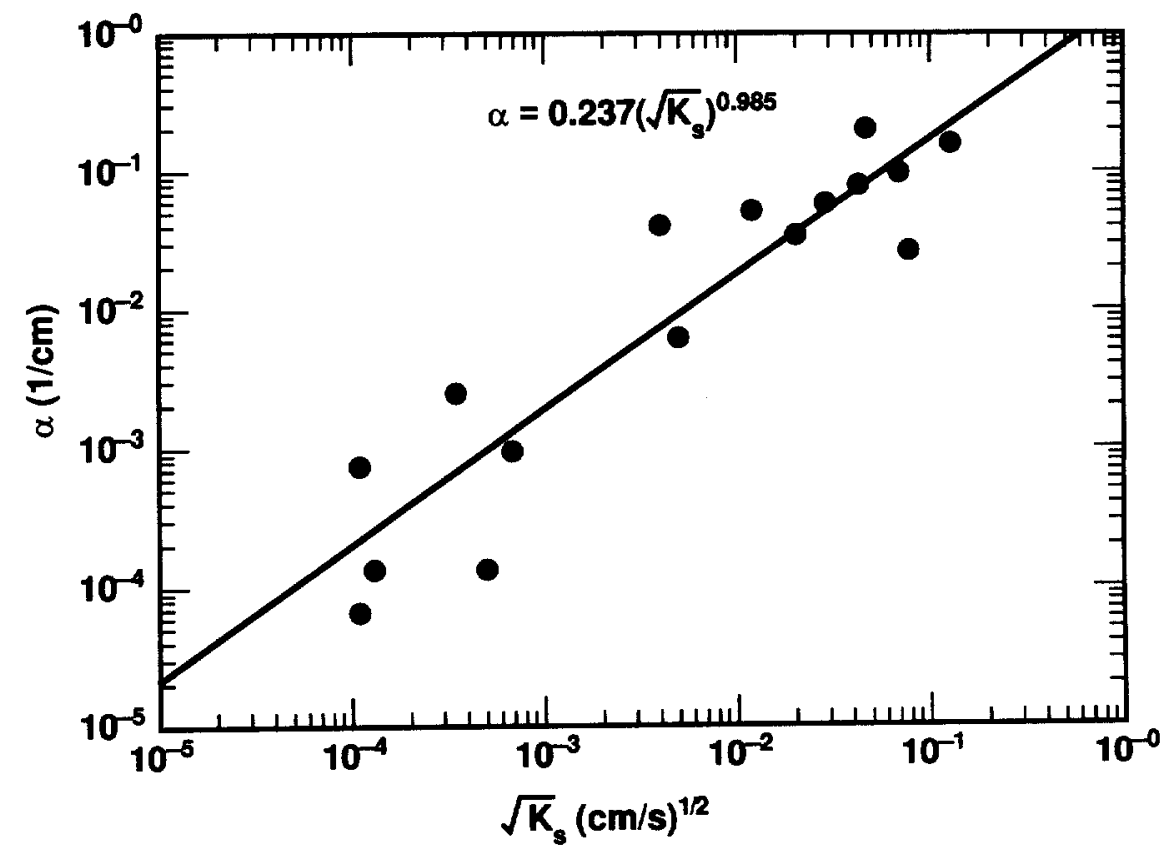

Figure 4.3: Regression plot of van Genuchten's $\alpha$ versus saturated hydraulic conductivity, $\mathrm{K}_{s}$, for soil samples recovered from the LLNL Building 292 Area.

where $\mathrm{P}_{c}^{\text {entry }}$ is the air entry pressure, $\approx 1 / \alpha, \mathrm{k}$ the absolute permeability, and $\phi$ the porosity. A similar relationship between $\alpha$ and permeability was also shown by Wang (1992) who found that the permeability of tuff and soil varies approximately as the square of $\alpha$.

\section{3 $\quad \mathbf{K}_{s}$ Data Statistics}

We present histograms showing two extensions of the saturated hydraulic conductivity data set. In the first histogram the original 16 data points are extended to 57 by including points from Boreholes $16,17,18$, and 19 , with $K_{s}$ values estimated from the $K_{s}$ versus D40 particle size correlation. In the second histogram, soft data obtained from the $\mathrm{K}_{s}$ versus $\theta_{i}$ were added, extending the data set to 132 points.

For both histograms, $\mathrm{K}_{s}$ was converted to natural logarithm of absolute or intrinsic permeability. The permeability ( $\mathrm{k}$ ) is expressed in $\mu$ darcy to avoid negative logarithm values. These values need to be positive for later application of kriging and stochastic 
simulation. The conversion from hydraulic conductivity to permeability was made using the relationship developed by Hubbert (1940):

$$
k=\frac{\mu}{\rho g} K_{s}
$$

where $\rho$ is the density of the liquid, $\mu$ the viscosity, and $g$ the gravitational constant. For water under standard conditions, the factor for conversion from hydraulic conductivity to intrinsic permeability, $\mu /(\rho g)$, is about 1040 darcy per $\mathrm{cm} / \mathrm{s}$.

A histogram of the 57-sample data set is shown in Figure 4.4. The mean permeability is 7.3 mdarcy and the median is 3.0 mdarcy, typical of soils in the silt range. The mean and median shown in the legend of Figure 4.4 are $\ln \mathrm{k}(\mu \mathrm{darcy})$ values. The permeability ranges over 7 orders of magnitude, from the lowest class of $1.2 \times 10^{-5}$ darcy, in the clay range, to the highest class of 24 darcy, in the clean sand range. The standard deviation of the natural log of permeability, $\sigma_{k}$, is 4.3 with permeability expressed in $\mu$ darcy. The coefficient of variation is 0.48 . The permeability values, along with LLNL sample coordinates and elevations, are tabulated in Appendix Table C.1.

A histogram of the larger 132-sample data set is shown in Figure 4.5. The shape is very similar to that of Figure 4.4. The mean permeability is 8.9 mdarcy and the median is 2.9 mdarcy. As with the smaller data set, these values are typical of soils in the silt range. The lowest permeability class is $1.2 \times 10^{-5}$ darcy, in the clay range, and the highest class is 98 darcy, in the clean sand to gravel range. $\sigma_{k}$ is 4.5 and the coefficient of variation is 0.49 . The permeability values, along with LLNL sample coordinates and elevations, are tabulated in Appendix Table C.2. 


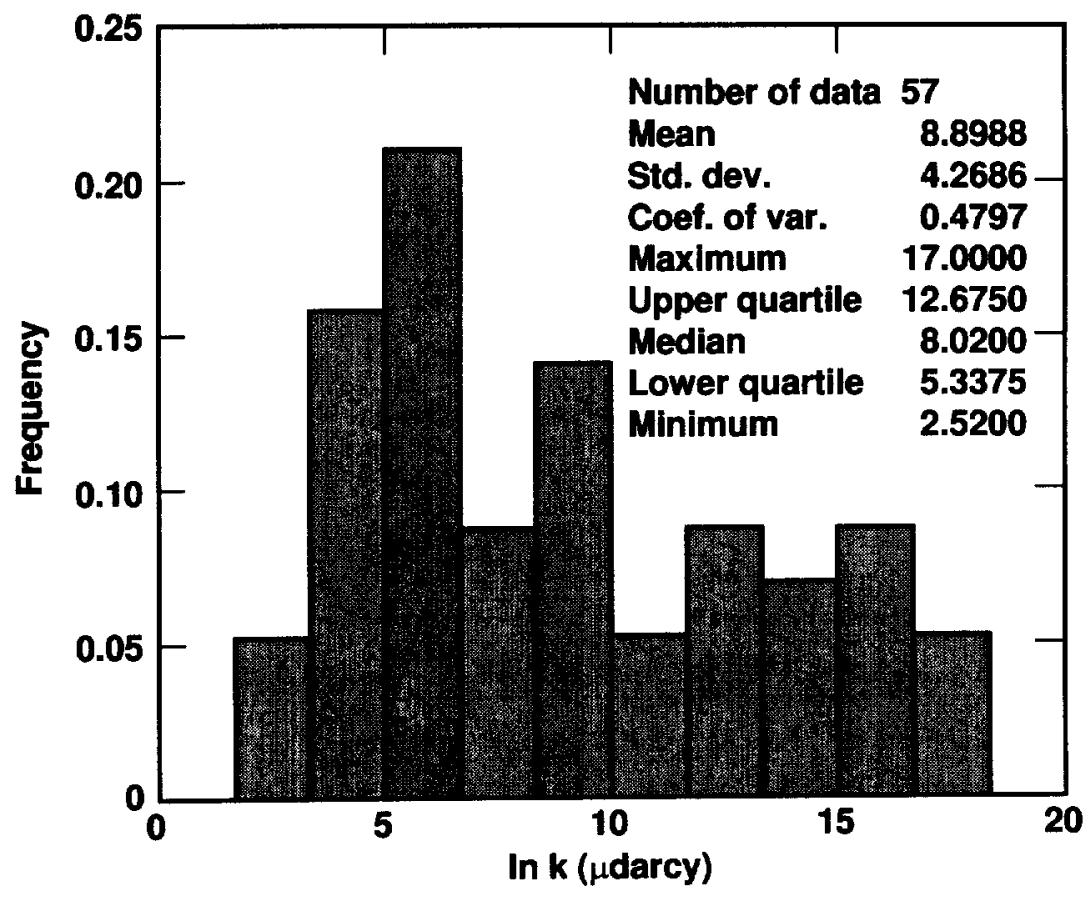

Figure 4.4: Permeability histogram of the 57-sample data set for soil samples from the LLNL Building 292 Area.

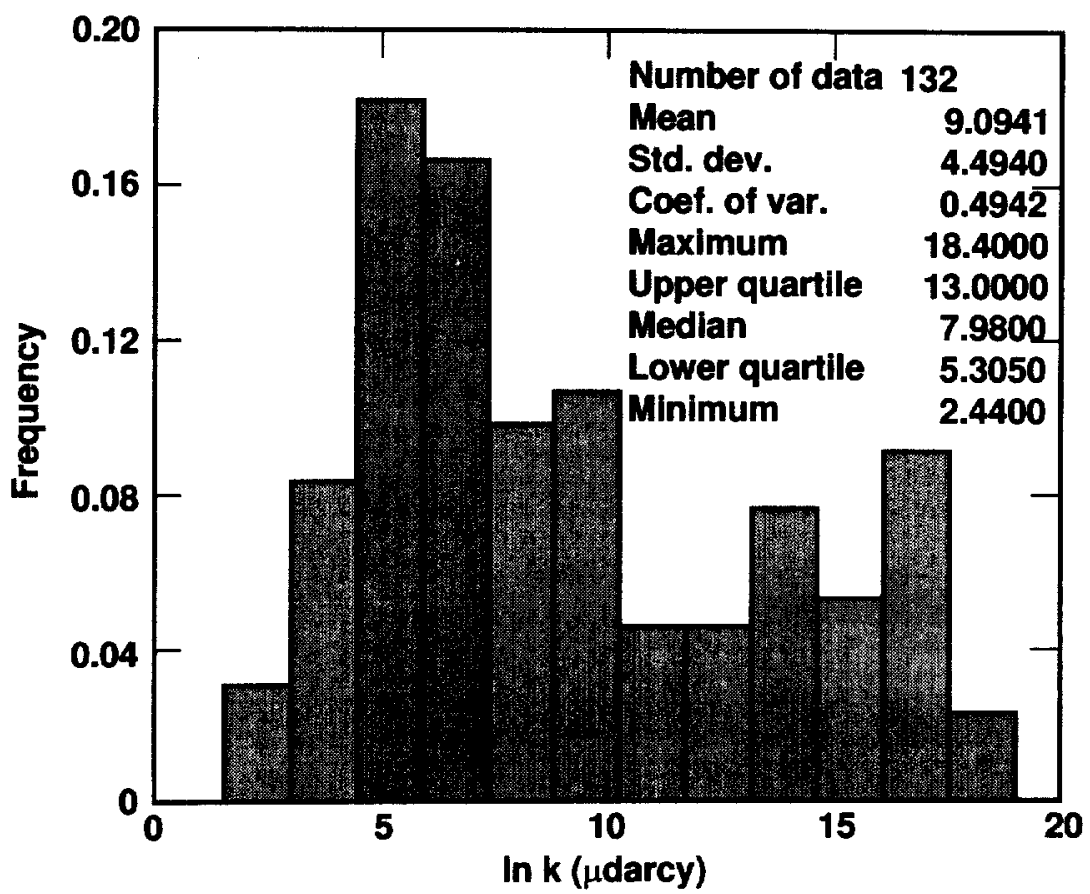

Figure 4.5: Permeability histogram of the 132-sample data set for soil samples from the LLNL Building 292 Area. 


\subsection{Spatial Variability of $\mathrm{K}_{s}$}

For both kriging and simulation, we need to develop sample variograms to characterize the spatial variability of $\mathrm{K}_{s}$. The variogram is half the expected squared difference between random variables separated by a specified distance (Isaaks and Shrivastava, 1989):

$$
\gamma(h)=\frac{1}{2} E\left\{[V(x)-V(x+h)]^{2}\right\}
$$

where $\gamma$ is the variogram, $\mathrm{V}(\mathrm{x})$ is the random variable at location $\mathrm{x}$, and $\mathrm{h}$ is the separation distance or lag.

\subsection{1 $\mathrm{K}_{s}$ Sample Variograms}

Variograms were generated from the data using GSLIB, a collection of geostatistical software developed at Stanford University (Deutsch and Journel, 1992). Sample values are input with full three-dimensional coordinates and the code returns points on the variogram curves for specified directions and lags.

Sample variograms for permeability of the soils are presented in Figures 4.6 for horizontal directions, and Figure 4.7 for the vertical. As with the histograms presented above, the variograms were constructed from saturated hydraulic conductivity data converted to natural logarithm of permeability expressed in $\mu$ darcy. Figure 4.6 shows the omnidirectional permeability variogram for lags measured in the horizontal, and an approximate fit to the spherical model which is one of a number of standard variogram models. The spherical model is defined by a range, $a$, and positive variance contribution or sill, $c$, according to the equation (Deutsch and Journel, 1992)

$$
\gamma(h)= \begin{cases}c\left[1.5 \frac{h}{a}-0.5\left(\frac{h}{a}\right)^{3}\right] & \text { if } h \leq a \\ c & \text { if } h>a\end{cases}
$$




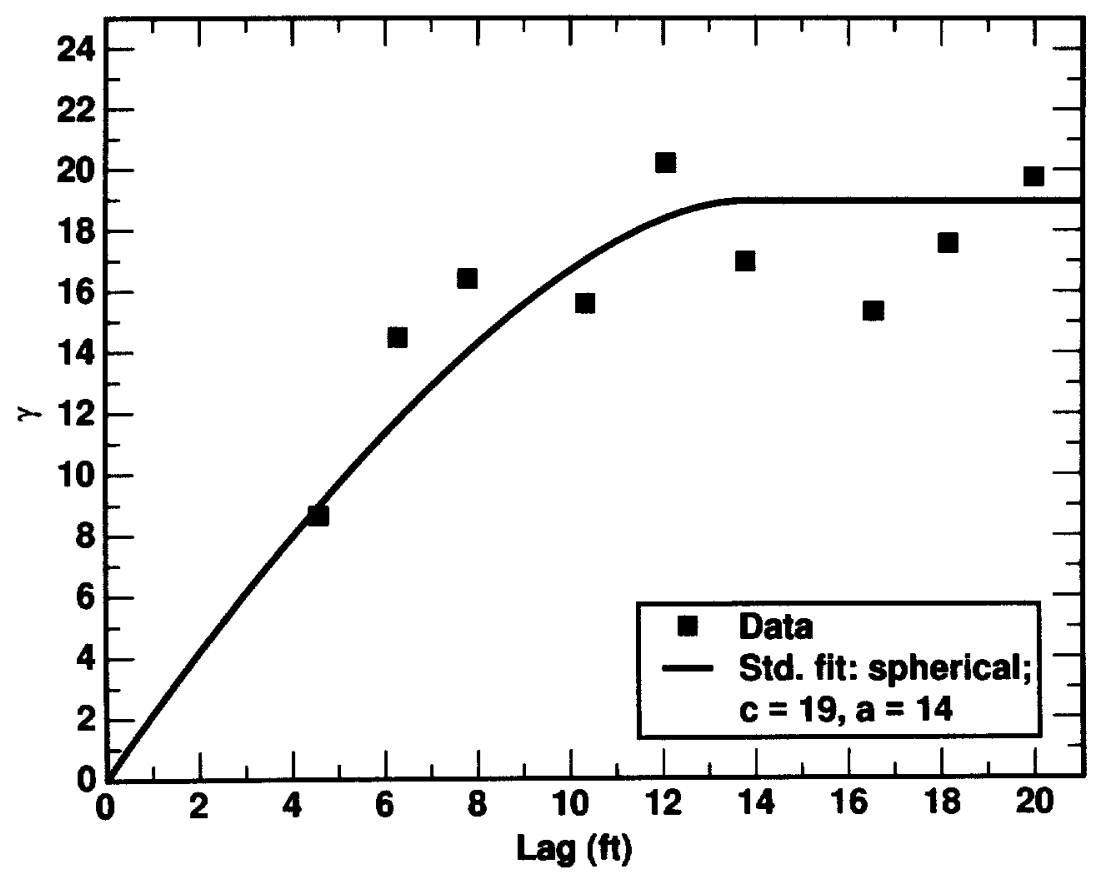

Figure 4.6: Horizontal soil permeability variogram for samples from the LLNL Building 292 Area.

The horizontal permeability variogram shows a range of about $14 \mathrm{ft}$ and a sill of 19 . The vertical permeability variogram, shown in Figure 4.7 , has a range of about $4.5 \mathrm{ft}$ and a sill of $17 \mathrm{ft}$.

\subsection{Kriging and Conditional Simulation}

\subsubsection{Kriging}

The estimation or interpolation technique known as kriging has its roots in the mining industry where it was first applied to ore reserve estimation. Mining engineers and geologists have always known that ore grade depends heavily on the position within the orebody and on the grades at surrounding locations. Traditional estimation techniques such as polygonal and triangular weighting, rectangular zones of influence, and inverse distance methods were all developed to use these two characteristics-spatial position and value of surrounding grades. In inverse distance weighting, for example, the weighting coefficient is inversely 


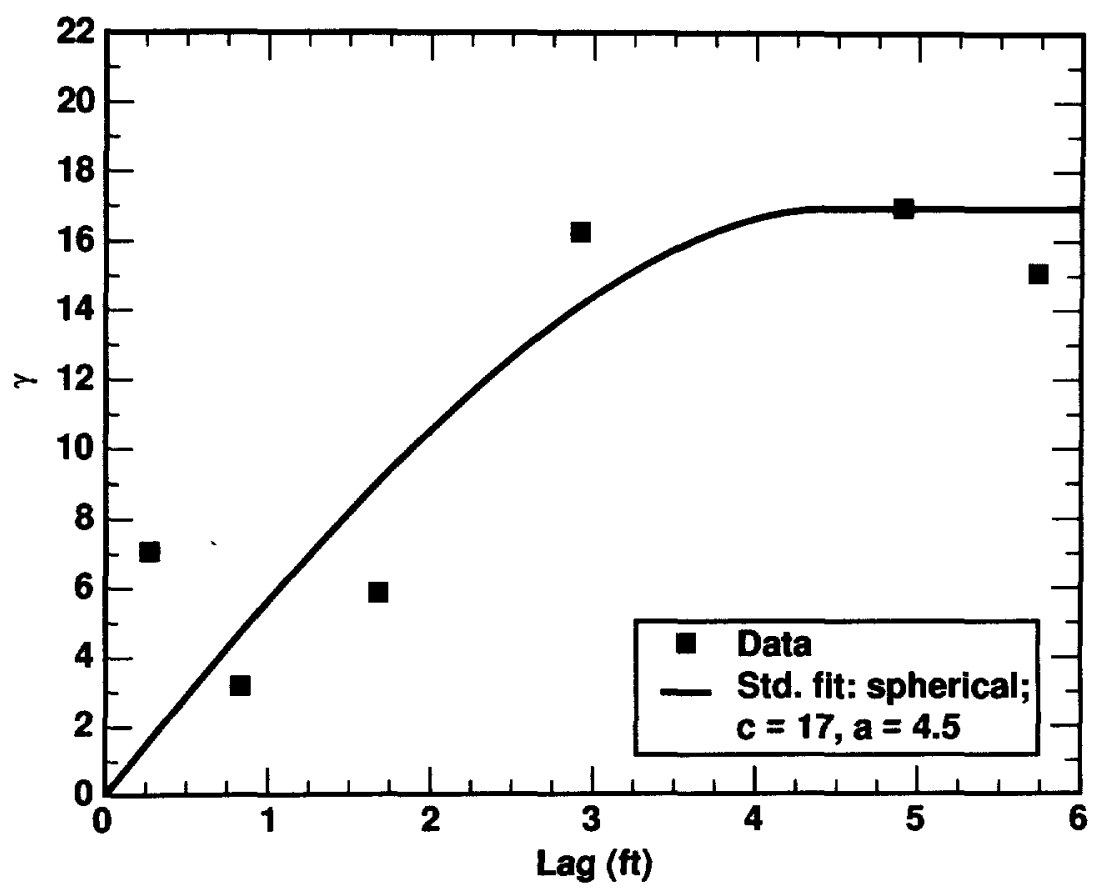

Figure 4.7: Vertical soil permeability variogram for samples from the LLNL Building 292 Area.

proportional to some power of the distance between the sample and estimation point. The exponent is chosen based on some general ideas of the variation in similar mineral deposits, but no reference is made to the particular variability of the orebody under study. Moreover, there is no objective method to measure the reliability of these estimates.

Following earlier empirical work by Krige (1951), Matheron (1963) developed the theory of regionalized variables to improve ore grade estimation. Geostatistics subsequently developed to provide more effective estimation procedures for a range of fields in the earth sciences, including hydrology. The underlying principles of geostatistics have been widely described in the literature (David, 1977; Journel and Huijgregts, 1978; Isaaks and Srivastava, 1989; Deutsch and Journel, 1992).

Ordinary kriging is a geostatistical estimation technique based on the spatial variability of a regionalized variable, as reflected in the sample variogram. Ordinary kriging provides 
the "best" linear "unbiased" estimate of the variable at an unsampled location from a linear combination of neighboring measured values. The estimate is described as "best" because the model attempts to minimize $\sigma_{R}^{2}$, the variance of the estimation errors; and "unbiased" because it attempts to achieve a zero mean residual error. A distinguishing feature of ordinary kriging is the aim of minimizing the estimation error variance.

The equations for ordinary kriging are developed on the assumption that the samples and the unknown true values are outcomes of random variables. The estimate, a linear combination of the samples, is therefore also a random variable:

$$
V_{e}\left(u_{0}\right)=\sum_{i=1}^{n} \beta_{i} V\left(u_{i}\right)
$$

where $V_{e}\left(u_{0}\right)$ is the estimated value at location $u_{0}, V\left(u_{i}\right)$ is the sample value at $u_{i}$, and $\beta_{i}$ is the weight at $u_{i}$. By setting the expected value of the estimation error to zero and minimizing the error variance, the following system of equations, commonly referred to as the ordinary kriging system, is derived (Isaaks and Srivastava, 1989):

$$
\begin{gathered}
\sum_{j=1}^{n} \beta_{j} \gamma_{i j}-\mu=\gamma_{i 0}, \quad i=1, \cdots, n \\
\sum_{i=1}^{n} \beta_{i}=1
\end{gathered}
$$

where $\gamma_{i j}$ is the value of the variogram between locations $u_{i}$ and $u_{j}$, and $\mu$ is the Lagrange parameter. The system has $n+1$ equations with $n+1$ unknowns and therefore can be solved to obtain the $\mathrm{n}$ unknown weights. The error variance is given by

$$
\sigma_{R}^{2}=\sum_{i=1}^{n} \beta_{i} \gamma_{i 0}+\mu
$$

\subsubsection{Conditional Simulation}

There is a significant difference between results obtained by kriging and stochastic simulation. The goal of kriging is to provide the best local estimate by minimizing local 
uncertainties at each unsampled location without regard to the resulting spatial statistics of the estimates. As with all moving-average-type estimates, the field variance is always larger than the variance of the estimates. One consequence of this decrease in variance is the smoothing effect, which is more pronounced in areas of sparser sampling. With simulation, on the other hand, the focus is more on preserving the global spatial features and statistics of the samples (mean, variogram, as well as probability distribution) and not on local estimation accuracy. The simulation is described as conditional if the resulting realizations honor the data values at sample locations (Christakos, 1992; Journel and Huijbregts, 1978).

Delhomme (1979) first introduced a framework for analyzing conditional simulation in a hydrologic context. In specific field situations a hydraulic variable, say hydraulic conductivity, is measured at a few locations and is therefore considered as being deterministic at those measured locations but uncertain at unmeasured locations. As more measurement locations are added, one would expect that the uncertainty about the hydraulic conductivity space would be reduced. In conditional simulation, the hydraulic conductivity is treated as a spatially random variable, but only realizations that honor the measured values at measurement locations are considered.

A conditional simulation of a regionalized variable may be obtained from kriging and non-conditional simulation (Journel and Huijbregts, 1978; Deutsch and Journel, 1992). Consider the variable $\mathrm{z}(\mathrm{u})$, where $\mathrm{z}$ is the natural logarithm of the soil permeability, and $\mathrm{u}$ is the location coordinates vector. The conditional simulation is written as

$$
z_{s c}(u)=z^{*}(u)+\left[z_{s}(u)-z_{s}^{*}(u)\right]
$$

where $z^{*}(u)$ is the permeability estimated by kriging on the real sample data, $z_{s}(u)$ the permeability obtained by non-conditional simulation with the real sample data, and $z_{s}^{*}(u)$ the kriging estimate from simulated data at the real data point locations. Kriging is there- 
fore conducted twice in this procedure: the first time on the original sample data, and the second time on the simulated values at the data point locations. The procedure is as follows:

- Perform ordinary kriging on original data to obtain $z^{*}$

- Perform nonconditional simulation on original data to obtain $z_{s}$

- Repeat ordinary kriging, using the simulation results at the original data point locations as the input data; the result is $z_{s}^{*}$

- Use Equation 4.15 to compute the conditional simulation field $z_{s c}$.

The expression $\left[z_{s}(u)-z_{s}^{*}(u)\right]$ represents the simulated error which is added to the estimated value $z^{*}(u)$ to obtain the conditional simulation. At the data point locations, the simulated error is zero and the conditional simulation is equal to the kriging estimate so that the data values are preserved.

We perform nonconditional simulations here by the turning bands method introduced by Matheron(1973) and Journel (1974) for isotropic Gaussian random fields in the space domain, and later developed for mining and other earth science applications by Journel and Huijbregts (1978). The method was later extended to the spectral domain by Mantoglou and Wilson (1982). The technique produces nonconditional simulations of a standard Gaussian field with a given covariance or variogram to describe the spatial variability. In the turning bands method, three-dimensional simulations are reduced to several independent one-dimensional simulations along lines which are then rotated in three-dimensional space. Tompson et al. (1989) enhanced the performance of the method by randomly selecting a larger number of lines, as opposed to the earlier practice of selecting only about 15 evenly spaced lines. One significant improvement demonstrated by Tompson et al. is a substantial reduction in artifact banding observed as linelike structures in the field. 
We use routines from the Geostatistical Software Library (Deutsch and Journel, 1992), with some minor modifications, and the turning bands model by Tompson et al. (1989), to generate three-dimensional permeability fields by kriging and nonconditional simulation. We wrote a number of fortran routines that prepare the field data for analysis by the geostatistical and stochastic simulation models, control execution of the models, and perform conditional simulation using the output from kriging and nonconditional simulation. The routines generate permeabilities from kriging and from conditional simulation in separate files, in an appropriate format for direct input into the NUFT code. This gives the user the option of performing a numerical flow and transport simulation using permeabilities generated by kriging, or generated as a realization from conditional simulation.

For the nonconditional simulation, we incorporate anisotropy in spatial variability by coordinate transformation. This transformation is necessary because the turning bands model of Tompson et al. (1989) handles only isotropic fields. Recall that the variograms presented in Figures 4.6 and 4.7 showed anisotropy, with the horizontal range about three times as large as the vertical range. To effect the transformation for equal grid dimensions in the $\mathrm{x}, \mathrm{y}$, and $\mathrm{z}$ directions, we use a vertical to horizontal grid size ratio equal to the ratio of the horizontal to vertical variogram range before conducting the simulation. On completion of the simulation, the grid is transformed back to equal dimensions in the three principal directions.

Our routines also select or estimate other unsaturated flow properties and parameters, based mainly on correlations with permeability. For the case where the field for numerical analysis was estimated by kriging, additional unsaturated flow parameters were selected from one of the 16 samples in Table 3.2 based on permeability. All unsaturated flow parameters of the sample with the closest permeability value were assigned to the estimated 
node. For the case where the permeability field was generated by conditional simulation, different approaches were used to estimate the various unsaturated flow parameters. van Genuchten's $\alpha$ parameter was estimated from the correlation of $\alpha$ versus $\sqrt{K_{s}}$, presented earlier in Figure 4.3 and Equation 4.6. van Genuchten's n parameter was selected randomly from a normal distribution with mean obtained from the data: $\mathrm{n}$ showed no correlation with $K_{s}$ or any other soil property. The porosity $(\phi)$ was also uncorrelated with $K_{s}$ or any other measured soil property and was randomly sampled from a normal distribution with mean obtained from the data. The parameters $\theta_{r}$ and $\theta_{s}$ were estimated based on correlations with $\mathrm{K}_{s}$ observed in Table 3.2, Chapter 3 .

\subsubsection{Estimation and Simulation of Permeability Field}

In this section we outline the steps taken in generating a permeability field from sample data and specification of the sample variogram. The sample input data file must contain the three-dimensional location coordinates and the permeability value for each data point. The data must be prepared in Geo-EAS format, as described by Deutsch and Journel (1992). We use the 132-point extended data set that includes permeability values obtained from $\mathrm{K}_{s}$ correlations with particle size and ambient water content. The $\mathrm{x}$ and $\mathrm{y}$ coordinates are the LLNL easting and northing, respectively, and the $z$ coordinate is the elevation. The regionalized variable shown is the natural log of permeability, expressed in $\mu$ darcy.

We list the steps taken in generating the three-dimensional permeability field as follows:

- Prepare an input file with sample permeabilities and 3-D location coordinates in GeoEAS format for ordinary kriging.

- Execute GSLIB 3-D ordinary kriging program $k t b 3 d m$ using an input parameter file and the input file with sample data. 
- Execute the turning bands nonconditional simulation model of Tompson et al. (1989), turn3d, which outputs a standard Gaussian field. The model generates a realization from a three-dimensional random field of zero mean and unit variance with specified variogram or covariance function.

- Run nscore which takes the standard Gaussian output from the turning bands simulation, and the sample data, and creates a transformation table that is used for transforming the results from Gaussian or normal space back to the original data space.

- Run backtr to complete the transformation of normalized scores back to the original data space, using the transformation table.

- Run snap to assign the nearest node values to data point locations for second ordinary kriging.

- Again execute the GSLIB ordinary kriging program, $k t b 3 d m$, this time with input data as the turning band results at the sample data point locations.

- Execute cond, a program that computes the conditional simulation field using Equation 4.15 , and prepares separate data files for post processing, giving permeability fields from

1. ordinary kriging,

2. nonconditional simulation (turning bands), and

3. conditional simulation.

- Run $x$ file to generate a grid file for imaging of results. 
Once the permeability field is generated by kriging or stochastic simulation with the field data, the results must be put in an appropriate input file format for the NUFT code. In addition, other unsaturated flow parameters must be assigned to each grid block or node in the domain defined for the numerical flow and transport simulation.

We developed a code, nufgsl, that takes a predefined grid for a NUFT simulation run, assigns a permeability field based on the kriging or conditional simulation results, then assigns other unsaturated flow properties using soil property correlation and other methods. Each NUFT node is assigned the permeability of the closest block from the kriging or simulation field. The NUFT grid may be two- or three-dimensional and grid size may be variable.

Operation of the code nufgsl is summarized as follows:

- Overlay the NUFT grid by the GSLIB grid, matching the leak point locations.

- Assign to each NUFT node the permeability of the nearest node from simulation or kriging.

- If the permeability field from kriging is selected, all other soil properties are assigned from the soil sample in Table 3.2 that has a permeability closest to that of the NUFT node, and no other properties need to be estimated by the code: the estimation of additional properties described below applies only to permeability fields generated by conditional simulation.

- Compute van Genuchten's $\alpha(1 / \mathrm{cm})$ from $\alpha$ - $\mathrm{K}_{s}$ correlation $\left(\mathrm{K}_{s}\right.$ in $\left.\mathrm{cm} / \mathrm{s}\right)$ obtained from the data. The correlation in Equation 4.6 may be rewritten in the form

$$
\log \alpha=.237+.985 \log \sqrt{K}_{s}+\alpha_{e r r} .
$$


The $\alpha_{\text {err }}$ term, which is the error due to scatter on the $\log$-log plot in Figure 4.3, is treated as a normally distributed random variable with mean zero and standard deviation $s_{e r r}$. The value of $s_{e r r}$ was calculated as 0.455 from the data. nufgsl calls the function subprogram gasdev (Press et al., 1986) which returns a normally distributed variable with zero mean and unit variance, based on a random number generated by the function $\operatorname{ran} 1$ (Press et al., 1986). The error is obtained from the normalized value by $\alpha_{e r r}=s_{e r r} \times z_{e r r}$ where $z_{e r r}$ is the normalized error from random sampling.

- The van Genuchten parameter, $\mathrm{n}$, is also randomly selected from a normal distribution, with mean 1.50 and standard deviation 0.63 , obtained from the data. The parameter $\mathrm{m}$ is obtained from $m=1-1 / n$.

- The porosity is randomly selected from a normal distribution of mean 0.35 and standard deviation 0.05 , obtained from the data.

- The van Genuchten parameters $S_{r}$ and $S_{m}$ are approximated from the data as

$$
\begin{aligned}
S_{r} & = \begin{cases}0 & \text { if } K_{s} \leq 7.7 \times 10^{-6} \mathrm{~cm} / \mathrm{s} \\
0.15 & \text { otherwise }\end{cases} \\
S_{m} & = \begin{cases}1.0 & \text { if } K_{s} \leq 1.75 \times 10^{-3} \mathrm{~cm} / \mathrm{s} \\
0.75 & \text { otherwise }\end{cases}
\end{aligned}
$$

$S_{r}$ and $S_{m}$ are related to the $\theta_{r}$ and $\theta_{m}$ by $S_{r}=\theta_{r} / \phi$ and $S_{m}=\theta_{m} / \phi$.

- Sections of a NUFT input data file that identify soil types and describe soil properties are prepared in the appropriate format.

\subsubsection{Examples of Permeability Fields from Kriging and Simulation}

We highlight the differences between results obtained by kriging and stochastic simulation by comparing a permeability field generated by kriging with a field generated by conditional simulation. Both fields were computed from the sample data. 
Figure 4.8 compares an east-west section through the two permeability fields. The section is drawn through the suspected leak point. Seven sample boreholes were located within the $\mathrm{x}$-range of about 909 to $930 \mathrm{ft}$, and 1 to $5 \mathrm{ft}$ north of the plane shown. The stochastic realization delivers a much better reproduction of the spatial variability exhibited by the data, even in areas of sparse sampling. On the other hand, the smoothing effect of kriging is evident. This smoothing effect is more pronounced in areas of sparse sampling. 

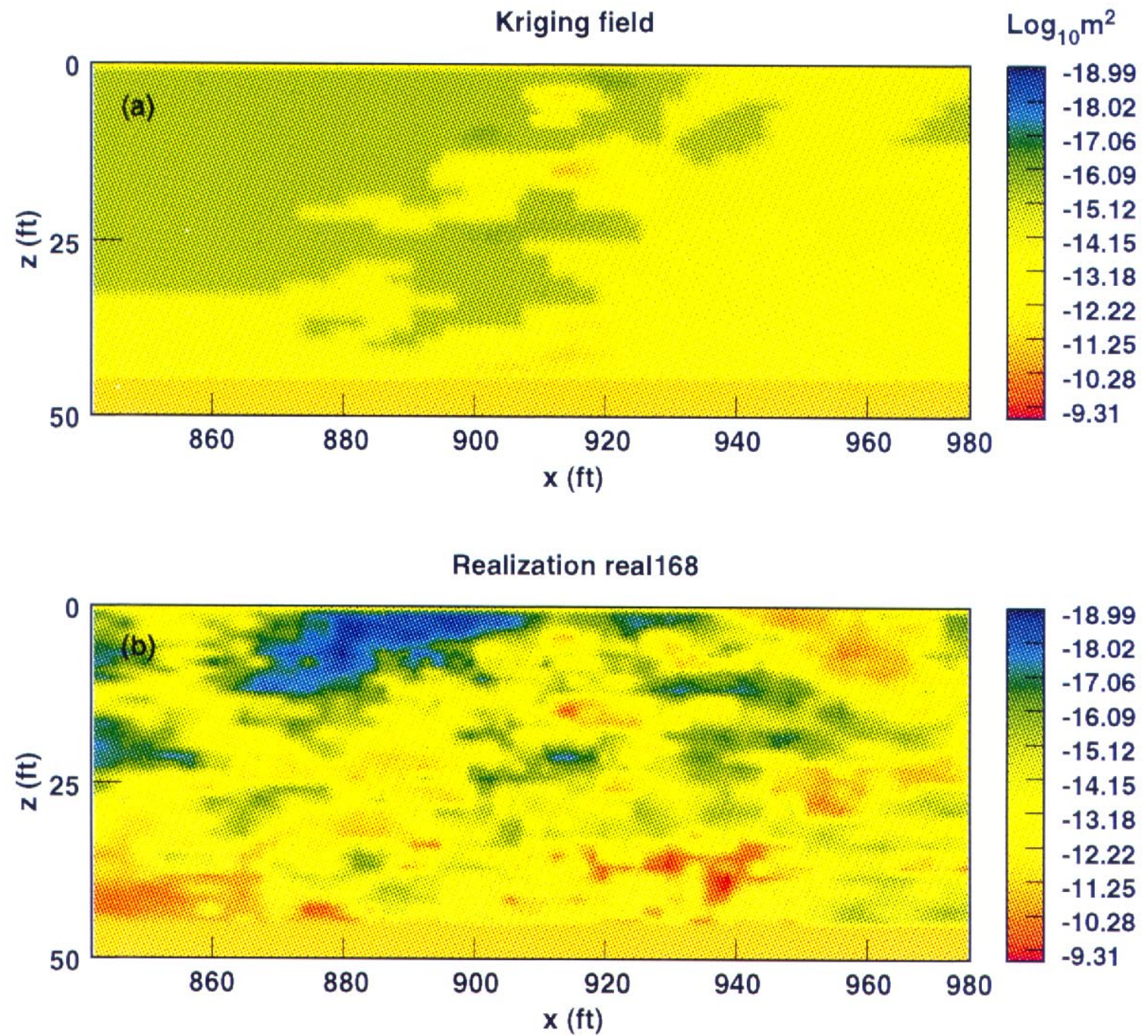

Figure 4.8: Comparison of permeability fields generated by kriging and conditional simulation, using the same sample data. The figure shows an east-west section through the leak point with permeability generated by (a) kriging, and (b) conditional simulation. 


\section{Estimation of the Initial Concentration Field}

\subsection{Introduction}

As part of the site characterization and monitoring program in the LLNL Building 292 Area, 23 boreholes were drilled between September 1989 and October 1992, and a number of soil core samples recovered from various depths. ${ }^{3} \mathrm{H}$ soil water concentration measurements were made on over 200 core samples by liquid scintillation counting. Some of the data are presented back in Chapter 3. The entire data set was presented by Mallon (1995).

A number of investigators have applied geostatistical estimation methods to the characterization of spatial distribution of contaminants in groundwater and soil. A geostatistical framework for a probabilistic assessment of groundwater contamination was presented by Rautman and Istok (1996). The applicability of geostatistical estimation methods to groundwater contamination was reviewed by Cooper and Istok (1988). The use of classical geostatistics to estimate the total contaminant mass at the Chem-Dyne site was presented by Istok and Cooper (1988). The application of classical geostatistical methods to characterize the spatial distribution of contaminated soils was reported by Barnes (1978), Myers and Bryan (1984), and Zirschky et al. (1985).

In this chapter, we estimate soil water ${ }^{3} \mathrm{H}$ concentrations at unsampled locations by applying kriging to the data. We estimate the concentration field and calculate the total ${ }^{3} \mathrm{H}$ activity in the vadose zone beneath the Building 292 Area. We also compute the tritium activity for different subsections of the site. The kriging requires construction of a variogram that describes the spatial variability of tritium concentrations in the soil.

The concentrations and activities estimated here represent average conditions at the site for the 26-month period between September 1989 and November 1991. One borehole, B-20, located about $240 \mathrm{ft}$ north of Tank R1U1, was actually drilled in October 1992, later than 


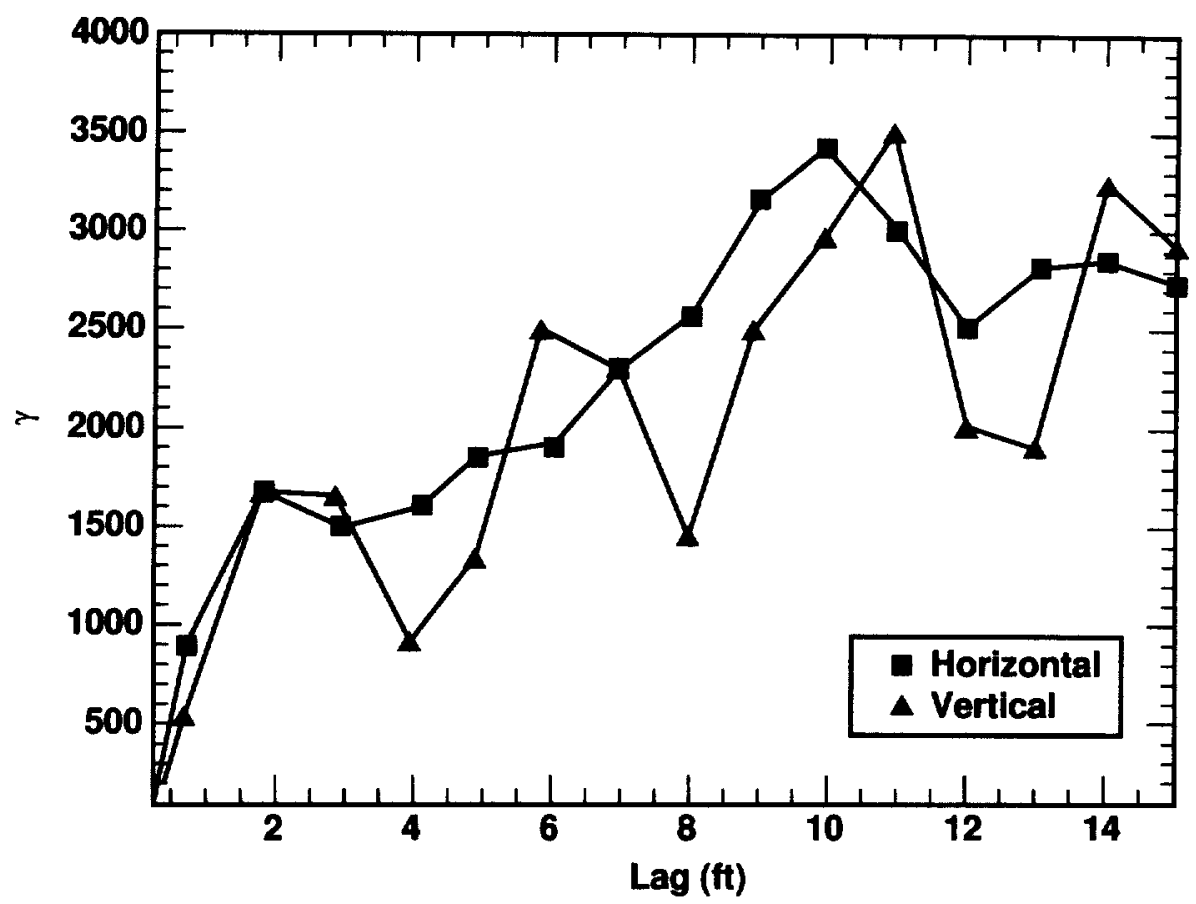

Figure 5.1: Sample variogram for soil water tritium concentration for samples recovered from the LLNL Building 292 Area.

the specified period, but no ${ }^{3} \mathrm{H}$ concentrations above the detection limit of $900 \mathrm{pCi} / \mathrm{L}$ was detected in the samples.

\subsection{Spatial Variability of Concentrations}

The tritium concentration variogram is shown in Figure 5.1. Tritium concentrations were expressed in $\mu \mathrm{Ci} / \mathrm{L}$ to construct the variogram. The figure suggests no significant difference between spatial variability of the concentrations in the horizontal and vertical directions. We therefore assume a statistically isotropic concentration field. The data were approximated by a standard spherical model with range $11.5 \mathrm{ft}$ and sill $2700(\mu \mathrm{Ci} / \mathrm{L})^{2}$. The spherical variogram model which expresses the variogram, $\gamma$, as a function of lag, $h$, is given by the equation

$$
\gamma(h)= \begin{cases}c\left[1.5 \frac{h}{a}-0.5\left(\frac{h}{a}\right)^{3}\right] & \text { if } h \leq a \\ c & \text { if } h>a\end{cases}
$$


with range $a$ and sill $c$.

\subsection{Field Concentrations from Kriging}

Ordinary kriging was applied to estimate ${ }^{3} \mathrm{H}$ concentrations on a 3 -D grid with a uniform spacing of $1.0 \mathrm{ft}$. The kriged domain is bounded by N12735 in the south, N12824 in the north, E8610 in the west, and E8690 in the east, giving horizontal rectangular dimensions of $89 \mathrm{ft}$ long by $80 \mathrm{ft}$ wide. The north side of the tank where the leak occurred is located close to the center of the rectangle. Concentrations from some boreholes outside this rectangle were included in the analysis. The vertical range kriged was from elevation $538 \mathrm{ft}$, about 1 $\mathrm{ft}$ below the water table, to elevation $587 \mathrm{ft}$, the approximate ground surface elevation in the Building 292 Area.

The plume configuration shows some limited lateral spreading in the vadose zone, and

substantially higher ${ }^{3} \mathrm{H}$ concentrations north of the tank. Figure 5.2 is an image of ${ }^{3} \mathrm{H}$ concentrations on a horizontal plane at an elevation of $575 \mathrm{ft}$, about $12 \mathrm{ft}$ below the ground surface. The peak soil water concentration in this plane, approximately $1.90 \times 10^{8} \mathrm{pCi} / \mathrm{L}$, occurs about 2 to $4 \mathrm{ft}$ directly north of the tank. The plume is approximately $65 \mathrm{ft}$ in east-west dimension and $\mathbf{5 0} \mathrm{ft}$ in north-south dimension along this plane.

Higher concentrations observed north of the tank might be explained partially by the tank causing some blockage to ${ }^{3} \mathrm{H}$ transport to the south. In addition, the highest average borehole permeabilities were found in Boreholes 1 and 15, located on the northern side of the tank. The higher permeabilities might have caused tank leakage to flow preferentially to the north. The reported practice of using the concrete pad to wash down equipment contaminated with HTO might also have contributed to higher ${ }^{3} \mathrm{H}$ concentrations observed north of the tank.

A north-south section through the plume is shown in Figure 5.3. The section is drawn 


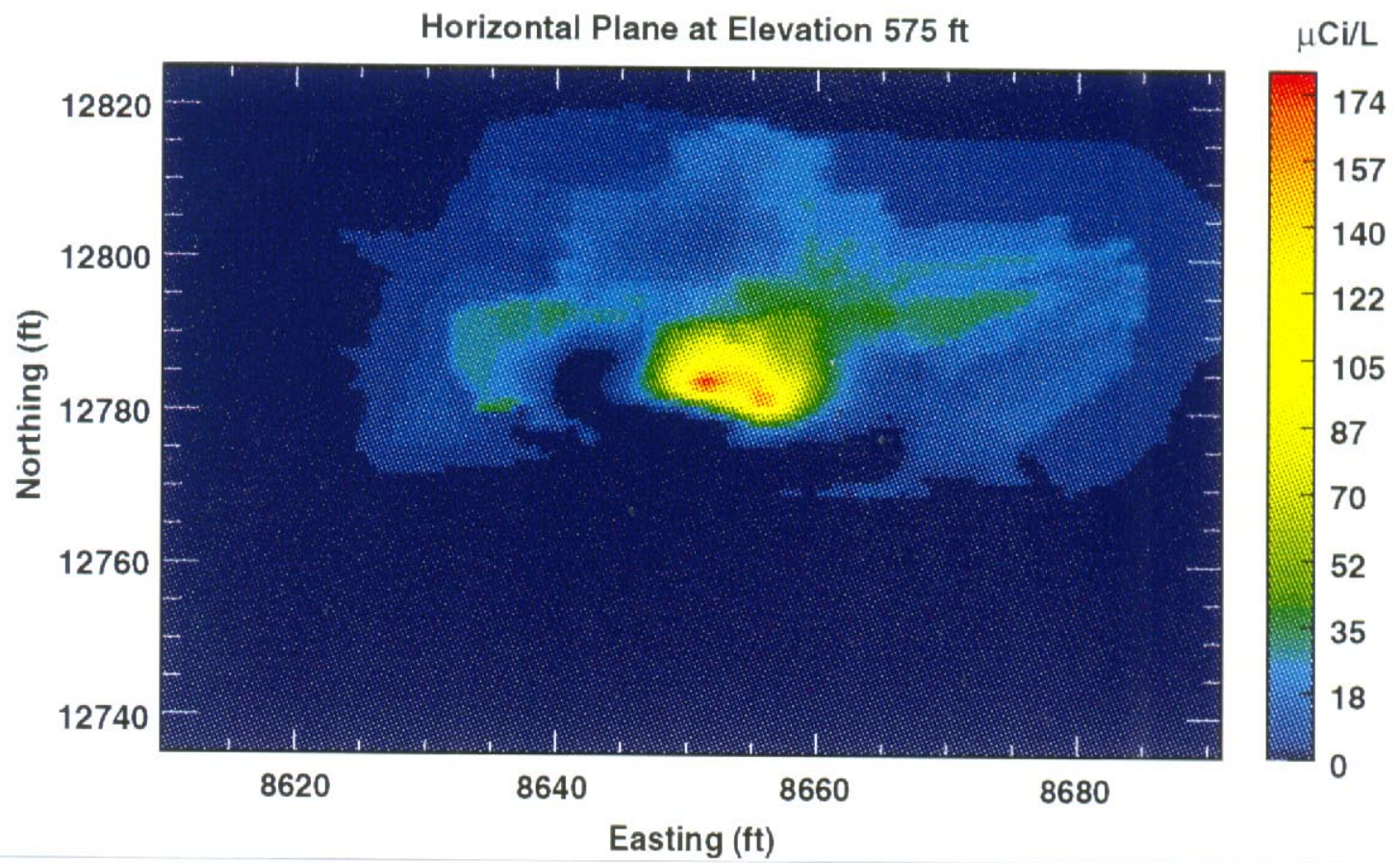

Figure 5.2: Tritium concentrations along horizontal plane at elevation $575 \mathrm{ft}$, about $12 \mathrm{ft}$ below the ground surface in the LLNL Building 292 Area. Concentrations estimated by kriging with the borehole sample data.

along the LLNL easting E8651, $4 \mathrm{ft}$ west of Borehole 1. The peak concentration observed along this section is approximately $1.90 \times 10^{8} \mathrm{pCi} / \mathrm{L}$, occurring at elevation $575 \mathrm{ft}$, about 12 $\mathrm{ft}$ below the ground surface. As observed in Figure $5.2,{ }^{3} \mathrm{H}$ concentrations north of the tank are substantially higher than concentrations to the south. Some moderate concentrations persist going north toward the concrete pad. These concentrations apparently did not result from tank leakage.

An east-west section through the plume is shown in Figure 5.4. The section is drawn along the LLNL northing N12783, about $3 \mathrm{ft}$ north of the tank's north face. The peak concentration seen along this section also occurs at elevation $575 \mathrm{ft}$. The center of mass of the plume seems to have shifted slightly to the east of the leak. Lower concentrations extend about $30 \mathrm{ft}$ to the west and $35 \mathrm{ft}$ to the east of the leak. 


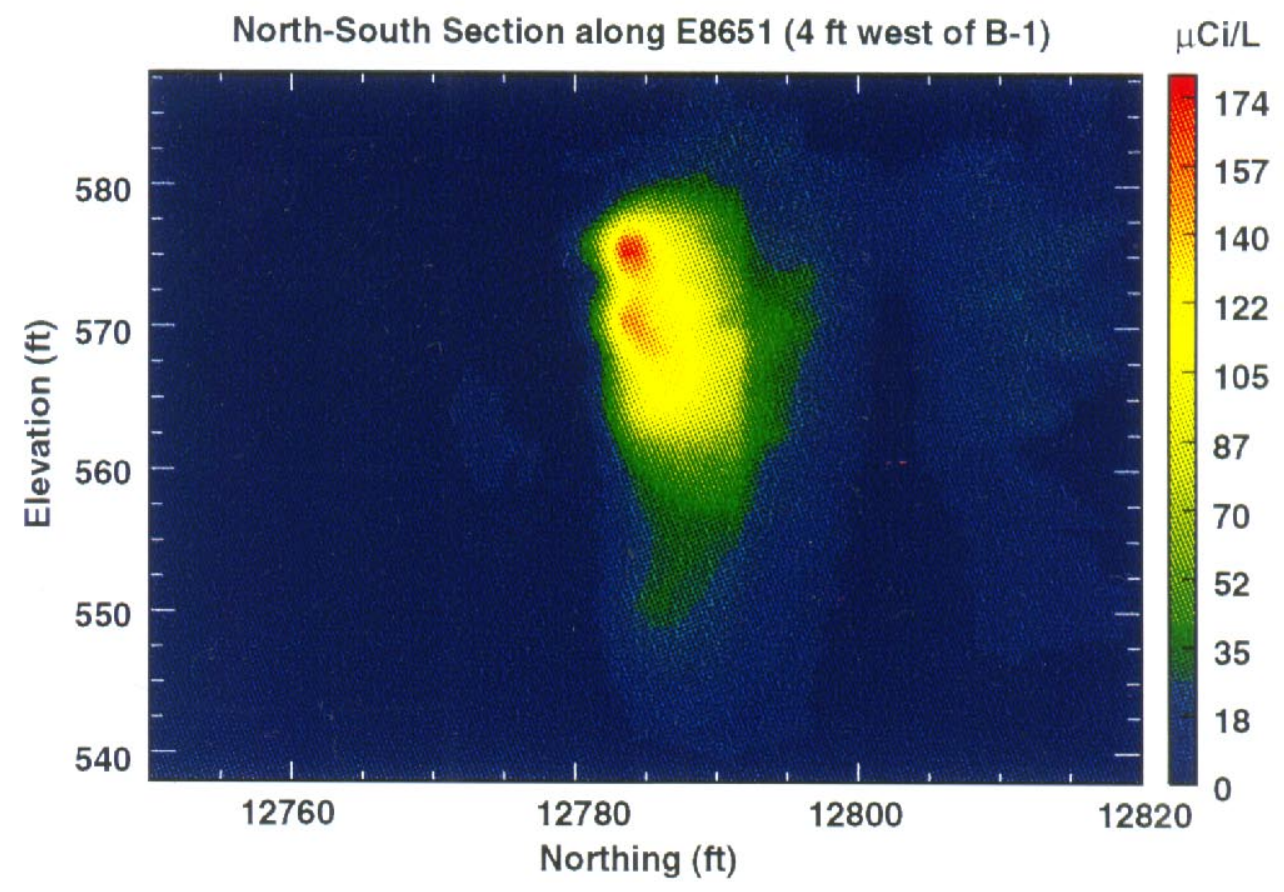

Figure 5.3: Tritium concentrations along north-south section through E8651, about $4 \mathrm{ft}$ west of Borehole 1 in the LLNL Building 292 Area. Concentrations estimated by kriging with the borehole sample data.

\subsection{Total Tritium Activity in Subsurface}

We estimate the total activity of ${ }^{3} \mathrm{H}$ in the vadose zone beneath the Building 292 Area by summing the activities of individual $1-\mathrm{ft}^{3}$ blocks. Block activity is estimated from bulk volume, soil water and soil gas concentration, and volumetric water content. Water content is estimated from the permeability field developed by kriging in Chapter 4 .

Each soil block was assigned the porosity and ambient water content of the sample from Table 3.2 in Chapter 3 with a permeability closest to that of the block. The tritium activity of the soil liquid in a block is

$$
A_{l}^{H T O}=V_{b} \theta_{l} \rho_{l} a_{l}^{H T O}
$$

where $\mathrm{A}_{l}^{H T O}$ is the soil water ${ }^{3} \mathrm{H}$ activity, $V_{b}$ is the bulk volume of the block, $\theta_{l}$ is the volumetric liquid water content, $\rho_{l}$ is the density of the liquid phase, and $a_{l}^{H T O}$ is the ${ }^{3} \mathrm{H}$ 


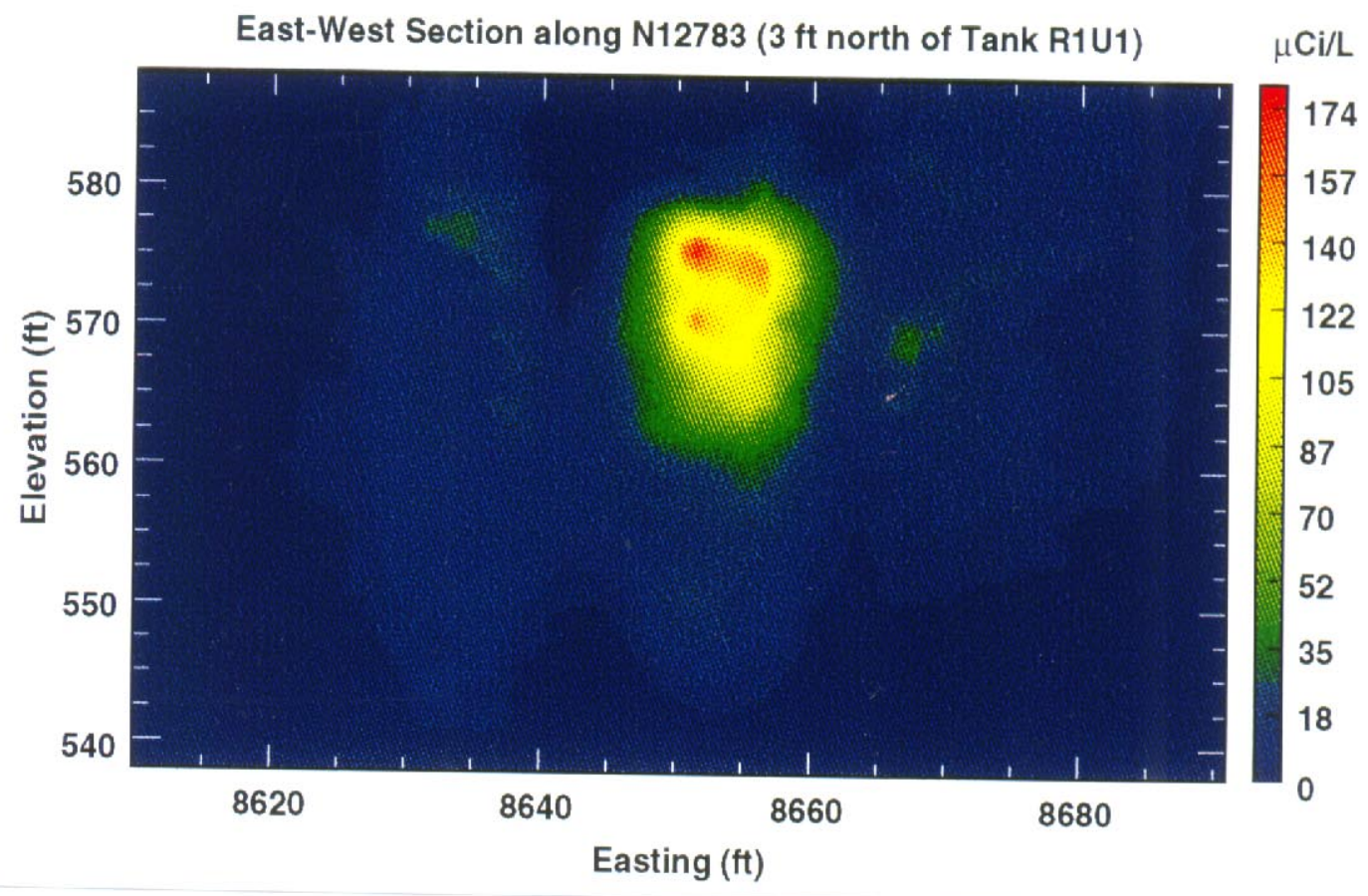

Figure 5.4: Tritium concentrations along east-west section through N12783, about $3 \mathrm{ft}$ north of the tank's north face in the LLNL Building 292 Area. Concentrations estimated by kriging with the borehole sample data.

activity per unit mass of liquid phase. The volumetric activity of ${ }^{3} \mathrm{H}$ in the liquid phase is

$$
C_{l}^{H T O}=\rho_{l} a_{l}^{H T O}
$$

therefore, Equation 5.2 can be rewritten as

$$
A_{l}^{H T O}=V_{b} \theta_{l} C_{l}^{H T O}
$$

The gas phase ${ }^{3} \mathrm{H}$ activity is

$$
A_{g}^{H T O}=V_{b} \theta_{g} \rho_{g} a_{g}^{H T O}
$$

where $\theta_{g}$ is the volumetric gas content, $\rho_{g}$ is the density of the gas phase, and $a_{g}^{H T O}$ is the

${ }^{3} \mathrm{H}$ activity per unit mass of gas phase. Now

$$
a_{g}^{H T O}=a_{v}^{H T O} \omega_{g}^{v}
$$


where $a_{v}^{H T O}$ is the tritium activity per unit mass of water vapor, and $\omega_{g}^{v}$ is the mass fraction of vapor in the gas phase. Therefore, the ${ }^{3} \mathrm{H}$ activity in the gas phase is

$$
A_{g}^{H T O}=V_{b} \theta_{g} \rho_{g} a_{v}^{H T O} \omega_{g}^{v}
$$

If we neglect the small difference in vapor pressure between HTO and water, then we can make the approximation

$$
a_{l}^{H T O}=a_{v}^{H T O}
$$

Substituting for $a_{v}^{H T O}$ into Equation 5.7 and using Equation 5.3 gives

$$
A_{g}^{H T O}=\frac{V_{b} \theta_{g} \rho_{g} \omega_{g}^{v} C_{l}^{H T O}}{\rho_{l}}
$$

Since adsorption of ${ }^{3} \mathrm{H}$ onto soil solids is usually very small relative to concentrations in the fluids, adsorbed activity is neglected here. The total activity in a soil block is therefore

$$
A_{T}^{H T O}=A_{l}^{H T O}+A_{g}^{H T O}
$$

It can be shown that the quantity of tritium in the gas phase is negligible compared to the quantity in the liquid. From Equation 5.4 and Equation 5.9, the ratio of ${ }^{3} \mathrm{H}$ activities in the liquid and gas phases is

$$
\begin{aligned}
\frac{A_{l}^{H T O}}{A_{g}^{H T O}} & =\frac{\theta_{l} \rho_{l}}{\omega_{g}^{v} \theta_{g} \rho_{g}} \\
& =\frac{S_{l}}{\omega_{g}^{v}\left(1-S_{l}\right)}\left(\frac{\rho_{l}}{\rho_{g}}\right)
\end{aligned}
$$

where $S_{l}$ is the liquid phase saturation. Air saturated with water vapor at $20^{\circ} \mathrm{C}$ and normal atmospheric pressure has a density of $1.18 \times 10^{-3} \mathrm{~g} / \mathrm{cm}^{3}$ and a water vapor mass fraction of 0.0145 (Linsley, Jr., et al., 1982). With the density of liquid water equal to $1.0 \mathrm{~g} / \mathrm{cm}^{3}$, the ratio $\rho_{l} / \rho_{g}$ is approximately 850 . From the sample data in Table 3.2 of Chapter $3, S_{l}$ varies from a minimum 0.15 for the coarser grained soils to near full saturation for the finer 
grained soils, so that $S_{l} /\left(1-S_{l}\right)$ has a minimum value of about 0.18 . The expected range of activity ratios from Equation 5.11 is therefore

$$
\frac{A_{l}^{H T O}}{A_{g}^{H T O}} \geq 1.05 \times 10^{4}
$$

At a liquid saturation of $90 \%, A_{l}^{H T O} / A_{g}^{H T O}$ equals $5.28 \times 10^{5}$.

We wrote a Fortran code, entitled $t r t s r c$, to read ${ }^{3} \mathrm{H}$ concentrations and permeabilities from kriging, compute the tritium activity of each block of soil, and sum the activities to obtain the activity of the entire study site. Aqueous phase as well as gas phase activities are calculated. The code can also compute the activity of any user-specified section of the site.

We made two separate estimates of the total tritium activity in the subsurface at the site. The first estimate is $4.6 \mathrm{Ci}$ and the second, more conservative estimate is $5.4 \mathrm{Ci}$. In the first estimate, a number of fictitious borings with background ${ }^{3} \mathrm{H}$ concentrations were added around the perimeter of the release site. These fictitious data enforce the assumption that concentrations outside of the tank area return to background levels. In the second estimate, no fictitious data were added, so that kriging estimates close to the perimeter were determined only by real sample concentrations. The second estimate is expected to yield higher, more conservative results. We use the average of the two estimates, $5 \mathrm{Ci}$, as the total subsurface ${ }^{3} \mathrm{H}$ activity at the site between 1989 and 1991 .

Additional calculations of ${ }^{3} \mathrm{H}$ activity in different sections of the site reveal that $91 \%$ of the total ${ }^{3} \mathrm{H}$ activity occurs north of the tank. The site was divided areally into four $33 \mathrm{ft}$ by $33 \mathrm{ft}$ square quadrants that meet at the leak point, E8652.1, N12780.5. We used the code trtsrc to compute the ${ }^{3} \mathrm{H}$ activity in the liquid phase, $\mathrm{A}_{l}$, the activity in the gas phase, $\mathrm{A}_{g}$, and the ratio $A_{l}^{H T O} / A_{g}^{H T O}$, for each quadrant. We used fictitious concentrations around the site, as described for the first ${ }^{3} \mathrm{H}$ activity estimate of the entire site. The results are 
presented in Table 5.1. The NW quadrant has $2.3 \mathrm{Ci}$ which represents $50 \%$ of the total ${ }^{3} \mathrm{H}$

Table 5.1: Tritium activities computed for quadrants of the ${ }^{3} \mathrm{H}$ release site centered at the leak point which has LLNL coordinates E8652, N12780.5. Each quadrant is taken as a square of length $33 \mathrm{ft}$.

\begin{tabular}{lccc}
\hline \hline Section & $\begin{array}{c}\text { Activity in } \\
\text { liquid, } \mathrm{A}_{l}^{H T O}(\mathrm{Ci})\end{array}$ & $\begin{array}{c}\text { Activity in } \\
\text { gas, } \mathrm{A}_{g}^{H T O}(\mathrm{Ci})\end{array}$ & $A_{l}^{\text {HTO }} / A_{g}^{H T O}$ \\
\hline NW quadrant & 2.3 & $1.2 \times 10^{-5}$ & $1.9 \times 10^{5}$ \\
NE quadrant & 1.9 & $1.3 \times 10^{-5}$ & $1.4 \times 10^{5}$ \\
SW quadrant & 0.1 & $6.5 \times 10^{-7}$ & $1.7 \times 10^{5}$ \\
SE quadrant & 0.3 & $2.9 \times 10^{-6}$ & $1.1 \times 10^{5}$ \\
Total area & 4.6 & $2.9 \times 10^{-5}$ & $1.6 \times 10^{5}$ \\
\hline \hline
\end{tabular}

activity at the site. Less than $9 \%$ of the total activity occur south of the tank's north face. As suggested by Equation 5.12, the total gas phase ${ }^{3} \mathrm{H}$ activity is negligible compared with the total aqueous phase activity. The ratio $A_{l}^{H T O} / A_{g}^{H T O}$ varies from $1.1 \times 10^{5}$ to $1.9 \times 10^{5}$ for the four quadrants. 


\section{Conceptual and Mathematical Models}

\subsection{Introduction}

In this chapter, we present conceptual and mathematical models of tritium transport in the vadose zone. We also describe NUFT, the flow and transport model used to conduct the numerical calculations. Although the focus here is on tritium transported as tritiated water (HTO), much of the material presented is applicable to the two-phase flow and transport of dissolved volatile contaminants in the vadose zone, including many synthetic organics and gasoline hydrocarbons.

\subsection{Conceptual Model}

Primary elements of the conceptual model are listed below.

- Three chemical components:

1. air (a pseudo-component with averaged properties);

2. water $\left(\mathrm{H}_{2} \mathrm{O}\right)$;

3. tritiated water (HTO).

- Two fluid phases:

1. an aqueous phase, 1 (mainly liquid water, with concentrations of HTO and dissolved air);

2. a gas phase, $\mathrm{g}$ (comprised of air, water vapor, and HTO vapor).

- One solid phase with no adsorption assumed.

- Isothermal model.

- Assume local chemical equilibrium for partitioning of components between phases. 
- Both the liquid and gas phases may be mobile.

- Radioactive decay of tritium with a half-life of $12.4 \mathrm{yr}$ (decay constant of $.0561 \mathrm{yr}^{-1}$ ).

- No chemical reactions in addition to radioactive decay.

- Volatilization/condensation of $\mathrm{H}_{2} \mathrm{O}$ and HTO.

- Vapor pressure lowering in porous media.

- Multiphase extension of Darcy's law, incorporating the concept of relative permeability, used to compute volumetric flow rate of each fluid phase.

- Assume water vapor in void space is at full saturation.

- Model equations formed from component mass balances, the multiphase extension of Darcy's law, and Fick's law.

- Assume nondeformable solid matrix, ie. $\phi \neq \phi(P)$

- No dissolution of the solid component.

- The domain is bounded above by the atmosphere and below by groundwater flowing at a specified velocity; infiltration may be applied at the ground surface.

\subsection{Mathematical Model}

The equations describing isothermal flow and transport through porous media, in a system of multiple multicomponent phases, are developed from the conservation of mass for each chemical component, and the flux laws that describe the movement of mass in the system (e.g., Bear, 1972; Aziz and Sattari, 1979; Bear and Nitao, 1993). Mass fluxes are described by Darcy's law and Fick's law. Combining these conservation and flux laws results in a 
number of partial differential equations which represent the core of the mathematical model. The complete model will also include constitutive relationships that define the behavior of the fluids and solids, and information on the initial and boundary conditions.

The mass balance equation for component $\gamma$, which may be radioactive and may partition between the fluid phases and adsorb onto the solid surfaces, is

$$
\begin{gathered}
\frac{\partial}{\partial t}\left(\phi \sum_{\alpha} S_{\alpha} \rho_{\alpha} \omega_{\alpha}^{\gamma}+\rho_{b} F^{\gamma}\right)=-\sum_{\alpha} \nabla \phi S_{\alpha}\left(\rho_{\alpha} \omega_{\alpha}^{\gamma} V_{\alpha}+J_{\alpha m}^{\gamma}+J_{\alpha}^{* \gamma}\right) \\
\quad-\lambda^{\gamma}\left(\phi \sum_{\alpha} S_{\alpha} \rho_{\alpha} \omega_{\alpha}^{\gamma}+\rho_{b} F^{\gamma}\right)+R^{\gamma}
\end{gathered}
$$

where the subscript $\alpha$ indicates the fluid phase $(1, \mathrm{~g})$, and the other variables are:

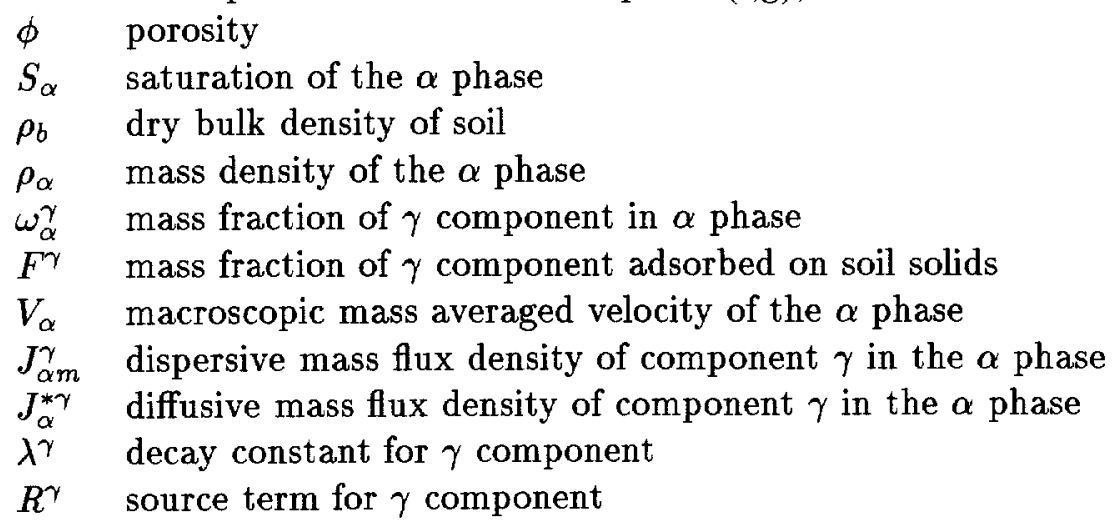

The dispersive and diffusive fluxes are expressed per unit area of the fluid phase and not per unit area of bulk soil.

We neglect adsorption since ${ }^{3} \mathrm{H}$ adsorption in soils is usually very small. Mechanical dispersion, modeled as a Fickian process, is not present, because most of our simulation runs are made using highly heterogeneous permeability fields generated by conditional simulation. The heterogeneous permeability field gives rise to dispersion at scales larger than that for pore scale dispersion. 
With $F^{\gamma}$ and $J_{\alpha m}^{\gamma}$ omitted, Equation 6.1 is rewritten as

$$
\begin{aligned}
& \frac{\partial}{\partial t}\left(\phi \sum_{\alpha} S_{\alpha} \rho_{\alpha} \omega_{\alpha}^{\gamma}\right)=-\sum_{\alpha} \nabla \phi S_{\alpha}\left(\rho_{\alpha} \omega_{\alpha}^{\gamma} V_{\alpha}+J_{\alpha}^{* \gamma}\right) \\
& \quad-\lambda^{\gamma} \phi \sum_{\alpha} S_{\alpha} \rho_{\alpha} \omega_{\alpha}^{\gamma}+R^{\gamma}
\end{aligned}
$$

The concept of relative permeability is applied to write the motion equation as the generalized form of Darcy's law for flow in a multiphase porous medium

$$
q_{\alpha}=\phi S_{\alpha} V_{\alpha}=-\frac{k k_{r \alpha}\left(S_{\alpha}\right)}{\mu_{\alpha}}\left(\nabla p_{\alpha}+\rho_{\alpha} g \nabla z\right)
$$

where the undefined variables are:

$\mathrm{k} \quad$ absolute or intrinsic permeability tensor

$k_{r \alpha}\left(S_{\alpha}\right) \quad \alpha$ phase relative permeability

$\mu_{\alpha} \quad \alpha$ phase absolute viscosity

$\mathrm{g}$ acceleration due to gravity

The diffusive flux is assumed Fickian:

$$
J_{\alpha}^{* \gamma}=-\rho_{\alpha} \tau_{\alpha} D_{\alpha}^{* \gamma} \nabla \omega_{\alpha}^{\gamma}
$$

where, $D_{\alpha}^{* \gamma}$ is the free phase molecular diffusion coefficient for the $\alpha$ phase, and $\tau_{\alpha}$ is the $\alpha$ phase tortuosity coefficient which varies with porosity and phase saturation.

For a system with $\mathrm{n}$ components, Equation 6.2 with expressions for $V_{\alpha}$ and $J_{\alpha}^{* \gamma}$ substituted from Equation 6.3 and Equation 6.4, represents $n$ independent differential equations. For a three-component system, we have three equations.

In order to solve the system uniquely, the number of independent relationships must equal the number of independent variables. For a system with three components in two fluid phases, the number of independent variables is 18 , as summarized in Table 6.1. Therefore, an additional 15 independent relationships are needed to solve the system uniquely. The sources of these constitutive relationships are: 
Table 6.1: List of independent variables.

\begin{tabular}{cc}
\hline \hline Variables & Number \\
\hline & \\
$S_{l}, S_{g}$ & 2 \\
$\omega_{l}^{\gamma}, \omega_{g}^{\gamma}$ & 6 \\
$P_{l}, P_{g}$ & 2 \\
$k_{r l}, k_{r g}$ & 2 \\
$\rho_{l}, \rho_{g}$ & 2 \\
$\mu_{l}, \mu_{g}$ & 2 \\
$\tau_{l}, \tau_{g}$ & 2 \\
\hline Total & 18 \\
\hline \hline
\end{tabular}

- Phase equilibra.

- PVT data.

- Relative permeability data.

- Conservation principles.

- Capillary pressure data.

The relationships are listed as follows:

1. The fluid phase saturations must sum to unity (one relationship)

$$
S_{l}+S_{g}=1
$$

2. In each phase, the mass fractions of components must sum to unity (two relationships)

$$
\sum_{\gamma} \omega_{l}^{\gamma}=\sum_{\gamma} \omega_{g}^{\gamma}=1
$$

3. Relative permeability as a function of phase saturation for each phase (two relationships)

$$
k_{r l}=k_{r l}\left(S_{l}\right)
$$




$$
k_{r g}=k_{r g}\left(S_{g}\right)
$$

4. Gas-liquid capillary pressure, $P_{c g l}$, as a function of the liquid phase saturation (one relationship)

$$
P_{g}-P_{l}=P_{c g l}\left(S_{l}\right)
$$

5. From PVT data, phase density and viscosity as functions of pressure, and phase composition are obtained (four relationships)

$$
\begin{gathered}
\rho_{l}=\rho_{l}\left(P, \omega_{l}^{c}, \omega_{l}^{w}, \omega_{l}^{a}\right) \\
\rho_{g}=\rho_{g}\left(P, \omega_{g}^{c}, \omega_{g}^{w}, \omega_{g}^{a}\right) \\
\mu_{l}=\mu_{l}\left(P, \omega_{l}^{c}, \omega_{l}^{w}, \omega_{l}^{a}\right) \\
\mu_{g}=\mu_{g}\left(P, \omega_{g}^{c}, \omega_{g}^{w}, \omega_{g}^{a}\right)
\end{gathered}
$$

The superscripts $\mathrm{c}, \mathrm{w}$, and a, indicate the three chemical components, contaminant (HTO), water, and air, respectively.

6. Equilibrium partitioning of chemical components between the two fluid phases (three relationships)

$$
\frac{n_{g}^{\gamma}}{n_{l}^{\gamma}}=\mathcal{K}_{g l}^{\gamma}\left(P, n_{l}^{\gamma}, n_{g}^{\gamma}\right)
$$

where $n_{\alpha}^{\gamma}$ denotes the mole fraction of the $\gamma$ component in the $\alpha$ phase, and $\mathcal{K}_{g l}^{\gamma}$ denotes the liquid-gas equilibrium partitioning coefficient for the $\gamma$ component. The 
mass and mole fractions are related by

$$
\omega_{\alpha}^{\gamma}=\frac{M^{\gamma} n_{\alpha}^{\gamma}}{\sum_{(\gamma)} M^{\gamma} n_{\alpha}^{\gamma}},
$$

where $M^{\gamma}$ is the molecular weight of the $\gamma$ component. Assuming ideal gas behavior of water vapor in the gas phase, the extension of Kelvin's law to porous media, given by Edlefsen and Anderson (1943), is written as

$$
\frac{n_{g}^{w}}{n_{l}^{w}}=\frac{P_{s a t}}{P_{g}} \exp \left[-\frac{\Phi_{m} M^{w}}{R T \rho_{l}^{w}}\right],
$$

where $\Phi$ denotes the matric potential, $P_{\text {sat }}$ is the saturated vapor pressure of water, and $P_{g}$ is the total gas phase pressure.

7. Diffusion tortuosity coefficients as functions of porosity and phase saturations (two relationships)

$$
\begin{gathered}
\tau_{l}=\tau_{l}\left(\phi, S_{l}\right) \\
\tau_{g}=\tau_{g}\left(\phi, S_{g}\right)
\end{gathered}
$$

We use the Millington (1959) tortuosity formulation

$$
\tau_{\alpha}=S_{\alpha}^{7 / 3} \phi^{1 / 3}
$$

\subsection{Boundary and Initial Conditions}

The boundary conditions are similar for all simulation runs. The upper boundary is the atmosphere at $100 \%$ relative humidity. The uppermost layer of soil receives a specified rate of infiltration. The lower boundary is the groundwater with hydraulic gradient equal to the value measured at the site. At least the last three layers of nodes at the base of the model are groundwater nodes, permitting lateral transport, and some vertical transport, of ${ }^{3} \mathrm{H}$ below the water table. The aquifer is $5 \mathrm{ft}$ thick. The base of the model is an impermeable 
boundary. The ends of the model are also impermeable within the vadose zone, but located at sufficiently large distances from the source to avoid any artificial effects on the transport calculations. The lowest level of groundwater nodes at the upstream and downstream ends of the model are held at fixed conditions to permit groundwater flow at the specified velocity.

The model is initialized by running to steady state without ${ }^{3} \mathrm{H}$ transport. Boundary conditions are set as described above and the model is run for a simulation time of 10,000 yr. The HTO component is omitted for initialization to reduce the computational burden. After initialization, the model is restarted with the HTO component introduced for the transport simulation.

\subsection{Description of NUFT}

The flow and transport model is solved using the NUFT code, developed by Nitao (1993) at LLNL. NUFT (Nonisothermal Unsaturated-Saturated Flow and Transport) is an integrated suite of models for numerical solution of thermal and isothermal flow and transport in porous media, with application to subsurface contaminant transport problems. The code simulates the coupled transport of heat and multiple multicomponent fluid phases in both the vadose and saturated zones. Components may be volatile. Grid systems may be cartesian or cylindrical, with one-, two-, or fully three-dimensional configurations possible.

NUFT features a modular design, with several models or simulator modules using a common set of utility routines and input file format. Multiple models can be executed simultaneously with information passing between models. For example, one model which generates a transient flow field may run together with a number of dilute species transport models; the transport models receiving updated flow field information from the same flow model. The modular design is also very useful for users interested in just one or two specific applications of the code. For example, a user interested in solving only a Richard's 
equation type unsaturated flow problem can use only the us1c module and avoid the more sophisticated and complex modules.

Up to three fluid phases may be simulated, where all three phases could be mobile. There are two liquid phases: (1) an aqueous phase, which is predominantly the component water but may contain other dissolved components; and (2) a nonaqueous phase liquid (NAPL), which is usually made up of hydrocarbon or organic components, some of which may be volatile. The third phase is the gas phase containing dry air (treated as a pseudocomponent), water vapor, and vapors of VOCs. Each phase may contain a variable number of components, with component phase changes and partitioning between the phases permitted. Phases may also disappear and reappear.

It is assumed that solid surfaces are always coated by at least a thin film of water, so that the solid phase interfaces only with the aqueous phase and, therefore, only solid-aqueous phase adsorption of components is possible. Adsorption may follow a linear or nonlinear isotherm.

Verification and benchmark testing of NUFT confirmed that the code was ready for application to a range of field and laboratory problems (Lee et al., 1994). "Verification" is used here to imply checking of the governing equations of the mathematical model to ensure that they have been properly programmed, and that the numerical solution algorithm works as intended. Code verification was performed by making direct comparisons between NUFT simulation results and known analytical or semianalytical solutions of appropriate problems. For problems that did not have analytical solutions, NUFT was satisfactorily benchmarked against well established codes.

NUFT has been applied in a number of thermal and isothermal subsurface modeling problems. The code was used to study the hydrothermal response of a rock mass to thermal 
loading, in the Yucca Mountain Site Characterization Project, where the Topopah Spring Tuff in the thick vadose zone in Yucca Mountain, Nevada, is being investigated as a possible host rock for permanent disposal of high-level radioactive waste (Lee, 1995). NUFT was used to simulate the transport of gases through fractured and porous media to test the ability of natural transport processes to move rapidly decaying radionuclides to the surface, and possibly reveal the occurrence of a clandestine nuclear event (Zucca et al., 1995; Carrigan, 1995; Carrigan et al., 1995; Carrigan et al., 1996) The code was also used to simulate multiphase flow and contaminant transport in subsurface systems heated by electrical currents (Carrigan and Nitao, 1997). 


\section{Two-Dimensional Analysis}

\subsection{Introduction}

In this chapter, we present the results of: (a) a Monte-Carlo analysis to investigate the effect of soil property data uncertainty on the tritium transport simulation results, and (b) sensitivity analyses to investigate the effect of infiltration and vapor diffusion on the ${ }^{3} \mathrm{H}$ transport. All simulation runs are two-dimensional (2D) with a simulation time of $100 \mathrm{yr}$.

The goal of this $2 \mathrm{D}$ analysis is to produce a quantitative assessment of possible effects of soil property uncertainty, infiltration, and vapor diffusion on numerical simulation of the impact of the ${ }^{3} \mathrm{H}$ release on groundwater quality at the site. We do not attempt to simulate the actual field transport in this chapter; more comprehensive three-dimensional simulations that better incorporate site features are reported in Chapter 8 . The results generated here will help us gain insight on the effect of parameter selection on the simulated effect of the ${ }^{3} \mathrm{H}$ release on groundwater quality at the site.

\subsection{Summary of Findings}

Major findings from the two-dimensional analysis presented in this chapter are summarized as follows:

- Numerical simulations that use soil permeability fields derived by kriging yield substantially lower groundwater concentrations than simulations that use permeability fields derived by conditional simulation. Kriging to estimate the hydraulic properties of soils for transport calculations under the present heterogeneous field conditions yields nonconservative and potentially misleading results.

- The Monte-Carlo analysis showed large variability in the calculated impact of the release on groundwater quality, indicating that the results are sensitive to the soil 
properties used.

- Under the present site conditions, vapor diffusion has a negligible effect on groundwater ${ }^{3} \mathrm{H}$ concentrations and only a very small effect on vadose zone concentrations.

- The ambient liquid saturation profile between the ground surface and water table correlates strongly with soil type and not with elevation; liquid saturation varies from about $15 \%$ in the coarse-grained sands and gravels to near full saturation in the finegrained clays.

- We estimate an infiltration rate of $2.1 \mathrm{in} / \mathrm{yr}$ for the study site, based on a comparison of simulated steady-state liquid saturation profiles at different infiltration rates and the liquid saturation profile measured in Borehole 19.

- The impact of the ${ }^{3} \mathrm{H}$ release on groundwater quality at the site increases strongly with infiltration rate.

- Plume arrival times at the water table are lognormally distributed.

- The maximum groundwater ${ }^{3} \mathrm{H}$ concentration is lognormally distributed, and the time of occurrence of the maximum concentration is normally distributed.

\subsection{Monte-Carlo Analysis}

We conducted transport simulations on 100 different realizations of soil property fields generated by conditional stochastic simulation and data correlation, and analyzed the statistics of the transport behavior. We also conducted a simulation using soil properties obtained by ordinary kriging, and compare results from the Monte-Carlo analysis with results from the kriging simulation. 
The Monte Carlo method as used here refers to a set of repetitive simulations to solve the deterministic flow and transport problem using different realizations of input parameters and the associated statistical analysis of the results. Freeze (1973) used the Monte Carlo technique to analyze the effect of a baseball batting order on team performance. The technique was also used by Freeze (1975) in a stochastic-conceptual analysis of onedimensional groundwater flow in heterogeneous media, and El-Kadi (1987) to study the effect of uncertainty in unsaturated zone parameters on the variability of infiltration.

We wrote a Unix shell script to automate the process of performing the 100 transport simulations, from reading the permeability sample data file and generating a realization of the permeability field, to preparing the input file for the NUFT code and executing the code. On completion of one simulation, the script restarts the cycle for a new realization. The script also extracted selected results from the NUFT output files. The results extracted include water table plume arrival time, peak ${ }^{3} \mathrm{H}$ concentrations in the groundwater and the vadose zone, the plume's center of mass location, total ${ }^{3} \mathrm{H}$ activity remaining in the vadose zone and groundwater, and plume geometry parameters.

The shell script file automatically executes a number of codes to accomplish the following:

- Perform ordinary kriging to estimate a full 3D permeability field after reading an input data file containing sample permeabilities and three-dimensional location coordinates, and a parameter file that defines the sample variogram describing the spatial variability of the permeability data.

- Apply the turning bands technique (Tompson et al., 1989) to perform nonconditional simulation of the permeability field, again using the sample variogram and the input permeability data; a random number seed is selected by manipulating the clock time. 
- Apply the conditioning technique (e.g. Deutsch and Journel, 1992) described in Chapter 4 to generate a realization of the field that honors data values at their measurement locations.

- Overlay the predesigned NUFT $2 \mathrm{D}$ grid by the selected vertical section of the 3D grid used for kriging and conditional simulation, and assign to each NUFT node the permeability of the nearest kriging node.

- Assign other unsaturated hydraulic soil parameters (i.e. van Genuchten's parameters, $\phi)$ based on soil property correlations with permeability and other data statistics, as described in Chapter 4.

- Generate matfil and rocktab, two modules of a NUFT input file; matfil specifies the soil type of each grid block, and rocktab describes soil properties for each soil type.

- Make appropriate modifications to a template of the main NUFT input file and execute NUFT for the new realization of soil properties.

- Extract some plume statistics parameters from NUFT output files.

The first step, kriging on the permeability sample data, had to be performed only once because the same kriged field is used with each new field from the turning bands simulation to generate a new field by conditional simulation. More details of the steps listed above were presented back in Chapter 4 .

\subsubsection{Generation of the 2D Permeability Field}

Because the turning bands method is not appropriate for generating realizations in two dimensions, a 3D field block was selected for conditional simulation, then an appropriate vertical section was chosen from which to transfer permeabilities to the NUFT grid. The 3D 
block is $164 \mathrm{ft}$ long, extending from E8570 to E8734, and $8 \mathrm{ft}$ wide, extending from N12778 to $\mathrm{N} 12786$. The lower boundary is at elevation $536 \mathrm{ft}$, about $2 \mathrm{ft}$ below the water table, and the upper boundary at elevation $586 \mathrm{ft}$, the approximate ground surface elevation. This block contains the suspected leak location on the north face of the tank. The suspected leak location has coordinates E8652, N12780, and elevation $577 \mathrm{ft}$.

The GSLIB 3D ordinary kriging program, $k t b 3 d m$ (Deutsch and Journel, 1992), was used to perform ordinary kriging with 132 permeability data points and the sample variogram presented in Chapter 4. A uniform one-foot grid spacing was used in all three principal directions, giving 165 blocks in the $\mathrm{x}$-direction (East-West), 9 blocks in the $\mathrm{y}$-direction (North-South) and 51 blocks in the z-direction, for a total of 75,735 blocks.

For the nonconditional simulation, we incorporate anisotropy in spatial variability by coordinate transformation, because the turning bands model of Tompson et al. (1989) handles only isotropic fields. Recall that the permeability sample variograms presented in Chapter 4 showed anisotropy, with the horizontal range about three times as large as the vertical range. To effect the transformation for equal grid dimensions in the $\mathrm{x}, \mathrm{y}$, and $\mathrm{z}$ directions, we use a vertical to horizontal grid size ratio equal to the ratio of the horizontal to vertical variogram range before conducting the simulation. On completion of the simulation, the grid is retransformed back to equal dimensions in the three principal directions.

After completion of conditional simulation (see Chapter 4 for implementation details), an East-West section through the simulated permeability field, along N12780, is selected to supply permeabilities for the NUFT grid blocks. This section passes through the suspected leak point. Assignment of permeabilities to the NUFT nodes is implemented in the code nufgsl. We overlay the NUFT grid (which has variable grid sizes) by the GSLIB section so that the leak nodes on the two grids coincide. Each NUFT node is then assigned the 
permeability of the nearest GSLIB node. NUFT nodes beyond the GSLIB range in the xdirection, about $82 \mathrm{ft}$ on either side of the leak point, are assigned the sample permeability closest to the median value from the 132-point permeability sample histogram. Other unsaturated soil properties are assigned based on soil property correlations and other data statistics, as described in Chapter 4.

\subsubsection{Numerical Simulation Model}

The flow and transport of tritium in the $2 \mathrm{D}$ domain is modeled using the conceptual model outlined in Chapter 6. The system consists of two fluid phases and three chemical components. The fluid phases are liquid (or aqueous) and gas, and the chemical components are air, treated as a pseudocomponent with averaged properties, water $\left(\mathrm{H}_{2} \mathrm{O}\right)$, and tritiated water (HTO). The liquid phase is comprised mainly of water, with dilute concentrations of HTO and air. The gas phase is comprised of air, water vapor and HTO vapor. Components may partition between the two phases. Both phases are mobile. Radioactive decay of tritium occurs with a half-life of $12.4 \mathrm{yr}$. Both liquid and vapor diffusion are modeled using the Millington (1959) formulation for tortuosity. Mechanical dispersion, modeled as a Fickian-based process, is not applied in these calculations. Mechanical dispersion is effected through explicit incorporation of the high degree of heterogeneity in permeability shown in the data.

\subsubsection{Grid Design}

The grid design features varying mesh sizes to allow higher resolution closer to the leak source, and decreasing resolution at greater distances away from the source. Figure 7.1 is a section of the grid showing the leak node. The grid consists of 86 nodes in the $\mathrm{x}$-direction 
and 38 nodes in the $z$-direction, giving a total of 3268 nodes. Of these nodes 340 were nullified, leaving a total of 2928 active nodes. The minimum grid size close to the leak is $0.82 \mathrm{ft}(0.25 \mathrm{~m})$ in the $\mathrm{z}$-direction and $1.3 \mathrm{ft}(0.40 \mathrm{~m})$ in the $\mathrm{x}$-direction. The model is 3.3 $\mathrm{ft}(1 \mathrm{~m})$ thick in the $\mathrm{y}$-direction.

\subsubsection{Initial and Boundary Conditions}

The domain is bounded above by the atmosphere at a relative humidity of $100 \%$ at 20 ${ }^{\circ} \mathrm{C}$. The lower boundary is the impermeable base of the 5 - $\mathrm{ft}$ thick unconfined aquifer. The lowest three layers of nodes represent the aquifer which has a uniform permeability of 5.5 darcy and a hydraulic gradient fixed to give a groundwater velocity of $33 \mathrm{ft} / \mathrm{yr}(9.9 \mathrm{~m} / \mathrm{yr})$. The aquifer permeability and groundwater velocity were obtained from pumping tests and water table elevation measurements conducted in the Building 292 Area.

Infiltration is specified through the exposed soil surface, the layer immediately below the atmosphere layer. Impermeable boundaries are used to the east and west at sufficiently great distances to avoid any significant influence on flow and transport calculations at the release site. Although the section modeled is partially covered by asphalt, we model the system as though the entire soil surface were exposed. Recall that most of the tank area is covered by asphalt and exposed soil occurs from about $6 \mathrm{ft}$ south of tank's south end; therefore, infiltration is not expected to cause vertical percolation directly through the source area. However, infiltration through the exposed soil surface is still expected to increase the impact of the ${ }^{3} \mathrm{H}$ release on groundwater quality. A net infiltration rate of $2.1 \mathrm{in} / \mathrm{yr}$ was selected based on a comparison of field water contents measured by neutron probe and average steady-state water contents from simulations (presented later in this chapter). The partial surface cover is modeled more explicitly in the three-dimensional 


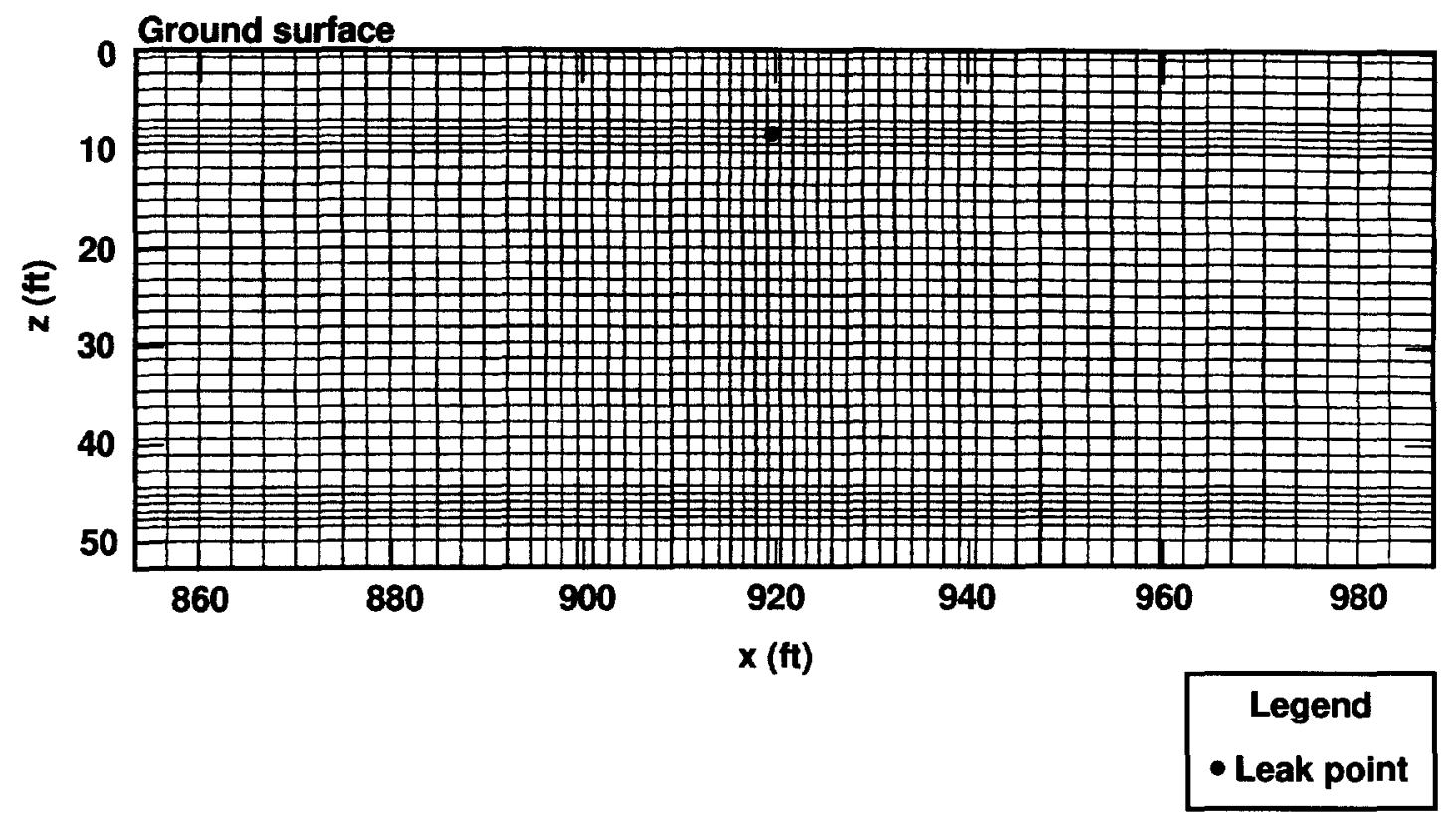

Figure 7.1: Grid design for 2D model. The leak node has coordinates (919.6, 9.0). 
analysis presented in Chapter 8 .

Initial conditions for each realization were reached by running the model to steady state, with the HTO component excluded. The transport simulation run was then conducted by restarting with the tritium source added, and using the state variable values from initialization as the initial conditions.

\subsubsection{Source Term}

We base our computation of the source term on the ${ }^{3} \mathrm{H}$ activity estimated in the $3.3-\mathrm{ft}$ thick east-west section through $\mathrm{N} 12780.5$, the northing of the suspected leak point. We used the code, trtsrc, to take the ${ }^{3} \mathrm{H}$ concentration field derived by kriging and compute an activity of $0.52 \mathrm{Ci}$ in the section. This activity is estimated to be in the soil around late 1990 . Assuming a constant aqueous phase release, the HTO release rate is obtained from

$$
A^{H T O}=\frac{R C_{l}^{H T O}}{\lambda}[1-\exp (-\lambda t)]
$$

where $\mathrm{A}^{H T O}$ is the total activity in the soil at time $t$ after the beginning of release, $\mathrm{R}$ is the

release rate of contaminated water, $\mathrm{C}_{l}^{H T O}$ is the tritium concentration of the release water, and $\lambda$ is the decay constant for tritium $\left(.0561 \mathrm{yr}^{-1}\right)$. Assuming a 5 -yr leak occurring from 1986 through 1990 , Equation 7.1 gives a ${ }^{3} \mathrm{H}$ release rate, $\mathrm{RC}_{l}$, of $0.12 \mathrm{Ci} / \mathrm{yr}$ or a total of 0.6 Ci over 5 yr. We assume a $\mathrm{C}_{l}$ value of $4.46 \times 10^{8} \mathrm{pCi} / \mathrm{L}$, the ${ }^{3} \mathrm{H}$ concentration measured in the tank water in 1989.

In the simulations, we use a $67 \%$ higher ${ }^{3} \mathrm{H}$ release rate of $0.2 \mathrm{Ci} / \mathrm{yr}$ for $5 \mathrm{yr}$ for a total activity if $1.0 \mathrm{Ci}$. With $\mathrm{RC}_{0}$ equal to $0.2 \mathrm{Ci} / \mathrm{yr}$, the release rate of contaminated water is $448 \mathrm{~L} / \mathrm{yr}$ or $0.32 \mathrm{gal} /$ day. The source term is specified as fixed fluxes of the components HTO and $\mathrm{H}_{2} \mathrm{O}$ over the first $5 \mathrm{yr}$ of simulation. One $\mathrm{Ci}$ of ${ }^{3} \mathrm{H}$ activity is equivalent to $6.9 \times 10^{-7} \mathrm{~kg}$ of HTO. 


\subsubsection{Results of Monte-Carlo Analysis}

In this section we present results of the Monte-Carlo analysis in which numerical transport calculations were performed using 100 different realizations of soil hydraulic properties obtained by conditional stochastic simulation. The simulations, numbered Real101 through Real200, were run for a simulation time of $100 \mathrm{yr}$ with the ${ }^{3} \mathrm{H}$ release occurring during the first 5 years. We present statistics of the results, and compare them with results of a transport simulation that used hydraulic properties obtained by ordinary kriging.

A number of parameters that describe the ${ }^{3} \mathrm{H}$ transport behavior through the vadose zone have been extracted from the NUFT output of the simulation runs. The parameters are listed as follows:

1. Plume arrival time at the water table.

2. Peak groundwater concentration.

3. Groundwater concentration $100 \mathrm{ft}(30.5 \mathrm{~m})$ downstream of leak.

4. Cumulative flux of ${ }^{3} \mathrm{H}$ across the water table.

5. Peak vadose zone ${ }^{3} \mathrm{H}$ concentration.

6. Depth at peak vadose zone ${ }^{3} \mathrm{H}$ concentration.

7. Center-of-mass depth.

8. Square root of the second spatial moment of concentration distribution in the $x$ direction, $\sigma_{x}$.

9. Square root of the second spatial moment of concentration distribution in the $z_{-}$ direction, $\sigma_{z}$. 
10. Total ${ }^{3} \mathrm{H}$ activity history in the vadose zone.

11. Total ${ }^{3} \mathrm{H}$ activity history in the groundwater.

Items Number 7 and 8 denote parameters that characterize dispersion or spreading characteristics of the plume (Fischer et al., 1979; Gelhar, 1993). In the x-direction, the second moment of the concentration distribution is

$$
\sigma_{x}^{2}=\frac{\int_{-\infty}^{\infty}(x-X)^{2} C d x}{\int_{-\infty}^{\infty} C d x}
$$

where $\mathrm{X}$ is the $\mathrm{X}$-coordinate, $\mathrm{X}$ is center-of-mass $\mathrm{x}$-coordinate, and $\mathrm{C}$ is the concentration. We estimate $\sigma_{x}^{2}$ in the model by

$$
\sigma_{x}^{2}=\frac{\sum_{i=1}^{n}\left(x_{i}-X\right)^{2} A_{i}}{\sum_{i=1}^{n} A_{i}}
$$

where the sum is taken over all nodes in the vadose zone, and $A_{i}$ is the total ${ }^{3} \mathrm{H}$ activity in node i. The square root of the second spatial moment of concentration distribution in the $\mathrm{x}$-direction is

$$
\sigma_{x}=\sqrt{\sigma_{x}^{2}}
$$

Similarly, the square root of the second spatial moment of concentration distribution in the z-direction is

$$
\sigma_{z}=\sqrt{\sigma_{z}^{2}}
$$

We first present a summary of the results and then follow with details on the statistics of the items listed above. We observe significant differences between transport results obtained using soil properties from kriging and conditional simulation (CS). With soil properties from kriging, the results show the following differences:

- Slower bulk downward movement of the plume. 
- Less lateral and vertical spreading in the vadose zone.

- Greater residence time in the vadose zone (means more time to decay).

- Less severe impact on groundwater quality.

Slower downward movement of the plume for kriging runs is shown by consistently lower values of the depth at peak concentration and the center-of-mass depth, compared with these parameters for the CS runs. The center-of-mass moved $35 \%$ deeper after $20 \mathrm{yr}$ and $29 \%$ deeper after $30 \mathrm{yr}$, for the CS case compared with kriging. Movement is measured from the release point located $9 \mathrm{ft}$ below the ground surface. Lower lateral dispersion for the kriging run compared with the CS runs is demonstrated by consistently lower values of $\sigma_{x}$ for kriging: $34 \%$ lower at $10 \mathrm{yr}, 64 \%$ lower at $20 \mathrm{yr}$, and $77 \%$ lower at $30 \mathrm{yr}$. The trend continues into later years. With slower downward movement of the plume and less lateral spreading shown for the kriging run, it is not surprising that the contaminant spends more time in the vadose zone, and groundwater concentrations are lower. We will examine the parameters in more detail in the following sections.

\section{Plume Arrival Times at Water Table}

Ninety-six percent of the CS runs gave water table plume arrival times less than the arrival time for the kriging case, and the kriging case arrival time is $56 \%$ greater than the mean for the CS case. We define water table arrival time as time of arrival of the $20,000-\mathrm{pCi} / \mathrm{L}$ isoconcentration line at the water table. The arrival times are summarized in the histogram of Figure 7.2. Results are shown for 99 realizations because the $20,000-\mathrm{pCi} / \mathrm{L}$ isoconcentration line for one realization, Real168, never arrived at the water table. The plume for real168 exhibited the greatest degree of lateral spreading observed for any of the realizations. 


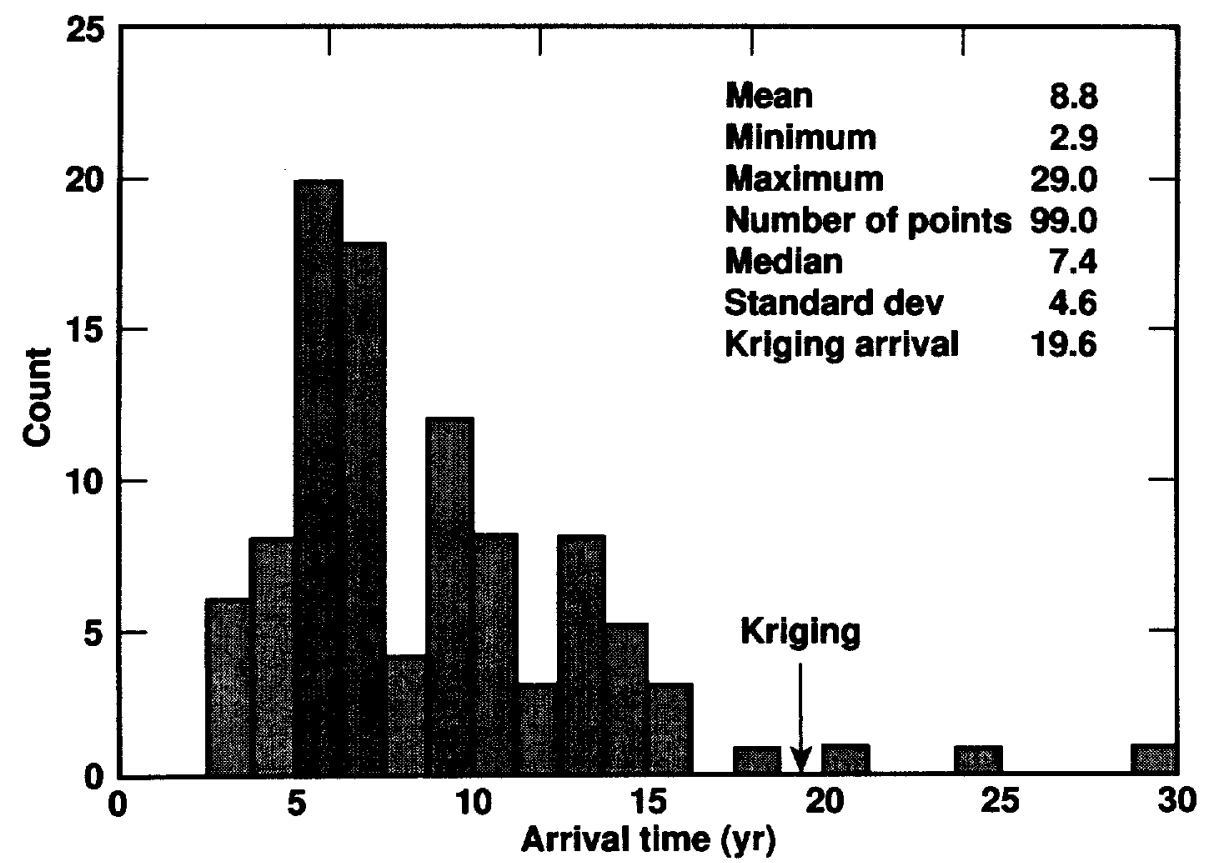

Figure 7.2: Histogram of plume arrival times at the water table for Monte-Carlo simulation runs. The histogram is drawn for 99 realizations because the $20,000-\mathrm{pCi} / \mathrm{L}$ isoconcentration line for one realization never reached the water table.

The arrival-time histogram appears to roughly approximate a lognormal distribution, with a mean of $8.7 \mathrm{yr}$, standard deviation of $4.5 \mathrm{yr}$, and a median of $7.4 \mathrm{yr}$. A histogram of the natural logarithm of plume arrival time at the water table is shown in Figure 7.3. The histogram has a mean of 2.1, a median of 2.0, and a standard deviation of 0.57 .

The distribution of plume arrival times at the water table appears to fit a lognormal distribution even closer when the times are adjusted to remove the effect of radioactive decay. We make the adjustment by modifying the arrival concentration according to

$$
C=C_{0} \exp -\lambda t
$$

so that the concentration used to define plume arrival is reduced with time. Consequently, the arrival times are decreased. Figure 7.4 is a histogram of the adjusted arrival times and Figure 7.5 is a histogram of the natural logarithm of the adjusted arrival times. Realization 


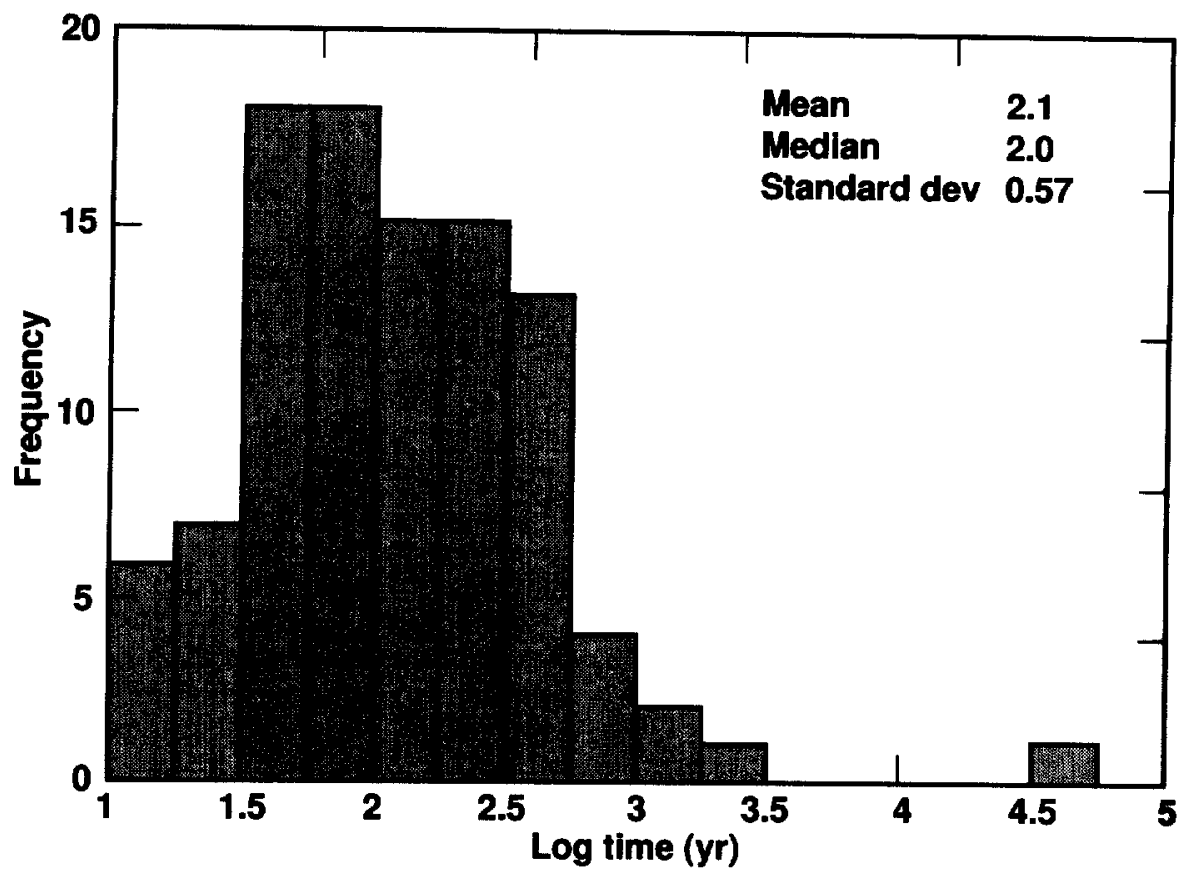

Figure 7.3: Histogram of natural logarithm of plume arrival times at the water table for Monte-Carlo simulation runs.

real168, the run that showed no water table plume arrival, has an adjusted arrival time of 26 yr.

If we approximate the distribution of the natural logarithm of plume arrival times by a normal distribution of mean 2.1 and standard deviation 0.57 , a $90 \%$ confidence level corresponds to a time range of $3.2-20.9 \mathrm{yr}$, and a $70 \%$ confidence level corresponds to a range of 4.5-14.7 yr. The probability of an arrival time less than $19.6 \mathrm{yr}$, the kriging arrival time, is 0.94. Apparently, many higher-permeability flow paths that are available with conditional simulation, which attempts to preserve the spatial variability of the system, are lost due to the artificial smoothing effect of kriging. Smoothing is a common artifact of kriging and other moving-average type interpolators. 


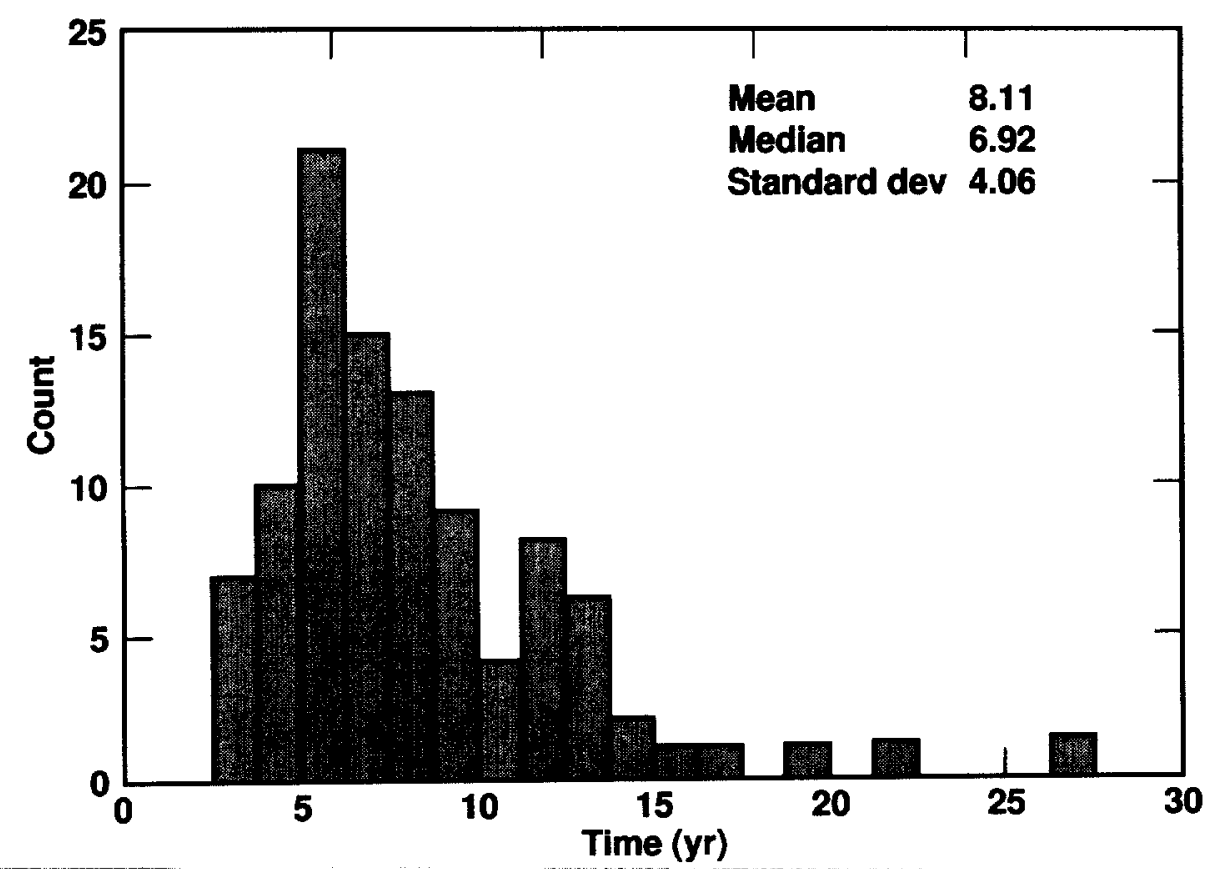

Figure 7.4: Histogram of plume arrival times at the water table, adjusted to remove the effect of radioactive decay.

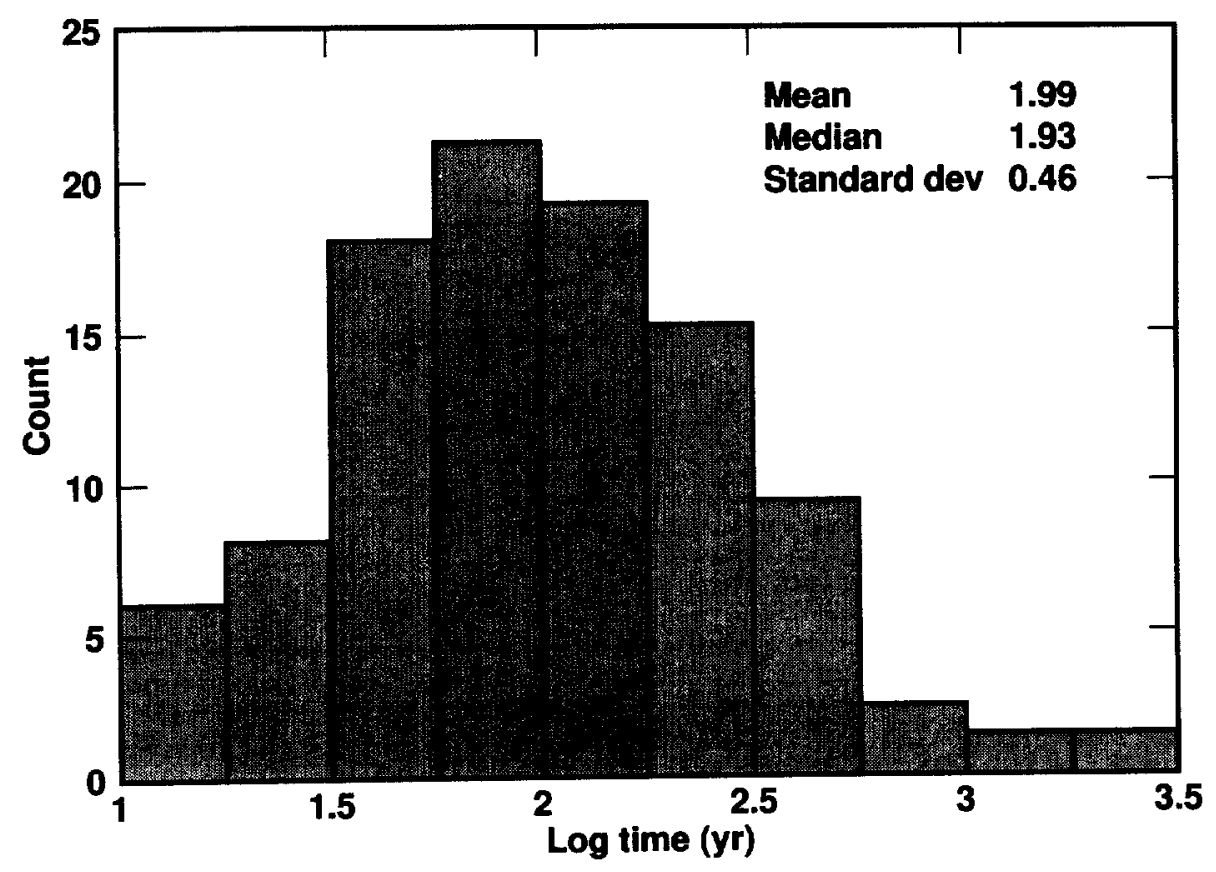

Figure 7.5: Histogram of natural logarithm of plume arrival times at the water table, adjusted to remove the effect of radioactive decay. 
Table 7.1: CS mean and coefficient of variation of peak groundwater ${ }^{3} \mathrm{H}$ concentrations 100 $\mathrm{ft}$ downstream of leak, compared with peak kriging concentrations.

\begin{tabular}{cccc}
\hline $\begin{array}{c}\text { Time } \\
(\mathrm{yr})\end{array}$ & $\begin{array}{c}\text { Mean conc } \\
(\mathrm{pCi} / \mathrm{L})\end{array}$ & $\begin{array}{c}\text { Coef of } \\
\text { Var }\end{array}$ & $\begin{array}{c}\text { Krig conc } \\
(\mathrm{pCi} / \mathrm{L})\end{array}$ \\
\hline 10.0 & $5.73 \times 10^{4}$ & 2.73 & $1.00 \times 10^{1}$ \\
20.0 & $5.08 \times 10^{5}$ & 1.44 & $3.78 \times 10^{3}$ \\
30.0 & $6.07 \times 10^{5}$ & 0.89 & $3.77 \times 10^{4}$ \\
40.0 & $4.10 \times 10^{5}$ & 0.56 & $9.61 \times 10^{4}$ \\
50.0 & $2.34 \times 10^{5}$ & 0.38 & $1.24 \times 10^{5}$ \\
60.0 & $1.26 \times 10^{5}$ & 0.33 & $1.09 \times 10^{5}$ \\
70.0 & $6.60 \times 10^{4}$ & 0.33 & $7.80 \times 10^{4}$ \\
80.0 & $3.41 \times 10^{4}$ & 0.36 & $4.97 \times 10^{4}$ \\
90.0 & $1.73 \times 10^{4}$ & 0.39 & $2.93 \times 10^{4}$ \\
100.0 & $8.73 \times 10^{3}$ & 0.44 & $1.64 \times 10^{4}$ \\
\hline \hline
\end{tabular}

\section{Groundwater Concentration}

In general, the conditional simulation results show groundwater quality is impaired earlier and more severely, compared with the kriging results. Figure 7.6 and Table 7.1 compare the mean groundwater tritium concentration history from conditional simulation with the history from kriging, for a water table location $100 \mathrm{ft}(30.5 \mathrm{~m})$ downstream of the leak. For the CS case, groundwater concentration increases much more rapidly, reaching the groundwater standard of $2.0 \times 10^{5} \mathrm{pCi} / \mathrm{L}$ in about $14 \mathrm{yr}$, and climbing to a maximum of $6.0 \times$ $10^{5} \mathrm{pCi} / \mathrm{L}$ at $30 \mathrm{yr}$ before starting to decline. The high coefficient of variation, particularly during the first 30 or 40 years, indicates the high variability of the concentrations from realization to realization. The peak groundwater concentration $100 \mathrm{ft}$ downstream, for all runs, occurred with realization Real121, and was $3.0 \times 10^{6} \mathrm{pCi} / \mathrm{L}$ after $15 \mathrm{yr}$. For the kriging case, the concentration does not start increasing until about $20 \mathrm{yr}$, reaches a maximum of $1.1 \times 10^{5} \mathrm{pCi} / \mathrm{L}$ at $50 \mathrm{yr}$, then declines thereafter. For the CS case, the (mean) maximum groundwater ${ }^{3} \mathrm{H}$ concentration $100 \mathrm{ft}$ downstream of the leak is therefore 5.5 times greater than the concentration for the kriging case and occurs $20 \mathrm{yr}$ earlier. 


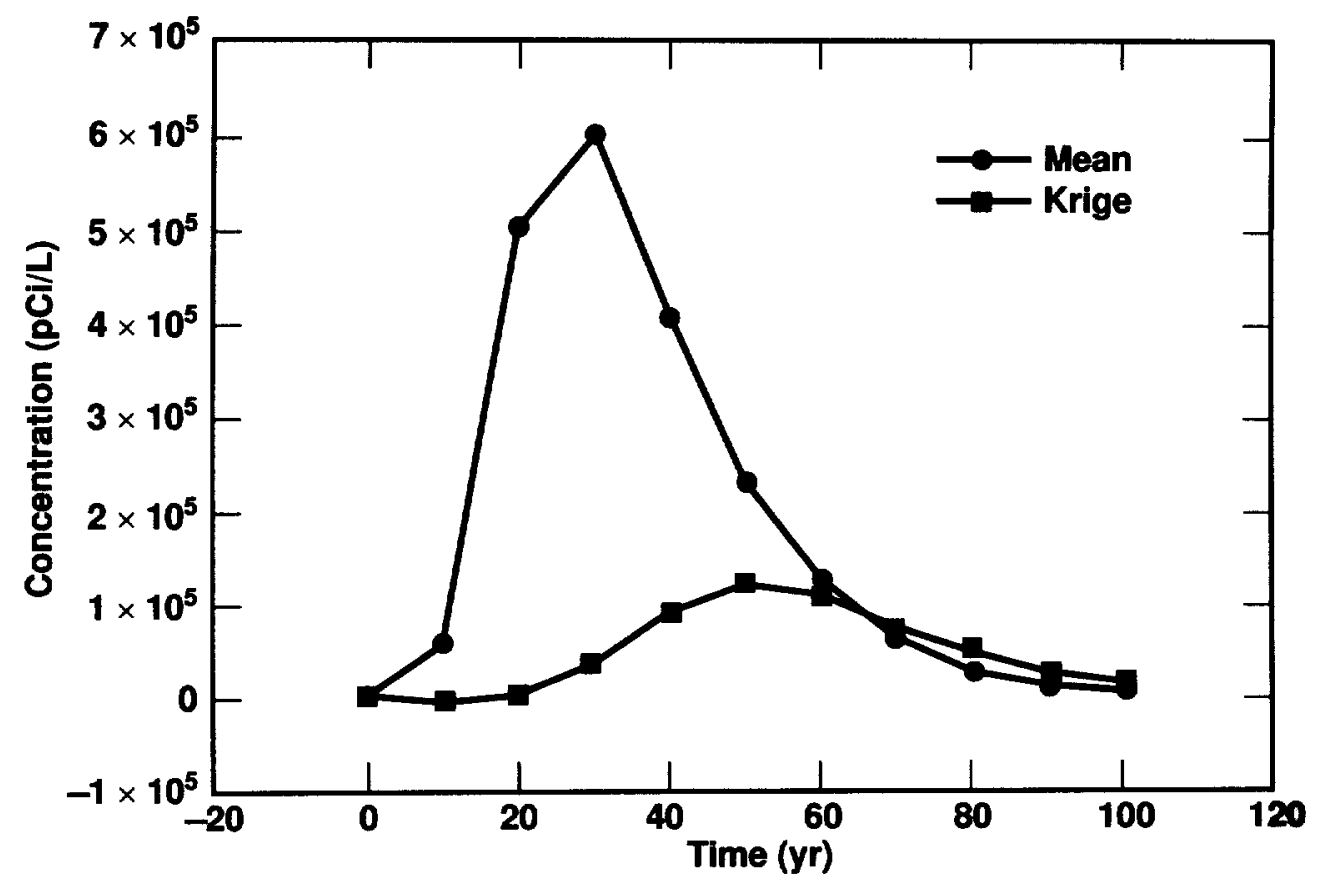

Figure 7.6: Groundwater ${ }^{3} \mathrm{H}$ concentration history at the water table $100 \mathrm{ft}$ downstream of leak; comparison of the CS and kriging cases.

Figure 7.7 shows the history of the peak groundwater ${ }^{3} \mathrm{H}$ concentration in the entire system: again the CS mean concentrations are compared with concentrations from the kriging case. The results are similar to those from the groundwater concentrations $100 \mathrm{ft}$ downstream: the CS results show higher groundwater concentrations at earlier times.

Figure 7.8 is a histogram of the maximum groundwater ${ }^{3} \mathrm{H}$ concentrations for realizations generated by conditional simulation. The concentrations have mean $2.16 \times 10^{6} \mathrm{pCi} / \mathrm{L}$, standard deviation $2.03 \times 10^{6} \mathrm{pCi} / \mathrm{L}$, and vary from $1.31 \times 10^{4} \mathrm{pCi} / \mathrm{L}$ for real168 to $8.99 \times$ $10^{6} \mathrm{pCi} / \mathrm{L}$ for real116. A histogram of the natural logarithm of maximum groundwater concentration is plotted in Figure 7.9. The maximum concentration and time of occurrence of the maximum for all realizations are tabulated in Appendix Table D.1. The maximum concentrations are roughly lognormal with mean 14.1 , median 14.2 , and standard deviation 1.1. A histogram of the time of occurrence of peak groundwater concentration is plotted 


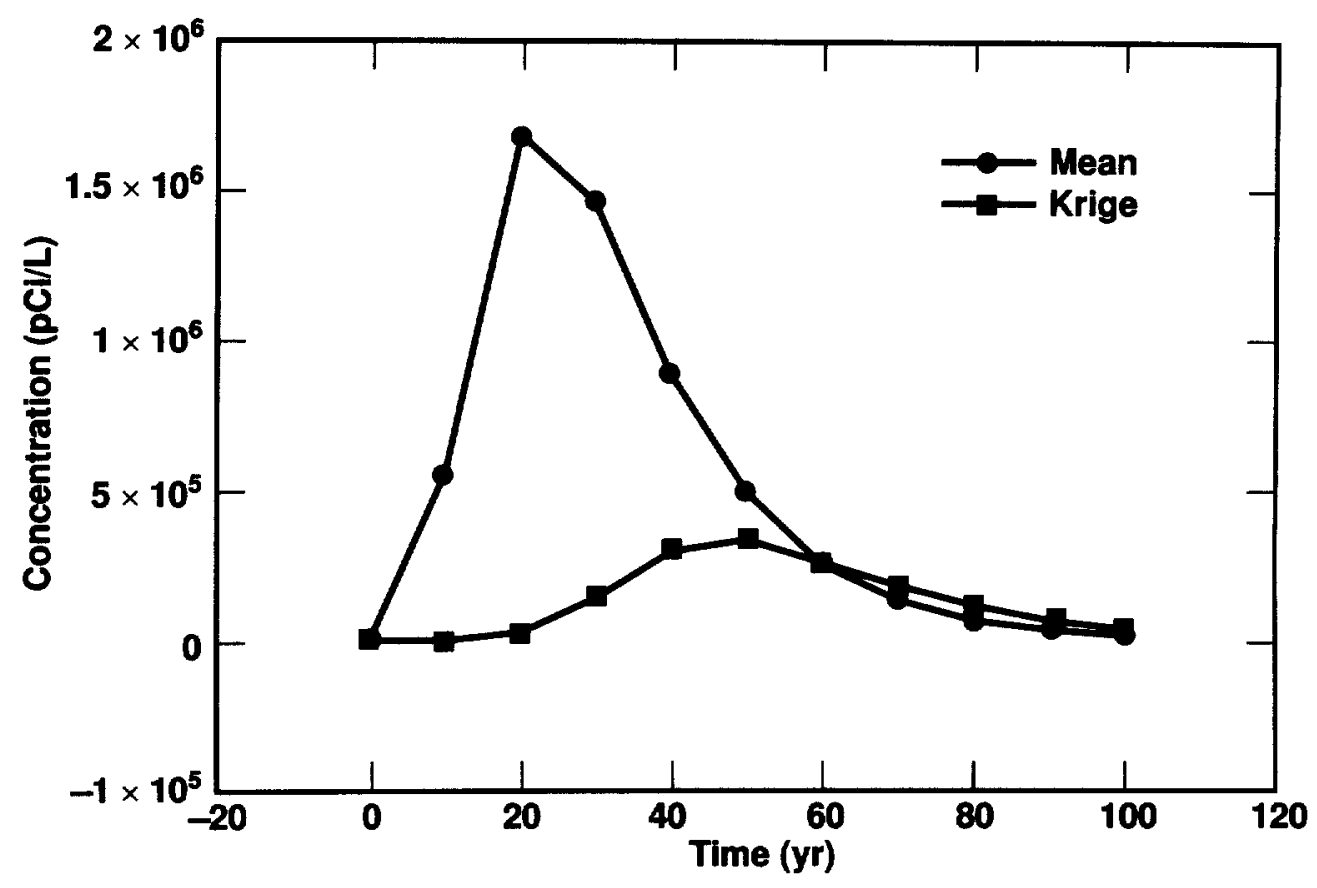

Figure 7.7: Comparison of peak groundwater ${ }^{3} \mathrm{H}$ concentration histories from the CS case and the kriging case.

in Figure 7.10. The distribution of times is approximately normal with mean $31.0 \mathrm{yr}$ and standard deviation $9.8 \mathrm{yr}$.

\section{Tritium Movement across Water Table}

Transport calculations using soil properties from conditional simulation showed substantially greater fluxes of ${ }^{3} \mathrm{H}$ across the water table than calculations using soil properties from kriging. Figure 7.11 shows the time histories of the cumulative ${ }^{3} \mathrm{H}$ fluxes for the two cases. For the CS case, the mean ${ }^{3} \mathrm{H}$ flux across the water table, equal to the slope of the curve, is greatest between about 10 and $40 \mathrm{yr}$, after which it starts to fall off, and is close to zero at $100 \mathrm{yr}$ after a cumulative activity of about $102 \mathrm{mCi}$. For the kriging case, the flux remains at zero for about $20 \mathrm{yr}$, rises slowly until about $60 \mathrm{yr}$, then levels off to near zero for a cumulative activity of about $25 \mathrm{mCi}$ at $100 \mathrm{yr}$. The mean $100-\mathrm{yr}$ cumulative flux for the 


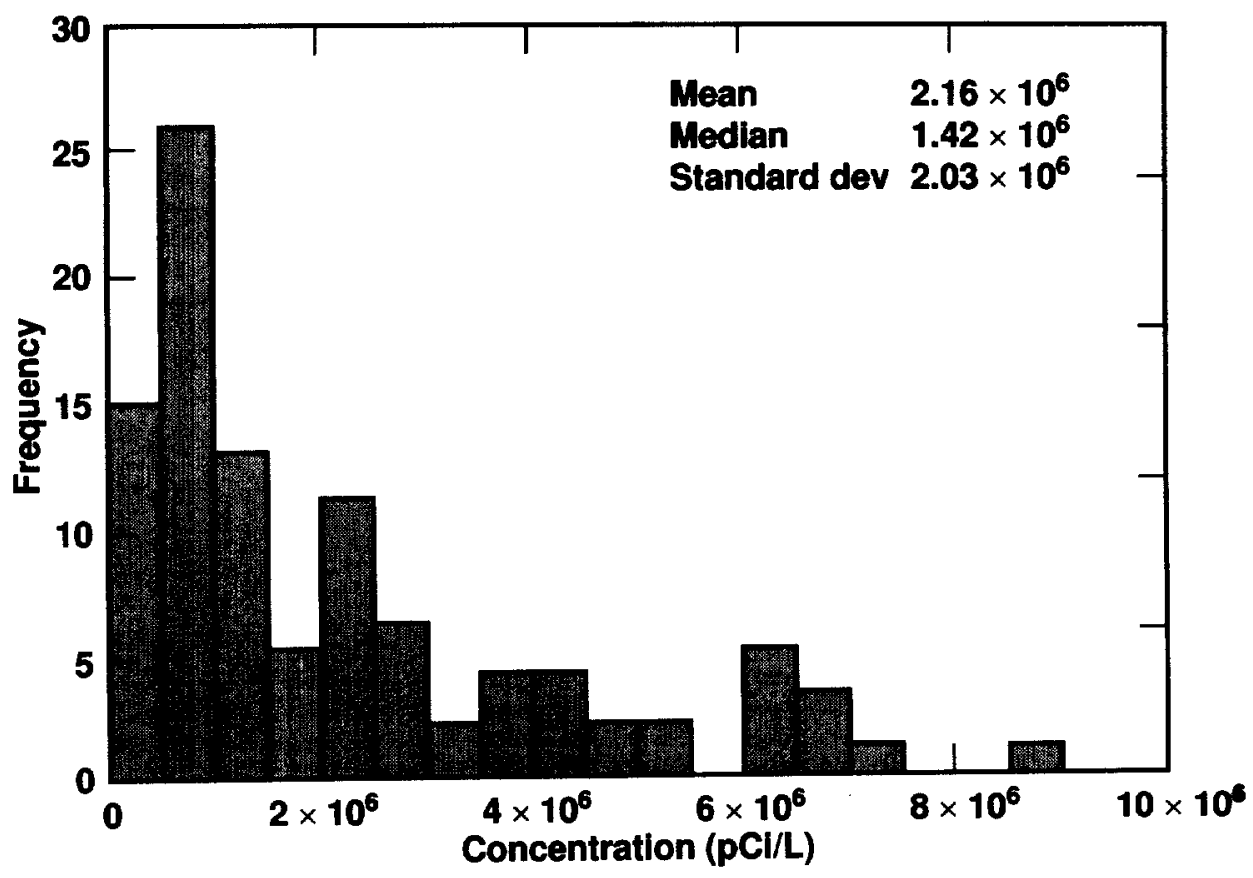

Figure 7.8: Histogram of maximum groundwater ${ }^{3} \mathrm{H}$ concentration for 100 realizations derived by conditional simulation.

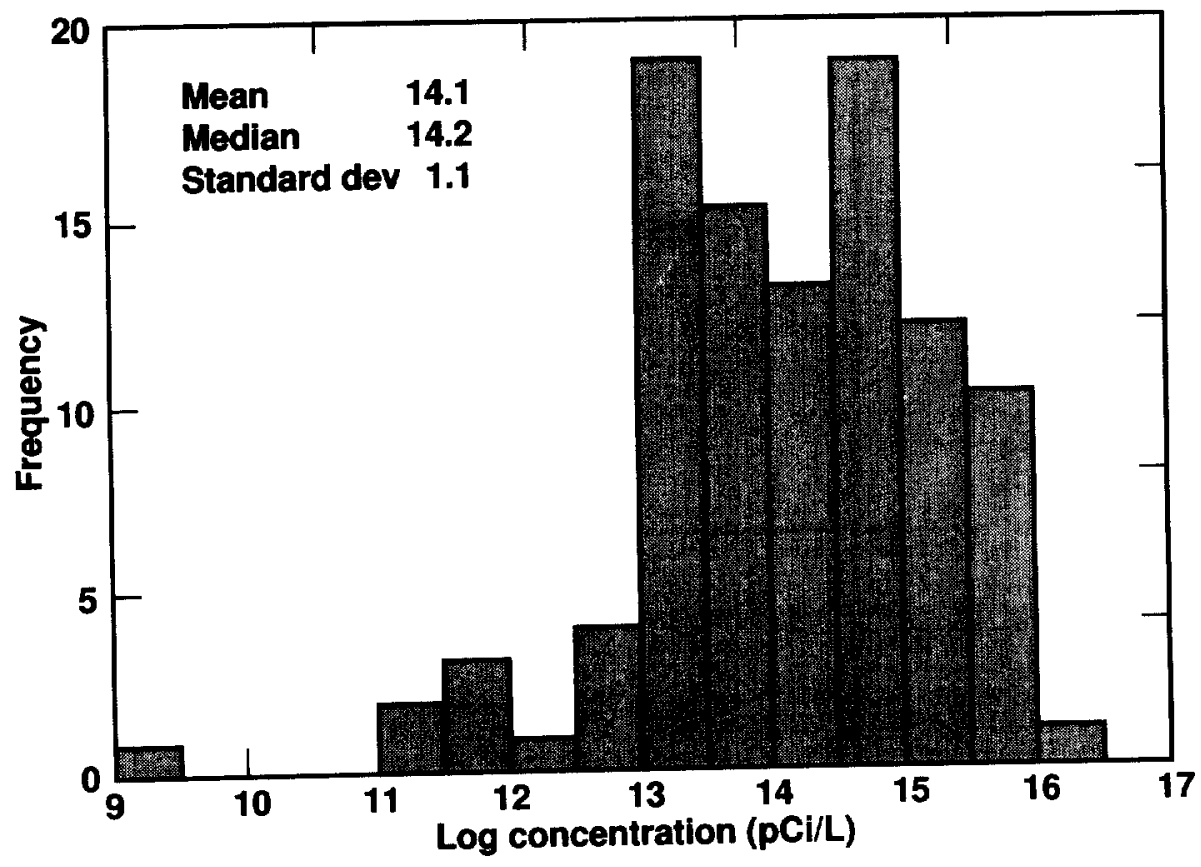

Figure 7.9: Histogram of natural logarithm of maximum groundwater ${ }^{3} \mathrm{H}$ concentration for 100 realizations derived by conditional simulation. 


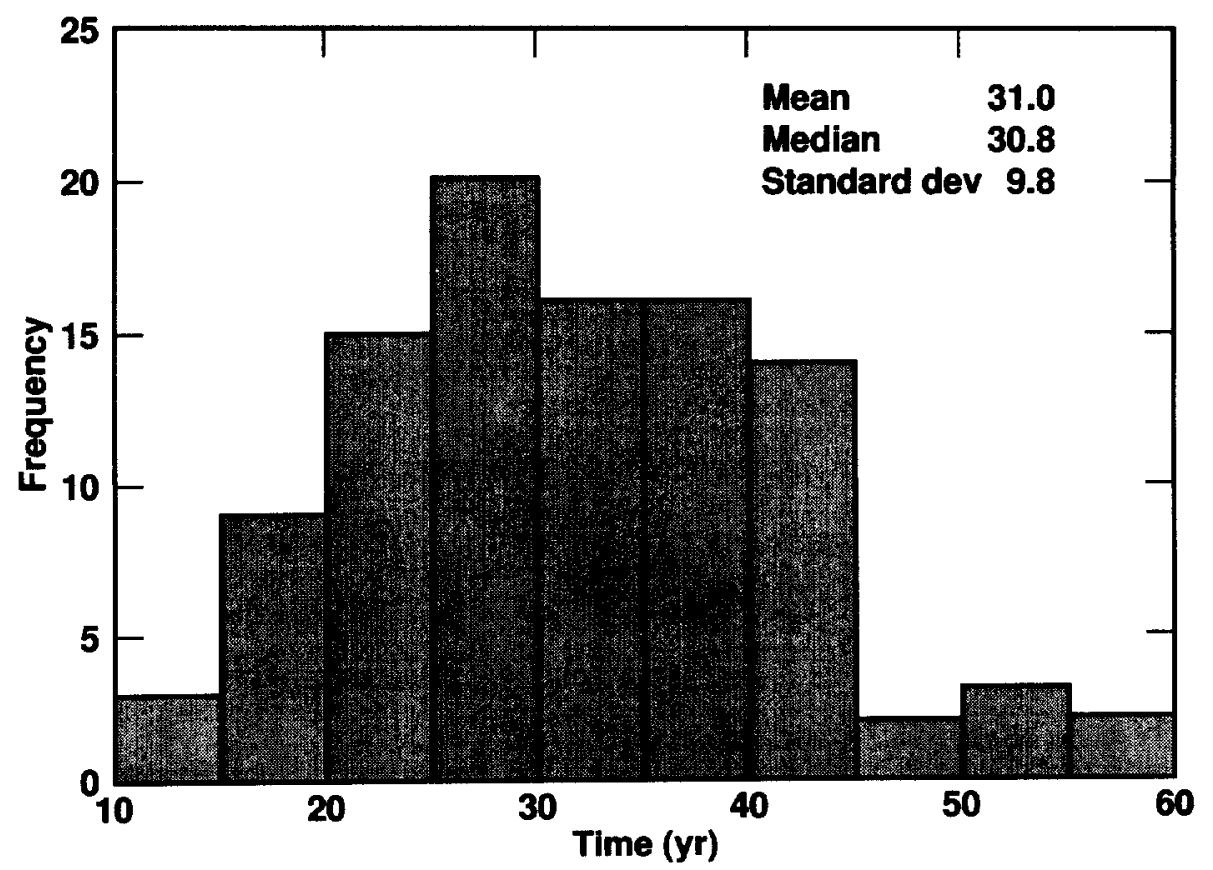

Figure 7.10: Histogram of time of occurrence of maximum groundwater ${ }^{3} \mathrm{H}$ concentration for 100 realizations derived by conditional simulation.

CS case is 4.0 times greater than the $100-\mathrm{yr}$ flux for the kriging case.

Figure 7.12 shows the total activity of ${ }^{3} \mathrm{H}$ in the groundwater, for the two cases. In the first 20 years, the mean activity for the CS case is slightly less than the cumulative flux received from the vadose zone across the water table, because the supply rate from the vadose zone dominates losses due to radioactive decay over the relatively short time period. At later times, as the supply from the vadose zone declines and radioactive decay becomes more dominant, the activity reaches a maximum of $28 \mathrm{mCi}$ at $30 \mathrm{yr}$ and then reduces, thereafter, falling to about $1 \mathrm{mCi}$ at $100 \mathrm{yr}$. For the kriging case, the curve rises more gradually, reaching a maximum of $6 \mathrm{mCi}$ at $60 \mathrm{yr}$ before falling to about $1 \mathrm{mCi}$ at $100 \mathrm{yr}$. Therefore, the (mean) maximum ${ }^{3} \mathrm{H}$ activity in the groundwater for the CS case is 4.7 times greater than the activity for the kriging case, and occurs $30 \mathrm{yr}$ earlier. 


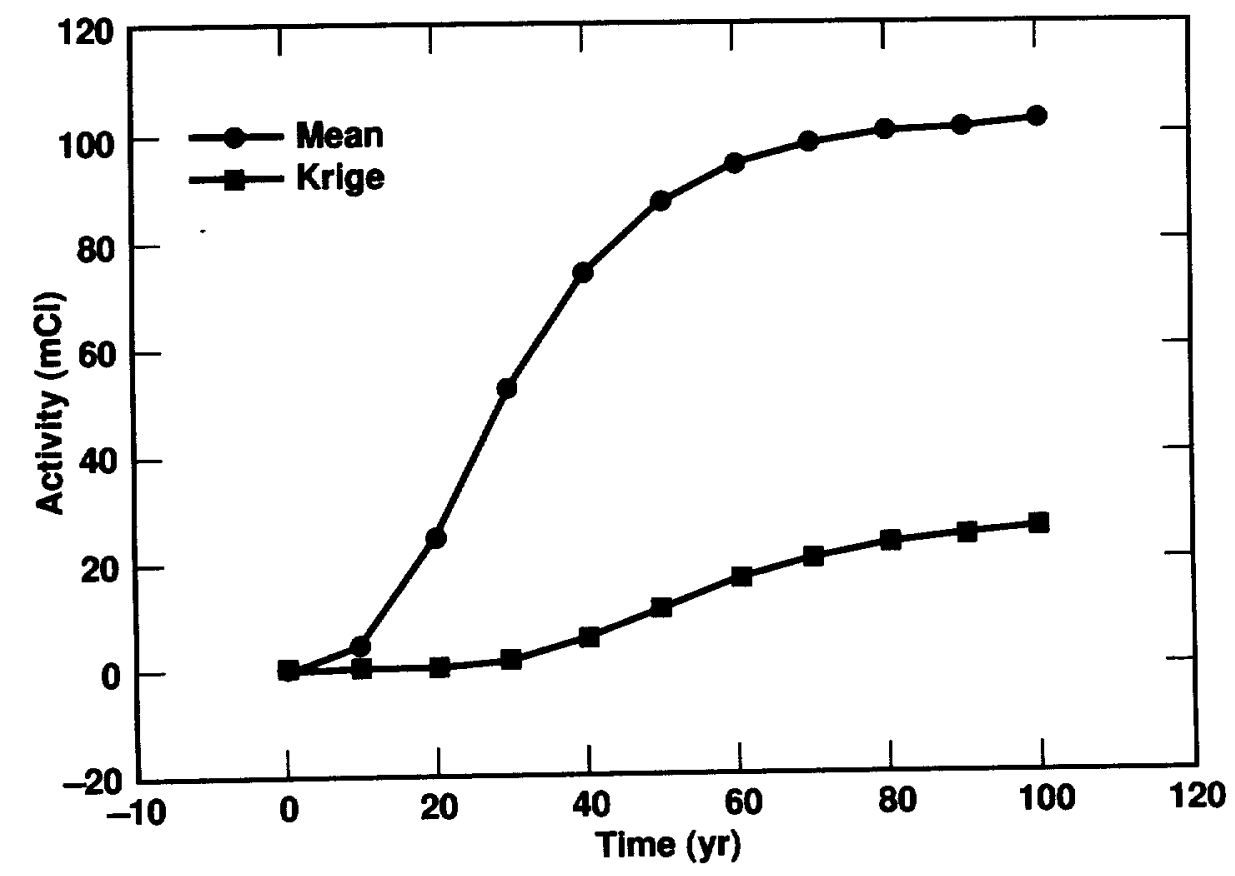

Figure 7.11: Comparison of cumulative ${ }^{3} \mathrm{H}$ activity histories across the water table for the CS case and the kriging case.

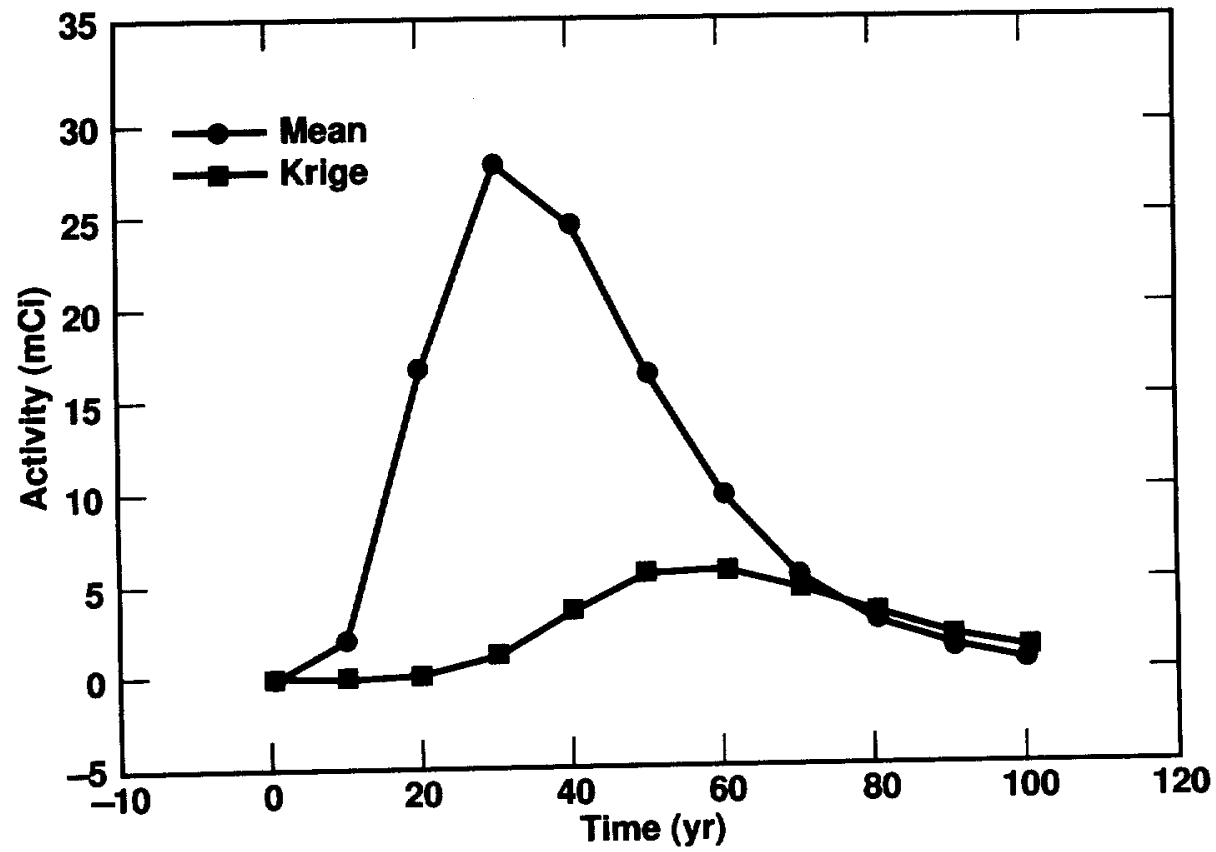

Figure 7.12: Comparison total groundwater ${ }^{3} \mathrm{H}$ activity histories for the mean CS case and the kriging case. 


\section{Movement of Plume's Center-of-mass in the Vadose Zone}

Figure 7.13 plots histories of the depth of the ${ }^{3} \mathrm{H}$ plume's center-of-mass (CM), for both the mean CS case and the kriging case. Both cases show slow downward bulk movement of the plume with velocity decreasing with time. The CS plume's CM moves faster over the initial $30 \mathrm{yr}$ but later slows down relative to the kriging plume's CM. For the CS case, the center-of-mass is at $25 \mathrm{ft}$ after $20 \mathrm{yr}$, which represents a vertical movement of $16 \mathrm{ft}$ from the release point at $9 \mathrm{ft}$ depth and an average velocity of $0.8 \mathrm{ft} / \mathrm{yr}$. For the kriging case over the same period, the center-of-mass to a depth of $19 \mathrm{ft}$, giving a vertical movement of $10 \mathrm{ft}$ for an average velocity of $0.5 \mathrm{ft} / \mathrm{yr}, 38 \%$ slower than the mean CS velocity. From 20 to 40 yr, the depths go to 32 and $27 \mathrm{ft}$ and the average velocities are reduced to $0.35 \mathrm{ft} / \mathrm{yr}$ and $0.40 \mathrm{ft} / \mathrm{yr}$, for the CS and kriging cases, respectively. Therefore, although both velocities decrease with time, the kriging velocity decreases at a lower rate and eventually becomes greater than the CS velocity. At $90 \mathrm{yr}$, the two CM depths are equal. However, by that time, the peak ${ }^{3} \mathrm{H}$ concentration in the vadose zone is reduced close to the groundwater standard by radioactive decay and dispersion.

Figure 7.14 shows the peak vadose zone ${ }^{3} \mathrm{H}$ concentration histories for the mean CS and kriging cases. The depths at peak concentration are plotted in Figure 7.15. Because of slower downward movement of the CM and lower dispersion, the peak concentration for the kriging case remains higher throughout the simulation period. The kriging concentration is higher by $16 \%$ at $10 \mathrm{yr}, 31 \%$ at $20 \mathrm{yr}$, and up to a maximum of $53 \%$ at $100 \mathrm{yr}$.

For the first 95 years of the 100 -year simulation period, the peak vadose zone ${ }^{3} \mathrm{H}$ concentrations remain above the groundwater standard, $2.0 \times 10^{5} \mathrm{pCi} / \mathrm{L}$. At $40 \mathrm{yr}$, the peak vadose zone concentration for the $\mathrm{CS}$ case is $1.1 \times 10^{7} \mathrm{pCi} / \mathrm{L}$, only about an order of magnitude lower than the the source concentration and still two orders of magnitude above 


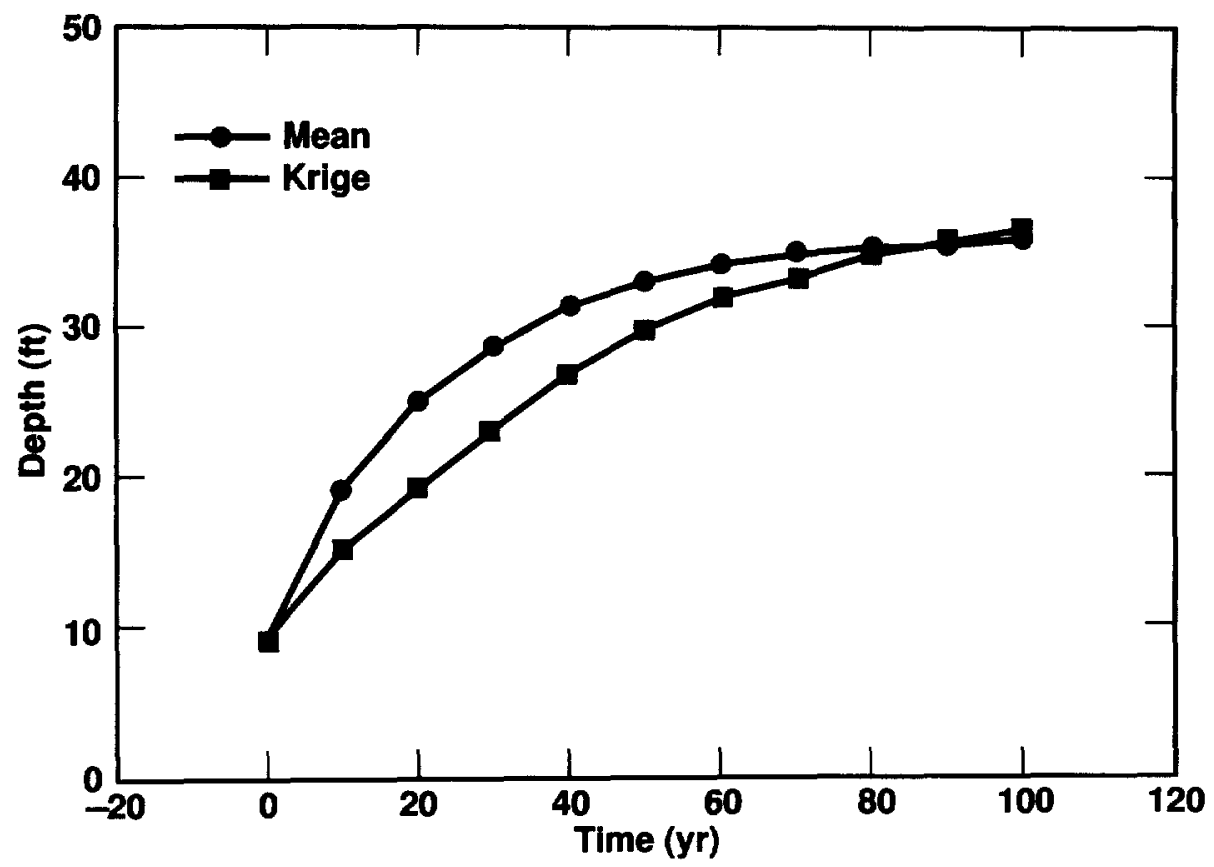

Figure 7.13: Comparison of history plots of the ${ }^{3} \mathrm{H}$ plume's center-of-mass depth in the vadose zone, for the mean $\mathrm{CS}$ case and the kriging case.

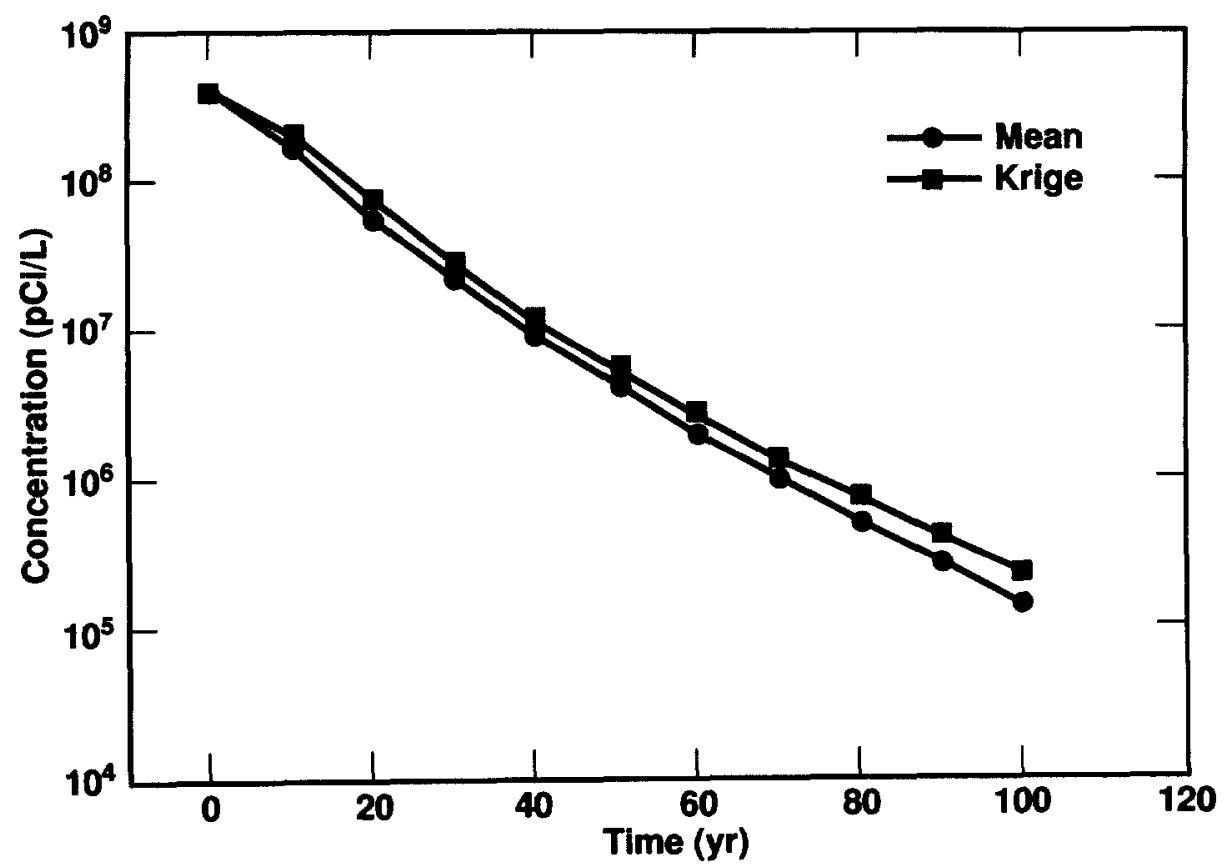

Figure 7.14: Comparison of the peak vadose zone ${ }^{3} \mathrm{H}$ concentration histories for the CS case and the kriging case. 


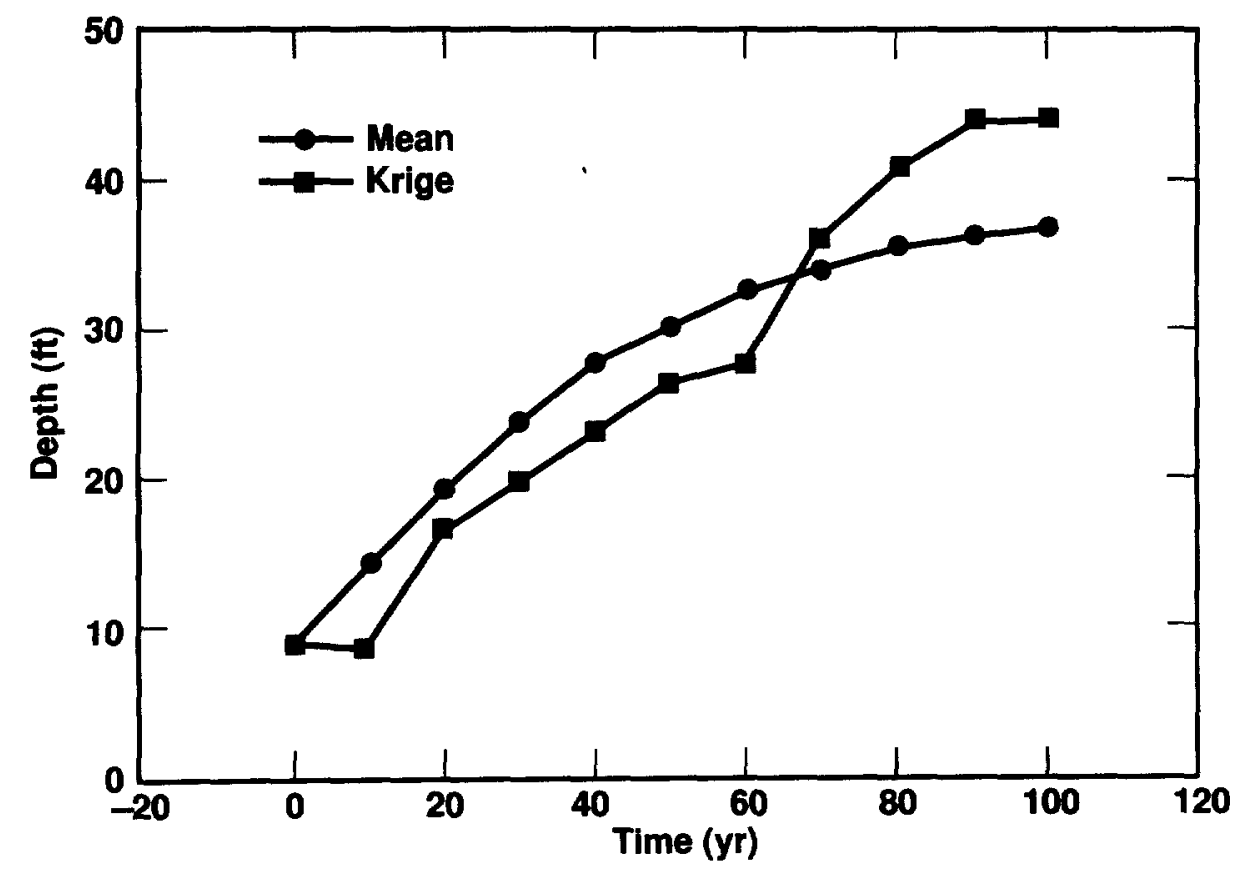

Figure 7.15: Histories of the depth at peak vadose zone ${ }^{3} \mathrm{H}$ concentration for the CS case and the kriging case.

the groundwater standard. At $60 \mathrm{yr}$, the peak concentration is $2.4 \times 10^{6} \mathrm{pCi} / \mathrm{L}$, still over an order of magnitude above the groundwater standard $\left(2.0 \times 10^{5} \mathrm{pCi} / \mathrm{L}\right)$. The first order decay equation is written

$$
C=C_{0} \exp (-\lambda t)
$$

where $\mathrm{C}$ is the concentration at time $t, \mathrm{C}_{0}$ is the initial concentration, and $\lambda$ is the decay constant for ${ }^{3} \mathrm{H}$ (equal to $.056 \mathrm{yr}^{-1}$ ). Based on radioactive decay alone, for the initial concentration of $4.46 \times 10^{8} \mathrm{pCi} / \mathrm{L}$, the peak concentration at $40 \mathrm{yr}$ is $4.7 \times 10^{7}$, and at 60 $\mathrm{yr}, 1.5 \times 10^{7} \mathrm{pCi} / \mathrm{L}$. Therefore, at 40 and $60 \mathrm{yr}$, the peak concentrations from the CS case are about $23 \%$ and $16 \%$ of the values expected if dispersive and diffusive processes were ignored. 


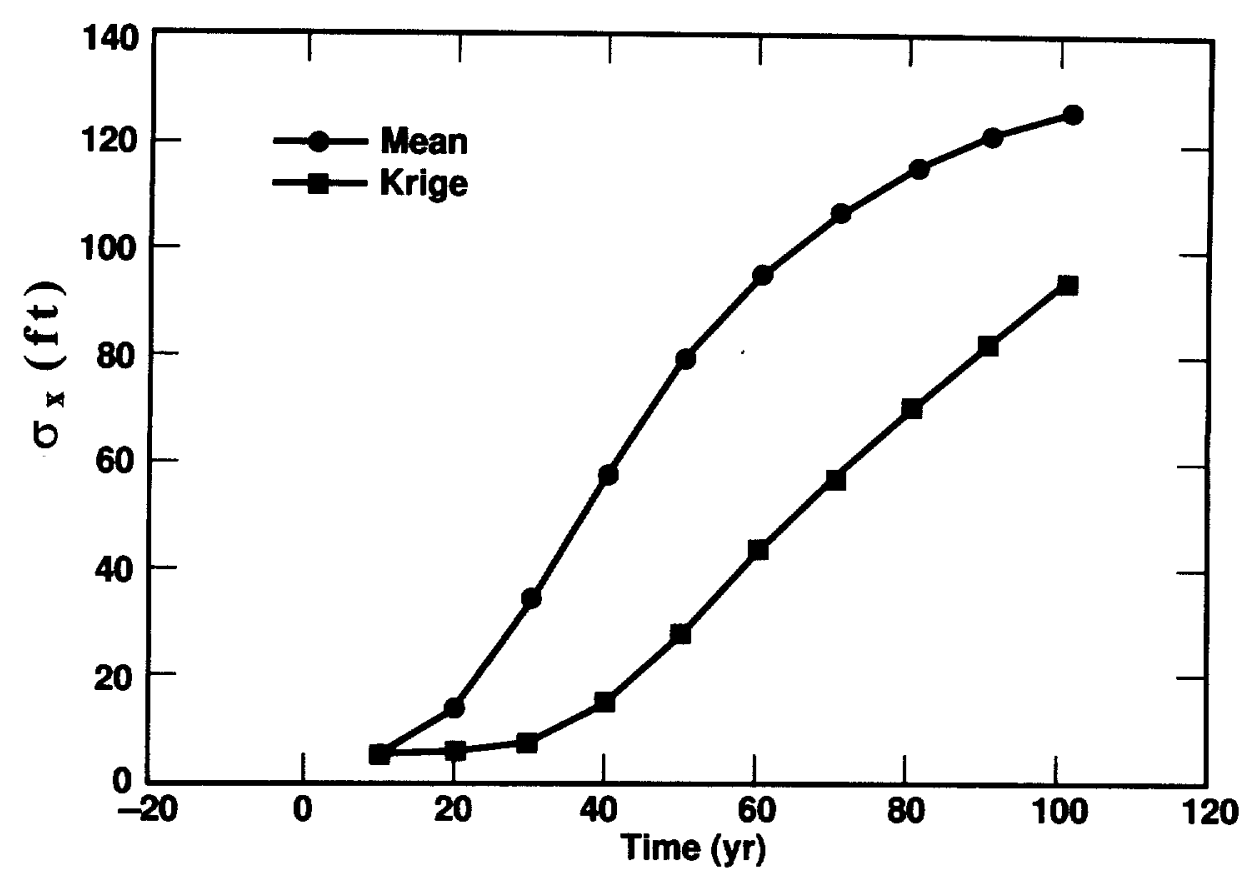

Figure 7.16: Histories of the spreading parameter in the X-direction, $\sigma_{x}$, for the mean CS and the kriging cases. $\sigma_{x}$ is the square root of the second moment of ${ }^{3} \mathrm{H}$ concentration distribution in the vadose zone.

\section{Dispersion in the Vadose Zone}

In Figure 7.16, the time history of the square root of the second moment of ${ }^{3} \mathrm{H}$ concentration distribution in the vadose zone, $\sigma_{x}$, is compared for the mean CS case and the kriging case. Throughout the 100-year simulation period, $\sigma_{x}$ is substantially greater for the CS case than for the kriging case, implying greater lateral spreading for permeability fields generated by conditional simulation. The mean $\sigma_{x}$ value for the CS case is $50 \%$ greater at $10 \mathrm{yr}, 180 \%$ greater at $20 \mathrm{yr}$, and up to $342 \%$ greater at $30 \mathrm{yr}$. The percent difference reduces thereafter, but still remains significant, dropping to $269 \%$ at $40 \mathrm{yr}$ and finally to $34 \%$ after $100 \mathrm{yr}$.

The square root of the second moment of ${ }^{3} \mathrm{H}$ concentration distribution in the vadose zone, $\sigma_{z}$, also shows greater spreading of the plume in the vertical direction, for the CS case over the kriging case. The $\sigma_{z}$ histories for the two cases are plotted in Figure 7.17. The $\sigma_{z}$ values are significantly lower than the $\sigma_{x}$ values, probably because of anisotropy in the 


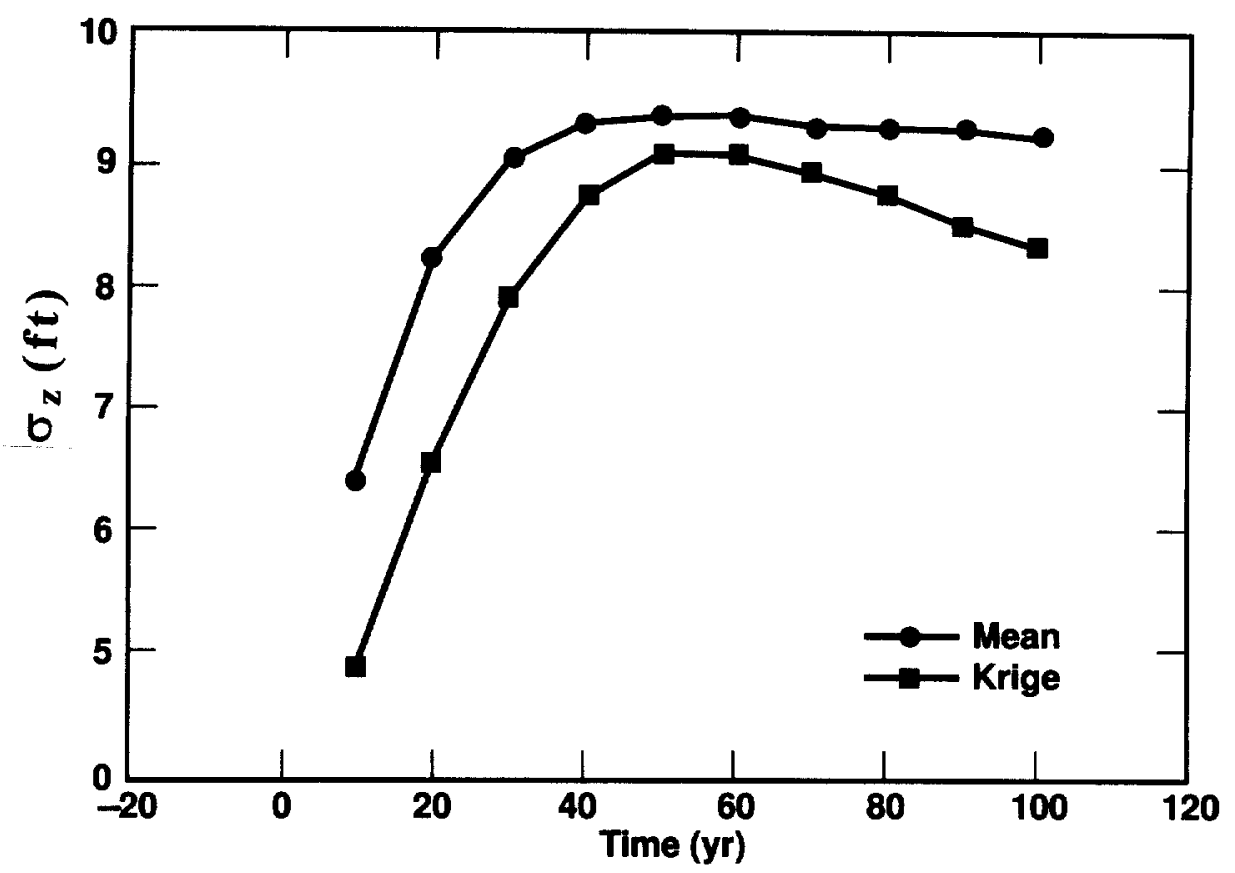

Figure 7.17: Histories of the spreading parameter in the z-direction, $\sigma_{z}$, for the mean CS and the kriging cases. $\sigma_{z}$ is the square root of the second moment of ${ }^{3} \mathrm{H}$ concentration distribution in the vadose zone.

spatial variability of the soil permeability: the horizontal range of the permeability sample variogram is about three times the vertical range. $\sigma_{z}$ is also smaller because of the limited depth of $48 \mathrm{ft}$ between the ground surface and the water table.

\section{Tritium Activity in the Vadose Zone}

Figure 7.18 compares the histories of total vadose zone ${ }^{3} \mathrm{H}$ activity for the mean $\mathrm{CS}$ and kriging cases. The total quantity of ${ }^{3} \mathrm{H}$ entering the vadose zone was $1000 \mathrm{mCi}$, released during the first $5 \mathrm{yr}$. Because the ${ }^{3} \mathrm{H}$ activity in the gas phase is negligible compared with the activity in the liquid phase, the liquid phase activity is taken as the total in the vadose zone. Only a small fraction of the total ${ }^{3} \mathrm{H}$ in the system enters the groundwater, even for the CS case. Therefore, the percent difference in vadose zone ${ }^{3} \mathrm{H}$ activity between the two cases remains relatively small throughout the simulation period. The difference in ${ }^{3} \mathrm{H}$ 


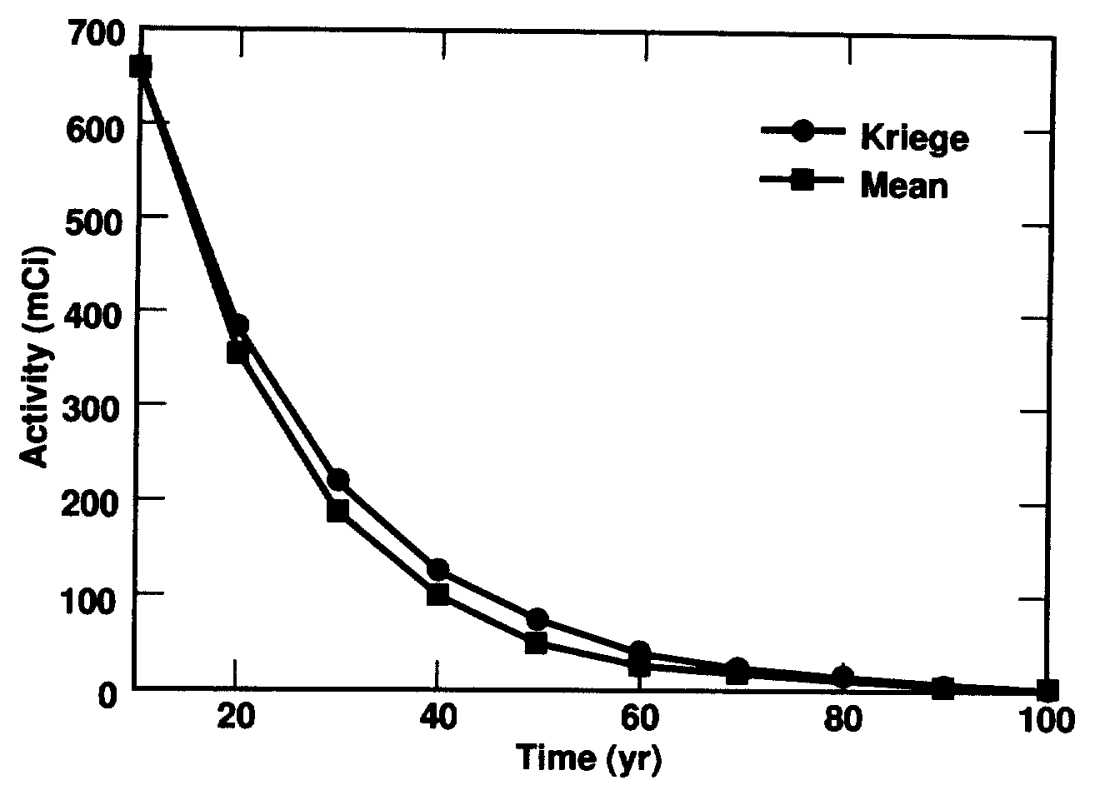

Figure 7.18: Comparison of total ${ }^{3} \mathrm{H}$ activity histories in the vadose zone for the $\mathrm{CS}$ and kriging cases.

activity is nearly zero before $10 \mathrm{yr}$ when very little ${ }^{3} \mathrm{H}$ has entered the groundwater and losses from the vadose zone are due mainly to radioactive decay. After $10 \mathrm{yr}$, the kriging case shows a higher activity due to slower downward movement of the plume resulting in lower losses to the groundwater. The kriging activity is $5 \%$ higher at $20 \mathrm{yr}, 15 \%$ higher at $30 \mathrm{yr}$, and goes up to $46 \%$ higher at $50 \mathrm{yr}$. The total vadose zone ${ }^{3} \mathrm{H}$ activity in the later years is substantially reduced from the $1000 \mathrm{mCi}$ released. The activity from kriging is down to $67 \mathrm{mCi}$ at $50 \mathrm{yr}$ and only $3 \mathrm{mCi}$ at $100 \mathrm{yr}$.

Because the fraction of total ${ }^{3} \mathrm{H}$ release that enters the groundwater in earlier years is small, total ${ }^{3} \mathrm{H}$ activity in the vadose zone can be estimated fairly accurately by considering only first order radioactive decay. The estimate remains good at later times when applied to the kriging case because of slower downward movement of the plume. Equation 7.1 with a release rate, $R_{l}^{H T O}$, of $0.2 \mathrm{Ci} / \mathrm{yr}$, gives an activity of $872 \mathrm{mCi}$ remaining in the vadose zone 
Table 7.2: Comparison of vadose zone ${ }^{3} \mathrm{H}$ activity at various times for the mean CS case, the kriging case, and estimates based on ${ }^{3} \mathrm{H}$ losses due only to radioactive decay.

\begin{tabular}{crrr}
\hline \hline $\begin{array}{c}\text { Time } \\
(\mathrm{yr})\end{array}$ & $\begin{array}{r}\text { Mean CS } \\
\text { Activity } \\
(\mathrm{mCi})\end{array}$ & $\begin{array}{r}\text { Kriging } \\
\text { Activity } \\
(\mathrm{mCi})\end{array}$ & $\begin{array}{r}\text { Decay } \\
\text { Activity } \\
(\mathrm{mCi})\end{array}$ \\
\hline 10 & 654 & 656 & 659 \\
20 & 361 & 378 & 376 \\
30 & 188 & 217 & 214 \\
40 & 94 & 123 & 122 \\
50 & 46 & 67 & 70 \\
60 & 23 & 36 & 40 \\
70 & 11 & 19 & 23 \\
80 & 6 & 10 & 13 \\
90 & 3 & 5 & 7 \\
100 & 1 & 3 & 4 \\
\hline \hline
\end{tabular}

after the source is turned off at $5 \mathrm{yr}$. The activity for later times can be computed using Equation 7.7 with the dependent variable as activity instead of concentration. Table 7.2 compares vadose zone ${ }^{3} \mathrm{H}$ activity at various times for the mean CS case, the kriging case, and estimates based on losses due only to radioactive decay.

\section{Ambient Liquid Saturation}

To choose an appropriate infiltration rate for simulation runs, we conducted initialization runs on the same realization at various infiltration rates, computed the mean steady-state water content for the nodes in each run, then selected the infiltration rate for which the computed mean water content matches the mean water content measured by neutron probe in the field. Results of Neutron probe measurements in Boreholes 17, 18, and 19 are presented by Mallon (1995). We used water content data from Borehole 19 only, because the other two boreholes are drilled through the blacktop and not through exposed soil, and our 2D numerical calculations assume exposed soil.

Figure 7.19 is a plot of steady-state water content versus infiltration rate for the realiza- 


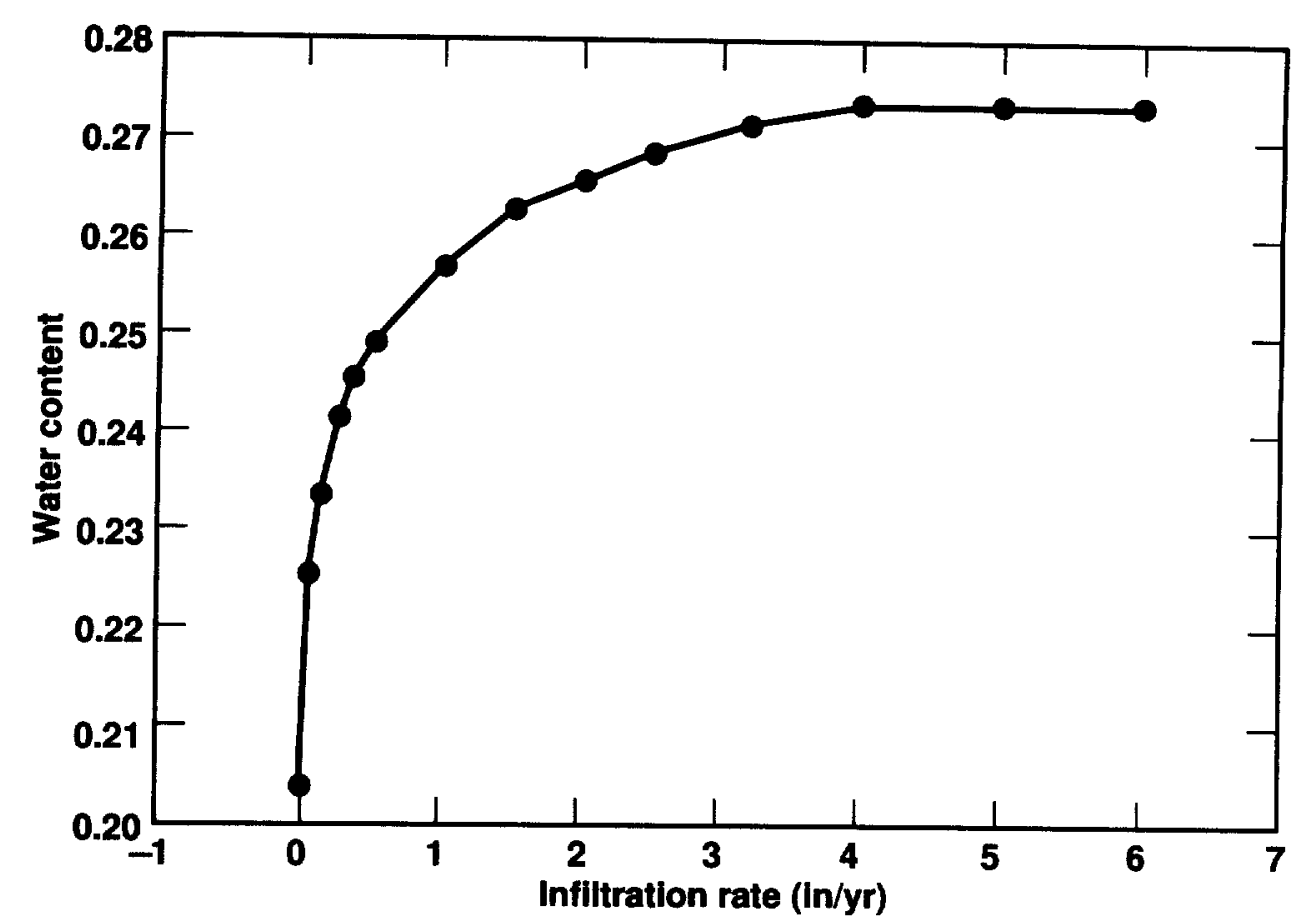

Figure 7.19: Steady-state water content versus infiltration rate for a realization of soil permeability field generated by conditional simulation.

tion. The water content increases with infiltration at a decreasing rate until it flattens out at a maximum of 0.274 . The mean water content measured in Borehole 19 is 0.267 , which matches an infiltration rate of $2.1 \mathrm{in} / \mathrm{yr}$.

Figure 7.20 is a histogram of the mean liquid saturation after initialization for simulation runs using soil properties from the 100 realizations. The liquid saturation varies from 0.61 to 0.84 with a mean of 0.75 . The coefficient of variation is 0.005 indicating low variability. Assuming the average porosity of 0.35 obtained from the data, the mean liquid saturation of 0.75 is equivalent to a water content of 0.26 . This water content approximately corresponds to an infiltration rate of $2.1 \mathrm{in} / \mathrm{yr}$, the infiltration rate used in the numerical simulations for the Monte-Carlo analysis. 


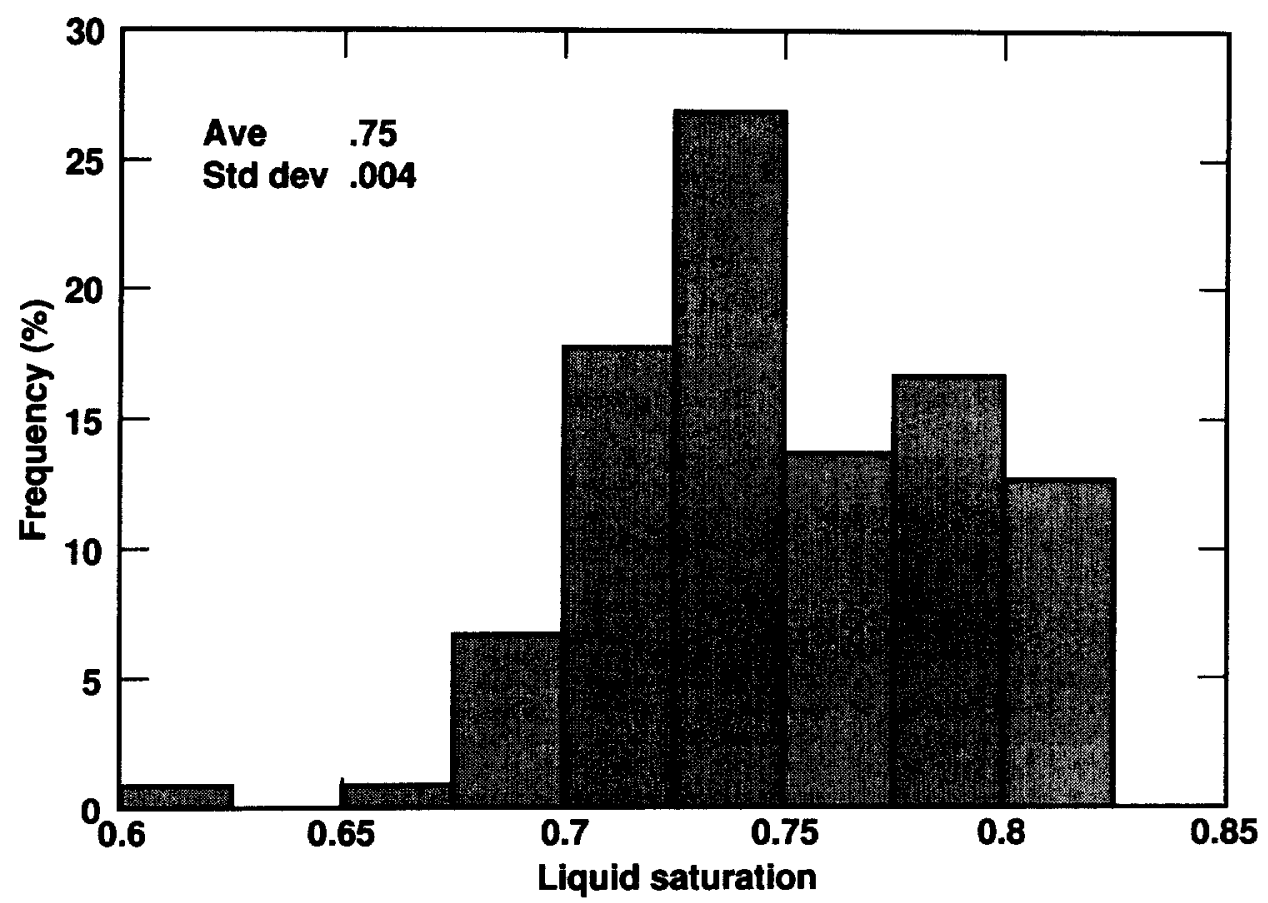

Figure 7.20: Histogram of mean liquid saturation after initialization for simulation runs using soil properties from 100 realizations.

\subsection{Effect of Infiltration and Vapor Diffusion on ${ }^{3} \mathbf{H}$ Transport}

Fourteen 2D simulation runs were conducted to investigate the effects of infiltration and vapor diffusion on groundwater quality. To observe the effect of infiltration, tritium plumes were compared for seven different infiltration rates. The effect of vapor diffusion was observed by comparing ${ }^{3} \mathrm{H}$ plumes generated with and without vapor diffusion at different infiltration rates. Vapor diffusion was modeled using the Millington (1959) formulation. The simulation runs were done using soil properties of a stochastic realization identified as Realization A.

\subsubsection{Effect of Infiltration}

We found that the impact of the ${ }^{3} \mathrm{H}$ release on groundwater quality increases strongly with infiltration rate. We conducted seven simulation runs with different infiltration rates to 
examine the effect of infiltration on the behavior of ${ }^{3} \mathrm{H}$ in the subsurface. We specified infiltration rates of $0.0,0.2,0.5,1.0,2.0,3.0$, and $5.0 \mathrm{in} / \mathrm{yr}$. The model is similar to the one used in the Monte Carlo analysis. The ${ }^{3} \mathrm{H}$ release rate is $0.2 \mathrm{Ci} / \mathrm{yr}$ applied over the first 5 yr as tritiated water at a concentration of $4.46 \times 10^{8} \mathrm{pCi} / \mathrm{L}$. The simulation period is 100 yr.

Figure 7.21 shows the history of peak groundwater ${ }^{3} \mathrm{H}$ concentration for different infiltration rates. Higher infiltration rates cause higher peak ${ }^{3} \mathrm{H}$ concentrations, and the higher concentrations occur at earlier times. For an infiltration rate of $5.0 \mathrm{in} / \mathrm{yr}$ the maximum groundwater ${ }^{3} \mathrm{H}$ concentration is $1.86 \times 10^{7} \mathrm{pCi} / \mathrm{L}, 4.2 \%$ of the source concentration. This maximum occurs at about 15 yr. For an infiltration rate of $2.0 \mathrm{in} / \mathrm{yr}_{\mathrm{r}}$ the maximum groundwater concentration is $1.81 \times 10^{6}, 0.41 \%$ of the source concentration, and the maximum occurs at about $20 \mathrm{yr}$. A $60 \%$ reduction in the infiltration rate from $5.0 \mathrm{in} / \mathrm{yr}$ to $2.0 \mathrm{in} / \mathrm{yr}$ causes an order of magnitude decrease in the maximum groundwater concentration. For an infiltration rate of $0.5 \mathrm{in} / \mathrm{yr}$ the maximum groundwater concentration is $6.58 \times 10^{3} \mathrm{pCi} / \mathrm{L}$, about 5 orders of magnitude less than the source concentration. For lower infiltration rates, there is essentially no impact on groundwater quality.

Figures 7.22 further demonstrates the strong impact of higher infiltration rates on groundwater quality. Figure 7.22 shows the history of total ${ }^{3} \mathrm{H}$ activity in the groundwater. For higher infiltration rates, the maximum groundwater activity is higher and occurs earlier. For an infiltration rate of $5.0 \mathrm{in} / \mathrm{yr}$ the maximum groundwater ${ }^{3} \mathrm{H}$ activity is $200 \mathrm{mCi}$, and for an infiltration rate of $1.0 \mathrm{in} / \mathrm{yr}$ the maximum activity is reduced to just $3 \mathrm{mCi}$. For infiltration rates of $0.5 \mathrm{in} / \mathrm{yr}$ and lower, total groundwater ${ }^{3} \mathrm{H}$ activity never exceeds 0.2 $\mathrm{mCi}$.

Figure 7.23 shows the effect of infiltration rate on movement of the plume's center of 


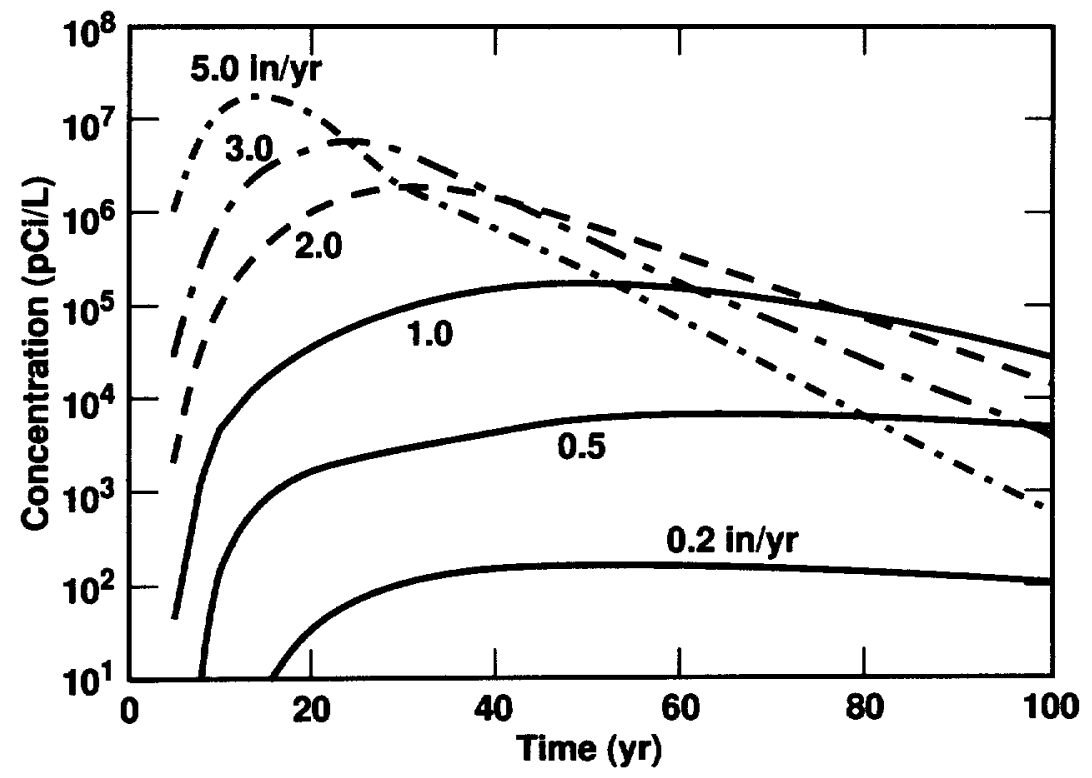

Figure 7.21: Peak groundwater ${ }^{3} \mathrm{H}$ concentration histories for various infiltration rates.

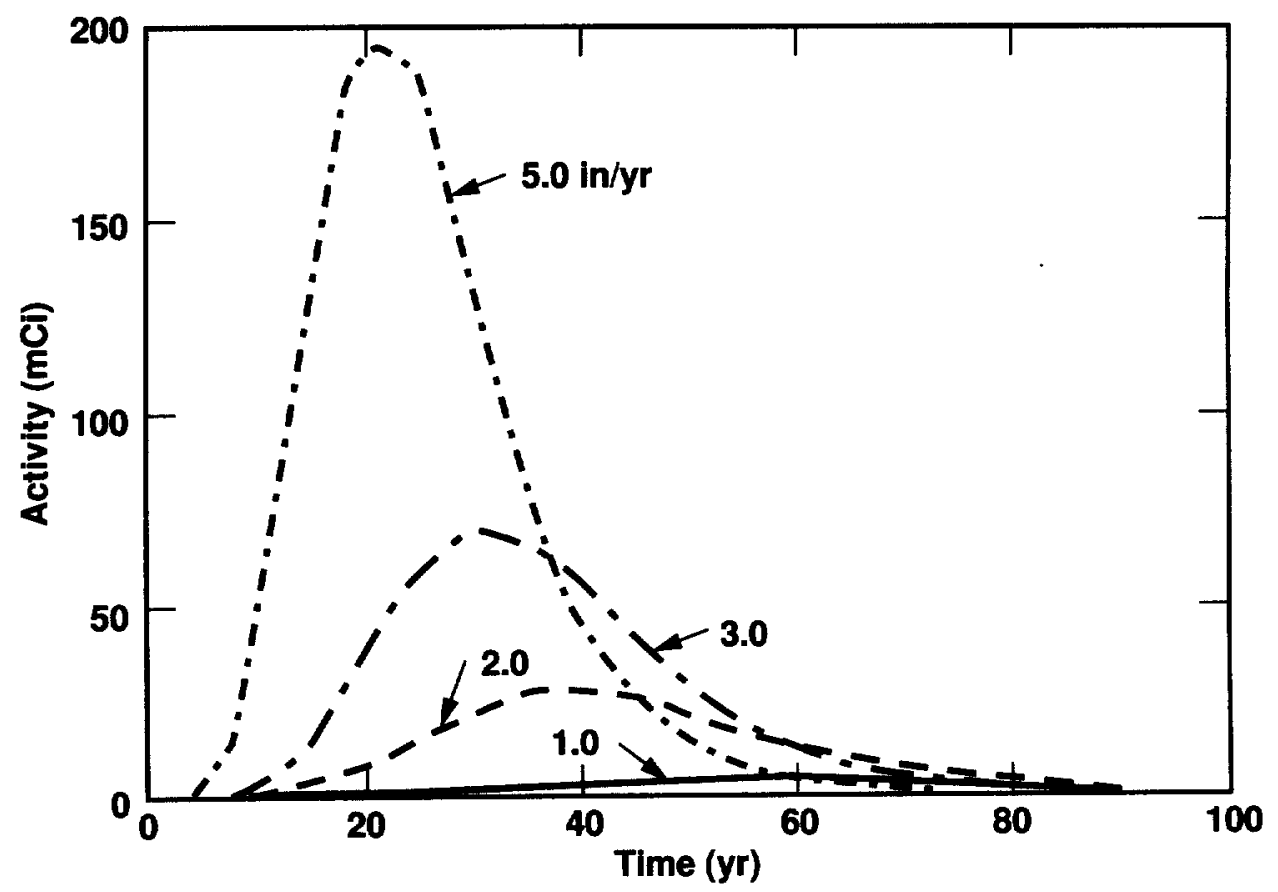

Figure 7.22: Histories of total groundwater ${ }^{3} \mathrm{H}$ activity for various infiltration rates. 


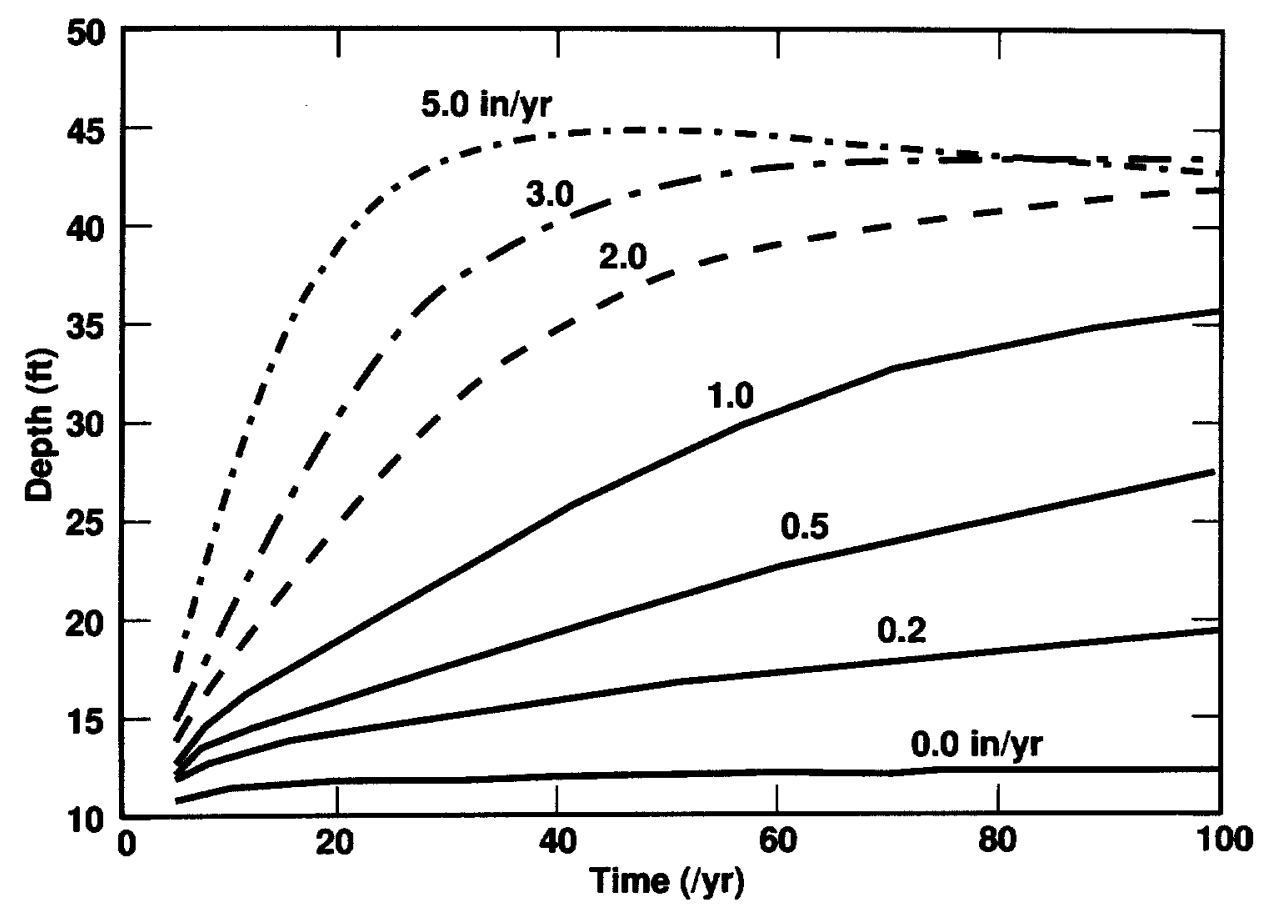

Figure 7.23: Histories of the plume's center-of-mass depth for various infiltration rates.

mass in the vadose zone, and Figure 7.24 shows the effect of infiltration rate on lateral spreading of the plume in the vadose zone. For higher infiltration rates, the center of mass approaches the water table faster, and greater lateral spreading occurs in the vadose zone.

The results show a strong relationship between infiltration rate and ambient liquid saturation profile. Figure 7.25 shows the steady-state liquid saturation profile through the leak node for four infiltration rates. Liquid saturation at every depth between the ground surface and the water table increases with infiltration rate. The saturations vary substantially, ranging from a low of $15 \%$ in the coarse-grained sands and gravels, to a high of nearly full saturation in the clays. Figure 7.26 , which compares the liquid saturation profile for $2.0 \mathrm{in} / \mathrm{yr}$ with the permeability profile, indicates that the saturation is dominated by soil type and not by elevation. Higher liquid saturation correlates with lower permeability and lower liquid saturation correlates with higher permeability.

The liquid saturation profiles of Figure 7.25 seem to be in general agreement with results 


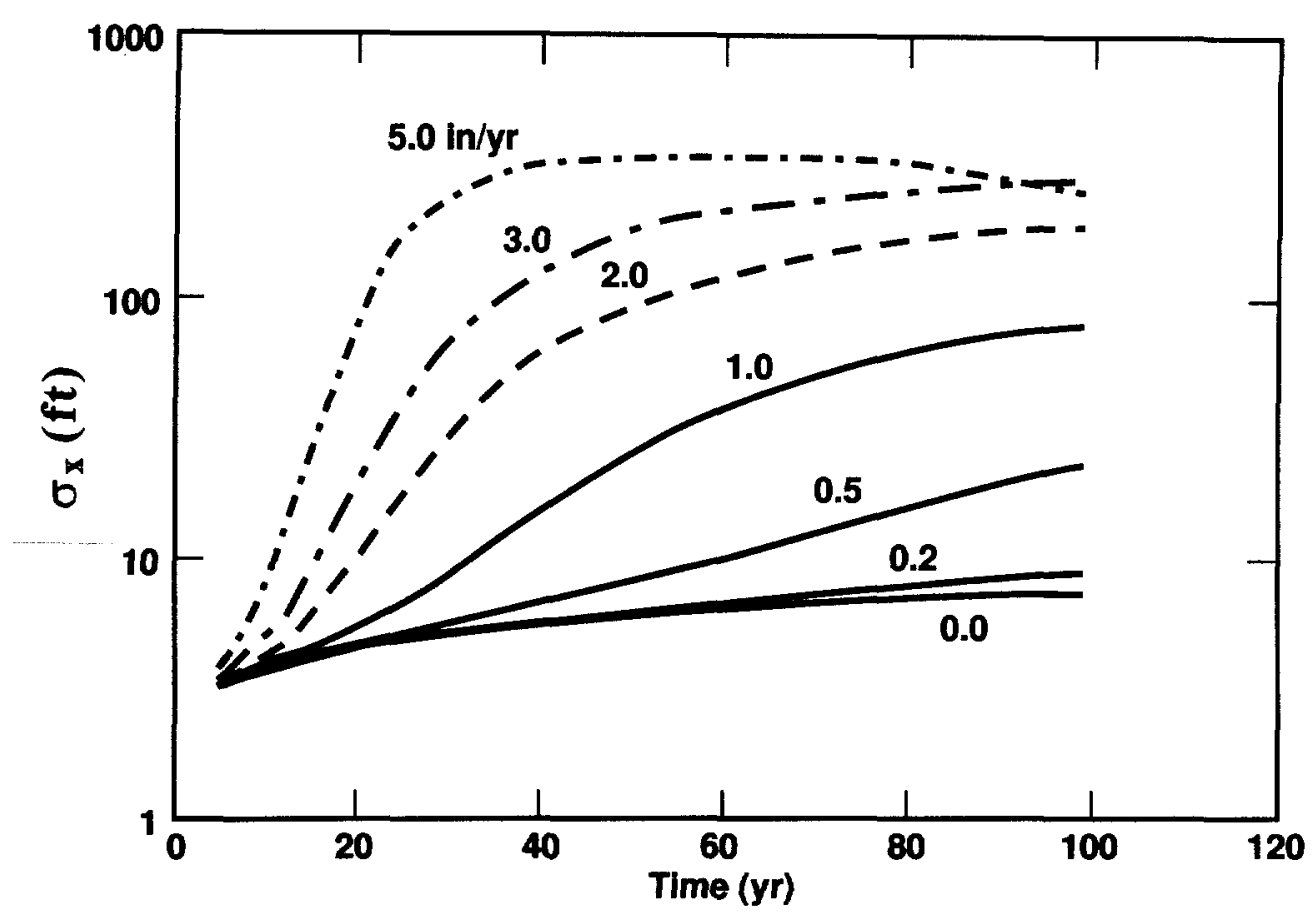

Figure 7.24: Histories of the ${ }^{3} \mathrm{H}$ plume's spreading parameter, $\sigma_{x}$, for various infiltration rates.

of neutron probe field measurements in the Building 292 Area (Mallon, 1995). Figure 7.27 shows neutron-count profiles for Boreholes 17, 18, and 19, measured in November 1991. The figure also gives lithologic descriptions for Boreholes 17 and 19. The count, which is directly proportional to volumetric water content, is higher for clays and lower for sands and gravels. The count also displays no general trend with depth.

\subsubsection{Effect of Vapor Diffusion}

We found that vapor diffusion has virtually no impact on groundwater quality and only a very limited impact on soil water concentrations in the vadose zone. To study the effect of vapor diffusion on groundwater quality, we turned off vapor diffusion and repeated the 7 simulation runs conducted to investigate the effect of infiltration. With the results of these 14 runs we are able to observe the effect of vapor diffusion on ${ }^{3} \mathrm{H}$ transport at different 


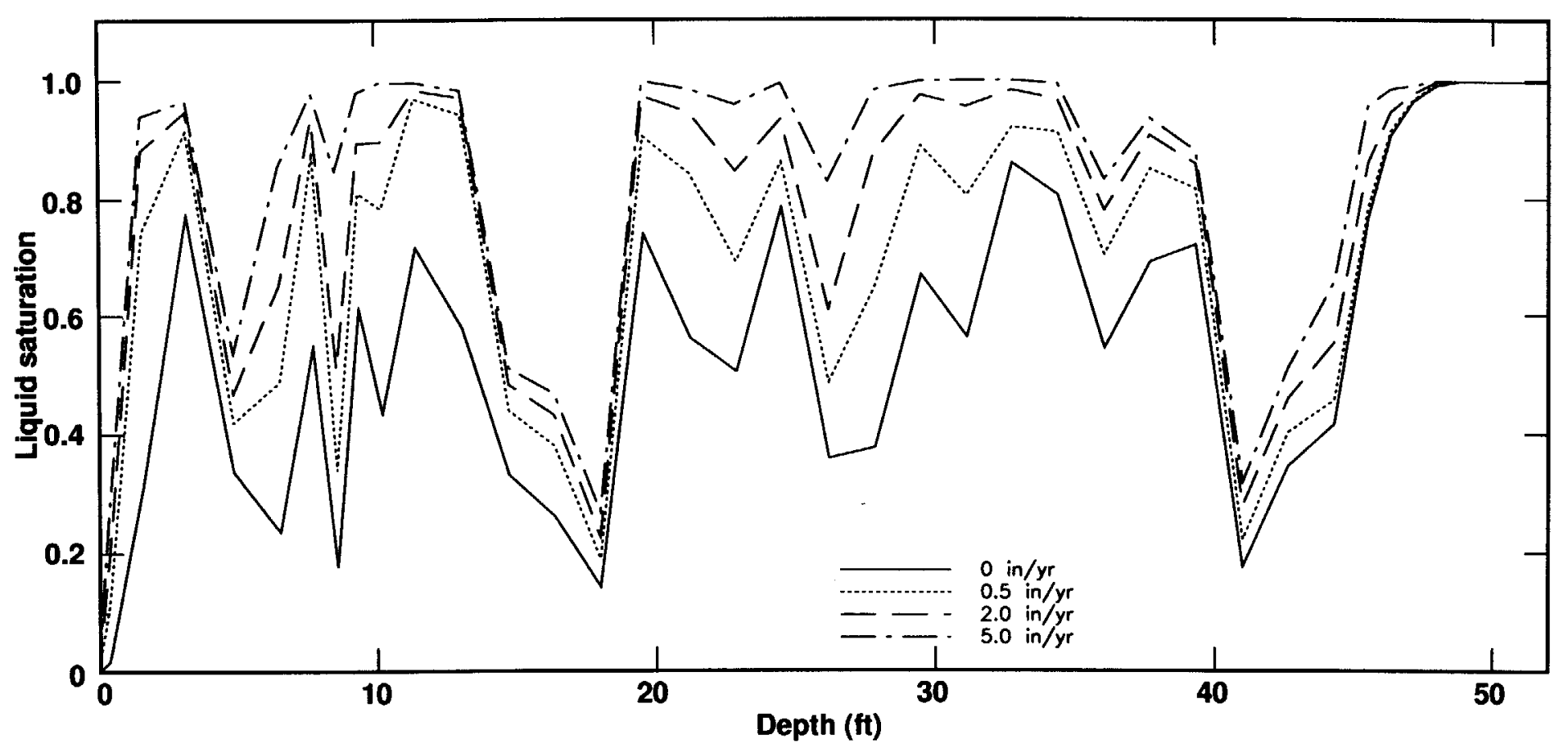

Figure 7.25: Steady-state liquid saturation profile through the leak node for four different infiltration rates. 


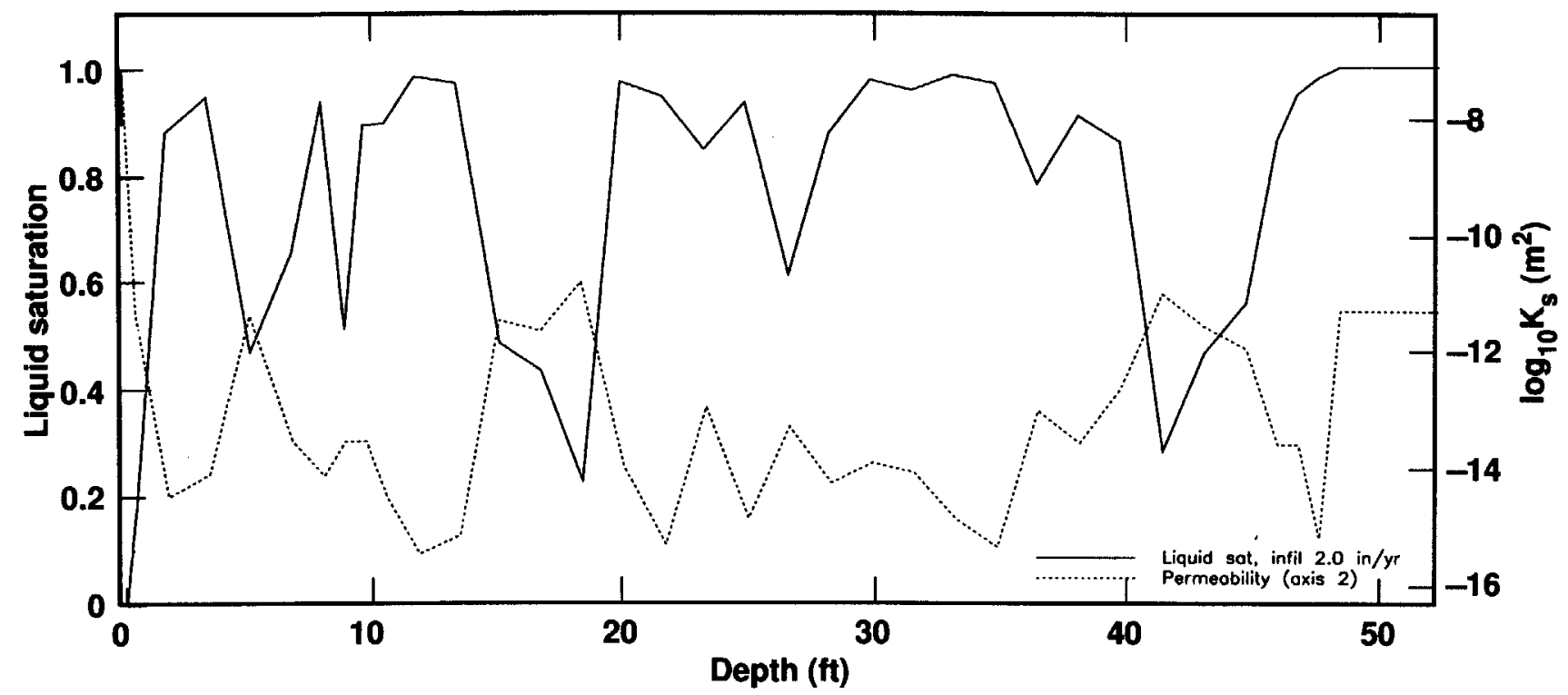

Figure 7.26: Relationship between vertical liquid saturation and permeability profiles through leak node. Liquid saturation profile shown for an infiltration rate of $2.0 \mathrm{in} / \mathrm{yr}$. 


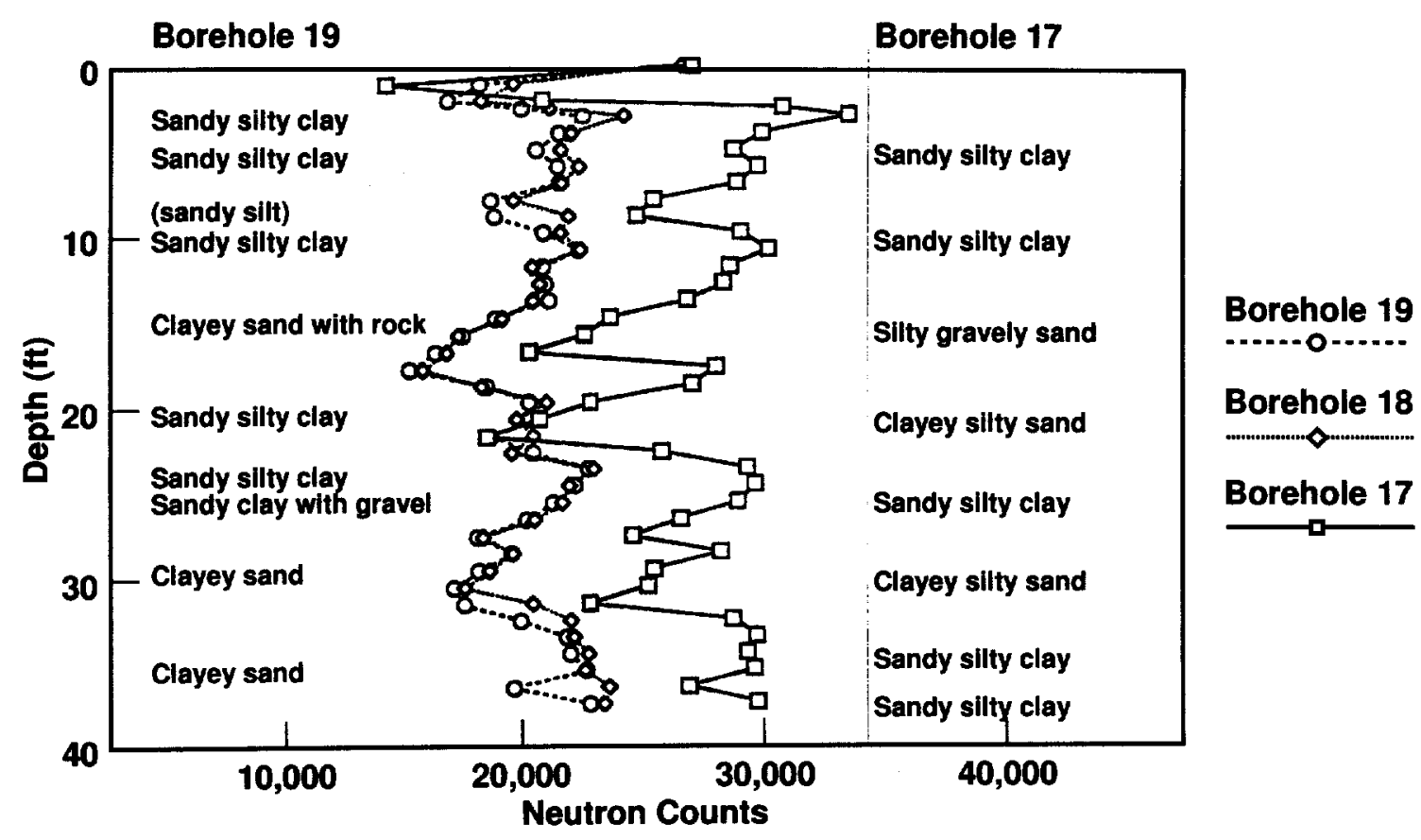

Figure 7.27: Results of neutron probe field measurements of water content profiles in Boreholes 17, 18, and 19, conducted in November 1991. Lithologic descriptions shown for Boreholes 17 and 19 obtained from analysis of core samples. (After Mallon, 1995). 


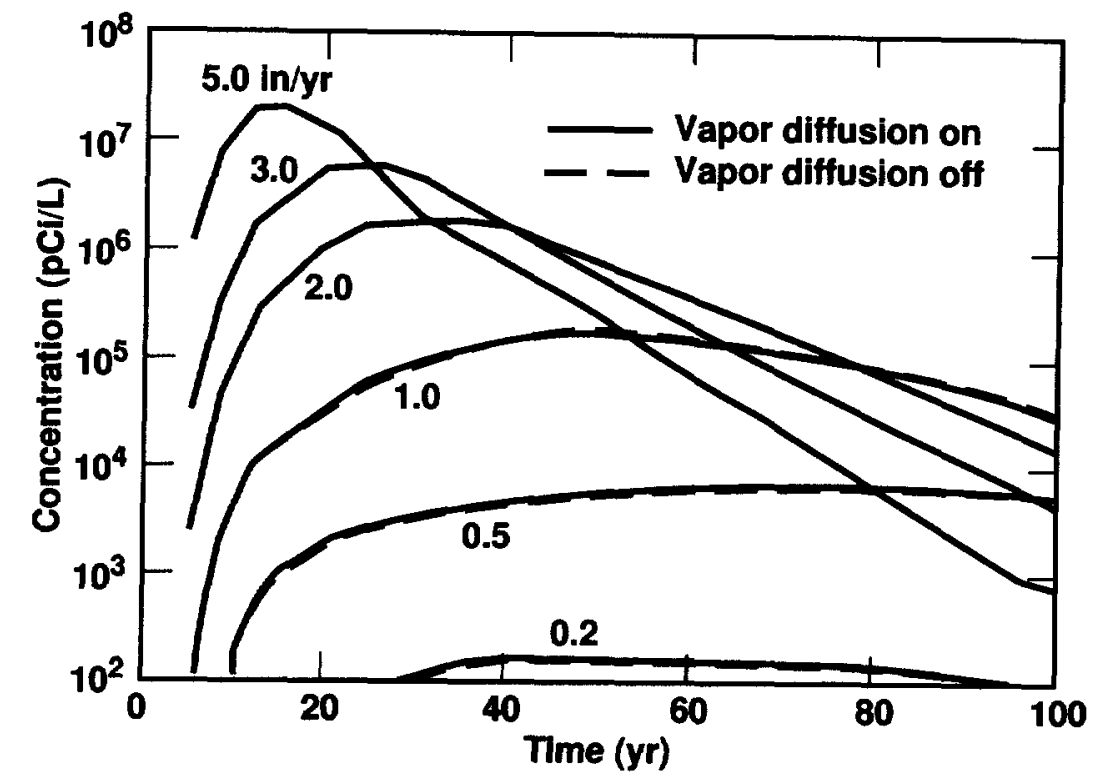

Figure 7.28: Effect of vapor diffusion on peak groundwater ${ }^{3} \mathrm{H}$ concentration history for various infiltration rates.

infiltration rates.

Figure 7.28 compares peak groundwater ${ }^{3} \mathrm{H}$ concentration histories with and without vapor diffusion, at various infiltration rates. For infiltration rates of $2.0 \mathrm{in} / \mathrm{yr}$ and higher, no detectable differences in groundwater concentrations are observed with and without vapor diffusion. For lower infiltration rates (when the impact of the release on the groundwater is insignificant), very small differences are just barely detectable. Figure 7.29 compares total groundwater ${ }^{3} \mathrm{H}$ activity histories with and without vapor diffusion, at various infiltration rates. Again, the results with vapor diffusion on and off appear identical for infiltration rates of $2.0 \mathrm{in} / \mathrm{yr}$ and above, and only minor differences are observed for lower infiltration rates.

The effect of vapor diffusion on ${ }^{3} \mathrm{H}$ concentrations in the vadose zone is also very small. In Figures $7.30,7.31$, and 7.32 , soil water ${ }^{3} \mathrm{H}$ concentrations along horizontal lines, with 


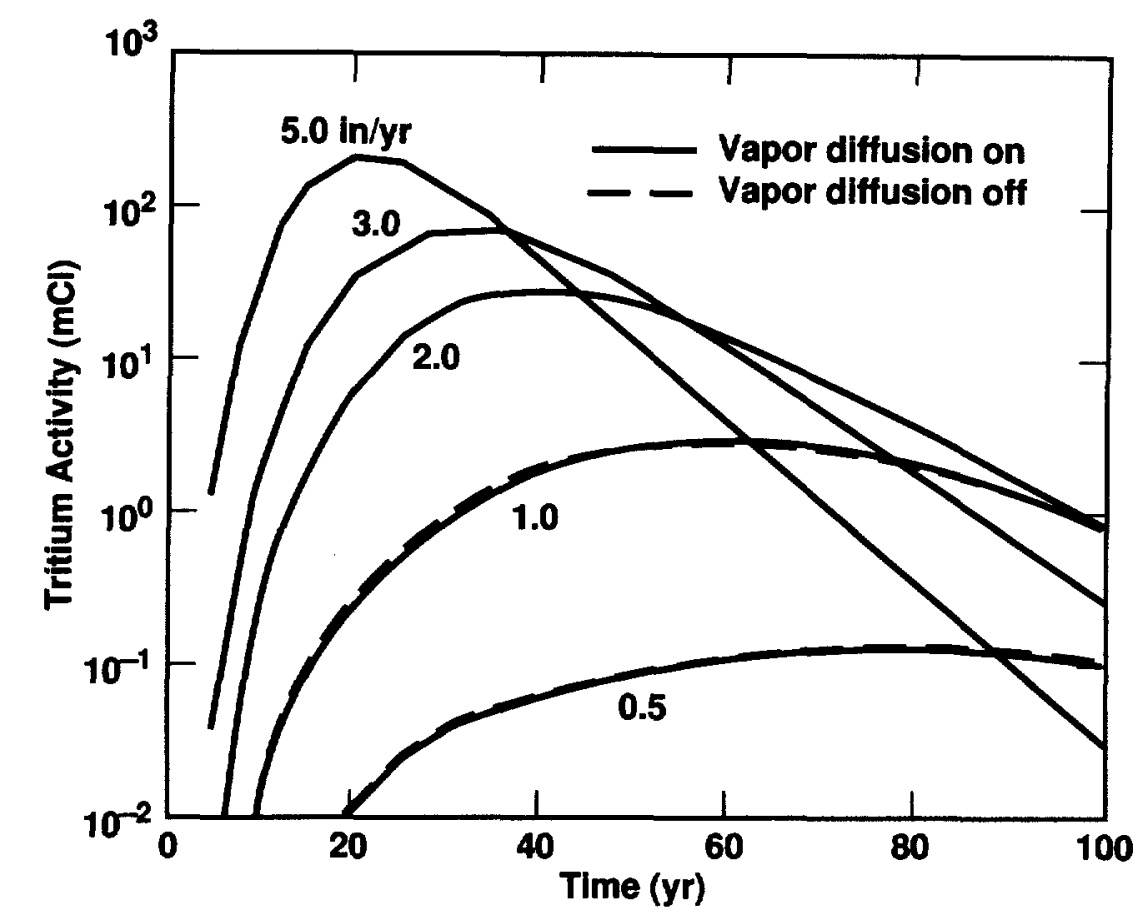

Figure 7.29: Effect of vapor diffusion on groundwater ${ }^{3} \mathrm{H}$ activity history for various infiltration rates.

and without vapor diffusion, are compared for different infiltration rates and times. The infiltration rates are $0.0,1.0$, and $5.0 \mathrm{in} / \mathrm{yr}$. For each of these infiltration rates, profiles are shown at 20,40,60, and $80 \mathrm{yr}$. Only minor differences in ${ }^{3} \mathrm{H}$ concentrations are observed between the two cases, with and without vapor diffusion. The differences are larger at lower infiltration rates, due to higher diffusion at higher gas phase saturation, and at later times, due to the additional time available for vapor diffusion to occur. The effect of vapor diffusion on plume dispersion in the vadose zone, for different infiltration rates, is shown in figure 7.33. The figure compares histories of the horizontal dispersion parameter, $\sigma_{x}$, for different infiltration rates. The results indicate that the vapor diffusion process does not significantly increase spreading of the ${ }^{3} \mathrm{H}$ plume in the vadose zone.

An analysis of the equations that describe vapor diffusion in porous media confirms the very low impact of the process on ${ }^{3} \mathrm{H}$ transport. From the mathematical model presented 


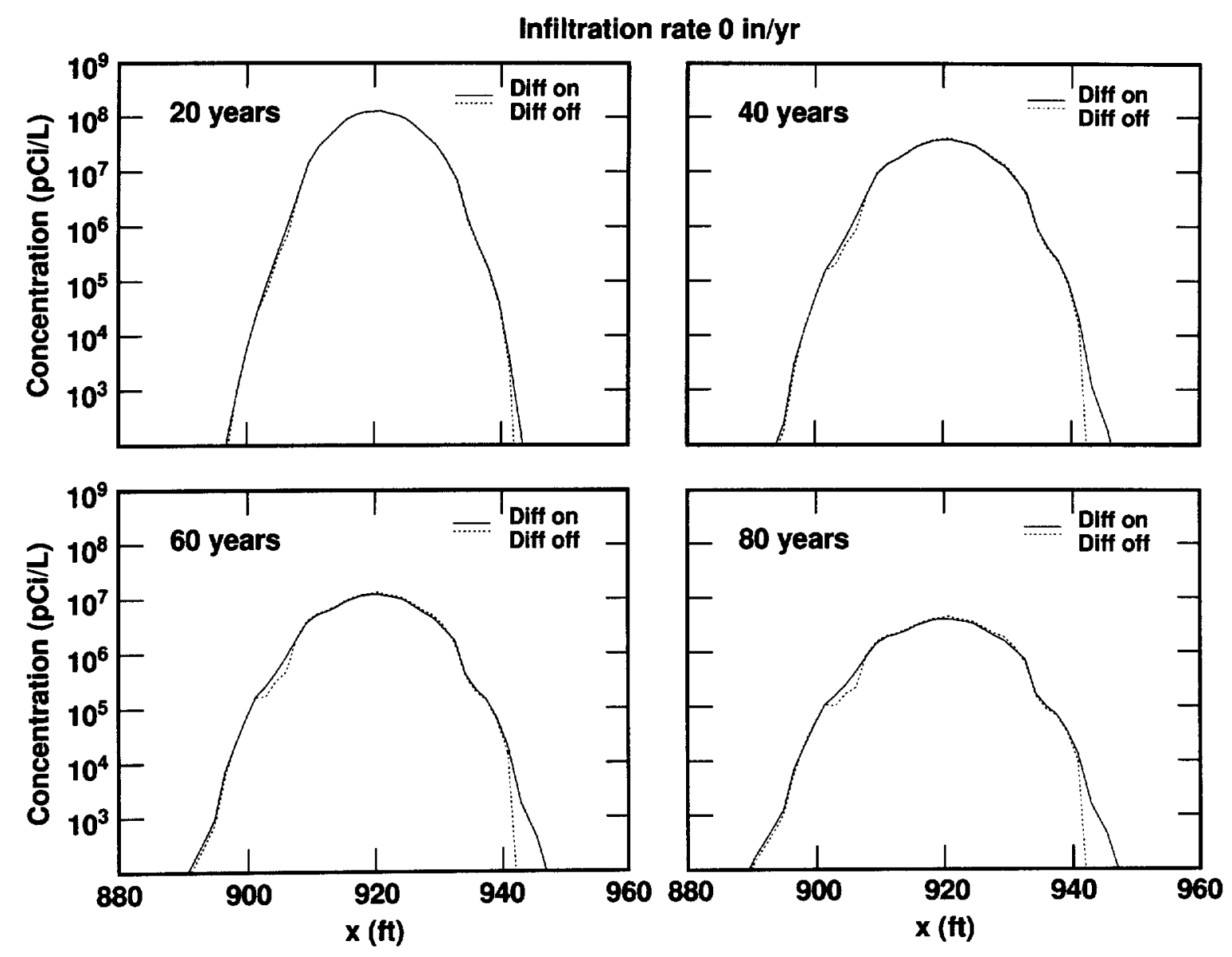

Figure 7.30: Effect of vapor diffusion on soil water ${ }^{3} \mathrm{H}$ concentration for an infiltration rate of $0.0 \mathrm{in} / \mathrm{yr}$. Concentrations are shown along a horizontal line through the depth of plume's center-of-mass at $20 \mathrm{yr}$. 


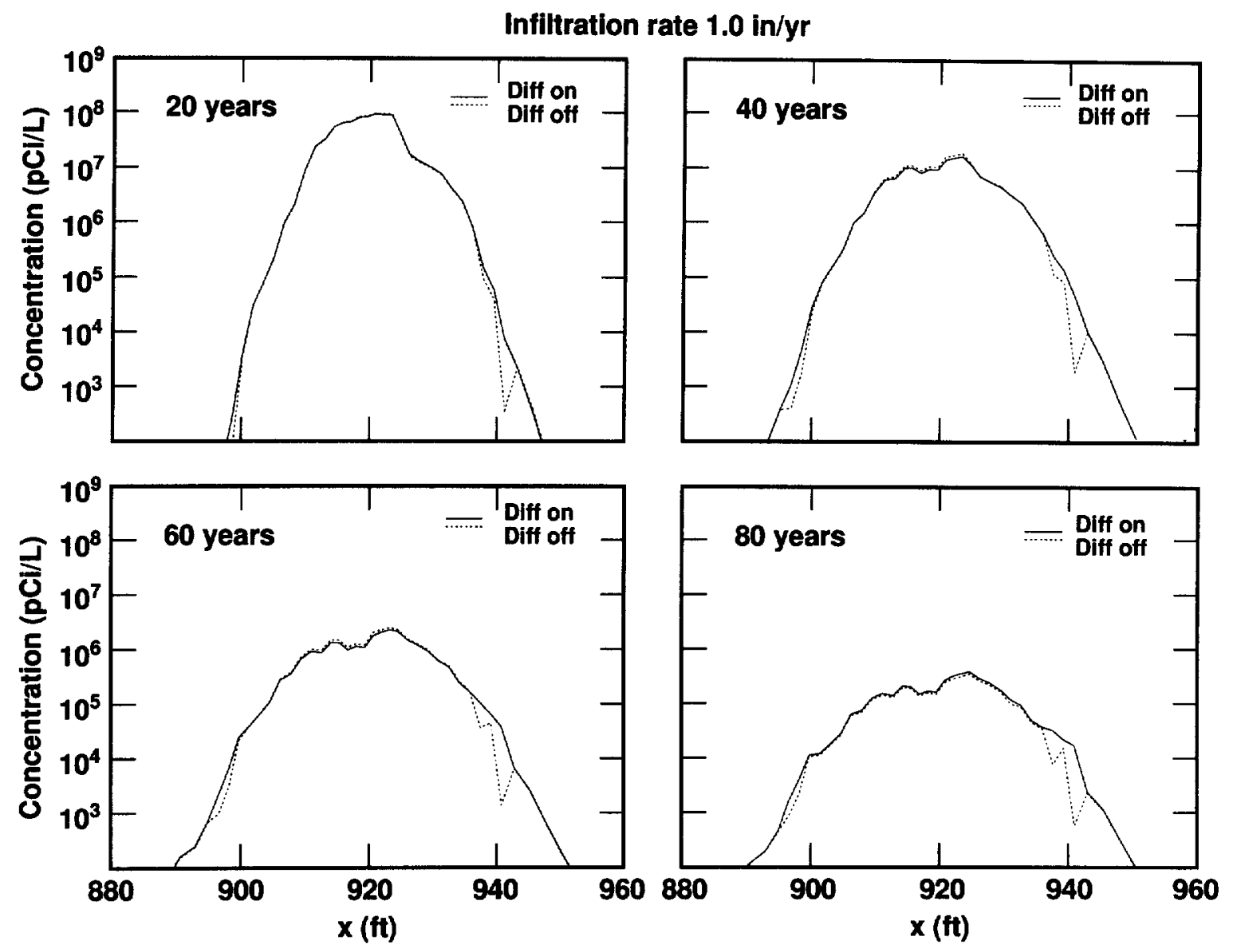

Figure 7.31: Effect of vapor diffusion on soil water ${ }^{3} \mathrm{H}$ concentration for an infiltration rate of $1.0 \mathrm{in} / \mathrm{yr}$. Concentrations are shown along a horizontal line through the depth of plume's center-of-mass at $20 \mathrm{yr}$. 


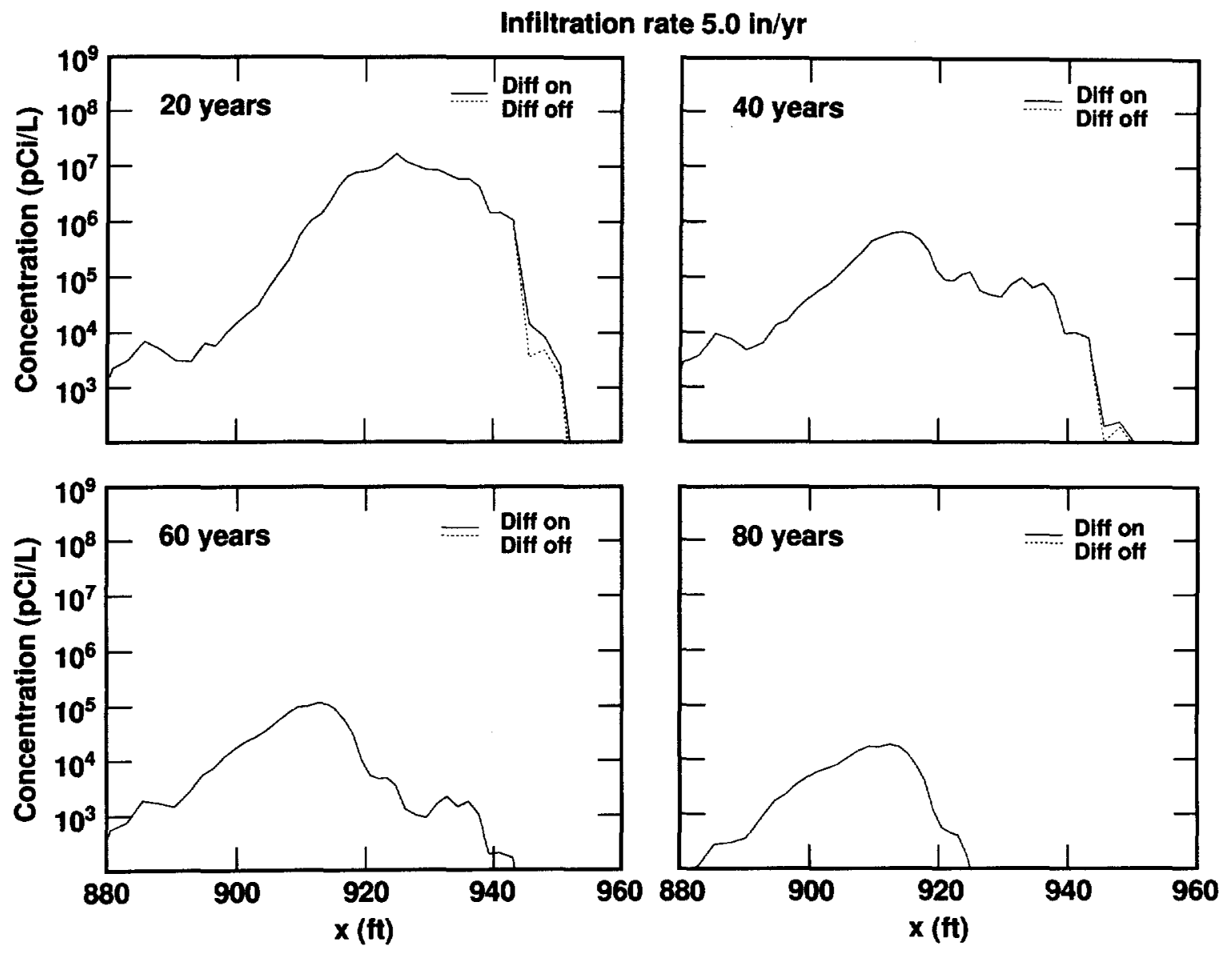

Figure 7.32: Effect of vapor diffusion on soil water ${ }^{3} \mathrm{H}$ concentration for an infiltration rate of $5.0 \mathrm{in} / \mathrm{yr}$. Concentrations are shown along a horizontal line through the depth of plume's center-of-mass at $20 \mathrm{yr}$. 


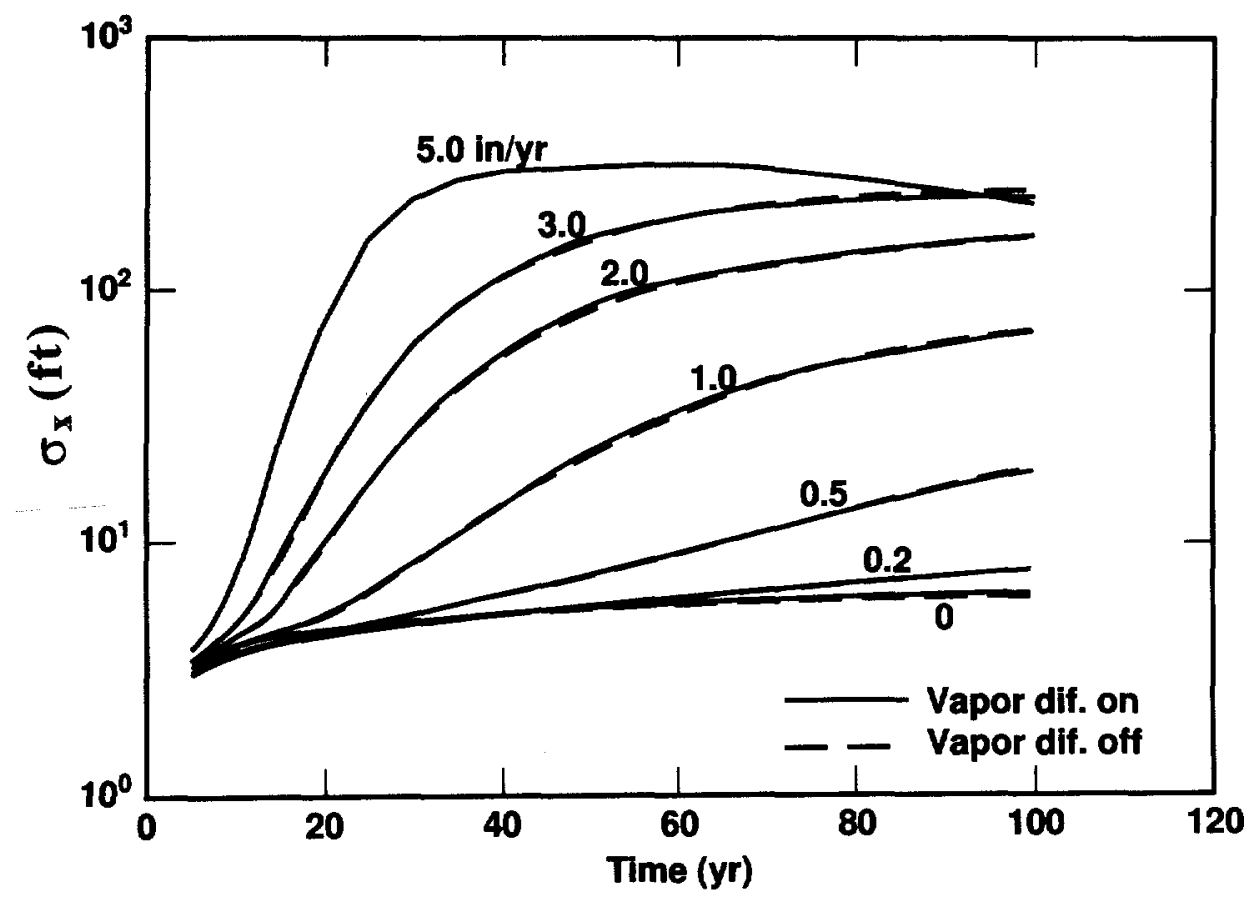

Figure 7.33: Effect of vapor diffusion on Histories of the horizontal plume dispersion parameter, $\sigma_{x}$, for various infiltration rates.

in Chapter 6, the diffusive flux of component $\gamma$ in phase $\alpha$, expressed per unit area of bulk soil, is given by

$$
J_{\alpha}^{* \gamma}=-\rho_{\alpha} \phi S_{\alpha} \tau_{\alpha} D_{\alpha}^{* \gamma} \nabla \omega_{\alpha}^{\gamma}
$$

where the variables are:

$\rho_{\alpha} \quad$ mass density of the $\alpha$ phase

$\phi \quad$ soil porosity

$S_{\alpha} \quad \alpha$ phase saturation

$\tau_{\alpha}^{\gamma} \quad$ tortuosity of $\gamma$ component in $\alpha$ phase

$D_{\alpha}^{* \gamma}$ free phase molecular diffusion coefficient for $\gamma$ in the $\alpha$ phase

$\omega_{\alpha}^{\gamma} \quad$ mass fraction of $\gamma$ in the $\alpha$ phase.

We use the Millington (1959) formulation to estimate tortuosity for diffusion in a porous medium:

$$
\tau_{\alpha}=S_{\alpha}^{7 / 3} \phi^{1 / 3}
$$


Table 7.3: Estimate of time required for various relative mass fractions of HTO to reach a distance of $10 \mathrm{ft}$ from the source by vapor diffusion. Estimates made by assuming onedimensional diffusion, $\phi=0.35$, and $S_{l}=0.75$.

\begin{tabular}{c|c}
\hline \hline$\omega_{g}^{\gamma} / \omega_{g, 0}^{\gamma}$ & Time $(\mathrm{yr})$ \\
\hline $2.0 \mathrm{e}-5$ & 120 \\
$1.0 \mathrm{e}-4$ & 140 \\
$1.0 \mathrm{e}-3$ & 200 \\
$1.0 \mathrm{e}-2$ & 330 \\
$1.0 \mathrm{e}-1$ & 800 \\
\hline
\end{tabular}

The differential equation that describes binary diffusion in one-dimension is Fick's second law:

$$
\frac{\partial \omega_{\alpha}^{\gamma}}{\partial t}=-\tau_{\alpha} D_{\alpha}^{* \gamma} \frac{\partial^{2} \omega_{\alpha}^{\gamma}}{\partial x^{2}}
$$

Equation 7.10 can be solved using the analytical solution of Crank (1956):

$$
\omega_{\alpha}^{\gamma}=\omega_{\alpha, 0}^{\gamma} \operatorname{erfc}\left(\frac{x}{2 \sqrt{D_{e} t}}\right)
$$

where $\omega_{\alpha, 0}^{\gamma}$ is the initial mass fraction of the $\gamma$ component in the $\alpha$ phase, erfc is the complementary error function, and $\mathrm{D}_{e}$ is an effective diffusion coefficient given by

$$
D_{e}=\tau_{\alpha} D_{\alpha}^{* \gamma}
$$

Typical values of the variables $\phi, \mathrm{S}_{\alpha}, \tau_{\alpha}^{\gamma}$, and $D_{g}^{* \gamma}$ for vapor diffusion $(\alpha=g)$ of HTO under site conditions are:

$$
\begin{array}{ll}
\phi & 0.35 \\
S_{g} & 0.25 \\
\tau_{g}^{\gamma} & .028(\text { Calculated from Equation } 7.9) \\
D_{g}^{* \gamma} & 2.4 \times 10^{-9} \mathrm{~m}^{2} / \mathrm{s} .
\end{array}
$$

With the above values, $\mathrm{D}_{e}$ is $6.7 \times 10^{-11} \mathrm{~m}^{2} / \mathrm{s}$, equal to $2.1 \times 10^{-3} \mathrm{~m}^{2} / \mathrm{yr}$.

Table 7.3, computed using Equation 7.11 for one-dimensional diffusion, illustrates the slowness of vapor diffusion in ${ }^{3} \mathrm{H}$ transport under the current site conditions. 
The table shows times required for different relative mass fractions, $\omega_{g}^{\gamma} / \omega_{g, 0}^{\gamma}$, to reach a distance of $10 \mathrm{ft}$ from the source, with vapor diffusion being the only active transport process. Because the tortuosity factor varies as the $7 / 3$ power of gas saturation, the rate of vapor diffusion in the vadose zone is very sensitive to changes in fluid saturation. If the gas phase saturation increases from $25 \%$ to $75 \%$, for example, $\tau_{g}$ increases from .028 to 0.36 , and the time for a point $10 \mathrm{ft}$ from the source to reach a relative HTO mass fraction of $2.2 \times 10^{-5}$ is reduced from $120 \mathrm{yr}$ to $9 \mathrm{yr}$. This estimate assumes a constant concentration source, zero initial concentration, and a semi-infinite domain. 


\section{Three-Dimensional Analysis}

\subsection{Introduction}

In this chapter we present the results of three-dimensional simulation runs that incorporate details of site features that could not be included in the two-dimensional runs presented earlier in Chapter 7. The goal is to use available data to perform fully three-dimensional transport simulation runs on a number of different realizations of soil property fields obtained by stochastic simulation, and on a field derived by kriging, in order to analyze the results to gain information on the impact of the ${ }^{3} \mathrm{H}$ release on future groundwater quality at the site. We generate 10 realizations by conditional simulation and prepare input files for the NUFT code using the techniques and procedures described in Chapters 4 and 7 . Results of numerical calculations using soil properties derived by conditional simulation are compared with results using properties from kriging.

We also examine the effect that variability in the van Genuchten parameters has on numerical transport calculations. We examine this effect by conducting 10 simulation runs using the same permeability field derived by kriging, but with different van Genuchten parameters.

\subsection{Summary of Results}

Following is a summary of the major results presented in this chapter:

- The ${ }^{3} \mathrm{H}$ release poses no serious long term threat to groundwater quality at the site. For $\mathrm{rl3d} 110$, the realization that showed the highest groundwater ${ }^{3} \mathrm{H}$ concentrations, the maximum concentration $100 \mathrm{ft}$ downstream of the leak was below the groundwater standard, with dispersion included in the model. For rl3d108, the realization that produced a concentration field closest to the measured concentrations, the peak 
concentration $100 \mathrm{ft}$ downstream of the leak was $7.59 \times 10^{3} \mathrm{pCi} / \mathrm{L}$, only $30 \%$ of the groundwater standard.

- Groundwater ${ }^{3} \mathrm{H}$ concentrations in the immediate Building 292 Area are expected to exceed the $20,000 \mathrm{pCi} / \mathrm{L}$ standard from about Year 6 through Year 41, a period of $35 \mathrm{yr}$, based on calculations using the best-fit realization, rl3d108; however, the plume length should not exceed about $30 \mathrm{ft}$ and the width $6 \mathrm{ft}$, with the maximum concentration remaining almost directly below the leak.

- A major factor that contributes to the limited impact on groundwater quality is the low flux of ${ }^{3} \mathrm{H}$ entering the groundwater from the vadose zone; the 100 -yr cumulative flux is low for all realizations with the blacktop in place, averaging $5.2 \mathrm{mCi}$ with a maximum of $13.9 \mathrm{mCi}$.

- The impact of the release on groundwater quality is substantially reduced by the blacktop that partially covers the leak site.

- Numerical simulation runs that used soil permeability fields derived by kriging yield significantly lower groundwater ${ }^{3} \mathrm{H}$ concentrations than runs that used fields derived by conditional simulation; kriging under the present conditions yields nonconservative and potentially misleading results.

- Because of low flow velocities in the finer grained soils, high soil water ${ }^{3} \mathrm{H}$ concentrations, over $1.0 \times 10^{7}$, are expected to persist in the vadose zone for the next $50 \mathrm{yr}$ or so.

- Ten simulation runs conducted using different van Genuchten parameters, with the same permeability field derived by kriging, showed significant variability in groundwa- 
ter ${ }^{3} \mathrm{H}$ concentrations from run to run; however the maximum concentrations remained very low and never exceeded the $20,000 \mathrm{pCi} / \mathrm{L}$ groundwater standard.

\subsection{Method of Analysis}

For the the 3D analysis, we adopt an approach similar to the one described in Chapter 7 for the $2 \mathrm{D}$ analysis. A number of the codes developed for application in the $2 \mathrm{D}$ analysis were modified and reused here. Code executions are controlled by a Unix shell script that reads the permeability sample data file, generates a realization of the permeability field, prepares a NUFT input file, and executes the NUFT code. From the NUFT output files, the script also extracts some key parameters that describe the transport behavior of ${ }^{3} \mathrm{H}$ in the subsurface. The parameters extracted include water table plume arrival time, peak ${ }^{3} \mathrm{H}$ concentrations in the groundwater and the vadose zone, center-of-mass location of the plume, total ${ }^{3} \mathrm{H}$ activity remaining in the vadose zone and groundwater, and plume geometry parameters.

Tasks performed by the shell script are listed as follows:

- Read an input data file containing sample permeabilities and three-dimensional location coordinates, and a parameter file that defines the permeability sample variogram, and perform ordinary kriging to estimate a full 3D permeability field.

- Apply the turning bands technique (Tompson et al., 1989) to perform nonconditional simulation of the permeability field, again using the sample data and the variogram.

- Apply the conditioning technique (e.g., Deutsch and Journel, 1992) described back in Chapter 4 to generate a realization of the field, honoring data values at their measurement locations.

- Overlay the NUFT 3D grid by the 3D kriging and conditional simulation grid and assign to each NUFT node the permeability of the nearest kriging node; assignment 
of permeabilities is implemented in the code $n f g s 3 d$.

- Assign other unsaturated hydraulic soil properties (i.e. van Genuchten parameters and $\phi$ ) based on soil property correlations with permeability and other data statistics, as described in Chapter 4.

- Generate a NUFT input file that identifies the soil type of each node and describes hydraulic properties for the various soil types.

- Run NUFT for the new realization of soil properties.

- Extract plume statistics parameters from NUFT output files.

The first step, kriging on the permeability sample data, had to be performed only once because the same kriged field is used with each new field from the turning bands simulation to generate a new field by conditional simulation. More details of the steps listed above were presented back in Chapter 4 .

\subsection{Description of the 3D Model}

In an effort to reduce the computational burden, the area selected for kriging and conditional simulation was limited to $100 \times 100 \mathrm{ft}$ square in plan. The area is bounded on the west and east by LLNL coordinates E8602 and E8701, and on the south and north by N12730 and $\mathrm{N} 12829$. The lower boundary is at elevation $538 \mathrm{ft}$ and the upper boundary at elevation $587 \mathrm{ft}$. Tank R1U1 is located close to the center of the square. The suspected leak location, on the north face of the tank, has LLNL coordinates E8652, N12780, and is at elevation $577 \mathrm{ft}$. Although the NUFT grid extends well beyond the square, no significant vadose zone transport occurs outside of the perimeter. Therefore, for vadose zone nodes outside of the perimeter, we use a uniform permeability approximately equal to the median value from the sample data histogram. 
The GSLIB 3D ordinary kriging program, ktb3dm (Deutsch and Journel, 1992), was used to perform ordinary kriging with 132 permeability data points and the sample variogram presented in Chapter 4. A uniform one-foot grid spacing was used in all three principal directions, giving 100 blocks in the x-direction (East-West), 100 blocks in the $\mathrm{y}$-direction (North-South) and 50 blocks in the z-direction, for a total of 500,000 blocks.

For the nonconditional simulation, we incorporate anisotropy in spatial variability by coordinate transformation, because the turning bands model of Tompson et al. (1989) handles only isotropic fields. Recall that the variograms presented back in Chapter 4 showed anisotropy, with the horizontal range about three times as large as the vertical range. To effect the transformation for equal grid dimensions in the $x, y$, and $z$ directions, we use a vertical to horizontal grid size ratio equal to the ratio of the horizontal to vertical variogram range before conducting the simulation. On completion of the simulation, the grid is retransformed back to equal dimensions in the three principal directions.

\subsubsection{Realizations of Permeability Field}

Figure 8.1 shows images of an east-west section through the 3D permeability field generated by ordinary kriging and each of the 10 realizations of the $3 \mathrm{D}$ permeability field generated by conditional simulation. The displayed section runs along N12780, and contains the suspected leak point at E8652 and elevation $577 \mathrm{ft}$. Borehole 1 was located about $1 \mathrm{ft}$ north of this section at E8655.4.

The stochastic images reveal substantial differences between the various realizations. However, a common feature of all the stochastic images is high spatial variability throughout each section. In contrast, the section through the field generated by kriging shows high variability close to Borehole 1 , but significant smoothing away from the borehole. The 

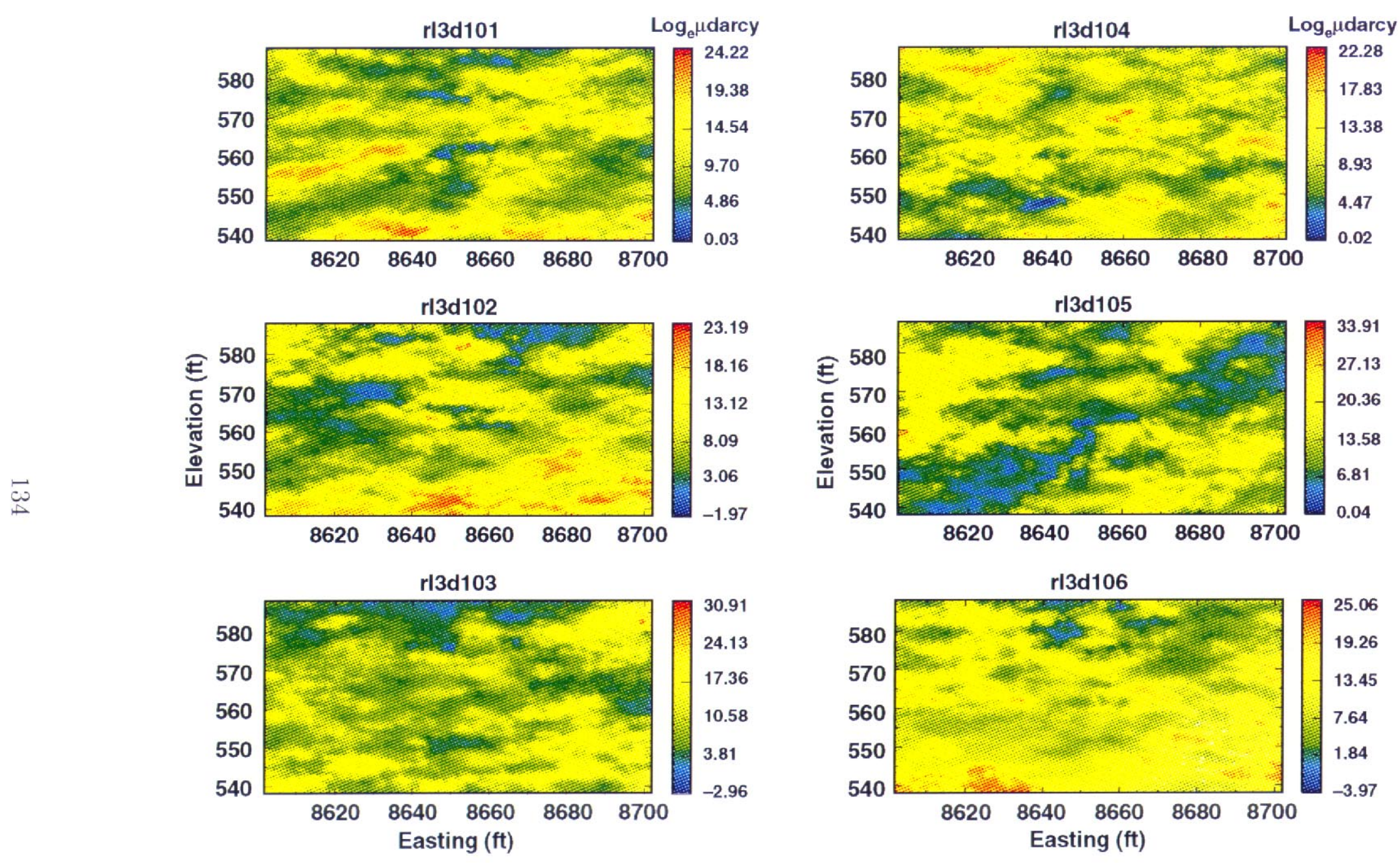

Figure 8.1a: Images of an east-west section through the 3D permeabililty field generated by kriging and each of the ten realizations of the field generated by conditional simulation. This figure shows images for realizations rl3d101 through rl3d106. The section passes through the suspected leak point at E8652, N12780. 

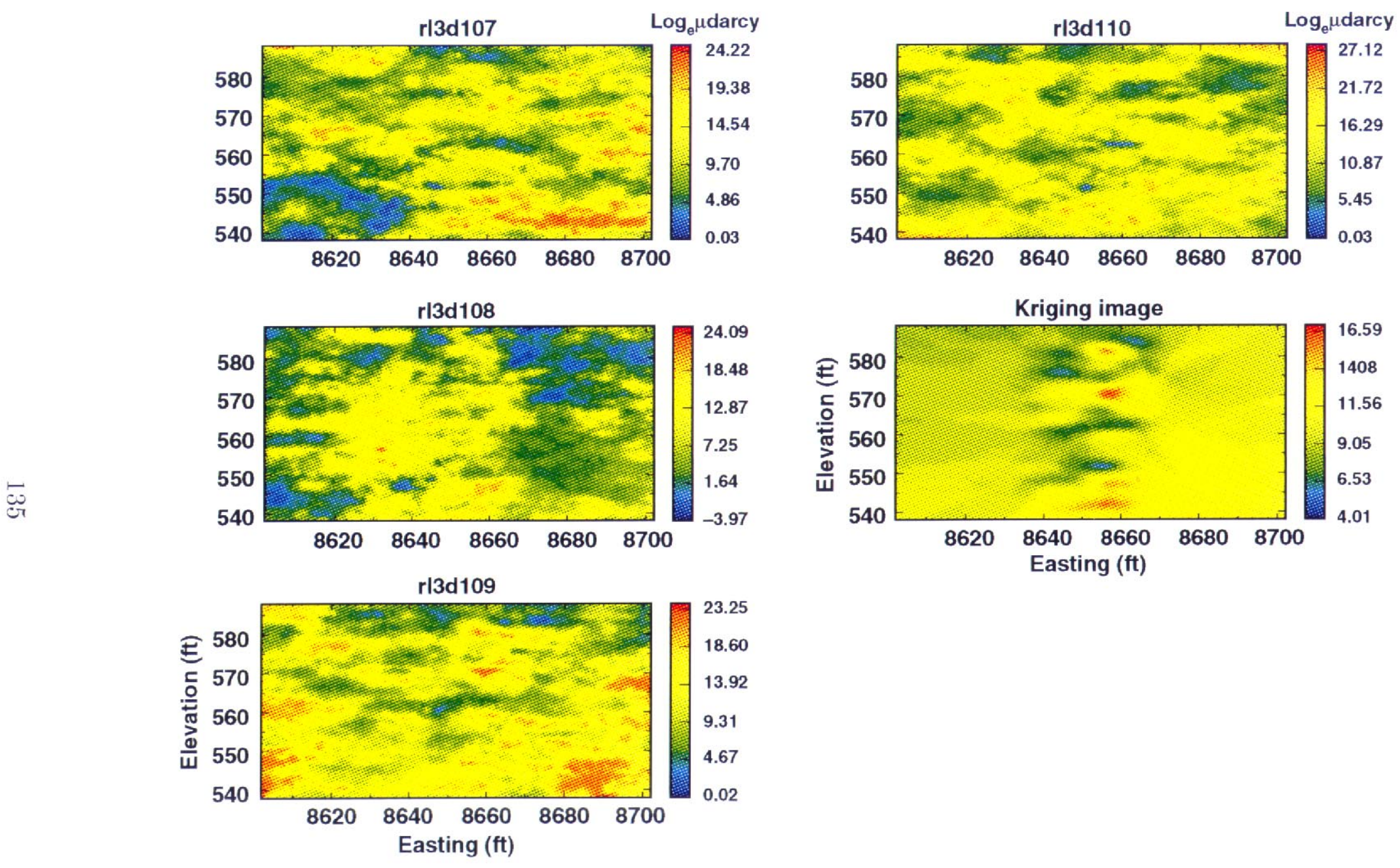

Figure 8.1b: Images of an east-west section through the 3D permeabililty field generated by kriging and each of the ten realizations of the field generated by conditional simulation. This figure shows images for realizations rl3d107 through rl3d110, and the field generated by kriging. The section passes through the suspected leak point at E8652, N12780. 
smoothing effect is more pronounced at greater distances away from the borehole. This artificial smoothing which increases in areas of sparser sampling is one of the disadvantages of kriging when applied to subsurface transport problems.

\subsubsection{Conceptual and Mathematical Models}

Flow and transport of tritium in the $3 \mathrm{D}$ domain are simulated using the conceptual and mathematical models outlined in Chapter 6. Two fluid phases and three chemical components are modeled. The fluid phases are liquid (or aqueous) and gas, and the chemical components are air (treated as a pseudocomponent with averaged properties), water $\left(\mathrm{H}_{2} \mathrm{O}\right)$, and tritiated water (HTO). The liquid phase is comprised mainly of water, with dilute concentrations of HTO and air. The gas phase is comprised of air, water vapor, and HTO vapor. Components may partition between the two phases. Both phases are mobile. Radioactive decay of tritium occurs with a half-life of 12.4 yr. Both liquid and vapor diffusion are modeled. Diffusion is modeled using the Millington (1959) formulation for tortuosity. Mechanical dispersion is incorporated by explicitly modeling the heterogeneous permeability field derived from the data.

\subsubsection{Grid Design}

The grid design features varying mesh sizes to allow higher resolution closer to the leak source, and decreasing resolution at greater distances away from the source. A section of the grid showing the leak node is drawn in Figure 8.2. The grid consists of 33 nodes in the $\mathrm{x}$-direction, and 25 nodes each in the $\mathrm{y}$ - and $\mathrm{z}$-directions, giving a total of 20,625 nodes. Of these nodes, 2750 were made inactive, leaving a total of 17,875 active nodes. The minimum grid size occurs at the leak node, with dimensions $1.6 \mathrm{ft}(0.5 \mathrm{~m})$ in the $\mathrm{x}$ - and $\mathrm{y}$-directions, 
and $1.3 \mathrm{ft}(0.4 \mathrm{~m})$ in the $\mathrm{z}$-direction. The leak node has coordinates $(632.2,373.0,9.0)$. The three layers of groundwater nodes at the base of the model extend to a distance of $630 \mathrm{ft}$ downstream of the leak.

\subsubsection{Initial and Boundary Conditions}

The upper boundary is the atmosphere at fixed relative humidity. The ground surface in the release area is partially covered by asphalt, as shown earlier in Figure 3.5. The tank is completely covered by asphalt. The asphalt cover ends about $6 \mathrm{ft}$ south of the southern edge of the tank, after which exposed soil occurs. No component fluxes are allowed through the asphalt. An infiltration rate of $2.1 \mathrm{in} / \mathrm{yr}$ is applied at the exposed soil surface. The infiltration rate was selected based on a comparison of soil water content measured by neutron probe in the field (Mallon, 1995) and average steady-state water content from initialization runs with different steady infiltration rates. The lower boundary is the impermeable base of the 5 -foot thick unconfined aquifer. The lowest three layers of nodes represent the aquifer which has a uniform permeability of 5.5 darcy and a hydraulic gradient fixed to give a groundwater velocity of $33 \mathrm{ft} / \mathrm{yr}(9.9 \mathrm{~m} / \mathrm{yr})$, flowing to the west. The aquifer permeability and groundwater velocity were obtained from pumping tests and water table elevation measurements conducted in the Building 292 Area. Impermeable lateral boundaries are placed at sufficiently great distances from the source to avoid any significant influence on flow and transport in the plume area.

Initial conditions for each realization were attained by running the model to steady state with the HTO component excluded. Exclusion of the HTO component for initialization reduces the computational burden without affecting the initial conditions. The transport simulation run is conducted by restarting after initialization, with the tritium source added, 

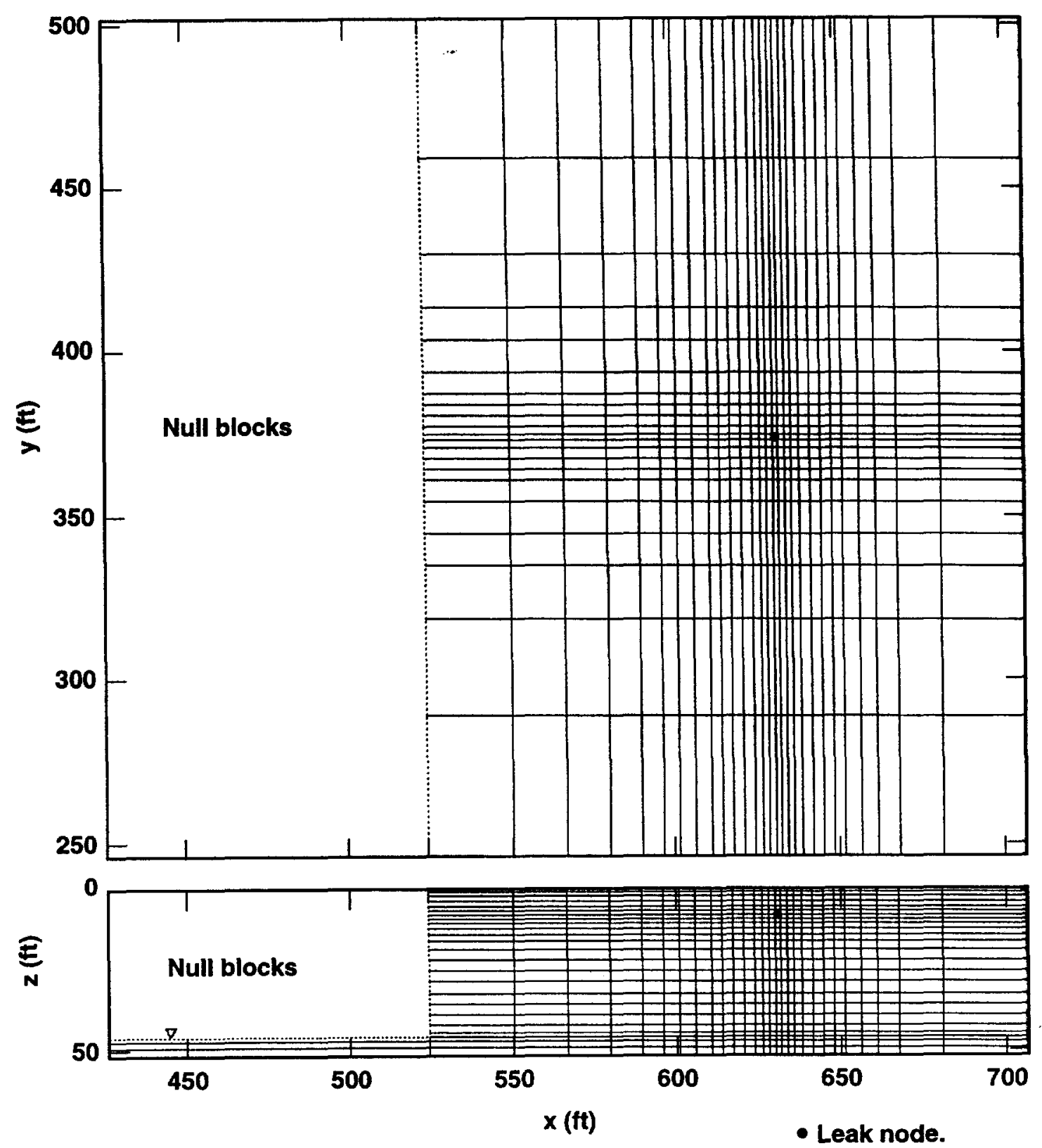

$x$ and $z$ coord of leak are $632.2,9.0 \mathrm{ft}$.

Figure 8.2: Grid showing discretization for three-dimensional calculations. 
and values of the state variables from initialization used for the initial conditions.

\subsubsection{Source Term}

We used the field concentrations derived from kriging to estimate a total tritium activity of about $5 \mathrm{Ci}$ in the subsurface of the LLNL Building 292 Area. Estimation of the ${ }^{3} \mathrm{H}$ activity was described back in Chapter 5. This activity is estimated to be that in the soil at around 1990. Assuming a uniform release, the release rate is obtained from

$$
A^{H T O}=\frac{R_{l} C_{l}^{H T O}}{\lambda}[1-\exp (-\lambda t)]
$$

where $\mathrm{A}^{H T O}$ is the total activity in the soil $(\mathrm{Ci})$ at time $t(\mathrm{~s}), \mathrm{R}_{l}$ is the release rate of contaminated liquid water $\left(\mathrm{m}^{3} / \mathrm{s}\right), \mathrm{C}_{l}^{H T O}$ is the tritium concentration of the release water $\left(\mathrm{Ci} / \mathrm{m}^{3}\right)$, and $\lambda$ is the decay constant for tritium $\left(.0561 \mathrm{yr}^{-1}\right)$. Assuming a 5 -yr leak

occurring from 1986 through 1990 , Equation 8.1 gives a ${ }^{3} \mathrm{H}$ release rate, $R_{l} C_{l}^{H T O}$, of 1.15 $\mathrm{Ci} / \mathrm{yr}$ for a total of $5.73 \mathrm{Ci}$ over $5 \mathrm{yr}$.

In order to make the simulations conservative, we use a $40 \%$ higher ${ }^{3} \mathrm{H}$ release rate of $1.6 \mathrm{Ci} / \mathrm{yr}$, for a total activity of $8.0 \mathrm{Ci}$ over $5 \mathrm{yr}$. We also use a $C_{l}^{H T O}$ value of $4.46 \times 10^{8}$ $\mathrm{pCi} / \mathrm{L}$, the ${ }^{3} \mathrm{H}$ concentration measured in the tank water in 1989 . With $R_{l} C^{H T O_{l}}$ equal to $1.6 \mathrm{Ci} / \mathrm{yr}$, the release rate of contaminated water, $R_{l}$, is $3.6 \mathrm{~m}^{3} / \mathrm{yr}$ or $2.6 \mathrm{gal} / \mathrm{day}$. The source term is specified as fixed fluxes of the components $\mathrm{HTO}$ and $\mathrm{H}_{2} \mathrm{O}$ over the first 5 yr of simulation. One $\mathrm{Ci}$ of ${ }^{3} \mathrm{H}$ activity is equivalent to $6.9 \times 10^{-7} \mathrm{~kg}$ of $\mathrm{HTO}$.

\subsection{Runs using Soil Properties from Conditional Simulation}

We generated 10 different three-dimensional soil permeability fields by conditional simulation, then used available data to estimate other hydraulic properties of the soil by correlation and random sampling. We conducted numerical transport calculations using each of the 10 
soil property fields, incorporating site conditions as closely as possible. These conditions include an infiltration rate of $2.1 \mathrm{in} / \mathrm{yr}$ through the exposed soil surface south of the tank, and partial cover of the area by a blacktop which we assume to be impermeable. The 10 runs are numbered rl3d101 through rl3d110. To examine the effect of the blacktop on

${ }^{3} \mathrm{H}$ transport, we repeated Runs rl3d101 and $\mathrm{rl3d} 110$ with the blacktop removed. These two additional runs are identified as $\mathrm{rl} 3 \mathrm{~d} 201$, a repeat of $\mathrm{r} 13 \mathrm{~d} 101$, and $\mathrm{rl} 3 \mathrm{~d} 210$, a repeat of rl3d110.

\subsubsection{Results}

We present the results using tables and graphs that show the plume parameters for different runs. A table that gives an overview of the results is first presented, followed by graphs that reveal more details of the ${ }^{3} \mathrm{H}$ transport and its variability from realization to realization.

\section{Overview of Results}

Results of the 12 runs using soil permeability fields generated by conditional simulation are summarized in Table 8.1. The table presents the following parameters that describe transport of the ${ }^{3} \mathrm{H}$ in the subsurface:

- Peak groundwater ${ }^{3} \mathrm{H}$ concentration for the 100 -year simulation period.

- Time of peak groundwater ${ }^{3} \mathrm{H}$ concentration.

- Time of arrival of the $2000-\mathrm{PCi} / \mathrm{L}$ isoconcentration surface at the water table.

- Time of arrival of the 20000-PCi/L isoconcentration surface at the water table.

- Cumulative 100 -year flux of ${ }^{3} \mathrm{H}$ across the water table.

- Depth of the plume's center-of-mass at $20 \mathrm{yr}$. 
Table 8.1: Summary of tritium transport results for three-dimensional simulation runs using realizations of soil permeability fields derived by conditional simulation. Run rl3d201 is a repeat of rl3d101 with the blacktop removed, and Run rl3d210 is a repeat of $\mathrm{rl3} d 110$ with the blacktop removed.

\begin{tabular}{|c|c|c|c|c|c|c|}
\hline Run ID & $\begin{array}{c}\text { Peak GW } \\
\text { Conc } \\
(\mathrm{pCi} / \mathrm{L})\end{array}$ & $\begin{array}{c}\text { Time of } \\
\text { Peak } \\
\text { GW Conc } \\
\text { (yr) }\end{array}$ & $\begin{array}{c}2000-\mathrm{PCi} / \mathrm{L} \\
\text { Arrival } \\
\text { Time at WT } \\
\text { (yr) }\end{array}$ & $\begin{array}{c}20000-\mathrm{PCi} / \mathrm{L} \\
\text { Arrival } \\
\text { Time at WT } \\
\text { (yr) }\end{array}$ & $\begin{array}{l}\text { Cum 100-yr } \\
{ }^{3} \mathrm{H} \text { Flux } \\
\text { across WT } \\
(\mathrm{mCi})\end{array}$ & $\begin{array}{c}\text { Center of } \\
\text { Mass Depth } \\
\text { at } 20 \mathrm{yr} \\
(\mathrm{ft})\end{array}$ \\
\hline rl3d101 & $9.23 \times 10^{4}$ & 19.5 & 6.3 & 8.5 & 5.2 & 17.0 \\
\hline rl3d102 & $4.12 \times 10^{4}$ & 21.6 & 7.8 & 12.1 & 1.4 & 11.7 \\
\hline $\mathrm{rl} 3 \mathrm{~d} 103$ & $8.29 \times 10^{3}$ & 35.0 & 15.0 & $\mathrm{NA}^{*}$ & 1.2 & 14.1 \\
\hline rl3d104 & $1.20 \times 10^{5}$ & 21.2 & 6.8 & 9.5 & 4.6 & 13.9 \\
\hline rl3d 105 & $1.31 \times 10^{4}$ & 25.0 & 11.2 & NA & 0.9 & 13.6 \\
\hline rl3d 106 & $1.12 \times 10^{5}$ & 24.8 & 6.6 & 9.5 & 7.1 & 14.9 \\
\hline rl3d107 & $3.52 \times 10^{5}$ & 18.0 & 6.0 & 7.3 & 11.7 & 14.9 \\
\hline rl3d108 & $1.71 \times 10^{5}$ & 12.4 & 5.6 & 6.9 & 3.5 & 14.6 \\
\hline $\mathrm{rl} 3 \mathrm{~d} 109$ & $2.27 \times 10^{4}$ & 25.0 & 8.3 & 19.3 & 2.0 & 15.6 \\
\hline rl3d110 & $3.56 \times 10^{5}$ & 13.5 & 4.5 & 5.8 & 13.9 & 17.6 \\
\hline Mean & $1.29 \times 10^{5}$ & 21.5 & 7.8 & - & 5.2 & 14.8 \\
\hline Std dev & $1.30 \times 10^{5}$ & 6.5 & 3.1 & - & 4.5 & 1.7 \\
\hline rl3d201 & $2.85 \times 10^{5}$ & 15.0 & 3.9 & 5.0 & 22.2 & 19.7 \\
\hline rl3d210 & $2.37 \times 10^{6}$ & 8.4 & 1.7 & 2.6 & 79.5 & 20.3 \\
\hline
\end{tabular}

* NA: $20,000 \mathrm{pCi} / \mathrm{L}$ isoconcentration surface never reached water table.

Depth of the plume's center-of-mass at $20 \mathrm{yr}$ is included as a general measure of bulk vertical movement of the plume for different realizations.

Results of simulation runs on the 10 realizations, with blacktop cover in place, show only a mild impact of the ${ }^{3} \mathrm{H}$ release on groundwater quality. For the $10 \mathrm{runs}$, the peak groundwater ${ }^{3} \mathrm{H}$ concentration over the 100 -year simulation period averaged only $1.29 \times 10^{5}$ $\mathrm{pCi} / \mathrm{L}, .03 \%$ of the release concentration of $4.46 \times 10^{8} \mathrm{pCi} / \mathrm{L}$. The peak concentration occurred at an average time of $21.5 \mathrm{yr}$. The average peak concentration is 6.5 times the EPA groundwater standard of $2.0 \times 10^{4} \mathrm{pCi} / \mathrm{L}$. The highest peak concentration, $3.56 \times 10^{5}$, was observed in rl3d110. A significant aspect of the results is the relatively low quantity of ${ }^{3} \mathrm{H}$ entering the groundwater. The cumulative ${ }^{3} \mathrm{H}$ activity that entered the groundwater over the 100 -year simulation period ranged from $0.9 \mathrm{mCi}$ for $\mathrm{rl} 3 \mathrm{~d} 105$ to $13.9 \mathrm{mCi}$ for $\mathrm{rl} 3 \mathrm{~d} 110$, and 
averaged only $5.2 \mathrm{mCi}$, about $.07 \%$ of the $8-\mathrm{Ci}$ release activity. Movement of the plume's center of mass did not vary much from realization to realization. Depth of the center of mass at $20 \mathrm{yr}$ averaged $14.8 \mathrm{ft}$ with a standard deviation of $1.7 \mathrm{ft}$. The $2,000-\mathrm{pCi} / \mathrm{L}$ isoconcentration surface took an average of $7.8 \mathrm{yr}$ to reach the water table; the arrival time varied from a low of $4.5 \mathrm{yr}$ for rl3d110 to a high of $15.0 \mathrm{yr}$ for rl3d103. The $20,000-\mathrm{pC} / \mathrm{L}$ isoconcentration surface did not arrive at the water table for two runs, rl3d103 and rl3d105: the fastest arrival time was $5.8 \mathrm{yr}$ for $\mathrm{rl} 3 \mathrm{~d} 110$.

Table 8.1 shows that removing the blacktop will significantly increase the impact of the release on groundwater quality. Comparison of results of rl3d201 with rl3d101, and rl3d210 with rl3d110, show that removal of the blacktop results in the following significant changes:

- increases in peak groundwater ${ }^{3} \mathrm{H}$ concentration;

- decreases in time of occurrence of peak groundwater concentration;

- increases in ${ }^{3} \mathrm{H}$ activity entering the groundwater;

- decreases in water table plume arrival times.

For rl3d101, the peak groundwater ${ }^{3} \mathrm{H}$ concentration more than tripled, from $9.23 \times 10^{4}$ to $2.85 \times 10^{5}$, and for $\mathrm{rl} 3 \mathrm{~d} 110$, the concentration increased by a factor of nearly 7 , from $3.56 \times 10^{5}$ to $2.37 \times 10^{6}$. For $\mathrm{r} 13 \mathrm{~d} 101$, the ${ }^{3} \mathrm{H}$ activity that entered the groundwater over the simulation period increased by a factor of over 4 , from $5.2 \mathrm{mCi}$ to $22.2 \mathrm{mCi}$, and for rl3d110, the activity increased by a factor of nearly 6 , from $13.9 \mathrm{mCi}$ to $79.5 \mathrm{mCi}$.

To confirm the limited impact of the ${ }^{3} \mathrm{H}$ release on groundwater quality, the run using the realization showing the highest groundwater ${ }^{3} \mathrm{H}$ concentrations with the blacktop in place, rl3d110, was repeated with mechanical dispersion in the aquifer. Recall that mechanical dispersion was not included in any of the previous runs. We used a longitudinal dispersivity 
of $1.0 \mathrm{~m}$ and a transverse dispersivity of $0.1 \mathrm{~m}$ based on scale-dependent dispersivity data presented by Gelhar et al. $(1985,1992)$. With this worst-case situation, the peak groundwater ${ }^{3} \mathrm{H}$ concentration $100 \mathrm{ft}$ downstream of the leak was $1.59 \times 10^{4} \mathrm{pCi} / \mathrm{L}, 80 \%$ of the groundwater standard. The peak concentration occurred at about $20 \mathrm{yr}$. We will later show that the peak

${ }^{3} \mathrm{H}$ concentration $100 \mathrm{ft}$ downstream of the leak is just $38 \%$ of the groundwater standard, for the realization with a concentration distribution that best matches the field data.

\section{Runs with Blacktop}

The column plots of Figure 8.3 and Figure 8.4 show the variability in peak groundwater ${ }^{3} \mathrm{H}$ concentration and cumulative ${ }^{3} \mathrm{H}$ flux entering the groundwater at $20 \mathrm{yr}$. With the mean concentration of $1.30 \times 10^{5} \mathrm{pCi} / \mathrm{L}$ equal to the standard deviation, the coefficient of variation equals 1.0 , indicating substantial variability in peak groundwater concentration from realization to realization. The lowest peak groundwater concentration was $8.29 \times 10^{3}$ $\mathrm{pCi} / \mathrm{L}$ for $\mathrm{rl3d} 103$, and the highest $3.56 \times 10^{5} \mathrm{pCi} / \mathrm{L}$ for $\mathrm{rl} 3 \mathrm{~d} 110$. The cumulative $100-\mathrm{yr}{ }^{3} \mathrm{H}$ flux across the water table also varies substantially, having a coefficient of variation of 0.87 , and a significantly low mean of $5.2 \mathrm{mCi}$. The maximum groundwater ${ }^{3} \mathrm{H}$ activity for all blacktop runs was $5.2 \mathrm{mCi}$ at $25 \mathrm{yr}$, for rl3d110. The highest groundwater concentration is over an order of magnitude greater than the groundwater standard. Results from the two runs, rl3d103 and rl3d110, will be examined in more detail later since these runs represent the limiting cases in terms of the impact on groundwater quality.

Figure 8.5 is a column plot showing arrival times of the leading edge of the ${ }^{3} \mathrm{H}$ plume at the watertable. The leading edge of the plume is defined here as the $2,000-\mathrm{pCi} / \mathrm{L}$ isoconcentration surface. For the 10 runs, rl3d101 through rl3d110, the arrival time averages $7.8 \mathrm{yr}$ with a standard deviation of $3.1 \mathrm{yr}$. Run rl3d110 had the shortest arrival time, 4.5 


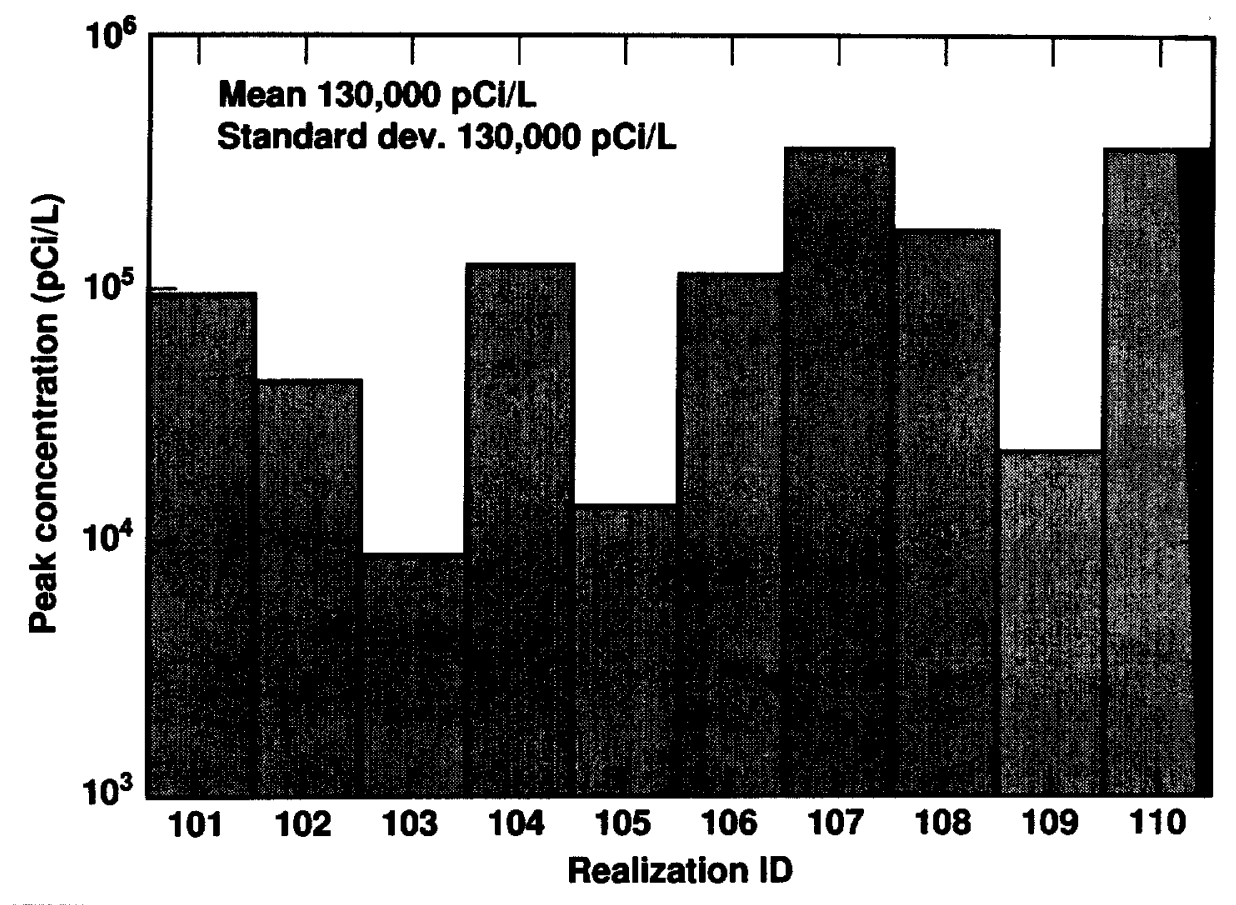

Figure 8.3: Column plot showing peak groundwater ${ }^{3} \mathrm{H}$ concentrations at $20 \mathrm{yr}$ for the ten realizations with partial blacktop cover.

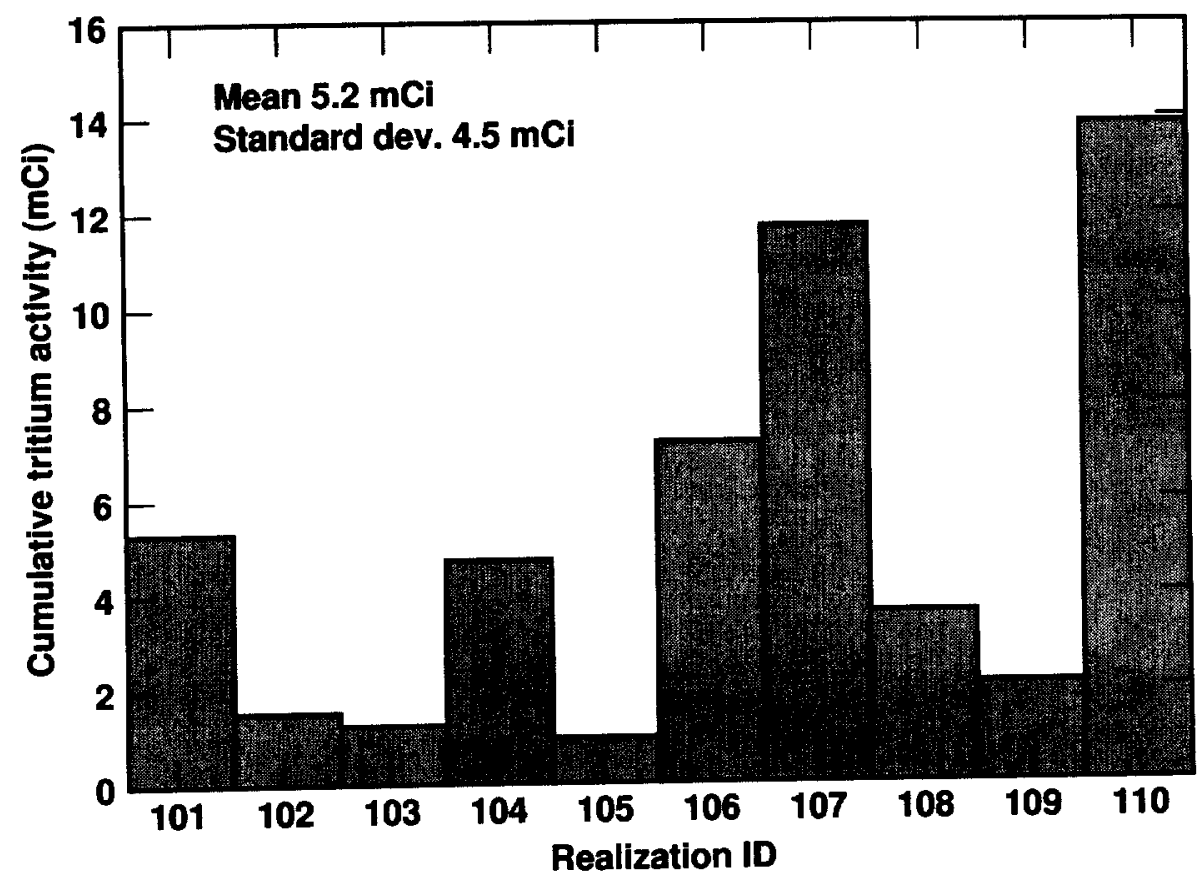

Figure 8.4: Column plot showing the cumulative flux of ${ }^{3} \mathrm{H}$ into the groundwater at $20 \mathrm{yr}$ for the ten realizations with partial blacktop cover. 


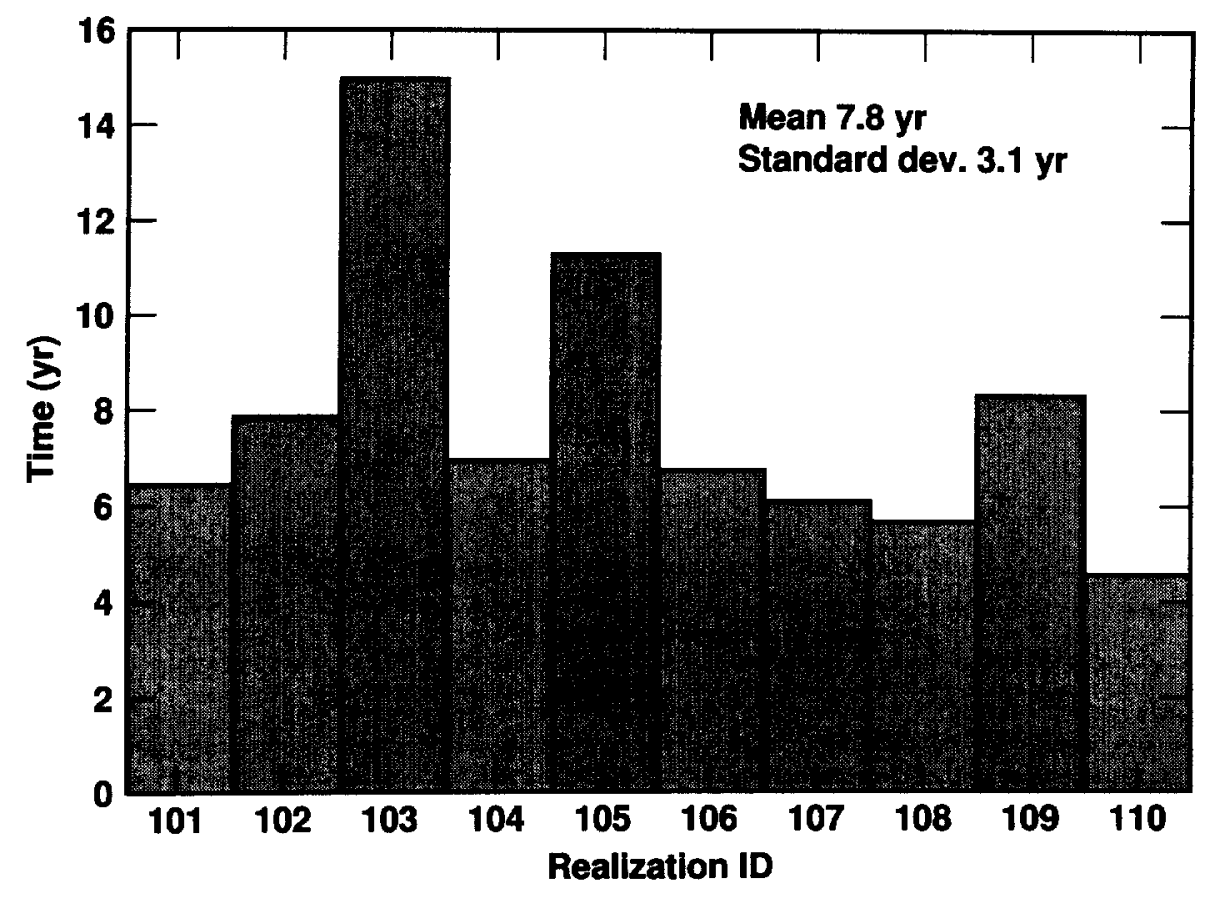

Figure 8.5: Column plot showing ${ }^{3} \mathrm{H}$ plume arrival times at water table for the ten realizations with partial blacktop cover.

yr; and Run rl3d103 had the longest arrival time, $15.0 \mathrm{yr}$. Groundwater concentrations for rl3d103 and rl3d105 never reached the $20,000-\mathrm{pCi} / \mathrm{L}$ groundwater standard.

Figure 8.6 is a column plot of the time of occurrence of peak groundwater ${ }^{3} \mathrm{H}$ concentration. The times average $21.5 \mathrm{yr}$ with a standard deviation of $6.5 \mathrm{yr}$. The peak concentration occurred earliest for rl3d108, at $12.4 \mathrm{yr}$, and latest for rl3d103, at $35.0 \mathrm{yr}$. The highest concentration of the 10 runs occurred for rl3d110 at $13.5 \mathrm{yr}$.

We present a number of history plots to show the temporal behavior of various parameters that describe the ${ }^{3} \mathrm{H}$ transport. On each graph we plot histories of the

- average parameter value for Runs rl3d101 through rl3d110

- parameter value for Run rl3d103

- parameter value for Run rl3d110. 


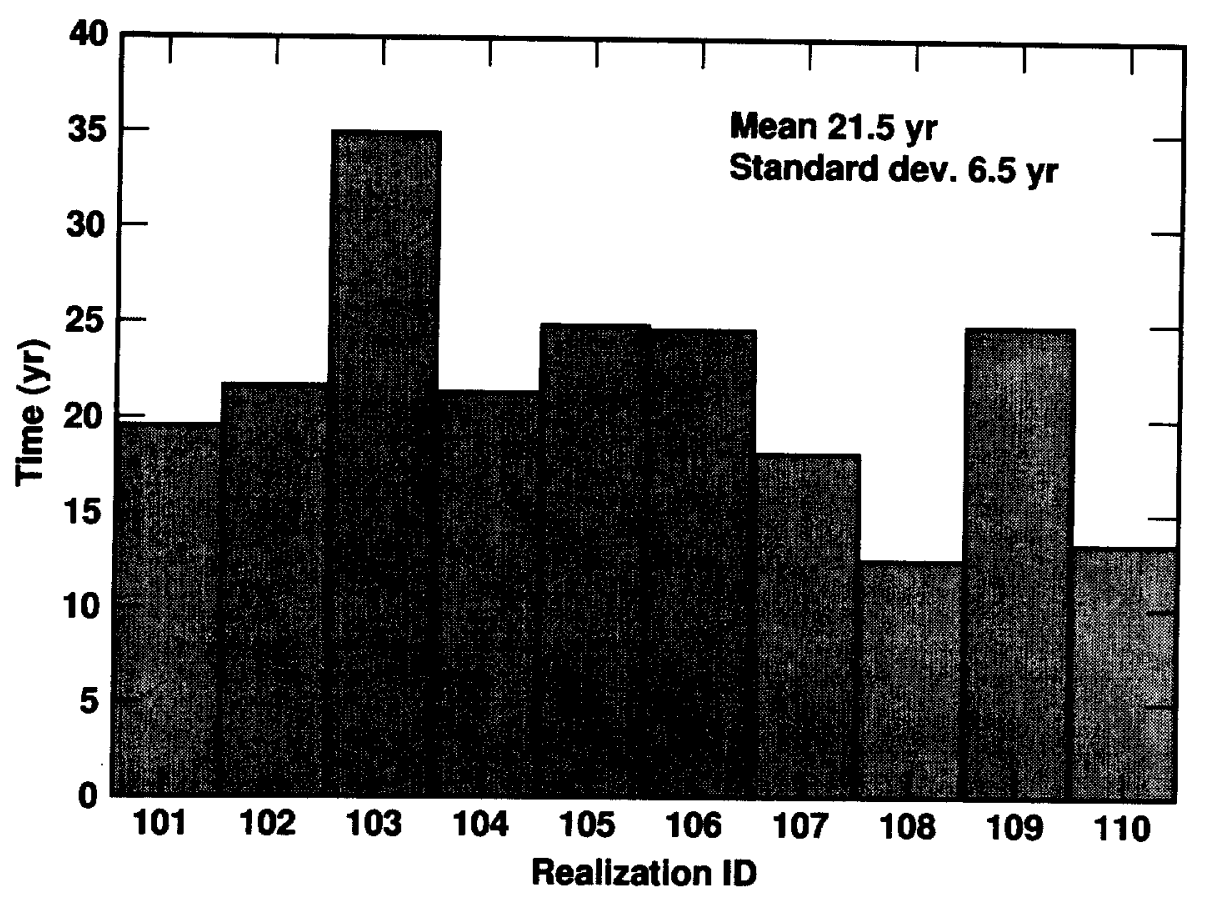

Figure 8.6: Column plot showing time of occurrence of the peak groundwater concentration. for ten realizations with partial blacktop cover.

The runs rl3d103 and rl3d110 were selected because they represent the limiting realizations in terms of impact of the ${ }^{3} \mathrm{H}$ release on groundwater quality; r13d103 gave the lowest impact and $\mathrm{rl} 3 \mathrm{~d} 110$ the highest impact on groundwater quality.

Figure 8.7 shows histories of the total ${ }^{3} \mathrm{H}$ activity in the vadose zone. The graph shows negligible differences between the three curves. This lack of variability is due to extremely small percentage losses of ${ }^{3} \mathrm{H}$ from the vadose zone into the groundwater, for all realizations. The percentage losses into the groundwater are consistently small even though actual fluxes into the groundwater vary considerably. Because of such small percentage losses to the groundwater, ${ }^{3} \mathrm{H}$ losses from the vadose zone are dominated by radioactive decay and the history plots in Figure 8.7 follow the decay curve for ${ }^{3} \mathrm{H}$ very closely.

Figure 8.8 shows histories of the maximum tritium concentration in the vadose zone, again for the average of the ten blacktop runs, Run rl3d103, and Run rl3d110. These results 


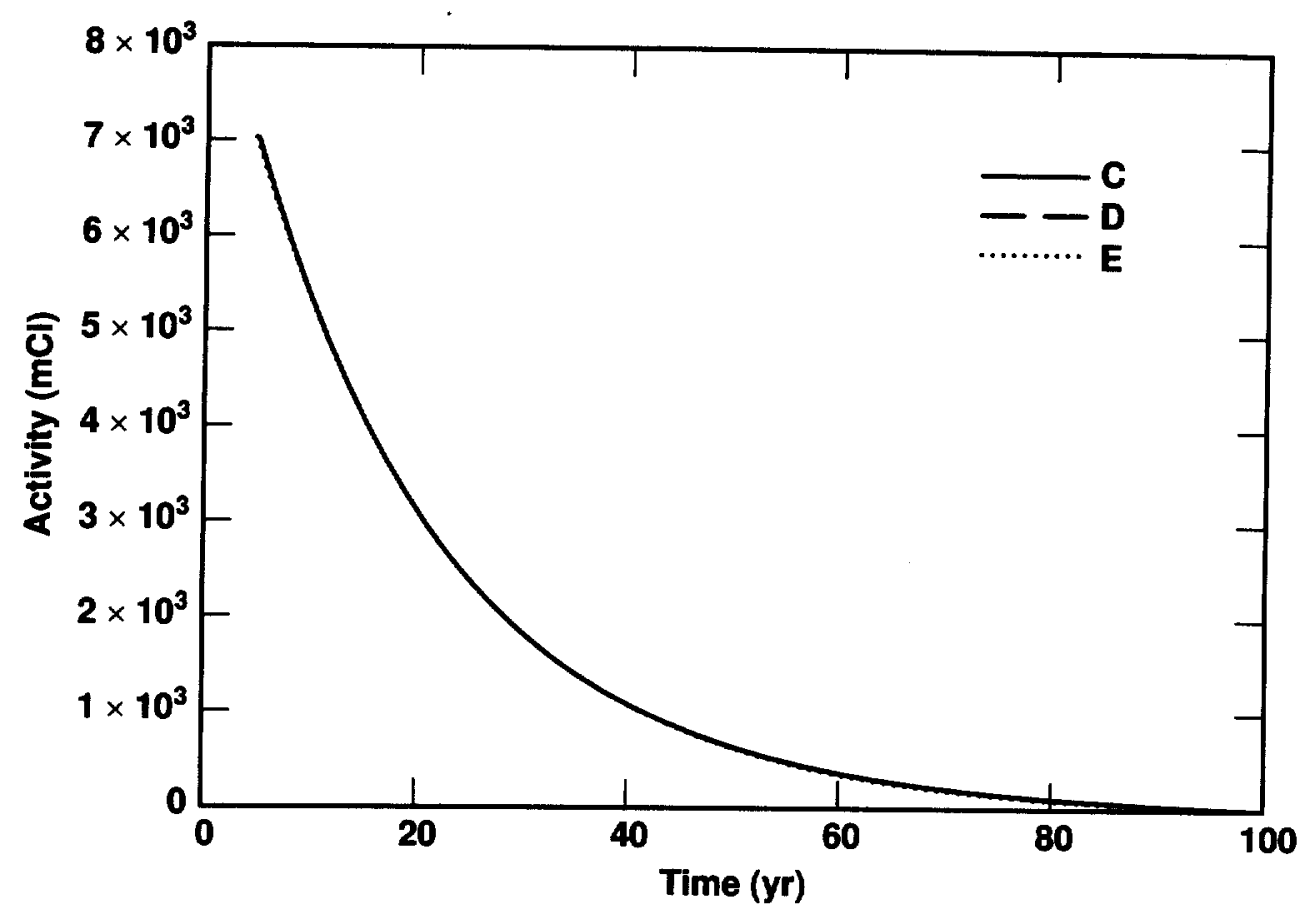

Figure 8.7: History of total ${ }^{3} \mathrm{H}$ activity in the vadose zone with partial blacktop cover. The three plots are 1) the average for Realizations rl3d101 through $\mathrm{rl3d} 110,2$ ) rl3d103, and 3) rl3d110.

also show very little variability between realizations, and the three curves closely follow the decay curve for ${ }^{3} \mathrm{H}$. This behavior may be explained by the presence of some immobile or nearly immobile low-permeability zones where concentration decreases are dominated by radioactive decay and not by transport.

Figure 8.9 shows significant differences between time histories of peak groundwater ${ }^{3} \mathrm{H}$ concentration for the average of the ten blacktop runs, Run rl3d103, and Run rl3d110. All three curves rise to reach a distinct maximum before decreasing. Higher peak concentrations are reached earlier than lower peak concentrations. For the average curve, the peak concentration is above the groundwater standard from about year 7 through year 55 .

Histories of the cumulative flux of ${ }^{3} \mathrm{H}$ into the groundwater for the three cases are plotted in Figure 8.10. The cumulative flux entering the groundwater after $100 \mathrm{yr}$ averages $5.2 \mathrm{mCi}$, and is $1.2 \mathrm{mCi}$ for $\mathrm{rl} 3 \mathrm{~d} 103$ and $13.9 \mathrm{mCi}$ for $\mathrm{rl} 3 \mathrm{~d} 110$. The lowest cumulative flux for the ten 


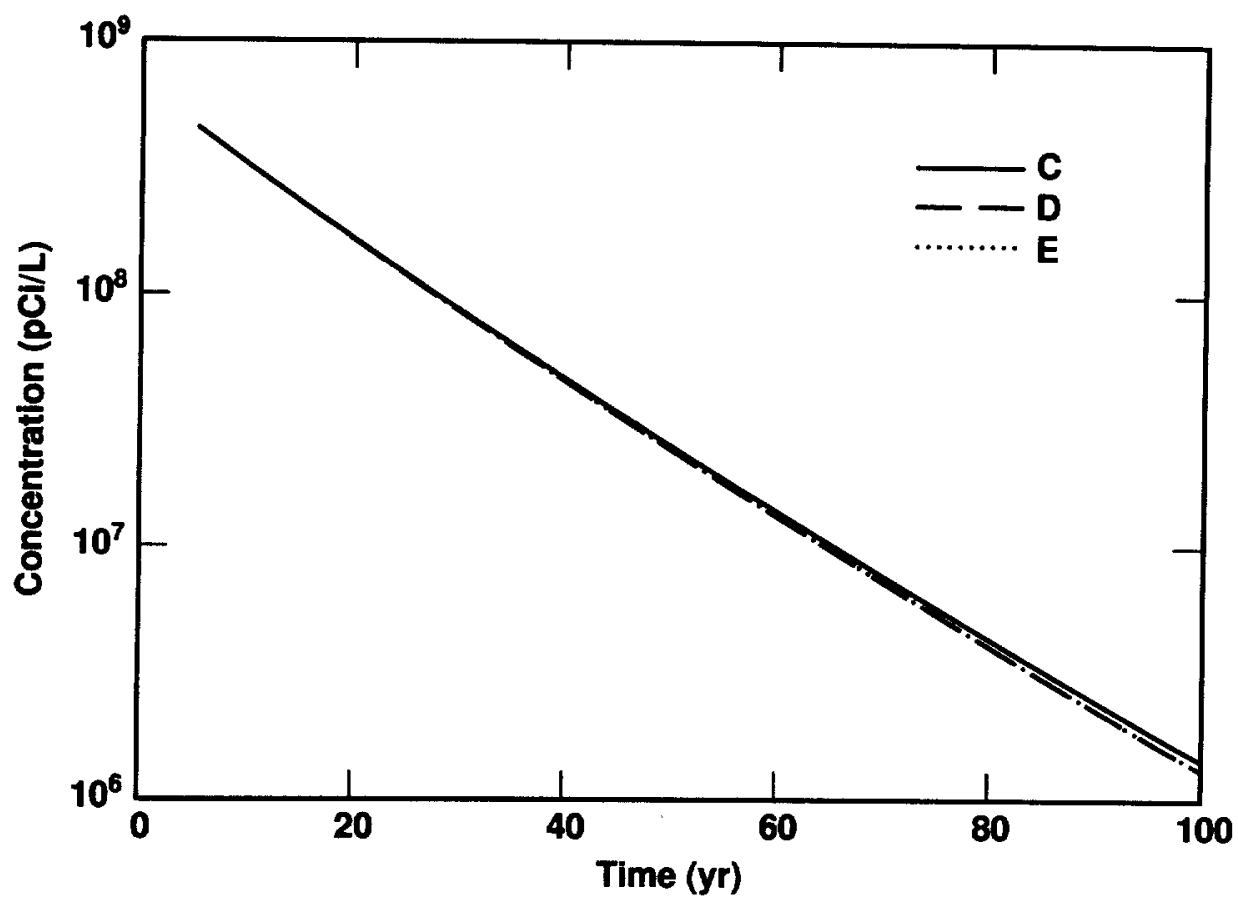

Figure 8.8: History of peak soil water ${ }^{3} \mathrm{H}$ concentration in the vadose zone with partial blacktop cover. The three plots are 1) the average for Realizations rl3d101 through rl3d110, 2) rl3d103, and 3) rl3d110.

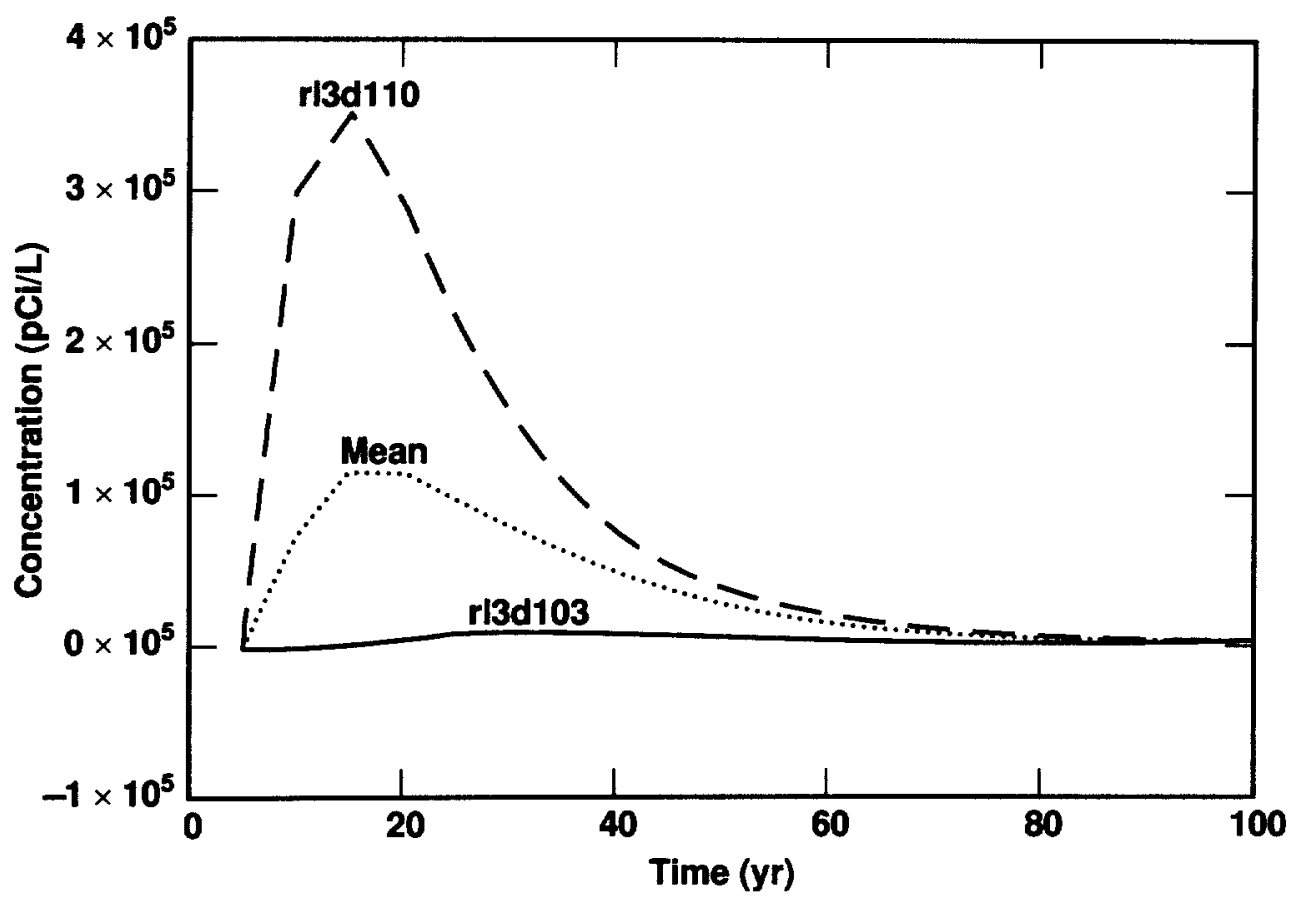

Figure 8.9: History of peak groundwater ${ }^{3} \mathrm{H}$ concentration in the vadose zone with partial blacktop cover. The three plots are 1) the average for Realizations rl3d101 through rl3d110, 2) rl3d103, and 3) rl3d110. 


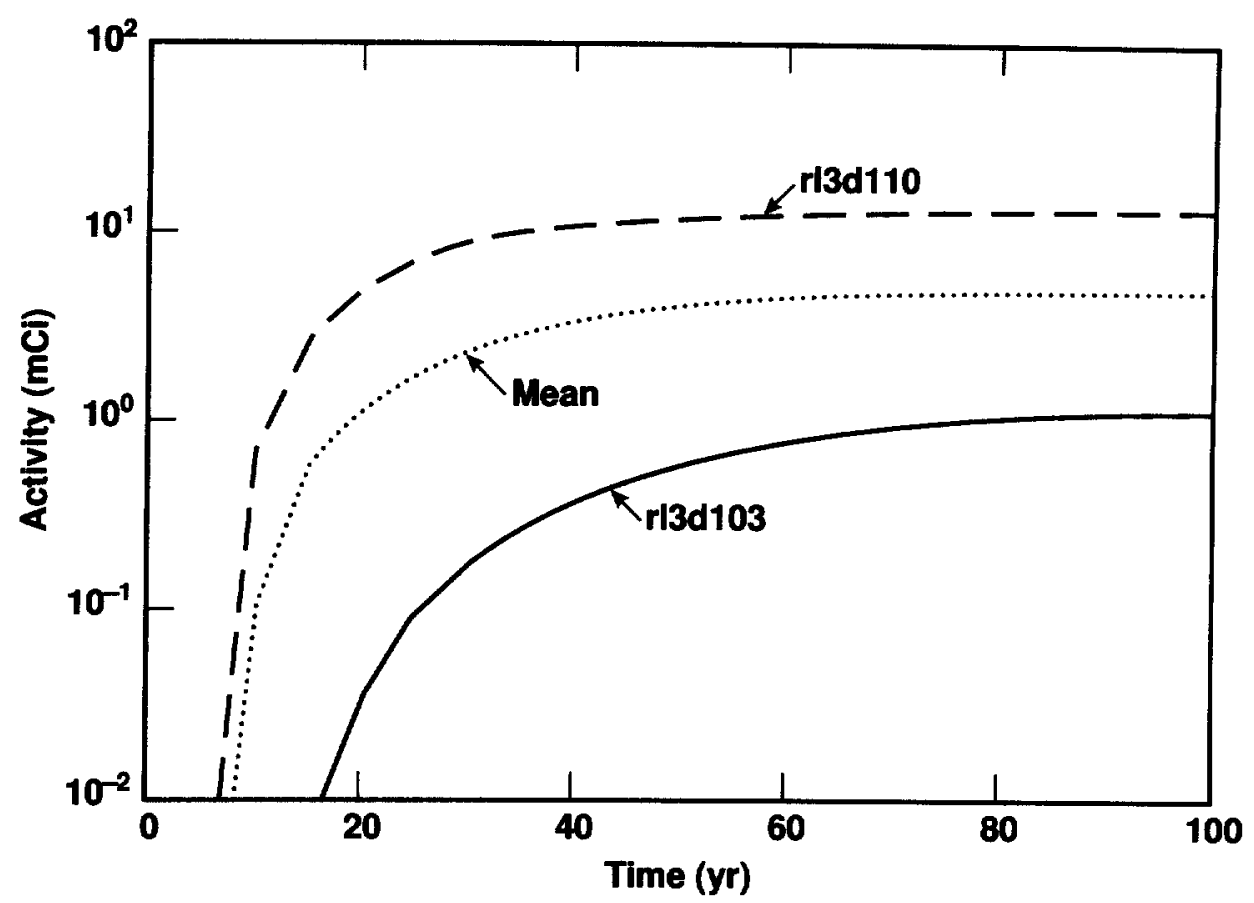

Figure 8.10: History of cumulative flux of ${ }^{3} \mathrm{H}$ into the groundwater with partial blacktop cover. The three plots are 1) the average for Realizations rl3d101 through rl3d110, 2) rl3d103, and 3) rl3d110.

runs is not the flux for rl3d103 but $0.9 \mathrm{mCi}$ for rl3d105. These activities are significantly small compared with the 8 - $\mathrm{Ci}$ source of ${ }^{3} \mathrm{H}$. The maximum 100 -year cumulative flux is only $0.17 \%$ of the source and the average 100 -year flux even lower at $0.07 \%$. Histories of the total ${ }^{3} \mathrm{H}$ activity in the groundwater, plotted in Figure 8.11 , show even smaller activities because of losses from radioactive decay. The maximum groundwater ${ }^{3} \mathrm{H}$ activity for all runs is $5.2 \mathrm{mCi}$ in $\mathrm{Rl} 3 \mathrm{~d} 110$. With such low ${ }^{3} \mathrm{H}$ activities entering the groundwater, even for Run rl3d110 which represents the worst case here, there appears to be no serious long term threat to groundwater quality at the release site.

Figure 8.12 shows downward movement of the plume's center of mass for the three cases. All three curves show more rapid movement of the center of mass up to about year 10 , followed by decreasing velocities in later years. The average velocity of the center of mass over the first $20 \mathrm{yr}$, considering an initial depth of $9.0 \mathrm{ft}$, is $0.26 \mathrm{ft} / \mathrm{yr}$ for $\mathrm{rl} 3 \mathrm{~d} 103,0.43$ 


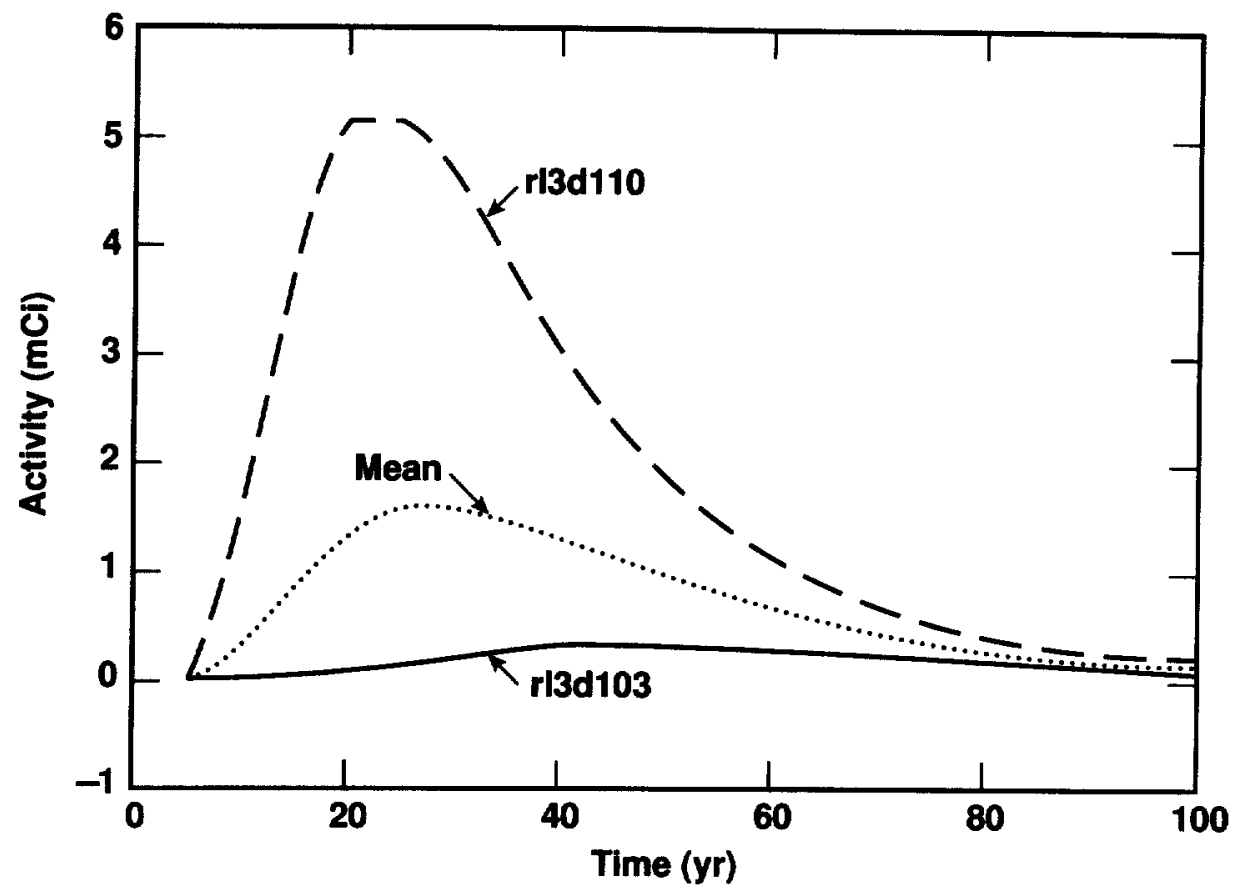

Figure 8.11: History of total ${ }^{3} \mathrm{H}$ activity in the groundwater with partial blacktop cover. The three plots are 1) the average for Realizations rl3d101 through rl3d110, 2) rl3d103, and 3) $\operatorname{rl} 3 \mathrm{~d} 110$.

$\mathrm{ft} / \mathrm{yr}$ for $\mathrm{rl} 3 \mathrm{~d} 110$, and $0.38 \mathrm{ft} / \mathrm{yr}$ for the average case. Between 20 and $60 \mathrm{yr}$, the average velocity reduces to $0.03 \mathrm{ft} / \mathrm{yr}$ for for all three cases. The center of mass for the three cases seems to move with approximately the same average velocities once the initial increase in saturation due to the source is removed from the system.

In Figure 8.13 and Figure 8.14 , the time history of the square root of the second moment of ${ }^{3} \mathrm{H}$ concentration distribution in the vadose zone is plotted for the $\mathrm{x}$ - and $\mathrm{y}$-directions, respectively. This parameter is a measure of plume spreading or dispersion, as described in Chapter 7. Both $\sigma_{x}$ and $s_{y}$ increase more rapidly during the first $10 \mathrm{yr}$, then continue to increase at a decreasing rate thereafter. The degree of spreading in the two directions appears to be similar. There appears to be no correlation between spreading and impact on groundwater quality. Run r13d103, with the least impact on groundwater ${ }^{3} \mathrm{H}$ concentrations, showed plume spreading in the y-direction greater than $\mathrm{rl} 3 \mathrm{~d} 110$, the run with greatest 


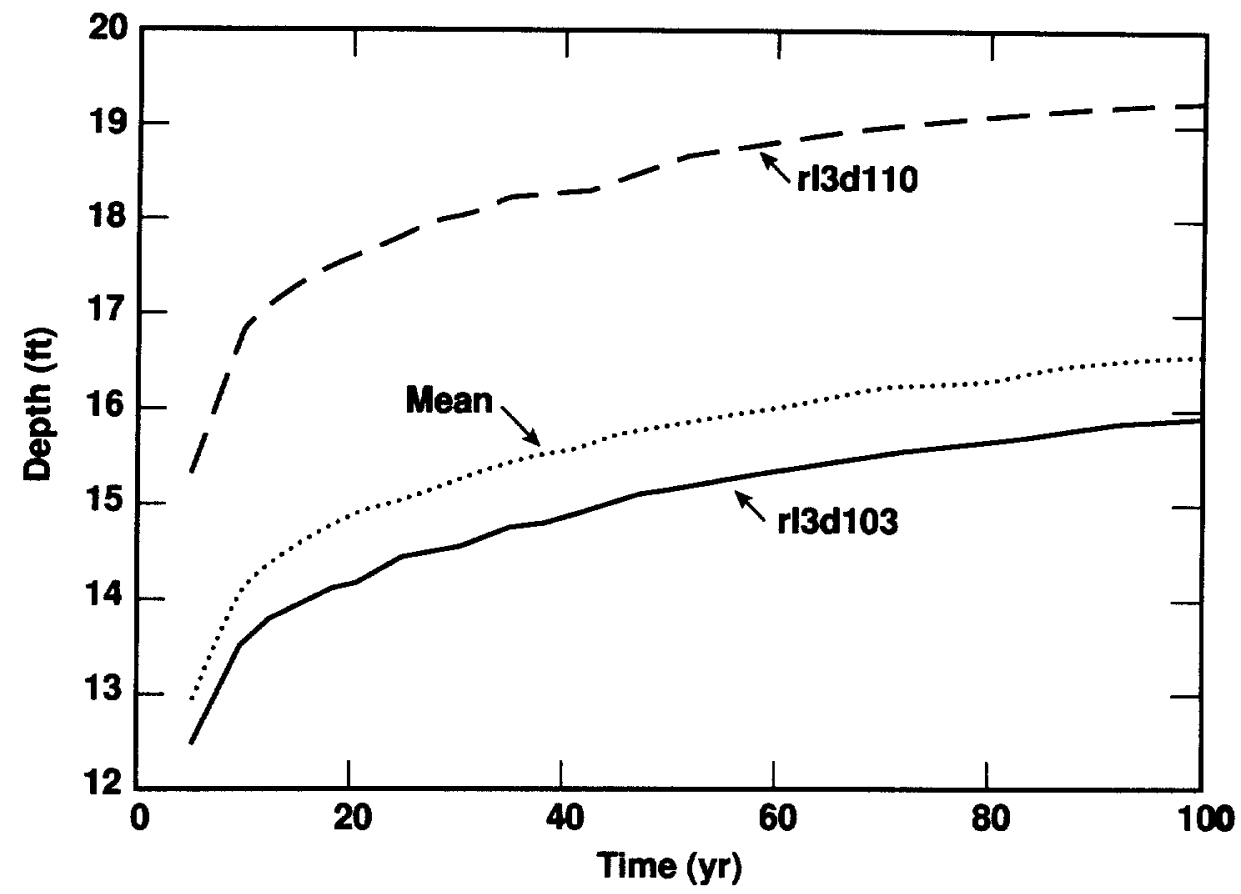

Figure 8.12: History of depth of plume's center-of-mass in the vadose zone with partial blacktop cover. The three plots are 1) the average for Realizations rl3d101 through rl3d110, 2) rl3d103, and 3) rl3d110.

impact on groundwater ${ }^{3} \mathrm{H}$ concentration. In the $\mathrm{x}$-direction, rl3d103 showed less spreading than rl3d110, except during the first 10 years.

\section{Effect of Removing Blacktop}

Simulation runs using two of the ten realizations were repeated with the blacktop removed to allow infiltration through the entire soil surface. These additional runs were done to study the effect of the soil cover on ${ }^{3} \mathrm{H}$ transport at the site. Recall that the runs rl3d101 through r13d110 included partial surface cover by the blacktop, with exposed soil occurring from the southern edge of the modeled domain to about $6 \mathrm{ft}$ south of the tank. The two runs without the blacktop surface cover are identified as rl3d201, which uses identical soil properties as rl3d101, and rl3d210 which uses identical soil properties as rl3d110.

The effect of blacktop removal on peak groundwater ${ }^{3} \mathrm{H}$ concentration for rl3d101 is 


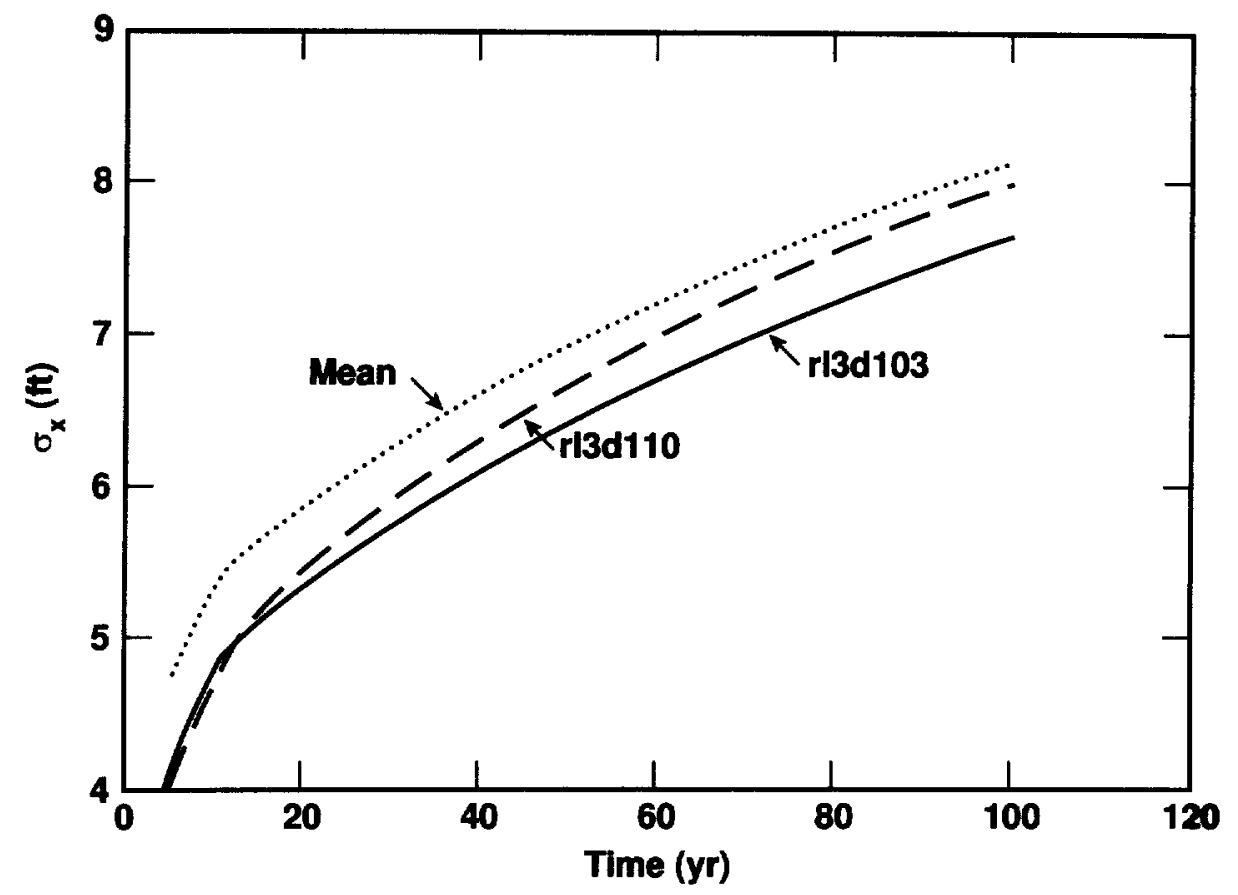

Figure 8.13: History of the spreading parameter $\sigma_{x}$ with partial blacktop cover. The three plots are 1) the average for Realizations rl3d101 through rl3d110,2) rl3d103, and 3) rl3d110.

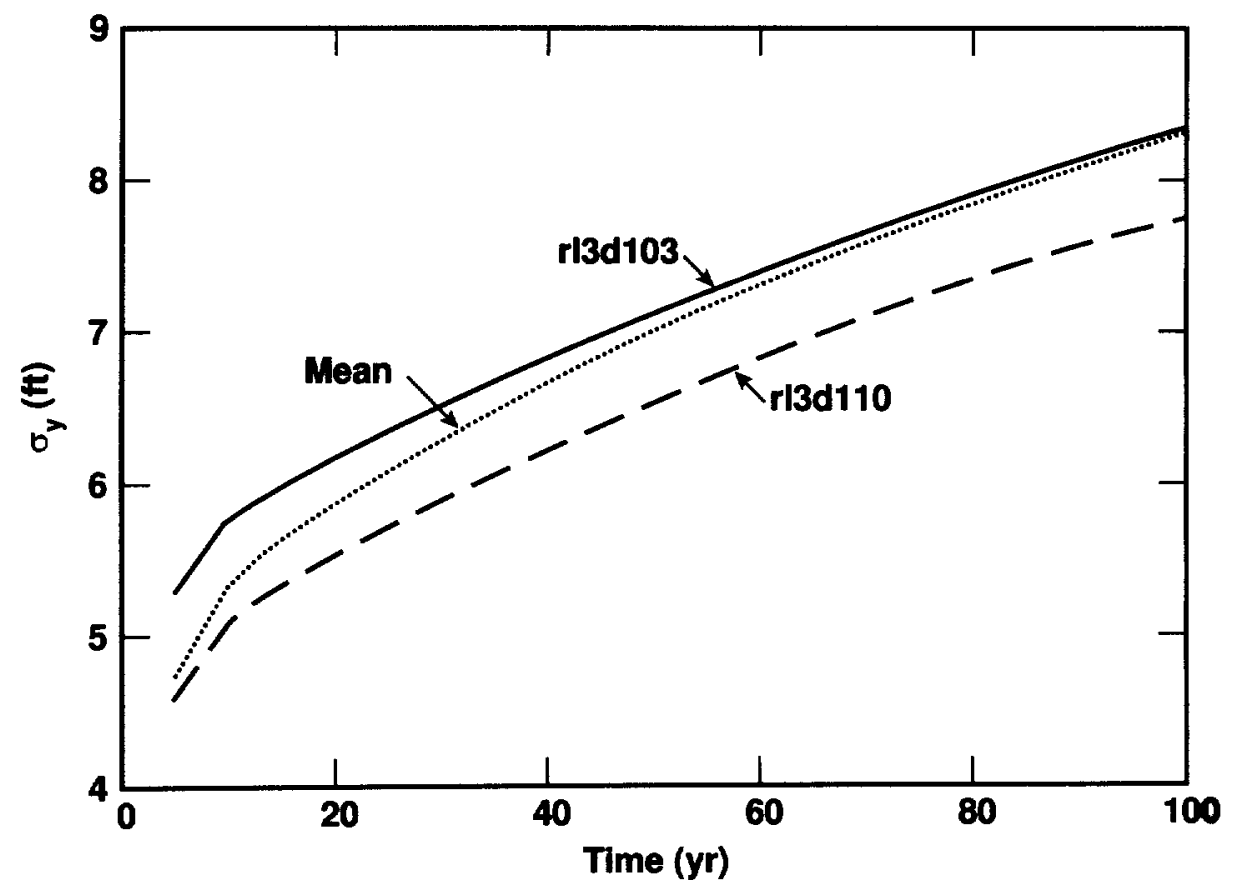

Figure 8.14: History of the spreading parameter $\sigma_{y}$ with partial blacktop cover. The three plots are 1) the average for Realizations rl3d101 through rl3d110, 2) rl3d103, and 3) rl3d110. 


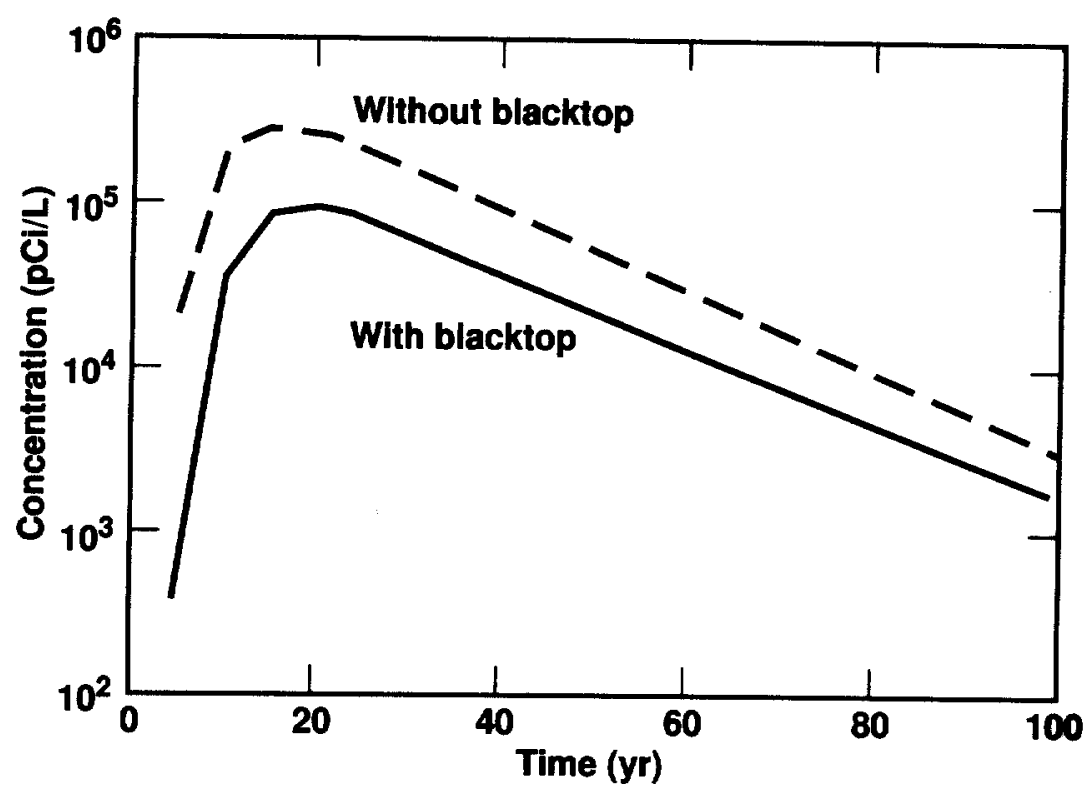

Figure 8.15: Effect of blacktop on peak groundwater concentration history for Realization rl3d101.

shown Figure 8.15. The figure shows histories of peak groundwater concentration for rl3d101, with and without the blacktop cover. Removing the blacktop causes the maximum groundwater ${ }^{3} \mathrm{H}$ concentration for the 100 -year simulation time to more than triple, rising from $9.23 \times 10^{4}$ to $2.85 \times 10^{5}$. The time taken to reach the maximum concentration is reduced from $19.5 \mathrm{yr}$ to $15.0 \mathrm{yr}$. For most of the simulation period, the peak concentration without the blacktop remains as least twice as large as the concentration with the blacktop in place.

The effect of blacktop removal on peak groundwater ${ }^{3} \mathrm{H}$ concentration for rl3d110 is similar to the effect observed for rl3d101. History plots of peak groundwater ${ }^{3} \mathrm{H}$ concentration for rl3d110, with and without the blacktop cover, are shown in Figure 8.16. Without the blacktop, the maximum groundwater ${ }^{3} \mathrm{H}$ concentration is increased by about a factor of seven, from $3.56 \times 10^{5}$ to $2.37 \times 10^{6}$, and the time to reach the maximum concentration 


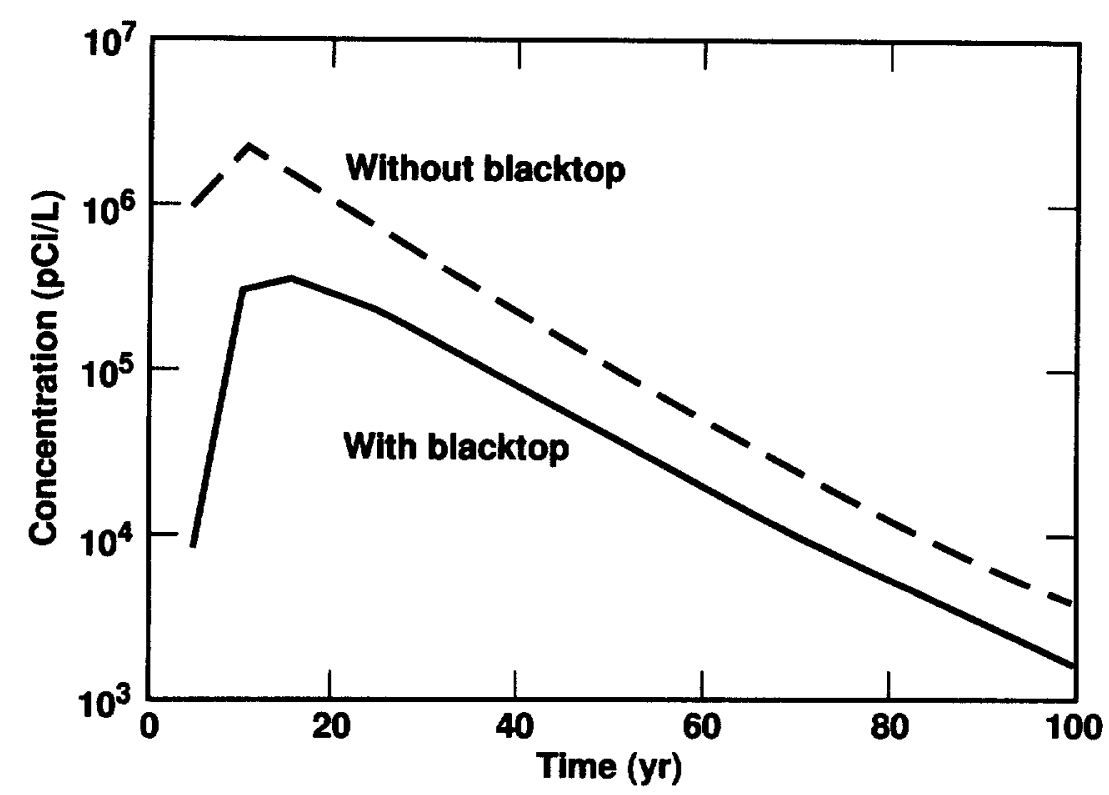

Figure 8.16: Effect of blacktop on peak groundwater concentration history for Realization rl3d110.

reduced from $13.5 \mathrm{yr}$ to $8.4 \mathrm{yr}$. Again, the concentration without the blacktop remains as least twice as large as that for the blacktop case for most of the simulation period.

For the two realizations, rl3d101 and rl3d110, we also compare the effect of blacktop removal on the cumulative tritium flux across the water table (Figure 8.17 and Figure 8.18), and movement of the plume's center-of-mass in the vadose zone (Figure 8.19 and Figure 8.20 ). For rl3d101, the 100 -yr cumulative ${ }^{3} \mathrm{H}$ flux across the water table increases by more than a factor of 4 , from $5.2 \mathrm{mCi}$ to $22.2 \mathrm{mCi}$, and for $\mathrm{rl} 3 \mathrm{~d} 110$, the flux increases by nearly a factor of 6 , from $13.9 \mathrm{mCi}$ to $79.5 \mathrm{mCi}$. Blacktop removal causes the plume's center-of-mass in the vadose zone to move downward faster. For rl3d101, removal of the blacktop causes the center of mass depth at $20 \mathrm{yr}$ to increase from $17.0 \mathrm{ft}$ to $19.7 \mathrm{ft}$, and the depth at $80 \mathrm{yr}$ to increase from $19.0 \mathrm{ft}$ to $22.0 \mathrm{ft}$. For most of the simulation period, the difference in depth of the center of mass, with and without the blacktop, increased slowly. 


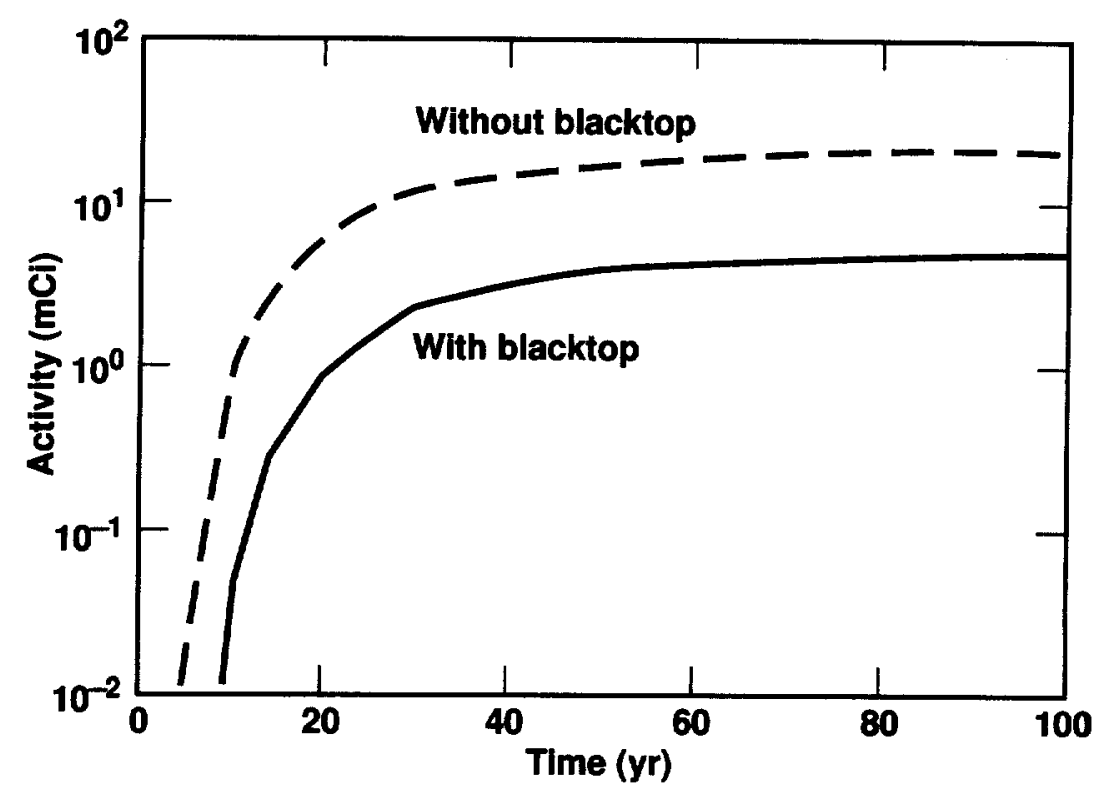

Figure 8.17: Effect of blacktop on cumulative flux of ${ }^{3} \mathrm{H}$ into the groundwater, for Realization $\mathrm{rl} 3 \mathrm{~d} 101$.

For rl3d110, removal of the blacktop causes the center of mass depth at $20 \mathrm{yr}$ to increase from $17.6 \mathrm{ft}$ to $19.7 \mathrm{ft}$, and the depth at $80 \mathrm{yr}$ to increase from $19.1 \mathrm{ft}$ to $22.2 \mathrm{ft}$. Again, the difference in depth of the center of mass, with and without the blacktop, increased slowly for most of the simulation period.

\subsection{Simulations using Soil Properties from Kriging}

Twelve simulation runs were conducted using a permeability field generated by kriging. The permeability field was the same for each run, but the van Genuchten parameters and porosity were varied from run to run, using the selection methods described in Chapter 4. van Genuchten's $\alpha$ was selected from the $\alpha-\mathrm{K}_{s}$ correlation (obtained from the data)

$$
\log \alpha=.237+.985 \log \sqrt{K}_{s}+\alpha_{e r r}
$$

The $\alpha_{\text {err }}$ term, which is the residual due to scatter on a log-log plot, is treated as a normally distributed random variable with mean zero and standard deviation $s_{e r r}$. The value of $s_{e r r}$ 


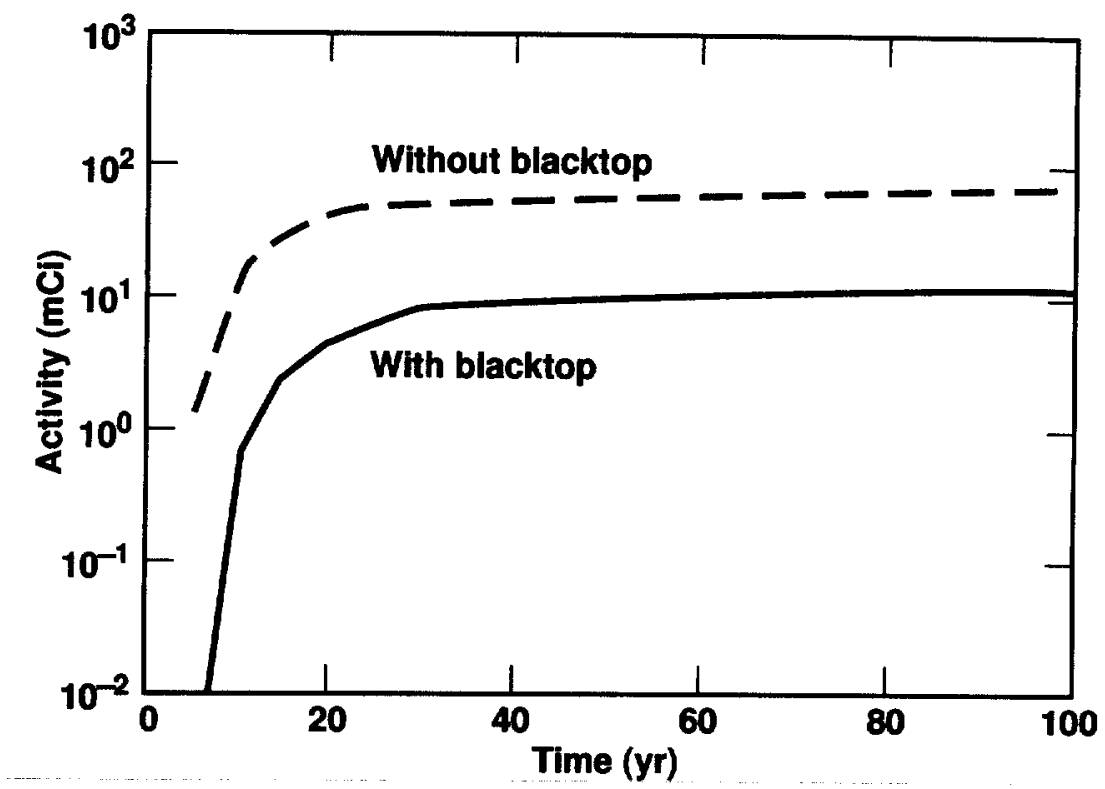

Figure 8.18: Effect of blacktop on cumulative flux of ${ }^{3} \mathrm{H}$ into the groundwater, for Realization rl3d110.

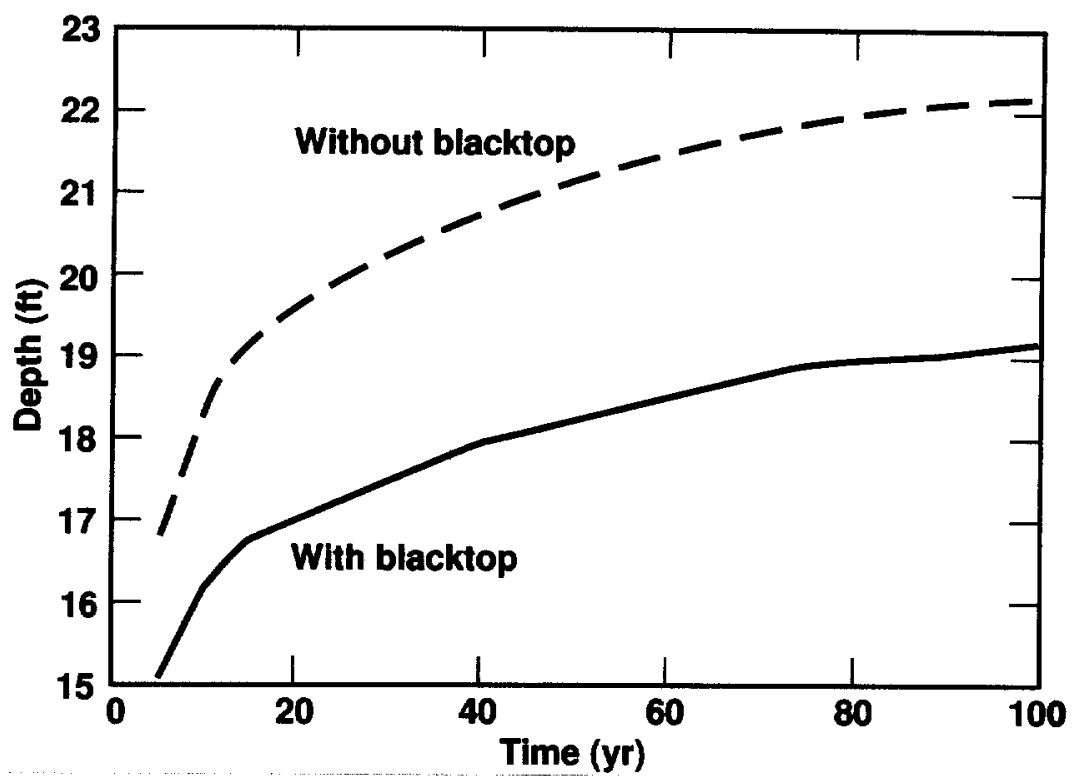

Figure 8.19: Effect of blacktop on movement of the plume's center-of-mass in the vadose zone, for Realization rl3d101. 


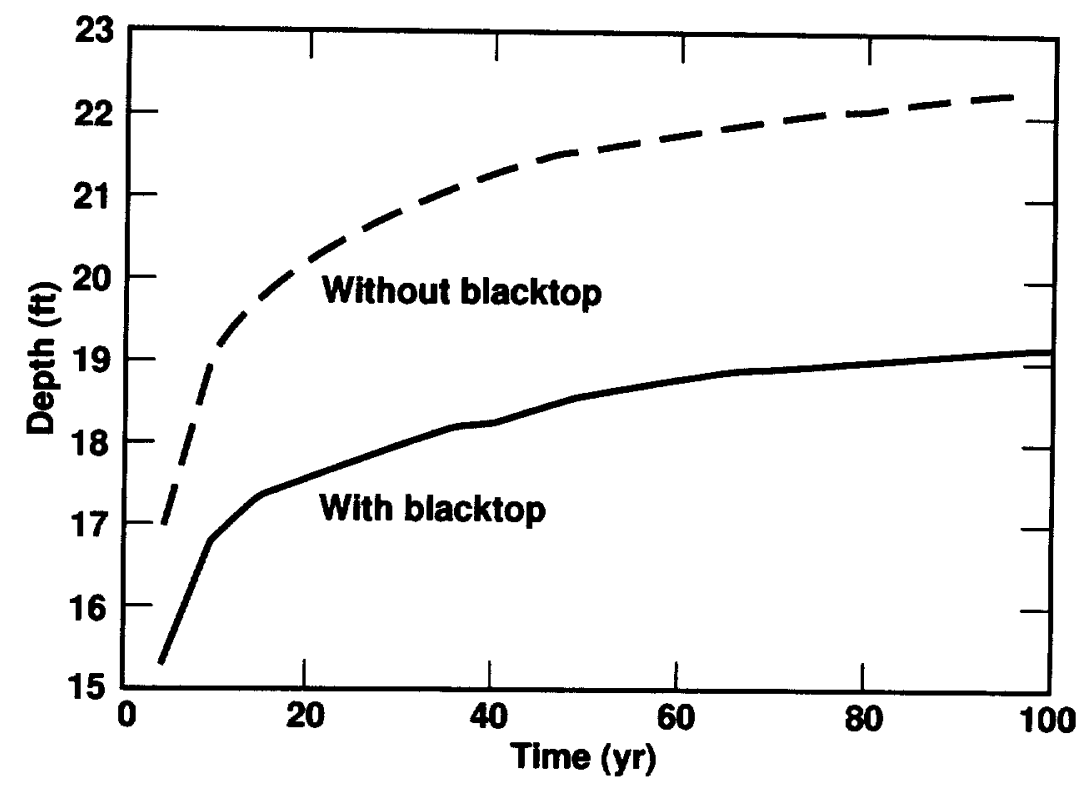

Figure 8.20: Effect of blacktop on movement of the plume's center-of-mass in the vadose zone, for Realization rl3d110.

was calculated as 0.455 from the data. The van Genuchten parameter, n, was randomly selected from a normal distribution of mean 1.50 and standard deviation 0.63 , values calculated from the data. Porosity was also randomly selected, from a normal distribution of mean 0.35 and standard deviation of 0.05 , also obtained from the data.

For the first ten runs, entitled rl3d301 through rl3d310, no infiltration was allowed through the blacktop; infiltration was allowed only through the exposed soil that occurred south of the tank. The remaining two runs, rl3d401 and rl3d410, were reruns of rl3d301 and rl3d310, respectively, with the blacktop removed to allow infiltration through the entire ground surface. 
Table 8.2: Summary of tritium transport results for three-dimensional simulation runs using a soil permeability field derived by ordinary kriging, with van Genuchten parameters and porosity selected using soil property correlations and random sampling. The same permeability field is used for each run, while the van Genuchten parameters and porosity vary from run to run. Run rl3d401 is a repeat of rl3d301 with the blacktop removed, and Run rl3d410 is a repeat of rl3d310 with the blacktop removed.

\begin{tabular}{||l|ccccc||}
\hline \hline Run ID & $\begin{array}{c}\text { Peak GW } \\
\text { Conc } \\
(\mathrm{pCi} / \mathrm{L})\end{array}$ & $\begin{array}{c}\text { Time of Peak } \\
\text { GW Conc } \\
(\mathrm{yr})\end{array}$ & $\begin{array}{c}\text { Plume Arrival } \\
\text { Time at WT } \\
(\mathrm{yr})\end{array}$ & $\begin{array}{c}\text { Cum 100-yr }{ }^{3} \mathrm{H} \\
\text { Flux across WT } \\
(\mathrm{mCi})\end{array}$ & $\begin{array}{c}\text { Center of Mass } \\
\text { Depth at 20 yr } \\
(\mathrm{ft})\end{array}$ \\
\hline rl3d301 & $1.67 \times 10^{4}$ & 25.0 & 9.9 & 1.20 & 13.5 \\
rl3d302 & $5.00 \times 10^{3}$ & 22.7 & 12.7 & 0.34 & 12.6 \\
rl3d303 & $3.31 \times 10^{3}$ & 30.0 & 18.3 & 0.33 & 12.8 \\
rl3d304 & $5.56 \times 10^{3}$ & 25.0 & 12.9 & 0.47 & 13.0 \\
rl3d305 & $3.64 \times 10^{3}$ & 28.4 & 18.2 & 0.30 & 12.9 \\
rl3d306 & $9.97 \times 10^{3}$ & 30.0 & 12.8 & 0.77 & 13.2 \\
rl3d307 & $1.08 \times 10^{4}$ & 30.0 & 12.7 & 0.84 & 12.5 \\
rl3d308 & $1.71 \times 10^{3}$ & 30.3 & NA* $^{*}$ & 0.26 & 12.7 \\
rl3d309 & $1.82 \times 10^{3}$ & 31.6 & NA & 0.34 & 12.6 \\
rl3d310 & $5.71 \times 10^{3}$ & 26.7 & 12.4 & 0.53 & 12.8 \\
& & & & & \\
Mean & $6.42 \times 10^{3}$ & 28.0 & - & 0.54 & 12.9 \\
Std dev & $4.73 \times 10^{3}$ & 2.9 & - & 0.31 & 0.3 \\
& & & & & \\
rl3d401 & $1.82 \times 10^{5}$ & 15.0 & 4.1 & 10.93 & 14.8 \\
rl3d410 & $7.58 \times 10^{4}$ & 15.0 & 5.0 & 6.78 & 14.8 \\
\hline \hline
\end{tabular}

* NA: $2,000 \mathrm{pCi} / \mathrm{L}$ isoconcentration surface never reached water table.

\subsubsection{Kriging Simulation Results}

Results of the kriging simulations are summarized in Table 8.2. The table presents peak groundwater concentration over the $100-\mathrm{yr}$ simulation period, the time this peak occurs, arrival time of the $2,000-\mathrm{pCi} / \mathrm{L}$ isoconcentration surface at the water table, the cumulative ${ }^{3} \mathrm{H}$ flux across the water table at $100 \mathrm{yr}$, and depth of the plume's center-of-mass at 20 yr. Peak groundwater concentrations for the blacktop-covered runs are also plotted in Figure 8.21.

The standard deviations and mean values in Table 8.2 show some variability in the transport results. The peak groundwater ${ }^{3} \mathrm{H}$ concentration, shown in Figure 8.21, varies moderately from run to run. However, these concentrations average only $6.42 \times 10^{3} \mathrm{pCi} / \mathrm{L}$, 


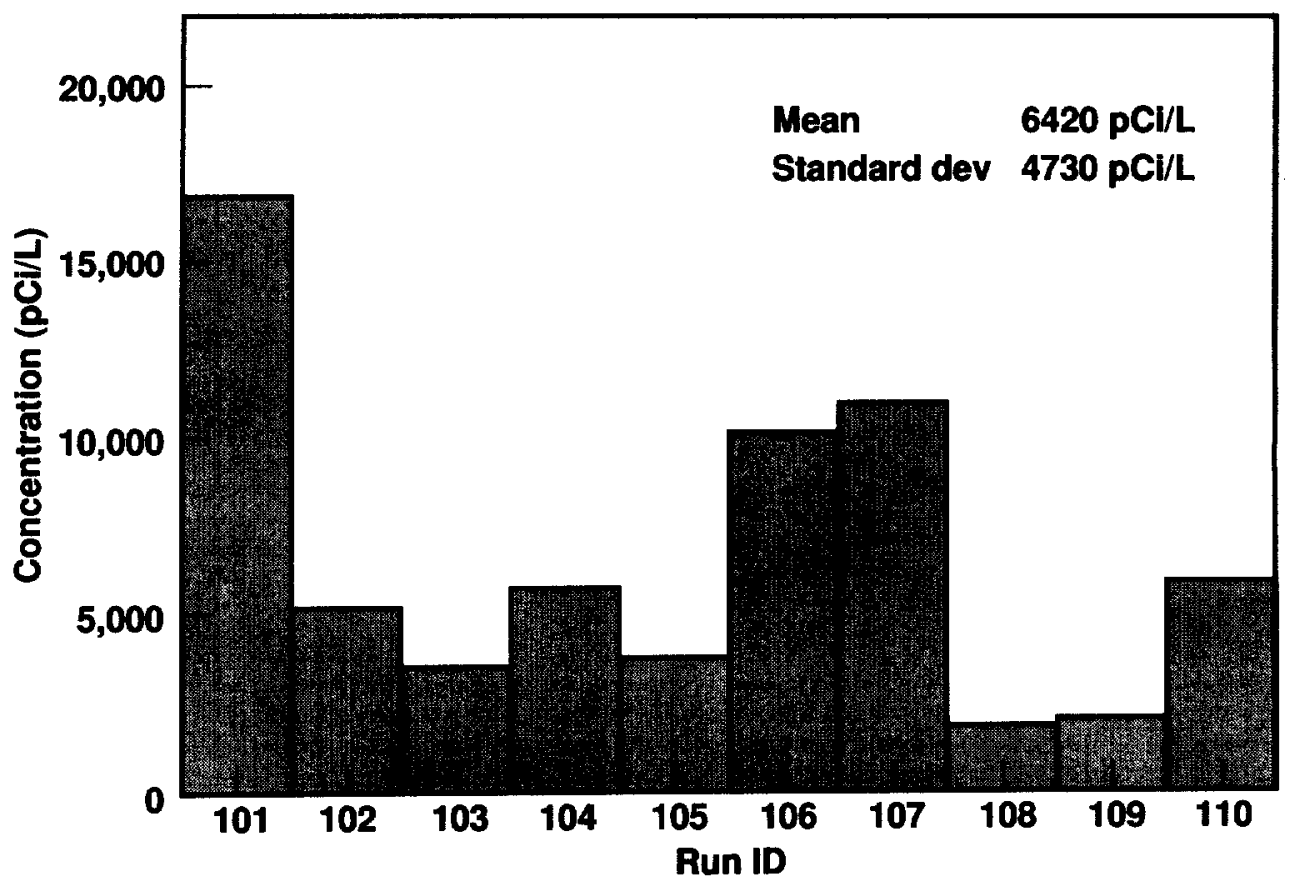

Figure 8.21: Peak groundwater ${ }^{3} \mathrm{H}$ concentrations for ten kriging runs with partial blacktop cover. The permeability field was the same for each run, but the van Genuchten parameter and porosity fields varied from run to run.

about 5 orders of magnitude lower than the source concentration of $4.5 \times 10^{8} \mathrm{pCi} / \mathrm{L}$. The groundwater concentrations here are therefore low enough to be considered in the "noise"; on the fringe of the accuracy of the calculations.

Since the permeability field is the same for all simulation runs, the variability observed here is all due to changes in water retention, relative hydraulic conductivity, and porosity. The results are not very sensitive to small changes in porosity. Therefore, the variability is probably due to changes in water retention and relative hydraulic conductivity resulting from random selection of the van Genuchten parameters. Similar results were presented by Schleuter and Pruess (1990) who showed that multiphase flow is sensitive to changes in relative permeability.

None of the blacktop-covered runs show any significant impact on groundwater quality. The peak groundwater concentration did not reach the groundwater standard in any of the 
runs. The highest groundwater concentration reached was $16,700 \mathrm{pCi} / \mathrm{L}$ for Run $\mathrm{rl3d} 301$. The $2,000-\mathrm{pCi} / \mathrm{L}$ isoconcentration surface arrived at the water table for eight of the ten runs. The cumulative activity of ${ }^{3} \mathrm{H}$ entering the groundwater was particularly low. For the ten runs, the average activity that entered the water table over the 100 -year simulation period was $0.54 \mathrm{mCi}$, which represents $0.007 \%$ of the 8 -curie source.

The impact on groundwater quality is increased substantially when Runs rl3d301 and rl3d310 are repeated (as rl3d401 and rl3d410) with the blacktop removed. Removal of the blacktop permits infiltration on the entire surface and therefore accelerates vertical transport of the ${ }^{3} \mathrm{H}$ through the vadose zone and into the groundwater.

Figure 8.22 compares the history of peak groundwater ${ }^{3} \mathrm{H}$ concentration for rl3d301 with and without the blacktop. Removal of the blacktop results in a much higher peak concentration, and the peak is reached earlier. Removing the blacktop for rl3d301 causes the peak concentration to increase over an order of magnitude, from $1.67 \times 10^{4}$ to $1.82 \times 10^{5}$. Time of the peak is reduced from $25 \mathrm{yr}$ to $15 \mathrm{yr}$. The effect of removing the blacktop on the cumulative flux of ${ }^{3} \mathrm{H}$ into the groundwater is shown in Figure 8.23. The 100-year cumulative ${ }^{3} \mathrm{H}$ activity crossing the water table is increased by nearly an order of magnitude, from 1.20 $\mathrm{mCi}$ to $10.9 \mathrm{mCi}$.

Figure 8.24 compares the history of peak groundwater ${ }^{3} \mathrm{H}$ concentration for $\mathrm{r} 13 \mathrm{~d} 310$ with and without the blacktop. As seen for rl3d301, removal of the blacktop results in a much higher peak concentration, and faster arrival of the peak. The peak concentration increased over an order of magnitude, from $5.71 \times 10^{3}$ to $7.58 \times 10^{4}$. Time of peak concentration is reduced from $27 \mathrm{yr}$ to $15 \mathrm{yr}$. The effect of removing the blacktop on the cumulative flux of ${ }^{3} \mathrm{H}$ into the groundwater is shown in Figure 8.25 . The 100 -year cumulative ${ }^{3} \mathrm{H}$ activity crossing the water table is increased over an order of magnitude, from $0.53 \mathrm{mCi}$ to $6.8 \mathrm{mCi}$. 


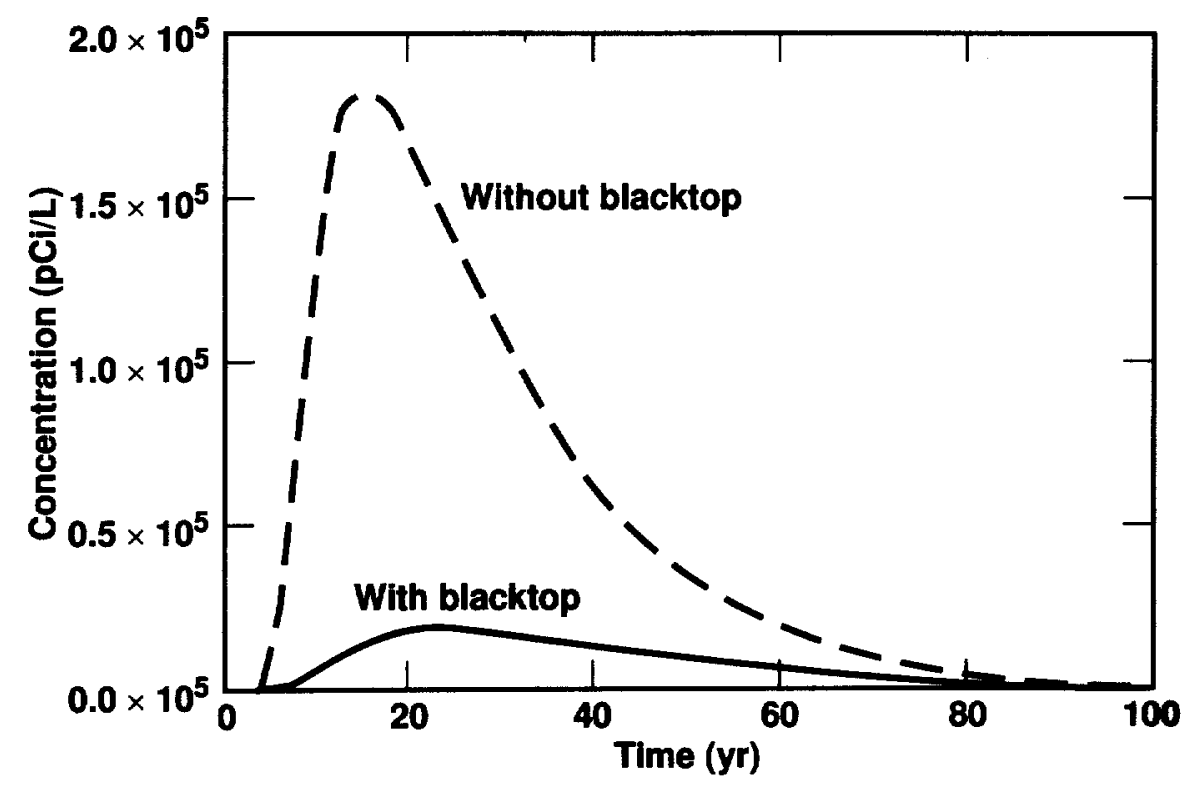

Figure 8.22: Effect of blacktop on history of peak groundwater ${ }^{3} \mathrm{H}$ concentration, using permeability field rl3d301 from kriging.

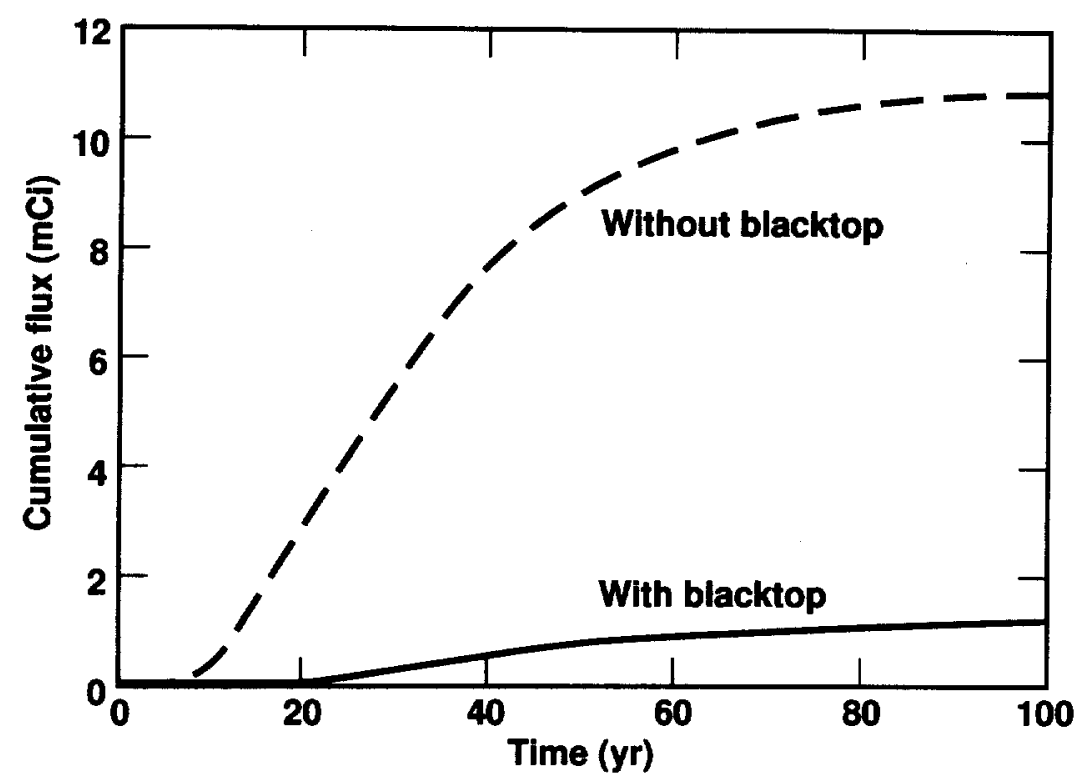

Figure 8.23: Effect of blacktop on history of cumulative ${ }^{3} \mathrm{H}$ activity entering the groundwater, using permeability field rl3d301 from kriging. 


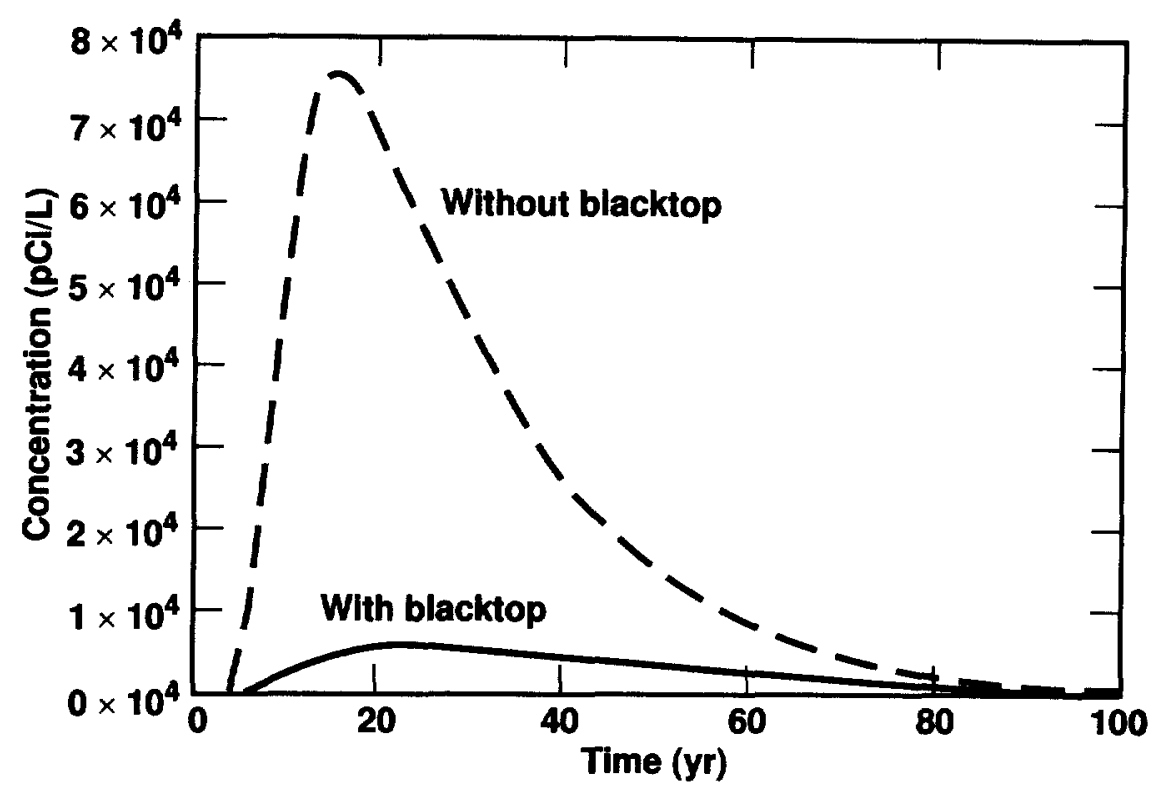

Figure 8.24: Effect of blacktop on history of peak groundwater ${ }^{3} \mathrm{H}$ concentration, using permeability field rl3d310 from kriging.

\subsection{Comparison of Transport Results Using Soil Properties from Condi- tional Simulation and Kriging}

Table 8.3 compares some of the ${ }^{3} \mathrm{H}$ transport parameters for the ten simulations that used soil properties obtained by conditional simulation with corresponding parameters for the ten simulations that used soil properties obtained by kriging. The table includes only the case where the blacktop is in place. Results using soil properties from conditional simulation show a significantly higher impact of the ${ }^{3} \mathrm{H}$ release on groundwater quality at the site. The peak groundwater ${ }^{3} \mathrm{H}$ concentration for the conditional simulation case is 20 times the value for the kriging case. The peak concentration for the kriging case, $6420 \mathrm{pCi} / \mathrm{L}$, is only $32 \%$ of the groundwater standard, $20,000 \mathrm{pCi} / \mathrm{L}$. The peak groundwater concentration for the conditional simulation case is reached $23 \%$ faster, $21.5 \mathrm{yr}$ versus 28.0 yr for the kriging 


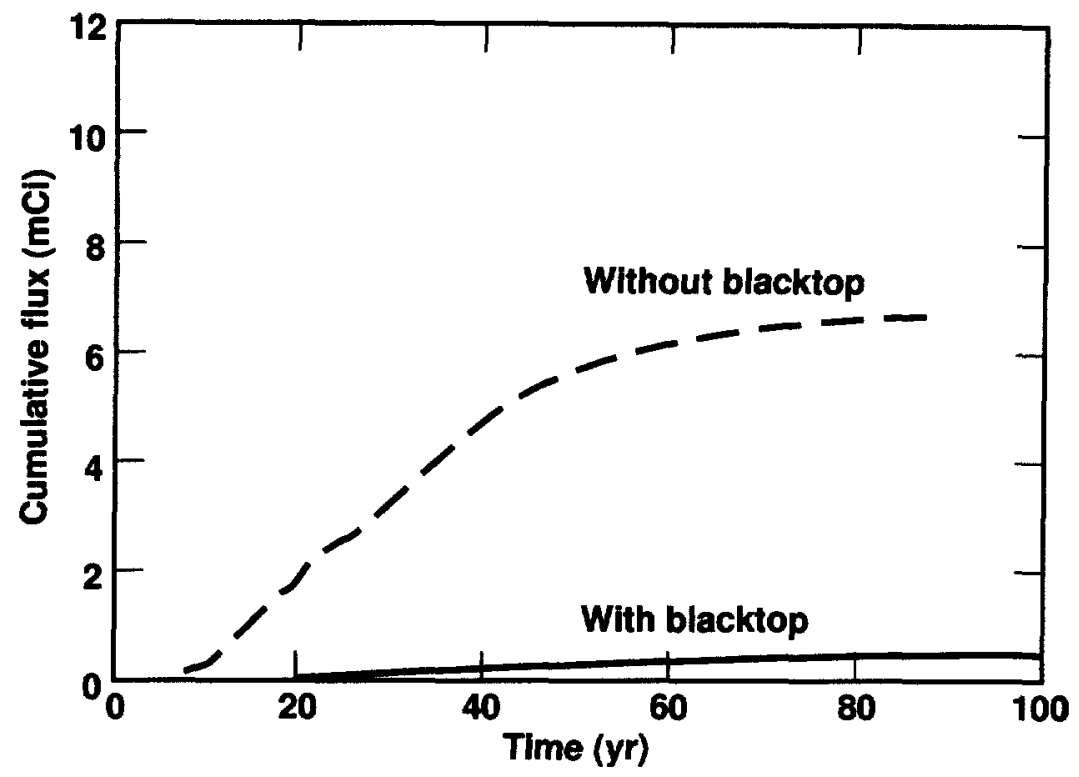

Figure 8.25: Effect of blacktop on history of cumulative ${ }^{3} \mathrm{H}$ activity entering the groundwater, using permeability field rl3d310 from kriging.

case. For both cases, only a very small fraction of the 8 -Ci source activity reaches the groundwater during the 100-year simulation period. For the conditional simulation case, about $0.07 \%$ of the source entered the groundwater, compared with $0.007 \%$ for the kriging case.

Table 8.3: Comparison of some parameters that describe the ${ }^{3} \mathrm{H}$ transport for simulations using soil properties from conditional simulation and kriging. The blacktop cover was in place for these simulations.

\begin{tabular}{|l|cc|cc|}
\hline \multirow{2}{*}{ Parameter } & \multicolumn{2}{|c|}{ Conditional Simulation } & \multicolumn{2}{|c|}{ Kriging } \\
\cline { 2 - 5 } & Mean & Std dev & Mean & Std dev \\
\hline Peak GW con (pCi/L) & $1.29 \times 10^{5}$ & $1.30 \times 10^{5}$ & $6.42 \times 10^{3}$ & $4.73 \times 10^{3}$ \\
Time of peak con (yr) & 21.5 & 6.5 & 28.0 & 2.9 \\
Cum 100-yr GW flux (mCi) & 5.2 & 4.5 & 0.54 & 0.31 \\
CM depth at 20 yr (ft) & 14.8 & 1.7 & 12.9 & 0.31 \\
\hline \hline
\end{tabular}


Table 8.4: Comparison of root mean squared difference (RMSD) between concentration fields from numerical calculations using conditional simulation and from field sampling.

\begin{tabular}{|c|cccc|}
\hline \hline \multirow{2}{*}{ Run ID } & \multicolumn{4}{|c|}{ RMSD $(\mathrm{pCi} / \mathrm{L})$} \\
\cline { 2 - 5 } & $5 \mathrm{yr}$ & $10 \mathrm{yr}$ & $15 \mathrm{yr}$ & $20 \mathrm{yr}$ \\
\hline rl3d101 & $5.86 \times 10^{7}$ & $4.08 \times 10^{7}$ & $2.92 \times 10^{7}$ & $2.21 \times 10^{7}$ \\
rl3d102 & $4.17 \times 10^{7}$ & $2.75 \times 10^{7}$ & $1.89 \times 10^{7}$ & $1.38 \times 10^{7}$ \\
rl3d103 & $3.37 \times 10^{7}$ & $2.29 \times 10^{7}$ & $1.57 \times 10^{7}$ & $1.10 \times 10^{7}$ \\
rl3d104 & $2.92 \times 10^{7}$ & $2.02 \times 10^{7}$ & $1.40 \times 10^{7}$ & $1.01 \times 10^{7}$ \\
rl3d105 & $2.66 \times 10^{7}$ & $1.84 \times 10^{7}$ & $1.27 \times 10^{7}$ & $9.13 \times 10^{6}$ \\
rl3d106 & $2.14 \times 10^{7}$ & $1.37 \times 10^{7}$ & $9.11 \times 10^{6}$ & $6.62 \times 10^{6}$ \\
rl3d107 & $2.38 \times 10^{7}$ & $1.61 \times 10^{7}$ & $1.11 \times 10^{7}$ & $7.99 \times 10^{6}$ \\
r13d108 & $1.66 \times 10^{7}$ & $1.00 \times 10^{7}$ & $6.42 \times 10^{6}$ & $4.66 \times 10^{6}$ \\
rl3d109 & $1.87 \times 10^{7}$ & $1.22 \times 10^{7}$ & $8.45 \times 10^{6}$ & $6.30 \times 10^{6}$ \\
rl3d110 & $1.77 \times 10^{7}$ & $1.14 \times 10^{7}$ & $7.70 \times 10^{6}$ & $5.59 \times 10^{6}$ \\
& & & & \\
Mean & $2.88 \times 10^{7}$ & $1.93 \times 10^{7}$ & $1.33 \times 10^{7}$ & $9.73 \times 10^{6}$ \\
\hline \hline
\end{tabular}

\subsection{Comparison of Numerical Calculations with Measured Concentra- tions}

In this section we compare vadose zone soil water ${ }^{3} \mathrm{H}$ concentrations calculated using perme-

ability fields obtained by conditional simulation and kriging with concentrations measured in the field, and then use the results to select the best-fit realization based on the minimum root mean squared difference (RMSD). The measured ${ }^{3} \mathrm{H}$ concentration field is the one estimated in Chapter 5 by applying ordinary kriging to ${ }^{3} \mathrm{H}$ concentrations from borehole samples collected between 1989 and 1992 .

RMSD values for the conditional simulation runs are are shown in Table 8.4, and values for the kriging run in Table 8.5. The tables show lower mean RMSD values for the conditional simulation case than for the kriging case, indicating that soil properties generated by conditional simulation generally matched the field conditions closer than properties generated by kriging. The run with the lowest RMSD is the conditional simulation run rl3d108. The results from this run will therefore be used, along with average results from all conditional simulation runs, to forecast the impact of the ${ }^{3} \mathrm{H}$ release on soil and groundwater 
Table 8.5: Comparison of root mean squared difference (RMSD) between concentration fields from numerical calculations using kriging and from field sampling.

\begin{tabular}{|c|cccc|}
\hline \hline \multirow{2}{*}{ Run ID } & \multicolumn{4}{|c|}{ RMSD (pCi/L) } \\
\cline { 2 - 5 } & $5 \mathrm{yr}$ & $10 \mathrm{yr}$ & $15 \mathrm{yr}$ & $20 \mathrm{yr}$ \\
\hline rl3d301 & $6.06 \times 10^{7}$ & $4.27 \times 10^{7}$ & $3.00 \times 10^{7}$ & $2.17 \times 10^{7}$ \\
rl3d302 & $4.27 \times 10^{7}$ & $3.00 \times 10^{7}$ & $2.08 \times 10^{7}$ & $1.48 \times 10^{7}$ \\
rl3d303 & $3.46 \times 10^{7}$ & $2.43 \times 10^{7}$ & $1.69 \times 10^{7}$ & $1.21 \times 10^{7}$ \\
rl3d304 & $3.04 \times 10^{7}$ & $2.16 \times 10^{7}$ & $1.51 \times 10^{7}$ & $1.08 \times 10^{7}$ \\
rl3d305 & $2.68 \times 10^{7}$ & $1.91 \times 10^{7}$ & $1.33 \times 10^{7}$ & $9.52 \times 10^{6}$ \\
rl3d306 & $2.46 \times 10^{7}$ & $1.75 \times 10^{7}$ & $1.23 \times 10^{7}$ & $8.91 \times 10^{6}$ \\
rl3d307 & $2.29 \times 10^{7}$ & $1.62 \times 10^{7}$ & $1.13 \times 10^{7}$ & $8.17 \times 10^{6}$ \\
rl3d308 & $2.10 \times 10^{7}$ & $1.48 \times 10^{7}$ & $1.03 \times 10^{7}$ & $7.41 \times 10^{6}$ \\
rl3d309 & $1.99 \times 10^{7}$ & $1.40 \times 10^{7}$ & $9.70 \times 10^{6}$ & $6.92 \times 10^{6}$ \\
rl3d310 & $1.91 \times 10^{7}$ & $1.36 \times 10^{7}$ & $9.49 \times 10^{6}$ & $6.84 \times 10^{6}$ \\
& & & & \\
Mean & $3.03 \times 10^{7}$ & $2.14 \times 10^{7}$ & $1.49 \times 10^{7}$ & $1.07 \times 10^{7}$ \\
\hline \hline
\end{tabular}

quality at the site.

\subsection{Simulation Results with Best-fit Realization}

We examine the simulation results obtained with the best-fit realization, rl3d108, to make predictions of future vadose zone and groundwater ${ }^{3} \mathrm{H}$ concentrations at the site. As with the worst-case realization, $\mathrm{rl3d} 110$, the blacktop run using rl3d108 was repeated to include mechanical dispersion in the aquifer. Results shown here are for the run that includes dispersion. The results are presented using concentration profiles and images at selected locations in the vadose zone and groundwater.

\subsubsection{Vadose Zone}

Figure 8.26 shows images of the vadose zone soil water ${ }^{3} \mathrm{H}$ concentration along an east-west section through the leak point, obtained using stochastic realization rl3d108. Images are presented at $5,10,15$, and $25 \mathrm{yr}$. The concentrations shown range from the groundwater standard, $2.0 \times 10^{4} \mathrm{pCi} / \mathrm{L}$, at the outer edge of the plume, to the maximum concentration 
of about $3.2 \times 10^{8} \mathrm{pCi} / \mathrm{L}$ shown in the 5-year image. Concentrations below the groundwater standard are not shown. The plume is relatively narrow, with a maximum width of about $57 \mathrm{ft}$ in the east-west direction. The arrival time at the water table, presented earlier in Table 8.1 , is $6.9 \mathrm{yr}$. The groundwater concentration is reduced to levels below the groundwater standard at a distance of about $30 \mathrm{ft}$ downstream of the leak. At $25 \mathrm{yr},{ }^{3} \mathrm{H}$ concentrations above the groundwater standard in this section occur only in the vadose zone. Two other important observations are the slow downward movement of the plume's center of mass and slow reduction of peak vadose zone concentrations.

Soil water ${ }^{3} \mathrm{H}$ concentration profiles along a vertical line through the leak are shown in Figure 8.27. Profiles are drawn at 10, 20,40,60, 80, and $100 \mathrm{yr}$. The slow reduction in vadose zone ${ }^{3} \mathrm{H}$ concentrations is again evident. There is no distinct downward movement of the crest of the profile. The crest becomes less defined with time as the initially steep concentration gradients are reduced. Vadose zone ${ }^{3} \mathrm{H}$ concentrations remain relatively high for several decades. At $40 \mathrm{yr}$, the profile between depths of $3 \mathrm{ft}$ and $20 \mathrm{ft}$ have concentrations that exceed $1.0 \times 10^{7} \mathrm{pCi} / \mathrm{L}$. Even at $80 \mathrm{yr},{ }^{3} \mathrm{H}$ concentrations at depths between about 5 $\mathrm{ft}$ and $20 \mathrm{ft}$ exceed $1.0 \times 10^{6} \mathrm{pCi} / \mathrm{L}$. The slow reduction in vadose zone ${ }^{3} \mathrm{H}$ concentrations for the entire model is shown in Figure 8.28. The figure shows histories of the maximum vadose zone concentration for $\mathrm{rl} 3 \mathrm{~d} 108$ and the mean for the ten conditional simulation runs with blacktop in place.

\subsubsection{Groundwater}

With mechanical dispersion in the aquifer modeled as a Fickian process, the peak groundwater ${ }^{3} \mathrm{H}$ concentration $100 \mathrm{ft}$ downstream of the leak is $7.59 \times 10^{3} \mathrm{pCi} / \mathrm{L}, 38 \%$ of the groundwater standard. This peak concentration occurs at about 15 yr. Figure 8.29 shows 

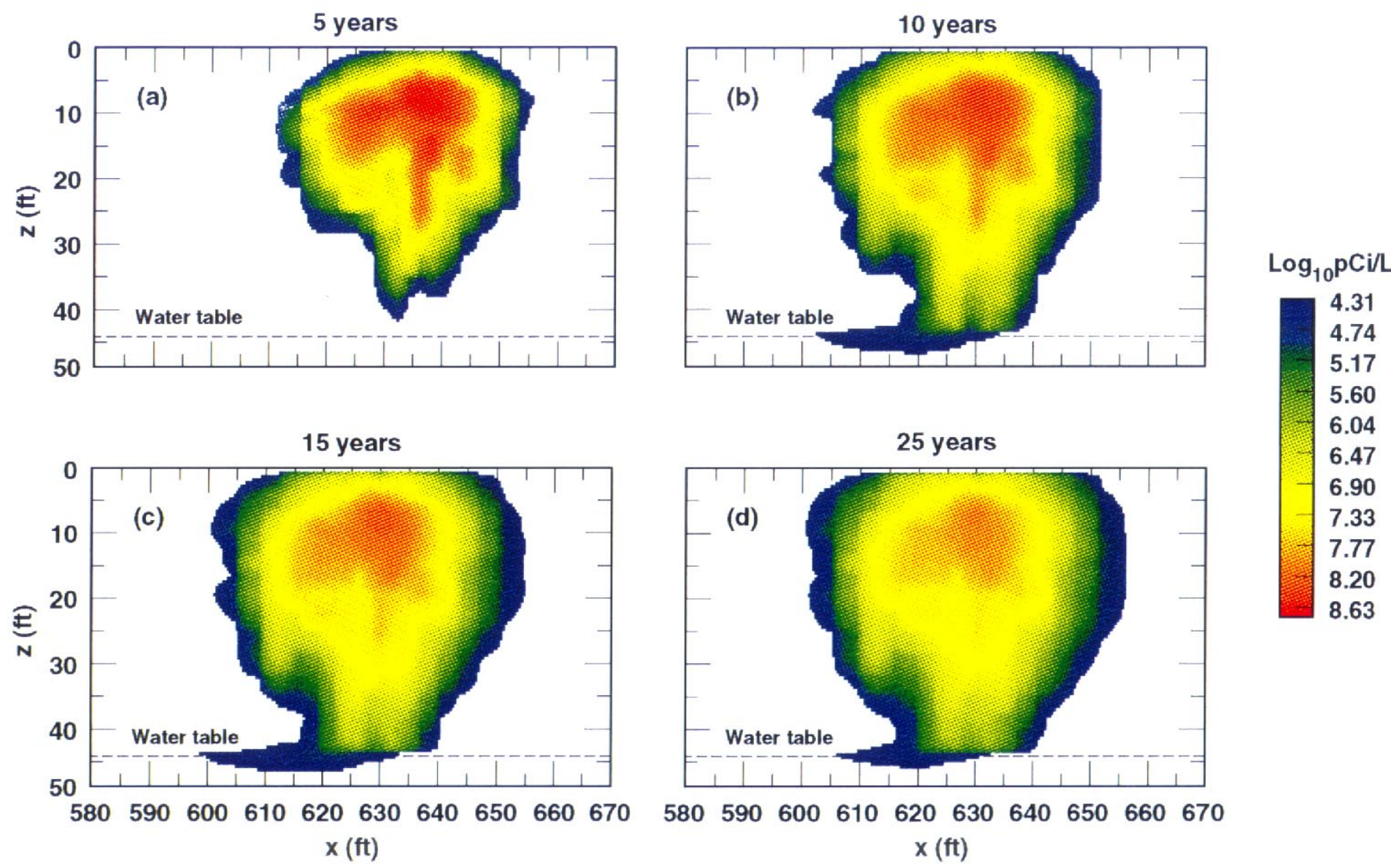

Figure 8.26: Images of vadose zone soil water ${ }^{3} \mathrm{H}$ concentrations along east-west section through the leak for simulation run using stochastic realization $\mathrm{rl} 3 \mathrm{~d} 108$. 


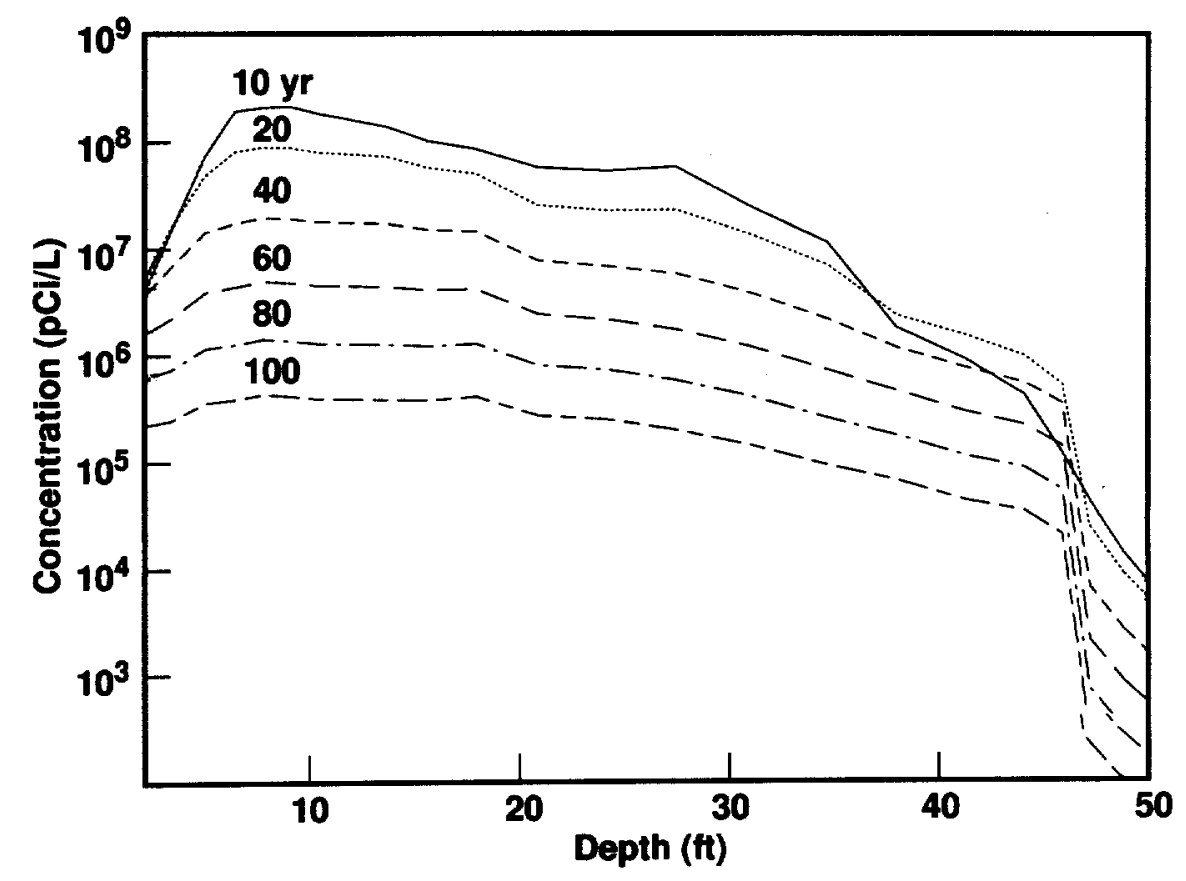

Figure 8.27: Soil water tritium concentration profile along vertical line through leak node at various times. Results of run using stochastic realization rl3d108.

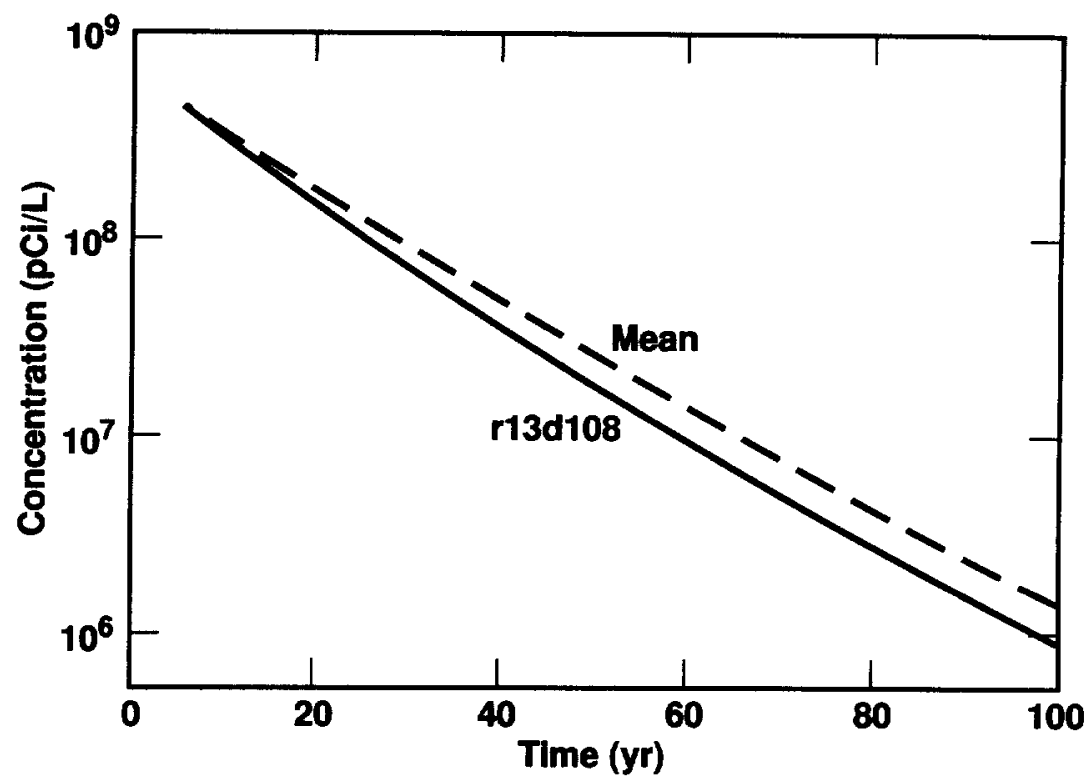

Figure 8.28: History of maximum vadose zone soil water ${ }^{3} \mathrm{H}$ concentration for stochastic realization $\mathrm{rl} 3 \mathrm{~d} 108$ and for the mean CS case. 


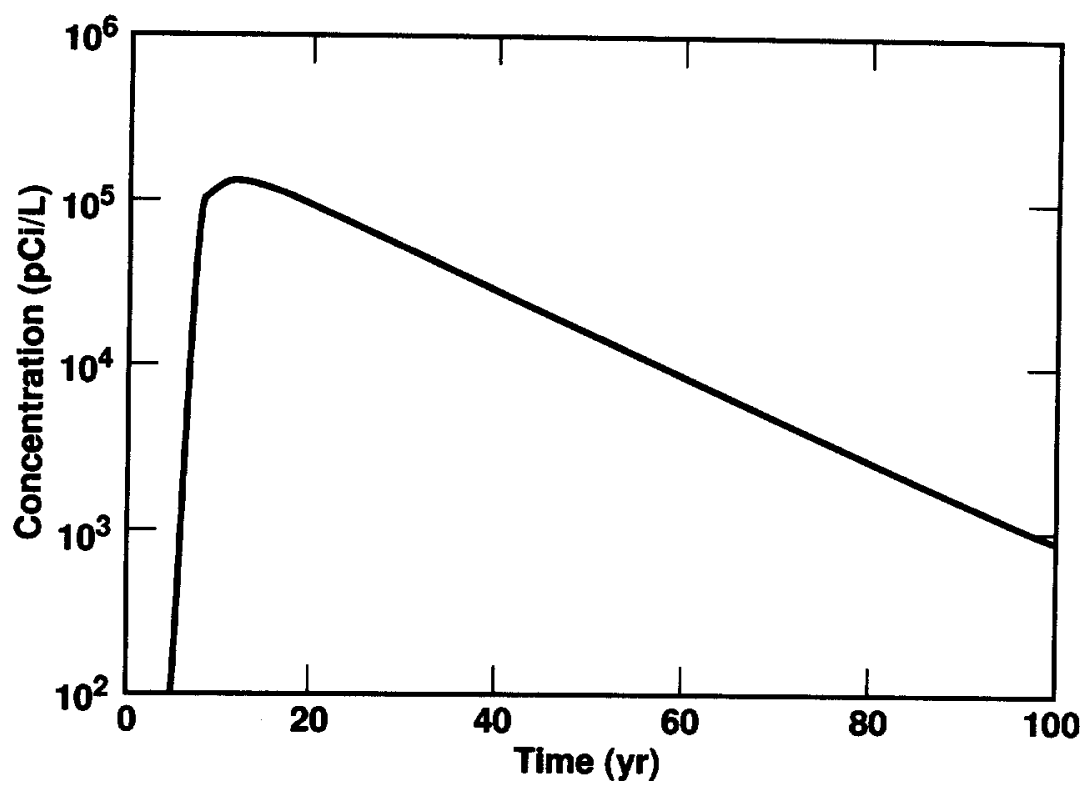

Figure 8.29: History of maximum groundwater ${ }^{3} \mathrm{H}$ concentration for best-fit stochastic realization rl3d108.

a history of the maximum groundwater ${ }^{3} \mathrm{H}$ concentration for the entire model. The peak concentration in the entire aquifer is $1.17 \times 10^{5} \mathrm{pCi} / \mathrm{L}$ at $11 \mathrm{yr}$, and the location is directly below the leak.

Figure 8.30 shows images of the groundwater ${ }^{3} \mathrm{H}$ plume obtained using rl3d108. The plume is shown in plan view at the water table beneath the leak point. Images are drawn at 10,15 , and $20 \mathrm{yr}$. As for the vadose zone, we define the outer edge of the plume as the $20,000 \mathrm{pCi} / \mathrm{L}$ concentration contour. The figure shows a groundwater plume that increases in size from $10 \mathrm{yr}$ to $15 \mathrm{yr}$ and then shrinks between $15 \mathrm{yr}$ and $20 \mathrm{yr}$. The maximum concentration shown in the three images is about $1.1 \times 10^{5} \mathrm{pCi} / \mathrm{L}$ at $10 \mathrm{yr}$. The maximum plume length is $26 \mathrm{ft}$, and maximum width $6 \mathrm{ft}$, both observed in the 15 -yr image. At $20 \mathrm{yr}$, only a thin 12-foot long strip of groundwater area remain at concentrations above 20,000 $\mathrm{pCi} / \mathrm{L}$. 


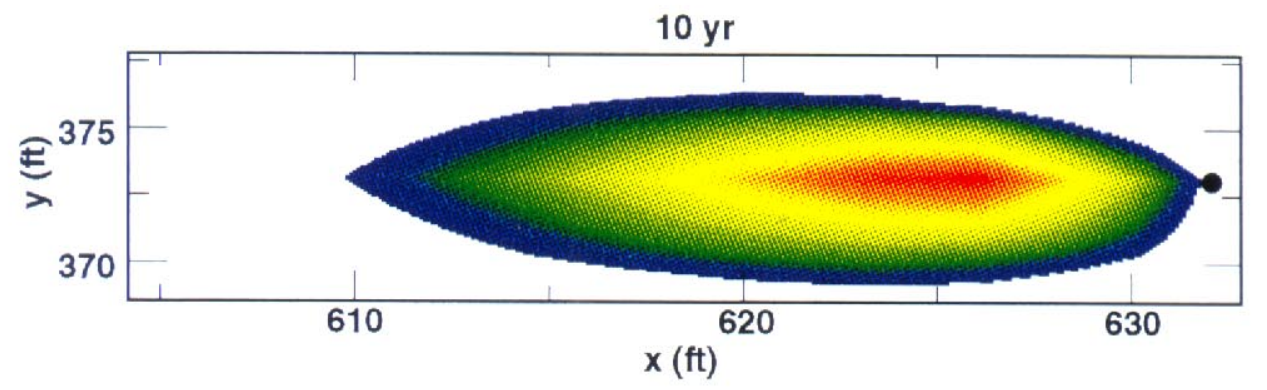

$\log _{10} p C i / L$

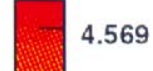

4.543

4.516

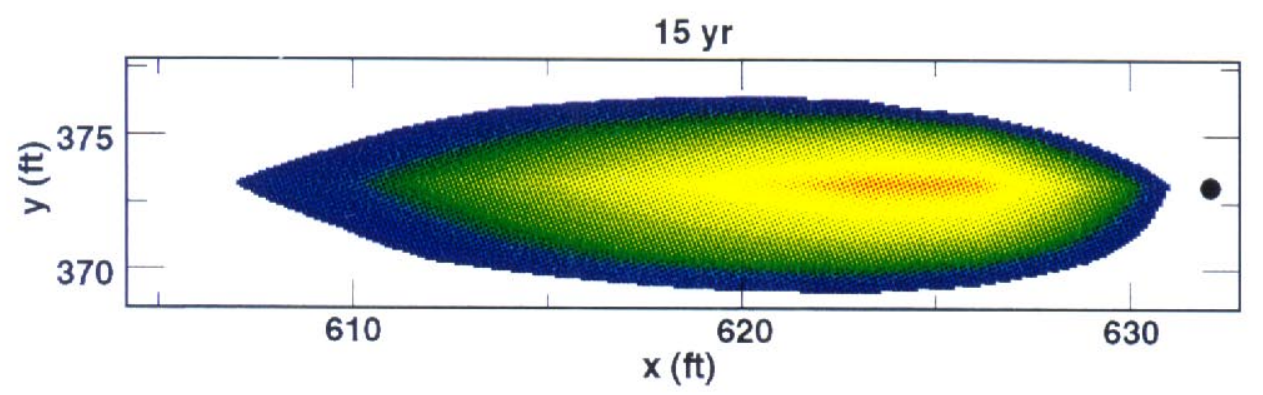

4.489

4.462

4.435

4.409

4.382

4.355

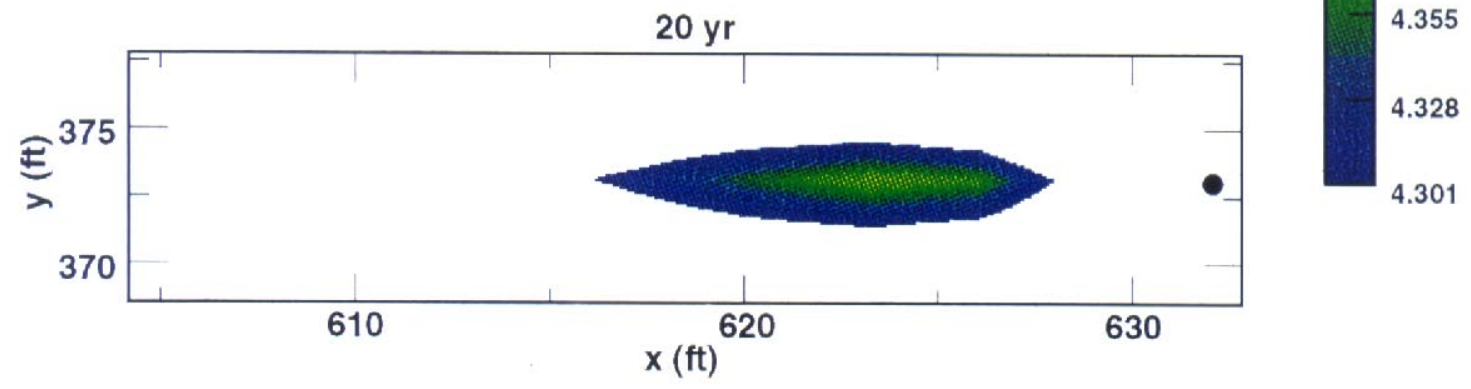

- Leak

Figure 8.30: Images of groundwater ${ }^{3} \mathrm{H}$ concentrations at the water table, from bestfit stochastic realization rl3d108. Outer edge of plume shown is the groundwater standard for ${ }^{3} \mathrm{H}, 20,000 \mathrm{pCi} / \mathrm{L}$. 


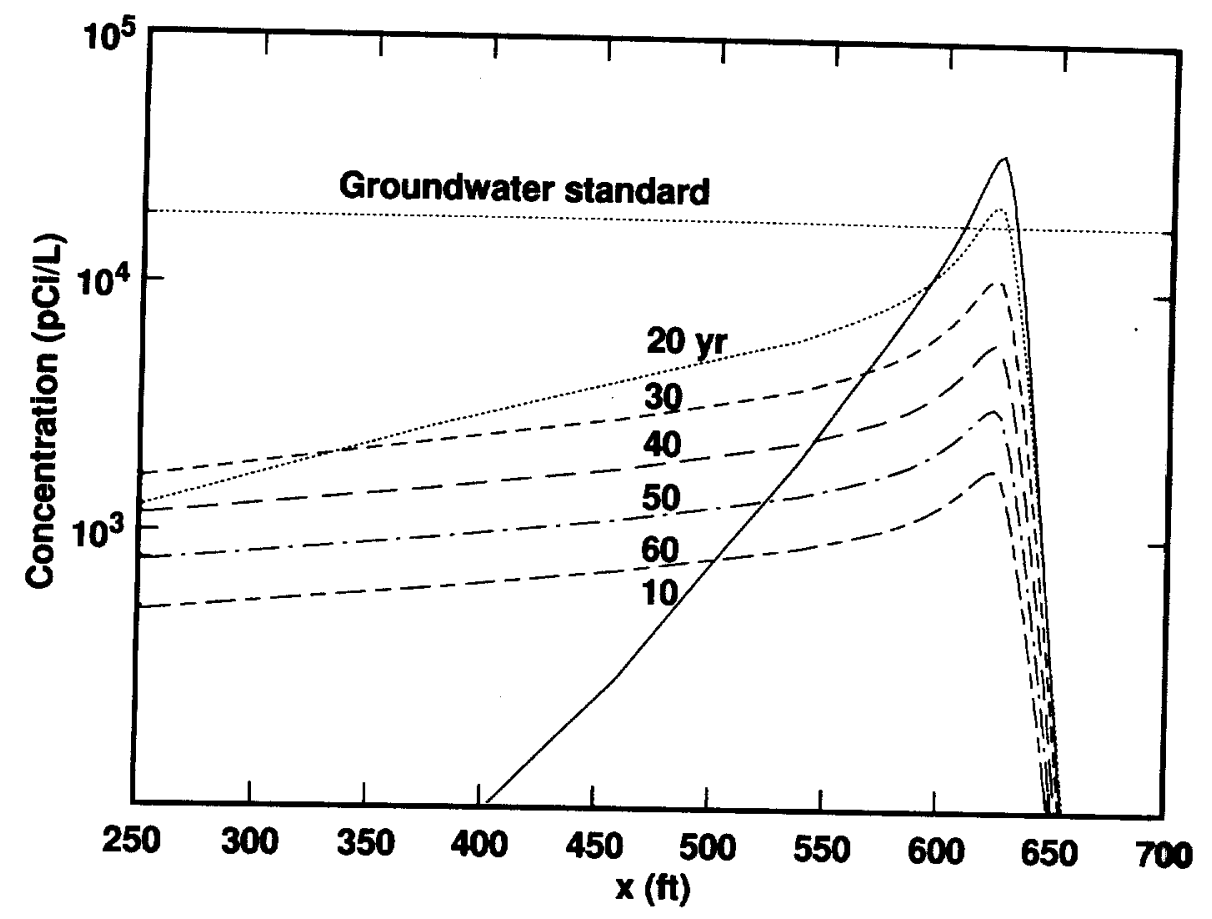

Figure 8.31: Groundwater ${ }^{3} \mathrm{H}$ concentrations along an east-west line at the water table directly beneath the leak. Results from best-fit stochastic realization $\mathrm{rl3d} 108$ at various times.

Figure 8.31 shows groundwater ${ }^{3} \mathrm{H}$ concentrations along an east-west line at the water table directly beneath the leak. Concentrations are shown at 10 year intervals, from $10 \mathrm{yr}$ through $60 \mathrm{yr}$. The highest concentration shown is $3.8 \times 10^{4} \mathrm{pCi} / \mathrm{L}$ at $10 \mathrm{yr}$. The highest concentration along the line is always directly below the leak which has an x-coordinate of $632 \mathrm{ft}$. The peak concentration drops off and concentration gradients flatten out with time. Concentrations exceed $20,000 \mathrm{pCi} / \mathrm{L}$ at $10 \mathrm{yr}$ and $20 \mathrm{yr}$ for short horizontal distances: the maximum distance observed is about $30 \mathrm{ft}$ at $10 \mathrm{yr}$. 


\section{Summary and Conclusions}

\subsection{Summary}

The analysis of contaminant transport in the vadose zone continues to present challenging problems for earth scientists. One of the more serious problems stems from the difficulty in using limited data to characterize the usually high degree of spatial variability observed at heterogeneous field sites. Site characterization for transport modeling in the vadose zone is much more complicated and expensive than in the saturated zone, mainly because a much larger number of model parameters is needed. Moreover, many vadose zone parameters are much more difficult and costly to measure. These problems highlight the need to find more effective methods of dealing with spatial variability in the analysis of vadose zone contaminant transport.

We have presented and demonstrated a methodology that will substantially increase the effectiveness of vadose zone contaminant transport analysis while reducing the high cost usually associated with site characterization in heterogeneous soils. Our approach combines stochastic simulation and other geostatistical techniques, soil property correlation, and numerical modeling to maximize the utilization of scarce data.

The study site is the Building 292 Area at Lawrence Livermore National Laboratory, where the soil close to an underground tank storing tritiated water was contaminated with ${ }^{3} \mathrm{H}$ at levels measured up to 220 million $\mathrm{pCi} / \mathrm{L}$ of soil water. Our primary objective was to investigate the applicability of geostatistical techniques, soil property correlation, and numerical modeling to study the transport behavior of tritium at a heterogeneous vadose zone site. A second objective was to use the data available from site characterization and monitoring to study the transport behavior of ${ }^{3} \mathrm{H}$ in the subsurface and to predict the impact of the release on future soil and groundwater quality at the site. 
In Chapter 4, we developed permeability sample variograms and soil property correlations from the data. Stochastic simulation and ordinary kriging techniques, also described in Chapter 4, were applied to develop realizations of soil permeability fields. In Chapter 5 , ordinary kriging was applied to estimate the distribution of ${ }^{3} \mathrm{H}$ concentration in the soil water and the total activity of ${ }^{3} \mathrm{H}$ in the vadose zone.

In Chapter 7, we described a series of two-dimensional simulation runs to examine how the impact of the release on groundwater and soil quality is affected by:

- uncertainty in soil properties due to heterogeneity

- the rate of infiltration

- vapor diffusion.

A Monte Carlo analysis was done to assess the effect of uncertainty in soil properties. The analysis included generating 100 realizations of the soil permeability field by conditional simulation and conducting two-dimensional numerical transport simulations using each of the realizations. Results of the Monte Carlo analysis were compared with the results of a numerical simulation run using a permeability field derived by ordinary kriging. We conducted a series of $2 \mathrm{D}$ runs as part of sensitivity analyses to investigate the effects of infiltration and vapor diffusion on the ${ }^{3} \mathrm{H}$ transport.

In chapter 8 , we described a three-dimensional analysis that included details of site features that could not be included in two-dimensions. The features included partial surface cover by a blacktop, which allowed infiltration through only a fraction of the upper surface. Transport runs were done using ten different realizations of soil property fields generated by conditional simulation. To observe the effect of the blacktop on ${ }^{3} \mathrm{H}$ transport, simulation runs for two of the realizations were repeated with the blacktop removed, allowing infiltra- 
tion through the entire upper surface of the model. The results obtained using soil properties from conditional simulation were compared with results using soil properties obtained by kriging. We also examined the effect that uncertainty in the van Genuchten parameters has on numerical transport calculations using a permeability field obtained by kriging. We examined this effect by conducting ten simulation runs using the same permeability field derived by kriging, but with different van Genuchten parameters.

We compared the calculated ${ }^{3} \mathrm{H}$ concentrations for each $3 \mathrm{D}$ realization at different times with concentrations measured in the field around 1990 to determine which realization best matches the conditions in the field. The quantitative measure of goodness-of-fit used as the basis for comparison is the root mean squared difference (RMSD) in concentration. The realization with the minimum RMSD, between about 5 yr to $20 \mathrm{yr}$ after leaking started, was selected as the best realization to use for a forecast of future groundwater quality at the site.

\subsection{General Findings}

- Traditional geostatistical analysis using ordinary kriging is a viable technique for estimating the initial mass distribution of contaminants at vadose zone sites.

- Traditional geostatistical analysis can be combined naturally with stochastic simulation to estimate the hydraulic properties of heterogeneous soils in vadose zone transport studies.

- The artificial smoothing effect of kriging removes high-permeability flow paths and causes a reduction in contaminant transport rates for heterogeneous vadose zone systems. Therefore, kriging is not a recommended technique for estimating hydraulic soil properties for contaminant transport analysis at heterogeneous vadose zone sites. 
The techniques presented in this study represent a practical approach to the analysis of contaminated, heterogeneous vadose zone sites with limited data. The method, which we refer to as the Best Fitting Realization or simply the BFR method, is summarized as follows:

1. Develop concentration sample variogram from field concentration data.

2. Estimate 3-D concentration field by kriging using sample data and variogram.

3. Develop soil permeability sample variogram from laboratory and field data.

4. Develop or use any available soil property correlations to expand the permeability data set and to estimate additional unsaturated soil properties; permeability versus particle size distribution parameters is an example of a useful correlation.

5. Generate a number of realizations of soil permeability fields, with other soil properties estimated from correlations, and conduct a numerical simulation run using each realization.

6. Compare the calculated concentration fields, at various times, with the measured concentration field, for which the time is usually not well known, and compute the RMSD for each realization at each time.

7. Select the realization with the minimum RMSD, at some appropriate time, and use the results from this best-fitting realization, along with average results, to forecast future site conditions.

\subsection{Findings Specific to Building 292 Area}

- The ${ }^{3} \mathrm{H}$ release poses no serious long term threat to groundwater quality at the LLNL Livermore Site or any neighboring sites. For rl3d110, the realization that showed 
the highest groundwater ${ }^{3} \mathrm{H}$ concentrations, the maximum concentration $100 \mathrm{ft}$ downstream of the leak was below the groundwater standard. For rl3d108, the best-fit realization, the peak concentration $100 \mathrm{ft}$ downstream of the leak was $7.59 \times 10^{3}$ $\mathrm{pCi} / \mathrm{L}$, only $38 \%$ of the groundwater standard.

- The impact of the release on groundwater quality is substantially reduced by the blacktop that partially covers the ground surface in the Building 292 Area. Results of the $3 \mathrm{D}$ analysis show that removing the blacktop results in large increases in groundwater ${ }^{3} \mathrm{H}$ concentrations and in the cumulative flux of ${ }^{3} \mathrm{H}$ entering the groundwater. The increases are due to higher downward liquid velocities in the vadose zone resulting from infiltration through the additional exposed soil surface.

- Numerical simulation runs using soil permeability fields derived by kriging yield significantly lower groundwater ${ }^{3} \mathrm{H}$ concentrations than runs using fields derived by conditional simulation. The artificial smoothing effect of kriging removes high-permeability flow paths that are preserved by conditional simulation. Kriging under the present conditions yields nonconservative and potentially misleading results.

- High soil water ${ }^{3} \mathrm{H}$ concentrations, over $1.0 \times 10^{7}$, are expected to persist in the vadose zone for the next $50 \mathrm{yr}$ or so. Because of low fluid velocities in the finer-grained soils, peak soil water ${ }^{3} \mathrm{H}$ concentrations in the vadose zone are controlled to a much greater extent by radioactive decay than by transport. The total activity of ${ }^{3} \mathrm{H}$ in the vadose zone at any time is also controlled largely by radioactive decay because the percentage lost to the groundwater is very small.

- We estimate a total ${ }^{3} \mathrm{H}$ activity of $5 \mathrm{Ci}$ in the vadose zone around $1990-1991$. This estimate was obtained by applying kriging and other geostatistical techniques to sample 
data collected between 1989 and 1992.

- Vapor diffusion is not important to ${ }^{3} \mathrm{H}$ transport under current site conditions.

- The soil permeability variogram has a horizontal range of $14.0 \mathrm{ft}$ and a vertical range of $4.5 \mathrm{ft}$.

- The Monte-Carlo analysis showed high variability in the calculated impact of the release on groundwater quality, indicating that the results are sensitive to the soil properties used.

- The ambient liquid saturation profile showed substantial saturation increases with infiltration rate.

- The impact of the ${ }^{3} \mathrm{H}$ release on groundwater quality at the site also increases strongly with infiltration rate.

- van Genuchten's $\alpha$ parameter is correlated to $\mathrm{K}_{s}$ according to

$$
\alpha=1.7 \sqrt{K}_{s}
$$

with $\alpha$ in $\mathrm{cm}^{-1}$ and $\mathrm{K}_{s}$ in $\mathrm{cm} / \mathrm{s}$.

- van Genuchten's $n$ parameter is uncorrelated with respect to $\mathrm{K}_{s}$.

- $\mathrm{K}_{s}$ is correlated to particle size distribution parameters; the best correlation is with the $\mathrm{D}_{40}$ size, according to

$$
K_{s}=3.31 \times 10^{-3} D_{40}^{2}
$$

with $\mathrm{K}_{s}$ in $\mathrm{cm} / \mathrm{s}$ and $\mathrm{D}_{40}$ in $\mathrm{mm}$.

- Initial water content, $\theta_{i}$, is correlated to $\mathrm{K}_{s}$ and not to depth; the relationship is

$$
\theta_{i}=\log K_{s}^{-.041}-9.2 \times 10^{-3}
$$


where $\mathrm{K}_{s}$ is expressed in $\mathrm{cm} / \mathrm{s}$.

- The initial liquid saturation, $S_{i}$, is relatively high for a large percentage of the soils on site; $S_{i}$ averages about $0.75 \mathrm{~m}$.

\subsection{Recommendations for Future Work}

\subsubsection{General}

Future extensions of this study might include the following:

- a Monte Carlo analysis using 3D simulation runs, and

- a study of the effect of soil permeability correlation length on ${ }^{3} \mathrm{H}$ transport.

The Monte Carlo analysis with 3D runs will permit probabilistic quantification of the findings. However, the computational burden is expected to be very high because of the large $\mathrm{CPU}$ requirements for $3 \mathrm{D}$ simulations and the large number of simulations needed to perform an adequate analysis. Since soil permeability data are usually insufficient to construct reliable variograms, many investigators estimate a correlation length based on limited data, or simply pick an "appropriate" value from the literature. A study of the effect of correlation length on transport will shed some light in this area.

\subsubsection{Building 292 Area}

Although the ${ }^{3} \mathrm{H}$ release poses no serious long term threat to groundwater quality on the LLNL Livermore Site, we recommend the following action to protect personnel at the site and to minimize the impact of the release on groundwater quality in the immediate Building 292 Area:

- Extend the blacktop cover about $20 \mathrm{ft}$ or so to the south and patch existing cracks. 
- Continue groundwater and vadose zone monitoring in the Building 292 Area for several decades.

- Additional calculations need to be performed to predict the effect of changes in water table elevation; the elevation has been rising steadily over the past few years. 


\section{References}

Allison, G.B., and M.W. Hughes (1975), "The use of Environmental Tritium to Estimate Recharge to a south-Australian Aquifer," J. Hydrol., 26, 245-254.

Amano, H., and C.T. Garten, Jr. (1991), "Uptake of Tritium by Plants," Environment International, Vol. 17, pp. 23-29.

Atakan, Y. (1972), Bomb Tritium Hydrology of a Sandy Unconfined Aquifer. Doctoral dissertation, University of Heidelberg, Heidelberg.

Aziz, K., and A. Sattari (1979), Petroleum Reservoir Simulation, Applied Science Publishers, New York.

Barnes, M.G. (1978), Statistical Design and Analysis in the Cleanup of Environmental Radionuclide Contamination, Desert Research Institute, Univ. of Nevada, NV. DRI Publication No. 45012.

Bear, J. (1972), Dynamics of fluids in porous media. American Elsevier, New York.

Bear, J., and J. J.Nitao (1993), Infiltration and Contaminant Transport in the Vadose Zone (Nonisothermal), Part 1: Conceptual and Mathematical Models, Lawrence Livermore National Laboratory, Livermore, CA (UCRL-JC-111742 pt 1).

Biggar, J.W., and D.R. Nielson (1962), "Miscible displacement: II, Behavior of Tracers." Soil Sci. Soc. Amer. Proc., 26:125-128.

Blume and Associates, Inc. (1972), Investigation of Faulting at the Lawrence Livermore Laboratory. Lawrence Livermore National Laboratory, Livermore, California (UCRL13568).

Brooks, R.H., and A.T. Corey (1964), Hydraulic Properties of Porous Media. Hydrology Paper No. 3, Colorado State Univ., Fort Collins, Colorado, 27 pp.

Brown, R.M. (1961), "Hydrology of Tritium in the Ottawa Valley," Geochim. Cosmochim., Acta, 21, 199.

Burdine, N.T. (1953), "Relative Permeability Calculations from Pore-size Distribution Data," Petrol. Trans. Am. Inst. Min., 198:71-77.

Burnham, C.D, R.M. Brown, G.L. Ogram, and F.S. Spencer (1988), "An Overview of Experiments at Chalk River on HT Dispersion in the Environment," Fusion Technology, Vol. 14.

Butters, G.L., and W.A. Jury (1989), "Field Scale Transport of Bromide in an Unsaturated Soil, 2, Dispersion Modeling," Water Resour. Res., 25(7), 1583-1589.

Carpenter, D.W., K.P. Puchlik, A.L. Ramirez, J.L. Wagoner, K.G. Knauss, and P.W. Kasameyer (1980), Status Report on the Geology of the Lawrence Livermore National Laboratory Site and Adjacent Areas, Lawrence Livermore National Laboratory, Livermore, California (UCRL-53065). 
Carpenter, D.W., J.J. Sweeney, P.W. Kasameyer, N.R. Burkard, K.G. Knauss, and R.J. Shelmon (1984), Geology of the Lawrence Livermore National Laboratory Site and Adjacent Areas, Lawrence Livermore National Laboratory, Livermore, California, UCRL$53316,150 \mathrm{pp}$.

Carrigan, C.R. (1995), "The Non-Proliferation Experiment and Gas Sampling as an On-site Inspection Activity: A Progress Report," Proceedings of the Symposium on the NonProliferation Experiment: Results and Implications for Test Ban Treaties, (CONF9404100), p. 8-51, 1995.

Carrigan, C.R., R. Heinle, and J.J. Zucca (1995), OSI Gas Tracer Experiment, Lawrence Livermore National Laboratory Report, UCRL - ID-120931.

Carrigan, C.R., Heinle, R.A., Hudson, G.B., J.J. Nitao, and J.J. Zucca (1996), "Trace Gas Emissions on Geological Faults as Indicators of Underground Nuclear Testing," Nature, Vol. 382, No. 6591.

Carrigan, C.R., and J.J. Nitao (1997), "A Fully Coupled Model for 3-D, Partially Saturated Flow and Transport in Soil Ohmically Heated by Application of Multiphase A.C. Electrical Potentials," Environmental Science and Technology, submitted for publication.

Childs, E.C., and N. Collis-George (1950), "The Permeability of Porous Materials," Proc. Roy. Soc. London, Ser. A., 201:392-405.

Christakos, G. (1992), Random Field Models in Earth Sciences, Academic Press, Inc. San Diego.

Conklin, J.J., and R.I. Walker, ed. (1987), Military Radiobiology, Academic Press, Inc., New York.

Cooper, R.M., and J.D. Istok (1988) "Geostatistics Applied to Groundwater Contamination. I. Methodology," Journal of Environmental Engineering, ASCE, Vol. 114, No. 2, pp. $270-286$.

Crank, J. (1956), The Mathematics of Diffusion. Oxford University Press, Oxford, 347 pp.

David M. (1977), Geostatistical Ore Reserve Estimation. Elsevier, Amsterdam.

Delhomme, J.P. (1979), "spatial Variability and Uncertainty in Groundwater Flow Parameters: A Geostatistical Approach," Water Resour. Res., 15(2), 269-280.

Deutsch, C. V., and A. G. Journel, (1992) GSLIB Geostatistical Software Library and User's Guide, Oxford University Press, New York.

Dibblee, T.W., Jr., and R.L. Darrow (1981) "Geology of the Northern Diablo Range and Livermore Valley Area," in Geology of Central and Northern Diablo Range, California, V. Frizzell, ed., (Pacific Section of SEPM, Los Angeles), pp. 77-112.

Edlefsen, N.E., and A.B.C. Anderson (1943), "Thermodynamics of Soil Moisture," Hilgardia, 15, 31-298. 
Egboka, B.C.E., J.A. Cherry, R.N. Farvolden, and E.O. Frind (1983), "Migration of Contaminants in Groundwaters at a Landfill, A Case Study, 3, Tritium as an Indicator of Dispersion and Recharge," J. Hydrol., 63, 51-80.

El-Kadi, A.I. (1987), "Variability of Infiltration Under Uncertainty in Unsaturated Zone Parameters," Journal of Hydrology, 90, 61-80.

Fischer, H. B., E. J. List, R. C. Y. Koh, J. Imberger, and N. H. Brooks (1979), Mixing in Inland and Coastal Waters, Academic Press, New York.

Foster, S.S.D (1975), "The Chalk Groundwater Tritium Anomaly-A Possible Explanation," J. Hydrol., 25, 159-165.

Freeze, R.A. (1973), "An Analysis of Baseball Batting Order by Monte Carlo Simulation," Operations Research, Vol. 22, No. 4, 728-735.

Freeze, R.A. (1975) "A Stochastic-Conceptual Analysis of One-Dimensional Groundwater Flow in Nonuniform Homogeneous Media," Water Resour. Res., Vol. 11, No. 5.

Freeze, R.A., and J.A. Cherry (1979), Groundwater, Prentice-Hall, Inc., New Jersey.

Gee, G.W., C.T. Kincaid, R.J. Lenhard, and C.S. Simmons (1991), "Recent studies of flow and transport in the vadose zone," Reviews of Geophys., Supplement, 227-239.

Gelhar, L.W. (1993), Stochastic Subsurface Hydrology. Prentice Hall, New Jersey.

Gelhar, L.W., A. Mantoglou, C. Welty, and K.R. Rehfeldt, A review of field-scale physical solute transport processes in saturated and unsaturated porous media, Electric Power Research Institute Report EA-4190, Project 2485-5, Palo Alto, CA, 1985.

Gelhar, C. Welty, and K.R. Rehfeldt (1992), "A critical review of data on field-scale dispersion in aquifers," Water Resour. Res., 28(7), 1955-1974.

Germann, P.F. (1985), "Kinematic Wave Approach to Infiltration and Drainage into and from Soil Macropores," Trans. Am. Soc. Agric. Engr., 28(3), 745-749.

Germann, P.F. (1988), "Rapid and Far-reaching Hydrologic Processes in the Vadose Zone," J. Contam. Hydrol., 3.

Gvirtzman, H., and M. Margaritz (1986), "Investigation of Water Movement in the Unsaturated Zone under an Irrigated Area using Environmental Tritium," Water Resour. Res., Vol. 22, No. 5, 635-643.

Haney, W.A., D.J. Brown, and A.E. Reisenauer (1962), Fission Product Tritium in Separations Wastes and in the Groundwater, USAEC Report No. HW-74536 (Hanford Atomic Products Operation, Richland, Washington).

Hawkins, D.B., and B.L. Schmaltz (1965), Environmental Tritium Studies at the National Reactor Testing Station, USAEC Report No. IDO-12043 (Idaho Operations Office, Idaho Falls, Idaho).

Herd, D.G. (1968), Geologic Map of the Las Positas, Greenville, and Verona Faults, Eastern Alameda County, California, U.S. Geological Survey Open-File Report 77-689. 
Hillel, D. (1987), "Unstable flow in Layered Soils: A Review," Hydrological Processes, $1: 143-147$.

Horton, J.H. (1963), Fission Product Tritium at the Savannah River Plant, USAEC Report No. DPSPU-63-30-38B (Savannah River Laboratory, Aiken, South Carolina.

Hubbert, M.K. (1940), "The Theory of Groundwater Motion," J. Geol., 48, pp. 785-794.

IAEA, (1983), Behavior of Tritium in the Environment, International Atomic Energy Agency Report, Vienna, Austria.

Iovenitti, J., J. J. Nitao, and D. J. Bishop (1992), Vadose Zone Investigations at the Lawrence Livermore National Laboratory Superfund Site: An Overview, Lawrence Livermore National Laboratory, Livermore, CA (UCRL-JC-110606).

Isaaks, H.I., and R.M. Srivastava (1989), An Introduction to Applied Geostatistics. Oxford University Press, New York

Istok, J.D., and R.M. Cooper (1988) "Geostatistics Applied to Groundwater Contamination. III: Global Estimates." Journal of Environmental Engineering, ASCE. Vol. 114, No. 4, pp. 914-928.

James, R.V., and J. Rubin (1986) "Transport of Chloride Ion in Water-unsaturated soil Exhibiting Anion Exclusion," Soil Sci. Soc. Am. J., 50 1142-1149.

Journel, A. (1974), "Geostatistics for Conditional Simulation of Orebodies." Economic Geology, 69:673-680.

Journel, A.G. and C.J. Huijbregts (1978), Mining Geostatistics. Academic Press, London.

Kaufmann, S., and W.F. Libby (1954), "The Natural Distribution of Tritium," Phys. Rev., $93,1337$.

Keller, C., and B. Lowry, Eds. (1990), A New Vadose Zone fluid Sampling System for Uncased Holes. American Water Well Convention, Las Vegas, Nevada.

Krige, D.G. (1951), "A Statistical Approach to Some Basic Mine Valuation Problems in the Witwatersrand," Journal of the Chemical, Metallurgical and Mining Society of South Africa, No. 52, pp. 119-139.

Krupp, H.K., J.W. Biggar, and D.R. Nielsen (1972), "Relative Flow Rates of Salt and Water in Soil," Soil Sci. Soc. Am. Proc., 36, 412-417.

Larson, G.J., M.R. Delcore, and S. Offer (1987), "Application of the Tritium Interface Method for Determining Recharge Rates to Unconfined Drift Aquifers, I, Homogeneous Case," J. Hydrol., 91, 59-72.

Lee, K. H., A. Kulshrestha, and J. J. Nitao (1993), Interim Report on Verification and Benchmark Testing of the NUFT Computer Code, Lawrence Livermore National Laboratory, Livermore, CA (UCRL-ID-113521).

Lee, K. H. (1995), Second Progress Report on Pre-test Calculations for the Large Block Test, Lawrence Livermore National Laboratory, Livermore, CA (UCRL-ID-122300). 
Leverett, M.C. (1941) "Capillary Behavior in Porous Solids," AIME Trans., Vol. 142, pp. 152-169.

Levine W.G. (1980) "Heavy Metals and Heavy-Metal Antagonists," In The Pharmacological Basis of the Therapeutics, (L.S. Goodman and A.G. Gilman, eds), 6th ed. Macmillan, New York.

Libby, W. F. (1946), "Atmospheric Helium-3 and Radiocarbon from Cosmic Radiation," Phys. Rev. No. 69, 671.

Luckner, L., M.Th. van Genuchten, and D.R. Nielsen (1989), "A Consistent Set of Parametric Models for the Two-Phase Flow of Immiscible Fluids in the Subsurface," Water Resour. Res., 25:2187-2193.

Mallon, B.J., K.H. Lee, J. Nitao, and J.S. Johnson (1994), "Effect of an Asphalt Soil Cover on Seasonal Moisture Movement in the Vadose Zone of a Semi-Arid Region," EOS, Fall 1994 Meeting, American Geophysical Union, San Francisco, CA.

Mallon, B.J. (1995), Migration of Tritiated Water from an Underground Leak at Building 292, Lawrence Livermore National Laboratory, Livermore, CA (UCRL-AR-112798).

Mantoglou, A., and Wilson, J. L., (1982), "The turning bands method for simulation of random fields using line generation by a spectral method," Water Resources Research, Vol. 18, No. 5, 1379-1394.

Martins, S.A. (1992), A Method for Collecting Soil Vapor from the Vadose Zone with an Instrumented Membrane System, Lawrence Livermore National Laboratory, Livermore California (UCRL-ID-101765).

Matheron, G. (1963), "Principles of Geostatistics," Economic Geology, No. 58, pp. 12461266.

Matheron, G. (1973), "The Intrinsic Random Functions and their Applications," Adv. Appl. Prob., 5, 439-468.

Millington, R.J. (1959), "Gas diffusion in porous media," Science, 130, 100-102, 1959.

Millington, R.J., and J.P. Quirk (1961), "Permeability of Porous Solids," Faraday Soc. Trans., 57:1200-1206.

Milly, P.C.D. (1988), "Advances in modeling of water in the unsaturated zone," Trans. Porous Media, 3, 491-514.

Mualem, Y. (1976), "A New Model for Predicting the Hydraulic Conductivity of Unsaturated Media," Water Resour. Res., 12, 513-522.

Murphy, C.E., C.W. Sweet, and R.D. Fallon (1982), "Tritium Transport around Nuclear Facilities," Nuclear Safety, Vol. 23, No. 6.

Myers, J.C., and R.C. Bryan (1984), "Geostatistics Applied to Toxic Waste: A Case Study. Geostatistics for Natural Resource Characterization, Part 2. G. Verly, M. David, A.G. Journel, and A. Merecal, eds. D. Reidel Publishing Co., Dordrecht, Holland, pp. 893901. 
NCRP, (1979), Tritium in the Environment, NCRP Report No. 62, National Council on Radiation Protection and Measurements, Washington, D.C. 20014.

Nir, A., S.T. Kruger, R.E. Lingenfelter, and E.J. Flamm (1966), "Natural Tritium," Rev. Geophys. Vol. 4, No. 4, 441.

Nitao, J.J. (1993) "The NUFT Code for Modeling Nonisothermal, Multiphase, Multicomponent Flow and Transport in Porous Media," AGU EOS, Vol. 74, No. 3, p 313.

Nitao, J.J., and J. Bear (1996), "Potentials and their Role in Transport in Porous Media," Water Resources Research, Vol. 32, No. 2, pp. 225-250.

Ogata, A. (1970), Theory of dispersion in a granular medium. U.S. Geol. Surv. Prof. Paper 411-A.

Parsons, P.J. (1963), The Movement of Tritium from the Chalk River Liquid Disposal Area, Report No. CRER-1146 (Atomic Energy of Canada Limited, Chalk River, Ontario.

Payne, B.R. (1972) "Isotope Hydrology," Adv. Hydrosci., 8, pp. 95-138.

Philip, J.R. (1957), "Numerical Solution of Equations of the Diffusion Type with Diffusivity Concentration-Dependent: 2," Australian Journal of Physics, 10(2), 29-42.

Phillips, F.M., J.L. Mattick, T.A. Duval, D. Elmore, and P.W. Kubik (1988), "Chlorine 36 and Tritium from Nuclear Weapons Fallout as Tracers for Long-Term Liquid and Vapor Movement in Desert Soils," Water Resour. Res. , Vol. 24, No. 11, 1877-1891.

Paillard, Ph., J.P. Calando, H. Clerc, R. Gros, and Y. Belot (1988), "Tritium Release Experiment in France, Results Concerning HT/HTO Conversion in the Air and Soil," Fusion Technology, Vol. 14, pp. 1226-1230.

Popov, M.M., and F.J. Tazemdinov (1960), "Vapor Pressure of $\mathrm{T}_{2} \mathrm{O}$," Atomic Energy, Vol. $8,420-424$.

Price, A.H. (1958), "Vapor Pressure of Tritiated Water," Nature, Vol. 181, No. 4604, 262.

Rautman, C.A., and J.D. Istok (1996), "Probabilistic Assessment of Ground-Water Contamination: 1. Geostatistical Framework," Groundwater, Vol. 34, No. 5, 899-909.

Robertson, W.D., and J.A. Cherry, (1989), "Tritium as an Indicator of Recharge and Dispersion in a Groundwater System in Central Ontario," Water Resour. Res., Vol. 25, No. 6, pp. 1097-1109.

Schleuter, E., and K. Pruess (1990) Sensitivity Studies on Parameters Affecting Gas Release from an Underground Rock Cavern, Lawrence Berkeley Laboratory, Rep. LBL28818 UC-403.

Schmalz, B.L., and W.L. Polzer (1969), "Tritiated Water Distribution in Unsaturated Soil," Soil Science, Vol. 108, No. 1, 43-47.

Springer, J.E. (1983), Structural Analysis of the Southeastern Livermore Basin, California, Lawrence Livermore National Laboratory, Livermore, California (UCID-19805). 
Sudicky, E.A., and P.S. Huyakorn (1991), "Contaminant migration in imperfectly known heterogeneous groundwater systems," Reviews of Geophys., Supplement, 240-253.

Sweeney, J.J., and J.E. Springer (1981), Geology of the Southeastern Livermore Valley, Alameda County, California, Lawrence Livermore National Laboratory, Livermore, California (UCRL-53200, Rev. 1).

Thorpe, R.K., W.F. Isherwood, M.D. Dresen, and C.P. Webster-Scholten (eds.) (1990), CERCLA Remedial Investigations Report for the LLNL Livermore Site, Lawrence Livermore National Laboratory, Livermore, CA (UCAR-10299).

Tompson, A.F.B., R. Ababou, and L.W. Gelhar (1989), "Implementation of the Threedimensional Turning Bands Random Field Generator," Water Resour. Res., 25(10),22272243 .

van Genuchten M.Th. (1980) "A Closed Form Equation for Predicting the Hydraulic Conductivity of Unsaturated Soils," Soil. Sci. Soc. Am. J., 44, 892-898.

van Genuchten M.Th., and D.R. Nielsen (1985) "On Describing and Predicting the Hydraulic Properties of Unsaturated Soils," Ann. Geophys., 3:615-628.

van Genuchten, M.Th., and P.J. Shouse (1989), "Solute Transport in Heterogeneous Field Soils,", pp. 177-187, In D.T. Allen, V.P. Cohen, and I.R. Kaplan, eds., Intermedia Pollutant Transport, Plenum Publishing, New York.

van Genuchten, M.Th. (1991), "Progress and Opportunities in Hydrologic Research," Reviews of Geophysics.

van Genuchten, M.Th., F.J. Leij, and S.R. Yates (1991a) The RETC Code for Quantifying the Hydraulic Functions of Unsaturated Soils. EPA Report No. EPA/600/2-91/065.

van Genuchten, M.Th., F.J. Leij, and L.J. Lund (eds.) (1991b) Indirect Methods for Estimating the Hydraulic Properties of Unsaturated Soils, Workshop Proceedings, Univ., of California, Riverside, California.

Van Grosse, A.V., W.M. Johnson, R.L. Wolfgang, and W.F. Libby (1951), "Tritium in Nature," Science, 113, pp. 1-2.

Wang, J.S.Y. (1992), "Variation of Hydrological Parameters of Tuff and Soil," in High Level Radioactive Waste Management, Proceedings of the Third International Conference, April 12-16, Las Vegas, Nevada, pp 727-731.

Wierenga, P.J., and D. Bachelet, eds (1988) International Conference and Workshop on the Validation of Flow and Transport Models for the Unsaturated Zone. Ruidoso, New Mexico.

Zirschky, J.H., G.P. Keary, R.O. Gilbert, and E.J. Middlebrooks (1985), "Spatial Estimation of Hazardous Waste Site Data," J. Environmental Engineering, ASCE, Vol. 111, No. 6, pp. 777-789. 


\section{APPENDIX}




\section{A Conversion from HTO Mass to ${ }^{3} \mathrm{H}$ Activity}

By definition

$$
\begin{aligned}
1 \mathrm{Ci} & =3.7 \times 10^{10} \text { disintegrations } / \mathrm{s} \\
& =\frac{3.7 \times 10^{10}}{N} \text { moles of HTO per } \mathrm{s} \\
& =\frac{3.7 \times 10^{10} \times M}{N} \mathrm{~kg} \text { of HTO per s }
\end{aligned}
$$

where $\mathrm{N}$ is Avagadro's number and M is the molecular mass of HTO expressed in $\mathrm{kg} / \mathrm{mole}$. The mass of HTO required for this decay rate is

$$
\frac{3.7 \times 10^{10} \times M}{N \lambda} \mathrm{kg}
$$

where $\lambda$ is the decay constant for ${ }^{3} \mathrm{H}$, equal to $1.779 \times 10^{-9} \mathrm{~s}^{-1}$. Therefore

$$
\begin{gathered}
1 \mathrm{Ci}=\frac{3.7 \times 10^{10} \times .020}{6.023 \times 10^{23} \times 1.779 \times 10^{-9}}=6.908 \times 10^{-7} \mathrm{~kg} \\
1 \mathrm{pCi}=6.908 \times 10^{-19} \mathrm{~kg}
\end{gathered}
$$

For HTO as a solute in water at standard temperature, the conversion between specific activity and mass fraction is

$$
1 \mathrm{pCi} / \mathrm{L}=\frac{6.908 \times 10^{-19} \mathrm{~kg}(\text { HTO })}{1 \mathrm{~kg}(\text { water })}=6.908 \times 10^{-19} \mathrm{~kg} / \mathrm{kg}
$$




\section{B Water Retention Data}

Table B.1: Retention data for 16 soil samples from the LLNL Building 292 area. The data, tabulated here as negative pressure head $\psi$ versus volumetric water content $\theta$, were obtained from the initial drainage curve.

\begin{tabular}{|c|c|c|c|c|c|}
\hline $\begin{array}{c}\text { Sample } \\
\text { ID }\end{array}$ & $\begin{array}{c}\psi \\
(-\mathrm{cm})\end{array}$ & $\begin{array}{c}\theta \\
\left(\mathrm{cm}^{3} / \mathrm{cm}^{3}\right)\end{array}$ & $\begin{array}{c}\text { Sample } \\
\text { ID }\end{array}$ & $\begin{array}{c}\psi \\
(-\mathrm{cm})\end{array}$ & $\begin{array}{c}\theta \\
\left(\mathrm{cm}^{3} / \mathrm{cm}^{3}\right)\end{array}$ \\
\hline \multirow[t]{7}{*}{$\mathrm{U} 292-001-5.75$} & 0 & .363 & \multirow[t]{7}{*}{ U292-001-10.25 } & 0 & .473 \\
\hline & 26 & .313 & & 30 & .406 \\
\hline & 77 & .087 & & 98 & .333 \\
\hline & 520 & .072 & & 520 & .256 \\
\hline & 1020 & .064 & & 1020 & .232 \\
\hline & 6476 & .031 & & 6935 & .169 \\
\hline & 19662 & .027 & & 14332 & .158 \\
\hline \multirow[t]{7}{*}{ U292-001-27.75 } & 0 & .339 & \multirow[t]{7}{*}{ U292-001-35.0 } & 0 & .377 \\
\hline & 17 & .321 & & 51 & .353 \\
\hline & 87 & .234 & & 163 & .352 \\
\hline & 602 & .155 & & 510 & .334 \\
\hline & 1020 & .143 & & 1581 & .315 \\
\hline & 5395 & .093 & & 4516 & .306 \\
\hline & 15651 & .083 & & 14920 & .237 \\
\hline \multirow[t]{8}{*}{ U292-001-45.5 } & 0 & .260 & \multirow[t]{8}{*}{ U292-015-4.3 } & 0 & .357 \\
\hline & 14 & .196 & & 48 & .350 \\
\hline & 30 & .160 & & 158 & .350 \\
\hline & 100 & .119 & & 316 & .349 \\
\hline & 408 & .095 & & 1010 & .344 \\
\hline & 5456 & .060 & & 3100 & .333 \\
\hline & 23810 & .051 & & 7190 & .318 \\
\hline & & & & 15073 & .257 \\
\hline \multirow[t]{8}{*}{ U292-015-5.8 } & 0 & .361 & \multirow[t]{8}{*}{ U292-015-10.3 } & 0 & .355 \\
\hline & 48 & .355 & & 54 & .343 \\
\hline & 158 & .349 & & 112 & .336 \\
\hline & 316 & .343 & & 306 & .320 \\
\hline & 1010 & .327 & & 1020 & .282 \\
\hline & 3100 & .310 & & 5099 & .268 \\
\hline & 7190 & .284 & & 13818 & .183 \\
\hline & 13002 & .209 & & & \\
\hline
\end{tabular}


Table B.1 (contd)

\begin{tabular}{|c|c|c|c|c|c|}
\hline $\begin{array}{c}\text { Sample } \\
\text { ID }\end{array}$ & $\begin{array}{c}\psi \\
(-\mathrm{cm})\end{array}$ & $\begin{array}{c}\theta \\
\left(\mathrm{cm}^{3} / \mathrm{cm}^{3}\right) \\
\end{array}$ & $\begin{array}{c}\text { Sample } \\
\text { ID }\end{array}$ & $\begin{array}{c}\psi \\
(-\mathrm{cm})\end{array}$ & $\begin{array}{c}\theta \\
\left(\mathrm{cm}^{3} / \mathrm{cm}^{3}\right) \\
\end{array}$ \\
\hline \multirow[t]{9}{*}{$\overline{\mathrm{U} 292-020-36.6}$} & 0 & .385 & \multirow[t]{9}{*}{ U292-015-15.3 } & 0 & .282 \\
\hline & 105 & .362 & & 10 & .261 \\
\hline & 510 & .353 & & 30 & .234 \\
\hline & 999 & .344 & & 100 & .196 \\
\hline & 3110 & .322 & & 309 & .167 \\
\hline & 4630 & .264 & & 1020 & .145 \\
\hline & \multirow[t]{3}{*}{16072} & \multirow[t]{3}{*}{.232} & & 4079 & .131 \\
\hline & & & & 15674 & .110 \\
\hline & & & & 7128 & .107 \\
\hline \multirow[t]{9}{*}{ U292-015-20.8 } & 0 & .254 & \multirow[t]{9}{*}{ U292-015-25.3 } & 0 & .333 \\
\hline & 9 & .224 & & 54 & .327 \\
\hline & 24 & .172 & & 112 & .324 \\
\hline & 95 & .116 & & 306 & .319 \\
\hline & 309 & .096 & & 1020 & .308 \\
\hline & 1020 & .084 & & 5099 & .281 \\
\hline & 4079 & .072 & & 19652 & .186 \\
\hline & 15674 & .058 & & & \\
\hline & 7200 & .056 & & & \\
\hline \multirow[t]{8}{*}{ U292-015-31.5 } & 0 & .379 & \multirow[t]{8}{*}{ U292-015-35.3 } & 0 & .370 \\
\hline & 48 & .313 & & 48 & .350 \\
\hline & 158 & .227 & & 158 & .330 \\
\hline & 316 & .201 & & 316 & .319 \\
\hline & 1010 & .178 & & 1010 & .297 \\
\hline & 3100 & .163 & & 3100 & .272 \\
\hline & 7190 & .147 & & 7190 & .250 \\
\hline & 15348 & .099 & & 12809 & .202 \\
\hline \multirow[t]{8}{*}{$\mathrm{U} 292-015-40.8$} & 0 & .320 & \multirow[t]{8}{*}{$\mathrm{U} 292-015-45.3$} & 0 & .219 \\
\hline & 48 & .203 & & 48 & .115 \\
\hline & 158 & .130 & & 158 & .081 \\
\hline & 316 & .117 & & 316 & .072 \\
\hline & 1010 & .101 & & 1010 & .063 \\
\hline & 3100 & .094 & & 3100 & .057 \\
\hline & 7190 & .084 & & 7190 & .050 \\
\hline & 15379 & .059 & & 18611 & .061 \\
\hline
\end{tabular}




\section{C $\quad K_{s}$ Data for the 57-sample and 132-sample Data Sets}

Table C.1: $\mathrm{K}_{s}$ with three-dimensional coordinates for the 57-sample data set. Hydraulic conductivity obtained by direct measurement and by correlation with particle size data.

\begin{tabular}{cccc}
\hline $\begin{array}{c}\text { Easting } \\
(\mathrm{ft})\end{array}$ & $\begin{array}{c}\text { Northing } \\
(\mathrm{ft})\end{array}$ & $\begin{array}{c}\text { Elevation } \\
(\mathrm{ft})\end{array}$ & $\begin{array}{c}K_{s} \\
(\mathrm{~cm} / \mathrm{s})\end{array}$ \\
\hline 8655.4 & 12781.0 & 581.05 & $0.570 \mathrm{E}-02$ \\
8655.4 & 12781.0 & 580.55 & $0.230 \mathrm{E}-01$ \\
8655.4 & 12781.0 & 576.55 & $0.150 \mathrm{E}-03$ \\
8655.4 & 12781.0 & 570.05 & $0.210 \mathrm{E}-01$ \\
8655.4 & 12781.0 & 569.30 & $0.240 \mathrm{E}-01$ \\
8655.4 & 12781.0 & 559.05 & $0.400 \mathrm{E}-03$ \\
8655.4 & 12781.0 & 551.80 & $0.460 \mathrm{E}-06$ \\
8655.4 & 12781.0 & 541.30 & $0.160 \mathrm{E}-01$ \\
8661.8 & 12784.0 & 582.90 & $0.120 \mathrm{E}-07$ \\
8661.8 & 12784.0 & 581.40 & $0.250 \mathrm{E}-06$ \\
8661.8 & 12784.0 & 576.90 & $0.120 \mathrm{E}-06$ \\
8661.8 & 12784.0 & 571.90 & $0.170 \mathrm{E}-02$ \\
8661.8 & 12784.0 & 566.40 & $0.450 \mathrm{E}-02$ \\
8661.8 & 12784.0 & 561.90 & $0.160 \mathrm{E}-07$ \\
8661.8 & 12784.0 & 555.70 & $0.150 \mathrm{E}-04$ \\
8661.8 & 12784.0 & 551.90 & $0.250 \mathrm{E}-04$ \\
8661.8 & 12784.0 & 546.40 & $0.760 \mathrm{E}-03$ \\
8661.8 & 12784.0 & 541.90 & $0.200 \mathrm{E}-02$ \\
8650.4 & 12784.4 & 580.00 & $0.170 \mathrm{E}-06$ \\
8650.4 & 12784.4 & 575.00 & $0.722 \mathrm{E}-06$ \\
8650.4 & 12784.4 & 569.75 & $0.564 \mathrm{E}-06$ \\
8650.4 & 12784.4 & 564.75 & $0.689 \mathrm{E}-06$ \\
8650.4 & 12784.4 & 560.00 & $0.970 \mathrm{E}-07$ \\
8650.4 & 12784.4 & 555.00 & $0.105 \mathrm{E}-05$ \\
8650.4 & 12784.4 & 548.75 & $0.292 \mathrm{E}-05$ \\
8650.4 & 12784.4 & 546.50 & $0.205 \mathrm{E}-06$ \\
8642.6 & 12781.6 & 580.05 & $0.113 \mathrm{E}-06$ \\
8642.6 & 12781.6 & 575.30 & $0.511 \mathrm{E}-07$ \\
8642.6 & 12781.6 & 570.30 & $0.476 \mathrm{E}-04$ \\
8642.6 & 12781.6 & 568.80 & $0.190 \mathrm{E}-03$ \\
8642.6 & 12781.6 & 563.80 & $0.480 \mathrm{E}-03$ \\
8642.6 & 12781.6 & 565.30 & $0.842 \mathrm{E}-05$ \\
8642.6 & 12781.6 & 559.80 & $0.187 \mathrm{E}-06$ \\
8642.6 & 12781.6 & 555.30 & $0.401 \mathrm{E}-05$ \\
8642.6 & 12781.6 & 550.30 & $0.656 \mathrm{E}-05$ \\
8642.6 & 12781.6 & 547.30 & $0.425 \mathrm{E}-06$ \\
\hline \hline & & &
\end{tabular}


Table C.1 (contd)

\begin{tabular}{cccc}
\hline $\begin{array}{c}\text { Easting } \\
(\mathrm{ft})\end{array}$ & $\begin{array}{c}\text { Northing } \\
(\mathrm{ft})\end{array}$ & $\begin{array}{c}\text { Elevation } \\
(\mathrm{ft})\end{array}$ & $\begin{array}{c}K_{s} \\
(\mathrm{~cm} / \mathrm{s})\end{array}$ \\
\hline 8649.2 & 12766.4 & 581.10 & $0.129 \mathrm{E}-06$ \\
8649.2 & 12766.4 & 576.10 & $0.205 \mathrm{E}-06$ \\
8649.2 & 12766.4 & 571.10 & $0.337 \mathrm{E}-02$ \\
8649.2 & 12766.4 & 570.80 & $0.350 \mathrm{E}-02$ \\
8649.2 & 12766.4 & 565.30 & $0.937 \mathrm{E}-06$ \\
8649.2 & 12766.4 & 561.30 & $0.824 \mathrm{E}-07$ \\
8649.2 & 12766.4 & 556.10 & $0.182 \mathrm{E}-04$ \\
8649.2 & 12766.4 & 551.10 & $0.594 \mathrm{E}-06$ \\
8649.0 & 12762.4 & 584.10 & $0.173 \mathrm{E}-07$ \\
8649.0 & 12762.4 & 583.30 & $0.313 \mathrm{E}-07$ \\
8649.0 & 12762.4 & 581.60 & $0.327 \mathrm{E}-06$ \\
8649.0 & 12762.4 & 576.60 & $0.440 \mathrm{E}-07$ \\
8649.0 & 12762.4 & 571.30 & $0.272 \mathrm{E}-03$ \\
8649.0 & 12762.4 & 568.60 & $0.900 \mathrm{E}-03$ \\
8649.0 & 12762.4 & 565.30 & $0.145 \mathrm{E}-05$ \\
8649.0 & 12762.4 & 561.30 & $0.313 \mathrm{E}-07$ \\
8649.0 & 12762.4 & 561.10 & $0.195 \mathrm{E}-05$ \\
8649.0 & 12762.4 & 556.10 & $0.100 \mathrm{E}-04$ \\
8649.0 & 12762.4 & 555.80 & $0.100 \mathrm{E}-04$ \\
8649.0 & 12762.4 & 550.30 & $0.105 \mathrm{E}-04$ \\
8649.0 & 12762.4 & 550.10 & $0.476 \mathrm{E}-04$ \\
\hline \hline
\end{tabular}


Table C.2: $\mathrm{K}_{s}$ with three-dimensional coordinates for the 132-sample data set. Hydraulic conductivity obtained by direct measurement and by correlation with particle size and ambient liquid saturation.

\begin{tabular}{cccc}
\hline \hline $\begin{array}{c}\text { Easting } \\
(\mathrm{ft})\end{array}$ & $\begin{array}{c}\text { Northing } \\
(\mathrm{ft})\end{array}$ & $\begin{array}{c}\text { Elevation } \\
(\mathrm{ft})\end{array}$ & $\begin{array}{c}K_{s} \\
(\mathrm{~cm} / \mathrm{s})\end{array}$ \\
\hline 8655.4 & 12781.0 & 585.05 & $0.500 \mathrm{E}-06$ \\
8655.4 & 12781.0 & 581.05 & $0.570 \mathrm{E}-02$ \\
8655.4 & 12781.0 & 580.55 & $0.230 \mathrm{E}-01$ \\
8655.4 & 12781.0 & 577.80 & $0.110 \mathrm{E}-04$ \\
8655.4 & 12781.0 & 577.55 & $0.680 \mathrm{E}-05$ \\
8655.4 & 12781.0 & 576.55 & $0.150 \mathrm{E}-03$ \\
8655.4 & 12781.0 & 576.03 & $0.230 \mathrm{E}-05$ \\
8655.4 & 12781.0 & 573.05 & $0.500 \mathrm{E}-06$ \\
8655.4 & 12781.0 & 570.05 & $0.210 \mathrm{E}-01$ \\
8655.4 & 12781.0 & 569.30 & $0.240 \mathrm{E}-01$ \\
8655.4 & 12781.0 & 565.30 & $0.370 \mathrm{E}-06$ \\
8655.4 & 12781.0 & 565.05 & $0.120 \mathrm{E}-05$ \\
8655.4 & 12781.0 & 560.55 & $0.340 \mathrm{E}-06$ \\
8655.4 & 12781.0 & 559.05 & $0.400 \mathrm{E}-03$ \\
8655.4 & 12781.0 & 556.55 & $0.750 \mathrm{E}-05$ \\
8655.4 & 12781.0 & 556.30 & $0.410 \mathrm{E}-04$ \\
8655.4 & 12781.0 & 551.80 & $0.460 \mathrm{E}-06$ \\
8655.4 & 12781.0 & 551.55 & $0.200 \mathrm{E}-07$ \\
8655.4 & 12781.0 & 546.80 & $0.100 \mathrm{E}-02$ \\
8655.4 & 12781.0 & 546.55 & $0.500 \mathrm{E}-02$ \\
8655.4 & 12781.0 & 541.30 & $0.160 \mathrm{E}-01$ \\
8645.6 & 12784.9 & 580.10 & $0.120 \mathrm{E}-06$ \\
8645.6 & 12784.9 & 575.10 & $0.100 \mathrm{E}-06$ \\
8645.6 & 12784.9 & 570.90 & $0.150 \mathrm{E}-02$ \\
8645.6 & 12784.9 & 565.40 & $0.370 \mathrm{E}-02$ \\
8645.6 & 12784.9 & 565.10 & $0.680 \mathrm{E}-02$ \\
8645.6 & 12784.9 & 560.10 & $0.680 \mathrm{E}-07$ \\
8645.6 & 12784.9 & 555.60 & $0.280 \mathrm{E}-05$ \\
8645.6 & 12784.9 & 555.40 & $0.410 \mathrm{E}-05$ \\
8645.6 & 12784.9 & 550.10 & $0.200 \mathrm{E}-07$ \\
8645.6 & 12784.9 & 545.40 & $0.830 \mathrm{E}-04$ \\
8645.6 & 12784.9 & 545.10 & $0.500 \mathrm{E}-03$ \\
8645.6 & 12784.9 & 540.10 & $0.200 \mathrm{E}-01$ \\
8644.7 & 12762.1 & 579.90 & $0.910 \mathrm{E}-07$ \\
8644.7 & 12762.1 & 575.20 & $0.140 \mathrm{E}-05$ \\
\hline \hline & & &
\end{tabular}


Table C.2 (contd)

\begin{tabular}{cccc}
\hline \hline $\begin{array}{c}\text { Easting } \\
(\mathrm{ft})\end{array}$ & $\begin{array}{c}\text { Northing } \\
(\mathrm{ft})\end{array}$ & $\begin{array}{c}\text { Elevation } \\
(\mathrm{ft})\end{array}$ & $\begin{array}{c}K_{s} \\
(\mathrm{~cm} / \mathrm{s})\end{array}$ \\
\hline 8644.7 & 12762.1 & 574.90 & $0.110 \mathrm{E}-06$ \\
8644.7 & 12762.1 & 570.90 & $0.100 \mathrm{E}-06$ \\
8644.7 & 12762.1 & 565.20 & $0.100 \mathrm{E}-06$ \\
8644.7 & 12762.1 & 564.90 & $0.900 \mathrm{E}-01$ \\
8644.7 & 12762.1 & 559.90 & $0.250 \mathrm{E}-05$ \\
8644.7 & 12762.1 & 555.40 & $0.280 \mathrm{E}-04$ \\
8644.7 & 12762.1 & 555.20 & $0.600 \mathrm{E}-05$ \\
8644.7 & 12762.1 & 549.90 & $0.300 \mathrm{E}-05$ \\
8644.7 & 12762.1 & 545.20 & $0.370 \mathrm{E}-03$ \\
8644.7 & 12762.1 & 544.90 & $0.100 \mathrm{E}-03$ \\
8654.2 & 12762.0 & 579.90 & $0.200 \mathrm{E}-06$ \\
8654.2 & 12762.0 & 575.20 & $0.300 \mathrm{E}-06$ \\
8654.2 & 12762.0 & 574.90 & $0.910 \mathrm{E}-06$ \\
8654.2 & 12762.0 & 570.70 & $0.920 \mathrm{E}-03$ \\
8654.2 & 12762.0 & 565.70 & $0.200 \mathrm{E}-01$ \\
8654.2 & 12762.0 & 565.40 & $0.190 \mathrm{E}-02$ \\
8654.2 & 12762.0 & 559.90 & $0.110 \mathrm{E}-05$ \\
8654.2 & 12762.0 & 555.40 & $0.750 \mathrm{E}-05$ \\
8654.2 & 12762.0 & 555.20 & $0.370 \mathrm{E}-05$ \\
8654.2 & 12762.0 & 550.00 & $0.110 \mathrm{E}-07$ \\
8654.2 & 12762.0 & 545.70 & $0.300 \mathrm{E}-01$ \\
8651.1 & 12802.0 & 585.50 & $0.610 \mathrm{E}-07$ \\
8651.1 & 12802.0 & 581.00 & $0.270 \mathrm{E}-07$ \\
8651.1 & 12802.0 & 576.50 & $0.170 \mathrm{E}-06$ \\
8651.1 & 12802.0 & 576.30 & $0.610 \mathrm{E}-07$ \\
8651.1 & 12802.0 & 571.30 & $0.150 \mathrm{E}-06$ \\
8651.1 & 12802.0 & 566.30 & $0.450 \mathrm{E}-06$ \\
8651.1 & 12802.0 & 566.00 & $0.150 \mathrm{E}-06$ \\
8651.1 & 12802.0 & 561.00 & $0.120 \mathrm{E}-06$ \\
8651.1 & 12802.0 & 556.50 & $0.280 \mathrm{E}-05$ \\
8651.1 & 12802.0 & 556.30 & $0.610 \mathrm{E}-06$ \\
8651.1 & 12802.0 & 552.00 & $0.200 \mathrm{E}-01$ \\
8651.1 & 12802.0 & 546.80 & $0.830 \mathrm{E}-06$ \\
8651.1 & 12802.0 & 546.50 & $0.300 \mathrm{E}-01$ \\
8651.1 & 12802.0 & 541.50 & $0.230 \mathrm{E}-01$ \\
8670.3 & 12769.3 & 580.50 & $0.150 \mathrm{E}-05$ \\
\hline \hline & & &
\end{tabular}


Table C.2 (contd)

\begin{tabular}{cccc}
\hline $\begin{array}{c}\text { Easting } \\
(\mathrm{ft})\end{array}$ & $\begin{array}{c}\text { Northing } \\
(\mathrm{ft})\end{array}$ & $\begin{array}{c}\text { Elevation } \\
(\mathrm{ft})\end{array}$ & $\begin{array}{c}K_{s} \\
(\mathrm{~cm} / \mathrm{s})\end{array}$ \\
\hline 8670.3 & 12769.3 & 575.80 & $0.410 \mathrm{E}-07$ \\
8670.3 & 12769.3 & 575.50 & $0.150 \mathrm{E}-06$ \\
8670.3 & 12769.3 & 571.30 & $0.180 \mathrm{E}-04$ \\
8670.3 & 12769.3 & 565.80 & $0.620 \mathrm{E}-01$ \\
8670.3 & 12769.3 & 565.50 & $0.750 \mathrm{E}-01$ \\
8670.3 & 12769.3 & 560.50 & $0.100 \mathrm{E}-05$ \\
8670.3 & 12769.3 & 556.00 & $0.250 \mathrm{E}-04$ \\
8670.3 & 12769.3 & 555.80 & $0.550 \mathrm{E}-05$ \\
8670.3 & 12769.3 & 550.30 & $0.750 \mathrm{E}-06$ \\
8670.3 & 12769.3 & 546.30 & $0.240 \mathrm{E}-01$ \\
8670.3 & 12769.3 & 546.00 & $0.260 \mathrm{E}-01$ \\
8670.3 & 12769.3 & 540.50 & $0.100 \mathrm{E}-02$ \\
8661.8 & 12784.0 & 582.90 & $0.120 \mathrm{E}-07$ \\
8661.8 & 12784.0 & 581.40 & $0.250 \mathrm{E}-06$ \\
8661.8 & 12784.0 & 576.90 & $0.120 \mathrm{E}-06$ \\
8661.8 & 12784.0 & 571.90 & $0.170 \mathrm{E}-02$ \\
8661.8 & 12784.0 & 566.40 & $0.450 \mathrm{E}-02$ \\
8661.8 & 12784.0 & 561.90 & $0.160 \mathrm{E}-07$ \\
8661.8 & 12784.0 & 555.70 & $0.150 \mathrm{E}-04$ \\
8661.8 & 12784.0 & 551.90 & $0.250 \mathrm{E}-04$ \\
8661.8 & 12784.0 & 546.40 & $0.760 \mathrm{E}-03$ \\
8661.8 & 12784.0 & 541.90 & $0.200 \mathrm{E}-02$ \\
8650.4 & 12784.4 & 580.00 & $0.170 \mathrm{E}-06$ \\
8650.4 & 12784.4 & 575.00 & $0.722 \mathrm{E}-06$ \\
8650.4 & 12784.4 & 569.75 & $0.564 \mathrm{E}-06$ \\
8650.4 & 12784.4 & 564.75 & $0.689 \mathrm{E}-06$ \\
8650.4 & 12784.4 & 560.00 & $0.970 \mathrm{E}-07$ \\
8650.4 & 12784.4 & 555.00 & $0.105 \mathrm{E}-05$ \\
8650.4 & 12784.4 & 548.75 & $0.292 \mathrm{E}-05$ \\
8650.4 & 12784.4 & 546.50 & $0.205 \mathrm{E}-06$ \\
8642.6 & 12781.6 & 580.05 & $0.113 \mathrm{E}-06$ \\
8642.6 & 12781.6 & 575.30 & $0.511 \mathrm{E}-07$ \\
8642.6 & 12781.6 & 570.30 & $0.476 \mathrm{E}-04$ \\
8642.6 & 12781.6 & 568.80 & $0.190 \mathrm{E}-03$ \\
8642.6 & 12781.6 & 565.30 & $0.842 \mathrm{E}-05$ \\
8642.6 & 12781.6 & 563.80 & $0.480 \mathrm{E}-03$ \\
\hline \hline & & &
\end{tabular}


Table C.2 (contd)

\begin{tabular}{cccc}
\hline \hline $\begin{array}{c}\text { Easting } \\
(\mathrm{ft})\end{array}$ & $\begin{array}{c}\text { Northing } \\
(\mathrm{ft})\end{array}$ & $\begin{array}{c}\text { Elevation } \\
(\mathrm{ft})\end{array}$ & $\begin{array}{c}K_{s} \\
(\mathrm{~cm} / \mathrm{s})\end{array}$ \\
\hline 8642.6 & 12781.6 & 559.80 & $0.187 \mathrm{E}-06$ \\
8642.6 & 12781.6 & 555.30 & $0.401 \mathrm{E}-05$ \\
8642.6 & 12781.6 & 550.30 & $0.656 \mathrm{E}-05$ \\
8642.6 & 12781.6 & 547.30 & $0.425 \mathrm{E}-06$ \\
8649.2 & 12766.4 & 581.10 & $0.129 \mathrm{E}-06$ \\
8649.2 & 12766.4 & 576.10 & $0.205 \mathrm{E}-06$ \\
8649.2 & 12766.4 & 571.10 & $0.337 \mathrm{E}-02$ \\
8649.2 & 12766.4 & 570.80 & $0.350 \mathrm{E}-02$ \\
8649.2 & 12766.4 & 565.30 & $0.937 \mathrm{E}-06$ \\
8649.2 & 12766.4 & 561.30 & $0.824 \mathrm{E}-07$ \\
8649.2 & 12766.4 & 556.10 & $0.182 \mathrm{E}-04$ \\
8649.2 & 12766.4 & 551.10 & $0.594 \mathrm{E}-06$ \\
8649.0 & 12762.4 & 584.10 & $0.173 \mathrm{E}-07$ \\
8649.0 & 12762.4 & 583.30 & $0.313 \mathrm{E}-07$ \\
8649.0 & 12762.4 & 581.60 & $0.327 \mathrm{E}-06$ \\
8649.0 & 12762.4 & 576.60 & $0.440 \mathrm{E}-07$ \\
8649.0 & 12762.4 & 571.30 & $0.272 \mathrm{E}-03$ \\
8649.0 & 12762.4 & 568.60 & $0.900 \mathrm{E}-03$ \\
8649.0 & 12762.4 & 565.30 & $0.145 \mathrm{E}-05$ \\
8649.0 & 12762.4 & 561.30 & $0.313 \mathrm{E}-07$ \\
8649.0 & 12762.4 & 561.10 & $0.195 \mathrm{E}-05$ \\
8649.0 & 12762.4 & 556.10 & $0.100 \mathrm{E}-04$ \\
8649.0 & 12762.4 & 555.80 & $0.100 \mathrm{E}-04$ \\
8649.0 & 12762.4 & 550.30 & $0.105 \mathrm{E}-04$ \\
8649.0 & 12762.4 & 550.10 & $0.476 \mathrm{E}-04$ \\
\hline \hline
\end{tabular}




\section{Maximum and Time of Occurrence of Maximum Groundwater Concentration for 2D Runs using Soil Properties Generated by Conditional Simulation.}

Table D.1: Maximum groundwater ${ }^{3} \mathrm{H}$ concentration and time of occurrence of the maximum for simulation runs using 100 realizations of soil property fields generated by conditional simulation.

\begin{tabular}{ccc}
\hline \hline Run ID & $\begin{array}{c}\text { Maximum } \\
\text { Concentration } \\
(\mathrm{pCi} / \mathrm{L})\end{array}$ & $\begin{array}{c}\text { Time of } \\
\text { Maximum } \\
(\mathrm{yr})\end{array}$ \\
\hline real101 & $0.147 \mathrm{E}+06$ & 51.5 \\
real102 & $0.476 \mathrm{E}+07$ & 21.5 \\
real103 & $0.118 \mathrm{E}+07$ & 33.5 \\
real104 & $0.143 \mathrm{E}+07$ & 35.0 \\
real105 & $0.636 \mathrm{E}+07$ & 18.6 \\
real106 & $0.529 \mathrm{E}+06$ & 40.0 \\
real107 & $0.108 \mathrm{E}+07$ & 31.6 \\
real108 & $0.444 \mathrm{E}+06$ & 33.0 \\
real109 & $0.240 \mathrm{E}+07$ & 26.5 \\
real110 & $0.330 \mathrm{E}+07$ & 16.8 \\
real111 & $0.522 \mathrm{E}+06$ & 40.0 \\
real112 & $0.509 \mathrm{E}+06$ & 41.4 \\
real113 & $0.386 \mathrm{E}+06$ & 42.3 \\
real114 & $0.326 \mathrm{E}+06$ & 42.3 \\
real115 & $0.493 \mathrm{E}+07$ & 22.6 \\
real116 & $0.899 \mathrm{E}+07$ & 14.4 \\
real117 & $0.638 \mathrm{E}+07$ & 17.4 \\
real118 & $0.182 \mathrm{E}+07$ & 30.9 \\
real119 & $0.166 \mathrm{E}+07$ & 30.0 \\
real120 & $0.143 \mathrm{E}+07$ & 33.9 \\
real121 & $0.673 \mathrm{E}+07$ & 16.7 \\
real122 & $0.265 \mathrm{E}+07$ & 25.8 \\
real123 & $0.295 \mathrm{E}+07$ & 22.9 \\
real124 & $0.874 \mathrm{E}+06$ & 23.9 \\
real125 & $0.782 \mathrm{E}+05$ & 57.0 \\
\hline \hline & &
\end{tabular}


Table D.1 (contd)

\begin{tabular}{|c|c|c|}
\hline$\overline{\text { Run ID }}$ & $\begin{array}{c}\text { Maximum } \\
\text { Concentration } \\
(\mathrm{pCi} / \mathrm{L})\end{array}$ & $\begin{array}{c}\text { Time of } \\
\text { Maximum } \\
(y r)\end{array}$ \\
\hline real126 & $0.794 \mathrm{E}+06$ & 39.6 \\
\hline real127 & $0.127 \mathrm{E}+07$ & 36.1 \\
\hline real128 & $0.909 \mathrm{E}+06$ & 27.8 \\
\hline real129 & $0.273 \mathrm{E}+07$ & 25.8 \\
\hline real130 & $0.389 \mathrm{E}+07$ & 25.0 \\
\hline real131 & $0.353 \mathrm{E}+07$ & 22.4 \\
\hline real132 & $0.218 \mathrm{E}+07$ & 25.9 \\
\hline real133 & $0.110 \mathrm{E}+06$ & 53.8 \\
\hline real134 & $0.616 \mathrm{E}+07$ & 20.7 \\
\hline real135 & $0.908 \mathrm{E}+06$ & 24.4 \\
\hline real136 & $0.514 \mathrm{E}+06$ & 37.1 \\
\hline real137 & $0.425 \mathrm{E}+07$ & 14.3 \\
\hline real138 & $0.448 \mathrm{E}+07$ & 17.6 \\
\hline real139 & $0.238 \mathrm{E}+07$ & 27.8 \\
\hline real140 & $0.393 \mathrm{E}+06$ & 43.7 \\
\hline real141 & $0.885 E+06$ & 36.8 \\
\hline real142 & $0.414 \mathrm{E}+06$ & 35.0 \\
\hline real143 & $0.580 \mathrm{E}+06$ & 36.0 \\
\hline real144 & $0.217 \mathrm{E}+07$ & 29.1 \\
\hline real145 & $0.260 \mathrm{E}+07$ & 25.0 \\
\hline real146 & $0.144 \mathrm{E}+07$ & 30.0 \\
\hline real147 & $0.511 \mathrm{E}+06$ & 40.0 \\
\hline real148 & $0.197 \mathrm{E}+07$ & 31.8 \\
\hline real149 & $0.243 \mathrm{E}+07$ & 25.0 \\
\hline real150 & $0.638 \mathrm{E}+07$ & 20.0 \\
\hline real151 & $0.230 \mathrm{E}+07$ & 25.8 \\
\hline real152 & $0.134 \mathrm{E}+07$ & 36.0 \\
\hline real153 & $0.142 \mathrm{E}+07$ & 21.3 \\
\hline real154 & $0.283 E+07$ & 25.0 \\
\hline real155 & $0.611 E+06$ & 42.4 \\
\hline real156 & $0.464 \mathrm{E}+06$ & 38.4 \\
\hline real157 & $0.107 \mathrm{E}+07$ & 35.9 \\
\hline real158 & $0.411 \mathrm{E}+07$ & 22.3 \\
\hline real159 & $0.646 \mathrm{E}+06$ & 42.8 \\
\hline real160 & $0.227 \mathrm{E}+07$ & 20.0 \\
\hline real161 & $0.653 \mathrm{E}+06$ & 35.0 \\
\hline real162 & $0.636 \mathrm{E}+06$ & 37.6 \\
\hline real163 & $0.721 \mathrm{E}+06$ & 41.3 \\
\hline real164 & $0.514 \mathrm{E}+06$ & 41.2 \\
\hline real165 & $0.213 \mathrm{E}+07$ & 30.9 \\
\hline
\end{tabular}


Table D.1 (contd)

\begin{tabular}{|c|c|c|}
\hline Run ID & $\begin{array}{c}\text { Maximum } \\
\text { Concentration } \\
(\mathrm{pCi} / \mathrm{L})\end{array}$ & $\begin{array}{c}\text { Time of } \\
\text { Maximum } \\
(\mathrm{yr})\end{array}$ \\
\hline real166 & $0.467 \mathrm{E}+06$ & 31.0 \\
\hline real167 & $0.135 \mathrm{E}+07$ & 25.0 \\
\hline real168 & $0.131 \mathrm{E}+05$ & 57.0 \\
\hline real169 & $0.907 \mathrm{E}+06$ & 36.1 \\
\hline real170 & $0.849 \mathrm{E}+06$ & 37.3 \\
\hline real171 & $0.706 \mathrm{E}+06$ & 32.5 \\
\hline real172 & $0.519 \mathrm{E}+07$ & 18.1 \\
\hline real173 & $0.879 \mathrm{E}+06$ & 26.2 \\
\hline real174 & $0.303 \mathrm{E}+07$ & 25.7 \\
\hline real175 & $0.970 \mathrm{E}+05$ & 46.5 \\
\hline real176 & $0.376 \mathrm{E}+07$ & 27.8 \\
\hline real177 & $0.211 E+07$ & 22.9 \\
\hline real178 & $0.688 \mathrm{E}+06$ & 41.2 \\
\hline real179 & $0.229 \mathrm{E}+07$ & 27.0 \\
\hline real180 & $0.251 \mathrm{E}+06$ & 45.0 \\
\hline real181 & $0.863 \mathrm{E}+06$ & 31.1 \\
\hline real182 & $0.148 \mathrm{E}+07$ & 30.8 \\
\hline real183 & $0.366 \mathrm{E}+07$ & 24.4 \\
\hline real184 & $0.646 \mathrm{E}+07$ & 17.6 \\
\hline real185 & $0.108 \mathrm{E}+07$ & 36.1 \\
\hline real186 & $0.675 \mathrm{E}+07$ & 15.5 \\
\hline real187 & $0.815 \mathrm{E}+06$ & 38.1 \\
\hline real188 & $0.688 \mathrm{E}+07$ & 16.7 \\
\hline real189 & $0.946 \mathrm{E}+06$ & 32.0 \\
\hline real190 & $0.492 \mathrm{E}+06$ & 42.2 \\
\hline real191 & $0.541 \mathrm{E}+07$ & 23.0 \\
\hline real192 & $0.510 \mathrm{E}+06$ & 43.5 \\
\hline real193 & $0.206 \mathrm{E}+07$ & 28.2 \\
\hline real194 & $0.161 \mathrm{E}+06$ & 50.0 \\
\hline real195 & $0.267 \mathrm{E}+07$ & 25.8 \\
\hline real196 & $0.404 \mathrm{E}+07$ & 21.4 \\
\hline real197 & $0.165 \mathrm{E}+07$ & 28.2 \\
\hline real198 & $0.702 \mathrm{E}+07$ & 12.4 \\
\hline real199 & $0.159 \mathrm{E}+07$ & 30.9 \\
\hline real200 & $0.133 \mathrm{E}+07$ & 32.5 \\
\hline
\end{tabular}




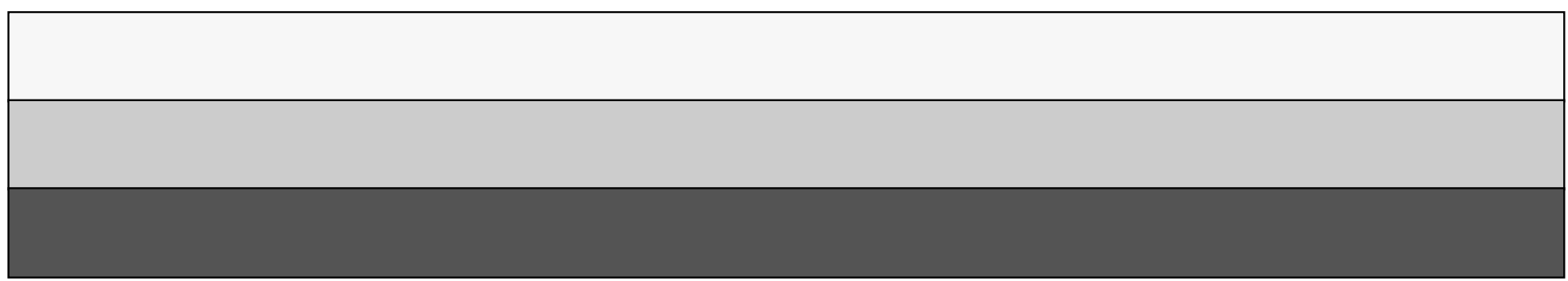

